\title{
Investigating Extended Linker Analogues of Risperidone for Treatment of Multiple Sclerosis
}

\author{
By
}

Thomas Bird

A thesis submitted to Victoria University of Wellington in partial fulfilment of the requirements for the degree of Master of Drug Discovery and Development by thesis.

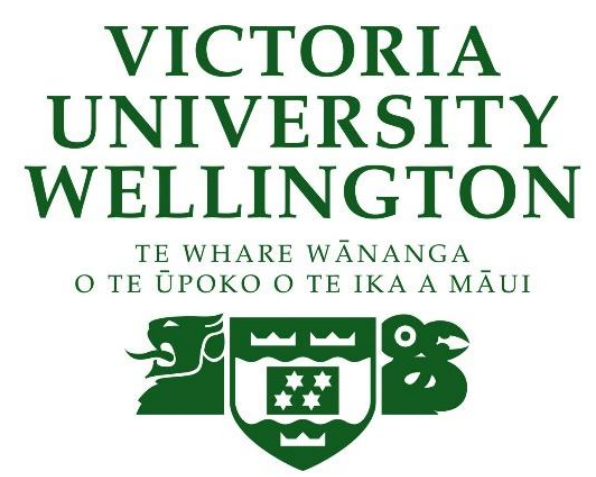

School of Chemical and Physical Sciences 


\begin{abstract}
Risperidone is a second-generation antipsychotic used to treat psychiatric disorders such as schizophrenia, bipolar disorder and autism. It targets dopamine $\mathrm{D}_{2}$ and serotonin $5-\mathrm{HT}_{2 \mathrm{~A}}$ receptors and has immunomodulatory properties. Multiple sclerosis is a chronic inflammatory disease that affects over 2 million people worldwide and currently has no cure. Recent research at Victoria University of Wellington has shown that risperidone is able to reduce disease severity in mouse models of multiple sclerosis. Further research has demonstrated that truncated and unsaturated analogues of risperidone have varying immunomodulatory effects in immune cells.

The current research describes the synthesis and preliminary in vitro testing of four extendedlinker analogues of risperidone. Structure-activity relationship studies with neurotropic drugs have shown that altering the length of the alkyl chain found in many of these compounds can have significant effects on receptor binding profiles. Synthesis and cytokine production assays of these analogues begin to provide further insight into how risperidone exerts its immunomodulatory effects and may contribute to the development of new treatments for multiple sclerosis.
\end{abstract}


"Completed it mate."

Jay Cartwright 


\section{Acknowledgments}

Firstly, I would like to thank Associate Professor Joanne Harvey. Your encouragement, constant positivity and incredible enthusiasm for all things chemistry has made this project what it is. I could not have asked for a better supervisor this year.

Ben and Jordan, you have been my big brothers this year in more ways than one. Ben, without the crazy amount of work you did in Honours I would not be here. Your methods actually work the first time! What a revolutionary idea. Jordan, I think I lucked out being in the fume hood beside you with your massive organic chemistry knowledge. Thank you for telling me it all for free. Thanks to both of you for giving me stick all year long, making me be a better chemist and a better person I hope. I look up to the both of you immensely. Laundry.

Ethan, thank you for putting up with my constant stream of questions all year. Your help with NMR has been brilliant, but more importantly, your sarcasm throughout the years has been a pleasure. Sarah, thank you for being the friendly face that helped in the beginning when I had no clue what I was doing. You helped me settle into the group so quickly. Tao, your hard work and dedication to your $\mathrm{PhD}$ has been an inspiration while writing this. I hope to see you back soon celebrating a successful defence. Matt, thank you for singing Stormzy every day, making crazy crystals and just being a ridiculously happy guy to be around. Hayden, thank you for asking mate. Sophie, thank you for waking me up every day. Katie, thank you for your positivity, your encouragement and your Scouse accent. I cannot thank you enough for reading through my drafts that should never have seen the light of day. But more importantly, thank you for the constant barrage of Inbetweeners quotes that manage to suit every situation.

A massive thank you to Dr. Helen Woolner for showing a chemist how to be a biologist. You have been a great teacher and made the whole process a lot less daunting. Also, to Associate Professor Paul Teesdale-Spittle for your helpful suggestions drawing from your vast biology and chemistry knowledge. Thank you to Ian for your help all year with NMR and solving the many technical issues I had.

I would also like to thank my grandparents for their support, encouragement and interest in everything I have done over the years, in and out of university. Lastly, I would like to thank my mum. Mum you have done so much for me over my life and the past few years especially, I will never be able to thank you enough. Thank you for letting me attempt to teach you everything I have learnt, you deserve a degree from it too. This thesis is for you, I hope it makes you proud. 
Table of Contents

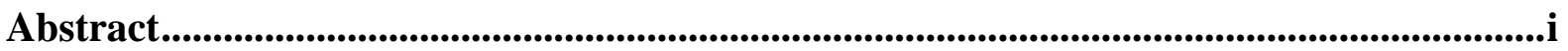

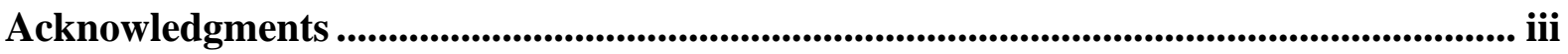

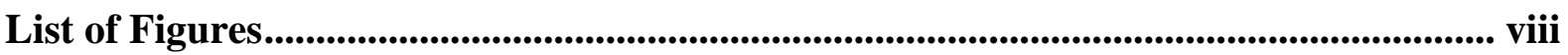

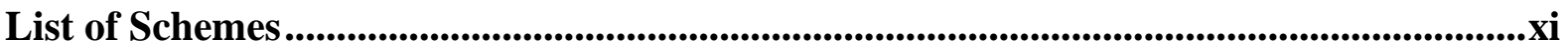

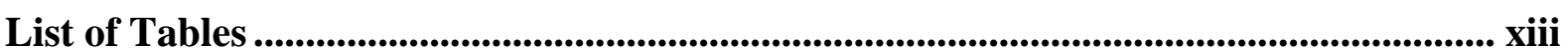

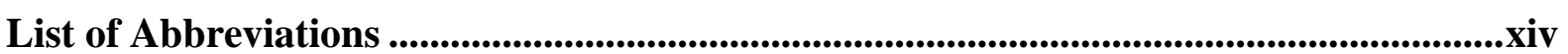

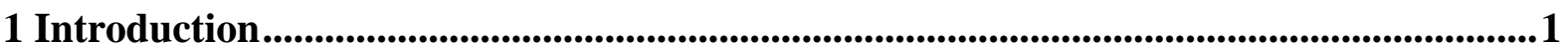

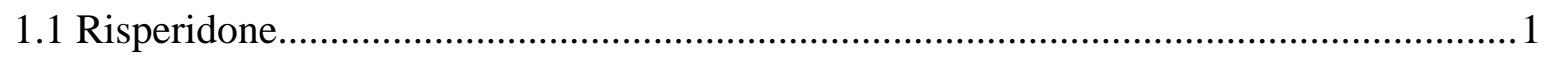

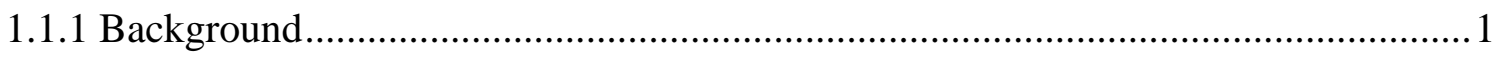

1.1.2 Pharmacokinetics and Receptor Affinities .....................................................

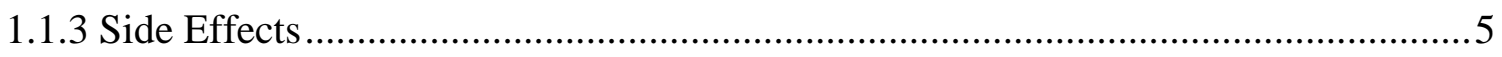

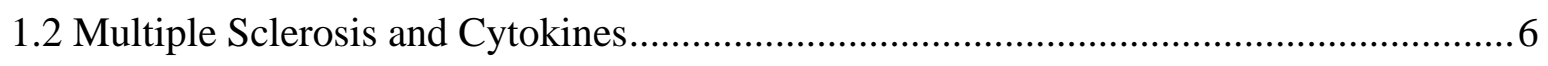

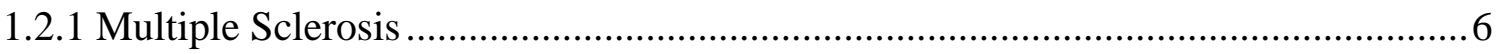

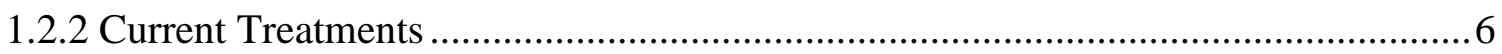

1.2.3 Cytokines and Multiple Sclerosis ................................................................

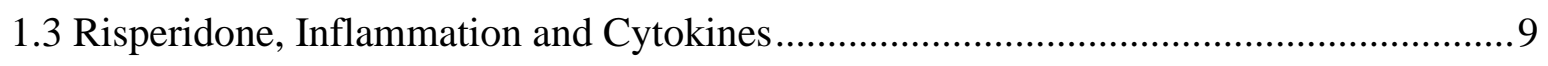

1.4 Alkyl Spacer Effects in Drug Molecules............................................................. 10

1.5 Previous Studies at Victoria University of Wellington ............................................. 12

1.5.1 Risperidone Reduces Disease Severity in EAE ................................................. 12

1.5.2 Immunomodulatory Activity of Risperidone Analogues in Macrophages.............. 13

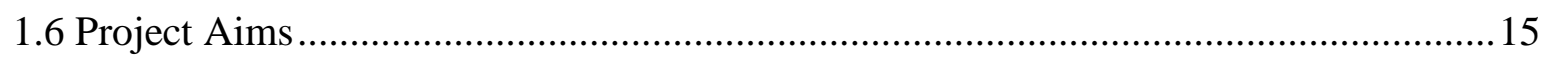


1.6.1 Synthetic Chemistry

1.6.2 In Vitro Assays

2 Synthesis of Risperidone Analogues

2.1 Retrosynthesis

2.2 Synthesis of the Benzisoxazole Fragment.

2.2.1 Isonipecotic Acid Acetylation .22

2.2.2 Friedel-Crafts Acylation of $\mathbf{1 0}$ .23

2.2.3 Oxime Formation. .25

2.2.4 Benzisoxazole Ring Closing. .27

2.3 Synthesis of Extended Linker Pyridopyrimidones. 30

2.3.1 Preparation of the Three-Carbon Alkylated Ethyl Acetoacetate .31

2.3.2 Preparation of the Four-Carbon Alkylated Ethyl Acetoacetate .35

2.3.3 Condensation of $\mathbf{1 7}$ and $\mathbf{1 8}$ with 2-aminopyridine .39

2.3.4 Pd/C Catalysed Hydrogenation of Pyridopyrimidones $\mathbf{1 9}$ and $\mathbf{2 0}$ 44

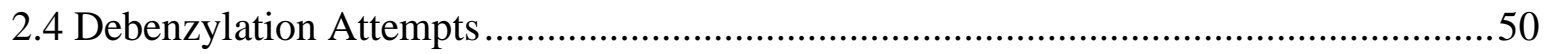

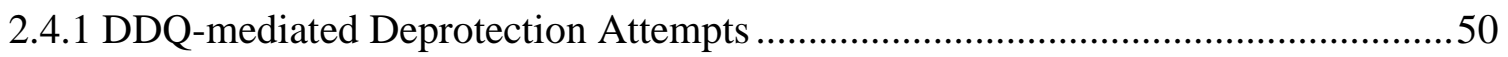

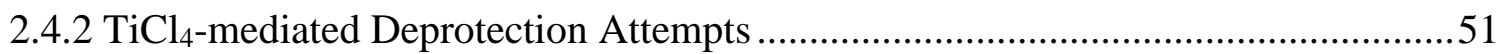

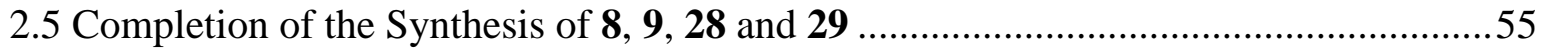

2.5.1 Synthesis of Four-Carbon Saturated Analogue 9 ................................................56

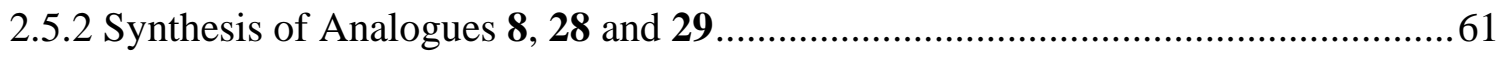

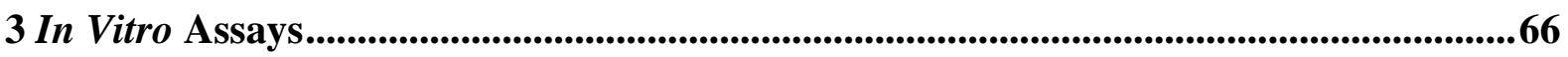

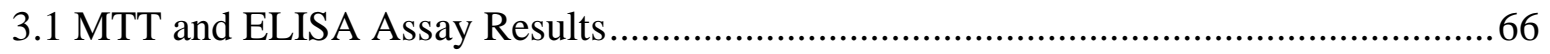


3.1.1 MTT Assay Results .66

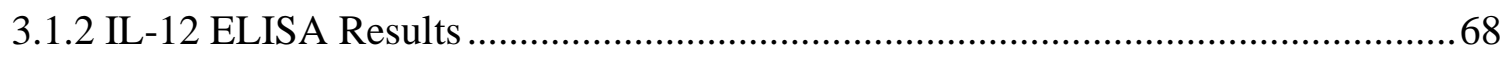

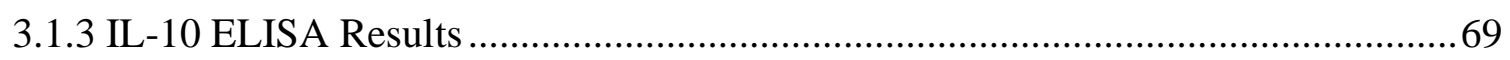

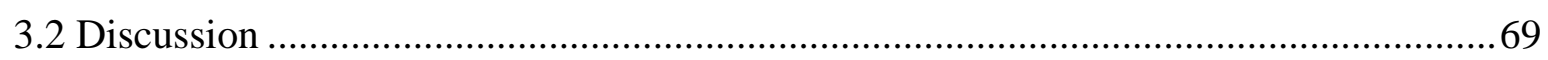

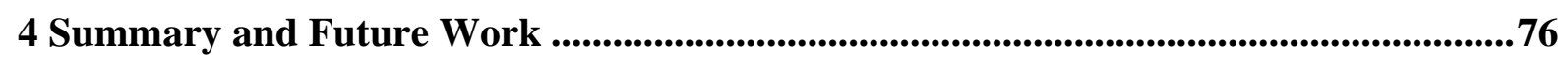

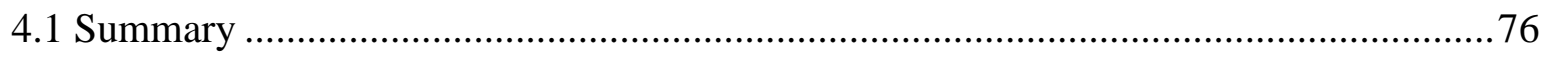

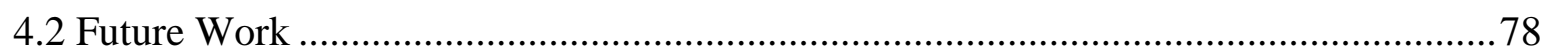

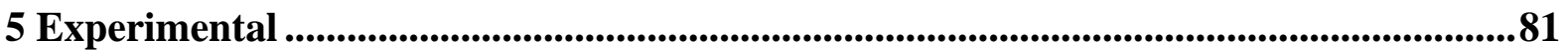

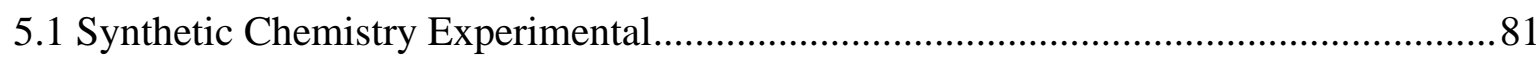

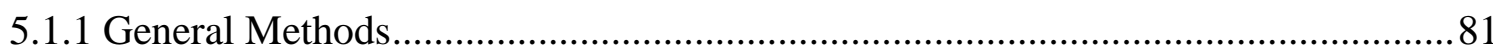

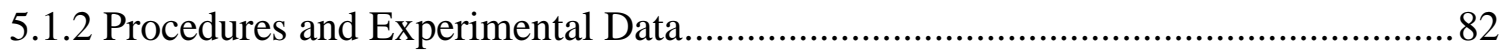

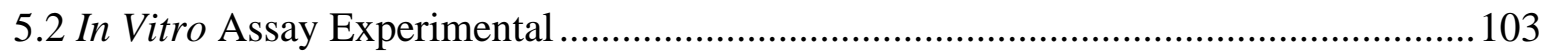

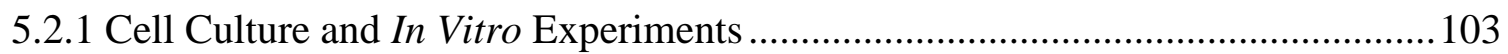

5.2.1.1 Quantification of Analogues ................................................................. 103

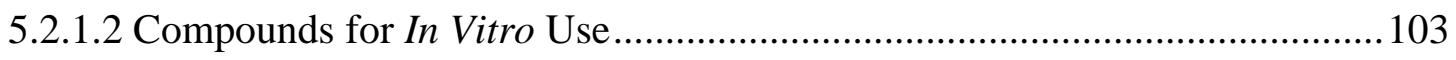

5.2.1.3 Culture and Maintenance of RAW 264.7 Macrophage Cell Line .................. 104

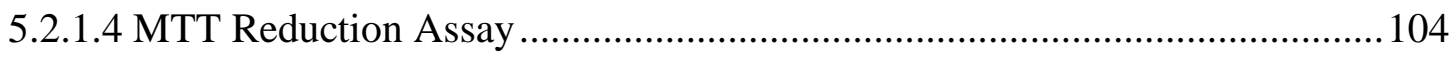

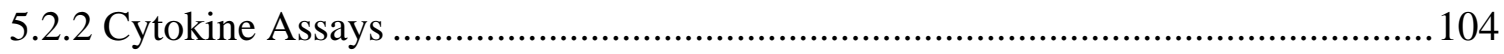

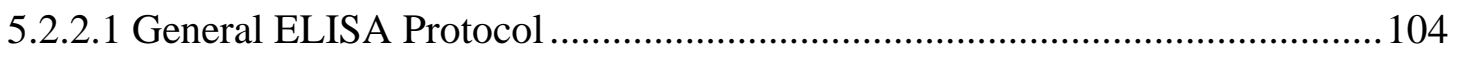

6 Appendix ............................................................................................................................................106

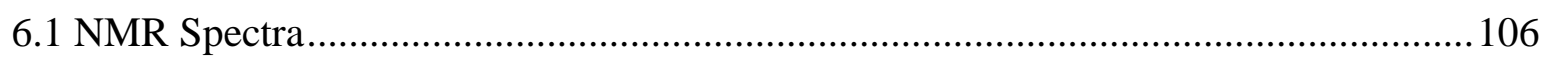

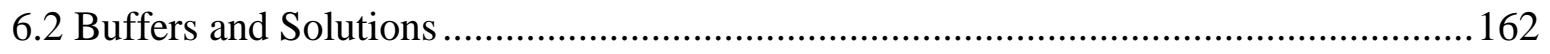


7 References ................................................................................................................................................. 165 


\section{List of Figures}

Figure 1. Risperidone and structurally related atypical antipsychotics.

Figure 2. Top left, top down view of risperidone (yellow) bound in the pocket created by transmembrane helices III, V and VI (not shown). Top right, risperidone bound to $\mathrm{D}_{2}$ receptor. Bottom, risperidone orientation when unbound vs bound to $\mathrm{D}_{2}$ receptor. Bottom right, overlaid unbound (green) and bound (yellow). Adapted from Wang et al. Structure of the $D_{2}$ dopamine receptor bound to the atypical antipsychotic drug risperidone. Nature $\mathbf{5 5 5}$, 269. ${ }^{10}$

Figure 3. Left, 3-dimensional structure of risperidone bound to 5- $\mathrm{HT}_{2 \mathrm{~A}}$ receptor. Right, interactions between risperidone and 5- $\mathrm{HT}_{2 \mathrm{~A}}$. Adapted from Kimura et al. Structures of the 5$H T_{2 A}$ receptor in complex with the antipsychotics risperidone and zotepine. Nature Structural

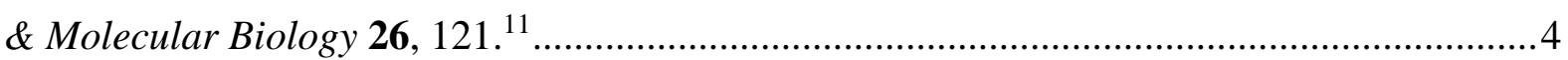

Figure 4. Oxindoles targeting 5-HT7 synthesised by Volk et al.$^{90}$....................................... 11

Figure 5. Quinoline- and isoquinoline-sulfonamides synthesised by Zajdel et al.$^{92}$............. 11

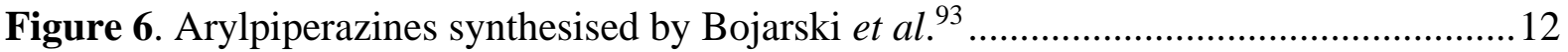

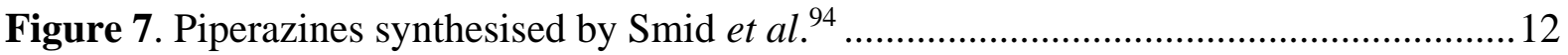

Figure 8. Risperidone analogues synthesised by VUW researchers. ${ }^{97}$.............................. 14

Figure 9. Three- and four-carbon linker analogues of risperidone. ...................................... 15

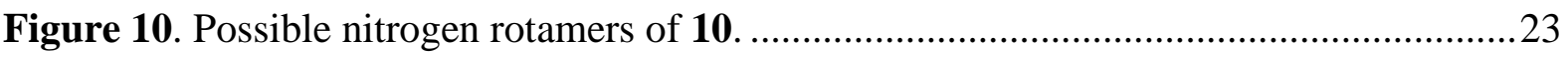

Figure 11. Comparison of ${ }^{1} \mathrm{H}$ NMR spectra of $N$-acetylated acid $\mathbf{1 0}$ and Friedel-Crafts product 12 .

Figure 12. Splitting of ${ }^{13} \mathrm{C}$ peaks caused by fluorine coupling to neighbouring carbons in product 12 .

Figure 13. Comparison of ${ }^{13} \mathrm{C}$ NMR spectra of alcohol 13 and iodide 15. Highlighted in green are the terminal carbon shifts.

Figure 14. Comparison of ${ }^{13} \mathrm{C}$ NMR spectra of iodide 15 and alkylated product 17.

Highlighted in green are shifts indicative of ketone (left) and ester (right) functionalities.....35

Figure 15. Key COSY and HMBC correlations of $\mathbf{1 8 .}$

Figure 16. Comparison of ${ }^{1} \mathrm{H}$ NMR spectra of 2-aminopyridine condensation crude reaction mixture (top) and purified (bottom) 19. Pyridine ring shifts are highlighted in green .....

Figure 17. Numbered carbon environments for pyridopyrimidone 20 ...............................4

Figure 18. Comparison of ${ }^{13} \mathrm{C}$ shifts of C-6 and C-8 in $\mathbf{1 9}$ (top) and 21 (bottom).................46

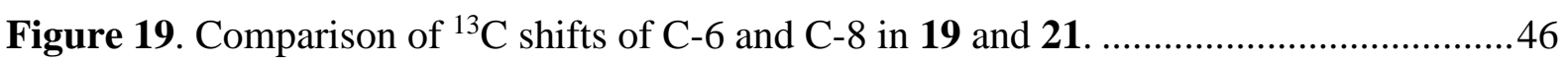


Figure 20. Possible resonance structures of $\mathbf{1 9}$

Figure 21. Photo (left) and schematic (right) of apparatus used for second hydrogenation attempt. 48

Figure 22. Comparison of ${ }^{1} \mathrm{H}$ NMR spectra of 19 (top), tetrahydropyridopyrimidone 21 (middle) and deprotected tetrahydropyridopyrimidone $\mathbf{2 3}$ (bottom). Highlighted are unsaturated pyridine shifts (green) and benzylic shifts (yellow).

Figure 23. Stacked ${ }^{1} \mathrm{H}$ NMR of protected alcohol 19 (top) and unknown DDQ-mediated deprotection product (bottom).

Figure 24. Stacked ${ }^{1} \mathrm{H}$ NMR spectra of one fraction of chromatographed $\mathrm{TiCl}_{4}$ reaction product (top) and combined fractions of $\mathrm{TiCl}_{4}$ reaction product (bottom). 52

Figure 25. The four proposed risperidone analogues. .54

Figure 26. Triplicate TLC analysis (acetone $+0.5 \%$ triethylamine) of crude reaction mixture pre-workup for Appel reaction on 24. Stained with ceric ammonium molybdate. $254 \mathrm{~nm} \mathrm{UV}$ active spots are outlined in red. .57

Figure 27. Quadruplicate TLC analysis (acetone $+0.5 \%$ triethylamine) of the crude reaction mixture of the coupling reaction towards 9. Stained with ceric ammonium molybdate. $254 \mathrm{~nm}$ UV active spots are outlined in red. .58

Figure 28. Stacked ${ }^{1} \mathrm{H}$ NMR spectra of benzisoxazole 3 (top) and crude condensation product 9 (bottom), focussed on shifts representative of positions C- $8^{\prime}$ and C-10'. .59

Figure 29. Expansion of HMBC spectrum of 9 with the key correlation circled. .60

Figure 30. Comparison of ${ }^{1} \mathrm{H}$ NMR spectra of analogue 9 in $\mathrm{D}_{2} \mathrm{O}$ (top) and $\mathrm{CDCl}_{3}$ (bottom).

Figure 31. Stacked ${ }^{1} \mathrm{H}$ NMR spectra of benzisoxazole $\mathbf{3}$ (top), iodide 25 (middle) and analogue 8 (bottom). Residual $\mathrm{PPh}_{3} \mathrm{O}$ is highlighted in red.

Figure 32. RAW264.7 cell viability measured by MTT assay. Presented as a percentage of vehicle control. RAW 264.7 cells were plated at 50,000 cells/well, primed with IFN- $\gamma$ (20 $\mathrm{U} / \mathrm{mL}$ ), and stimulated with LPS for 24 hours in increasing concentrations of analogues $\mathbf{8 , 9}$, 28, 29 and risperidone at 1\% DMSO. Shown are means and SEM of triplicate wells from one experiment..

Figure 33. IL-12 in the supernatant measured by ELISA. .68

Figure 34. IL-10 in the supernatant measured by ELISA. 69

Figure 35. Acarbose binding site alignments in 4- $\alpha$-glucanotransferase and glucoamylase.

Binding sites are highlighted in red and ligands are presented in orange. Adapted from Haupt 
et al. Drug Promiscuity in PDB: Protein Binding Site Similarity Is Key. PLOS ONE 2013, 8 (6), e65894. ${ }^{141}$

Figure 36. Overlay of 9 (green) and risperidone (red), demonstrating their proposed positions in relation to a tryptophan residue (yellow) in the $\mathrm{D}_{2}$ receptor.

Figure 37. Proposed deep-pocket ligand-protein interactions of $\mathbf{8}$ (top) and risperidone (bottom)

Figure 38. Proposed shallow-pocket ligand-protein interactions of $\mathbf{8}$ (left) and risperidone (right). .75

Figure 39. Proposed five- and six-carbon linker analogues of risperidone. .79

Figure 40. Proposed rigidified analogues of $\mathbf{8}$. 80 


\section{List of Schemes}

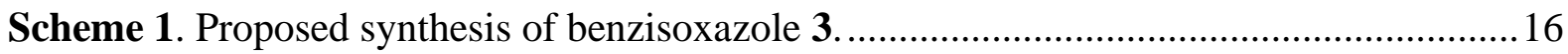

Scheme 2. Proposed synthesis of extended linker coupled pyridopyrimidones $\mathbf{1 9}$ and 20.....17

Scheme 3. Outcome of Durrant's Pd-catalysed hydrogenation reactions. ${ }^{98}$.......................... 18

Scheme 4. Proposed DDQ-mediated deprotection of 21 and 22 ........................................ 18

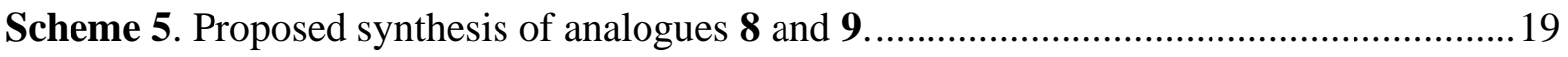

Scheme 6. Retrosynthesis of extended linker analogues of risperidone. ..............................21

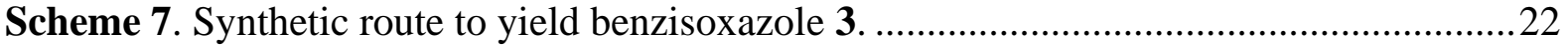

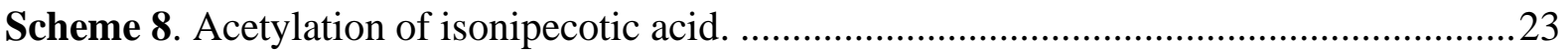

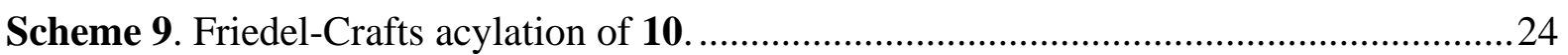

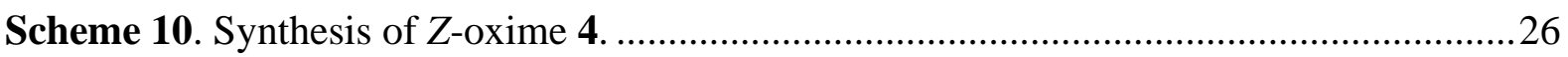

Scheme 11. Proposed mechanism of oxime formation. ....................................................27

Scheme 12. Proposed mechanism of oxime isomeric conversion.........................................2 27

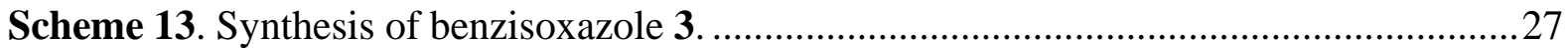

Scheme 14. Proposed mechanism of benzisoxazole formation..........................................28

Scheme 15. Proposed synthetic route tetrahydropyridopyrimidones 23 and $\mathbf{2 4}$...................31

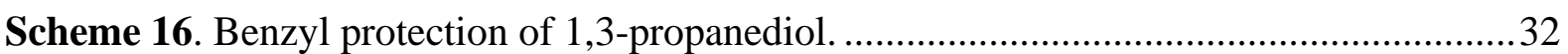

Scheme 17. Proposed mechanism of $\mathrm{Ag}_{2} \mathrm{O}$ mediated 1,3-propanediol.................................... 32

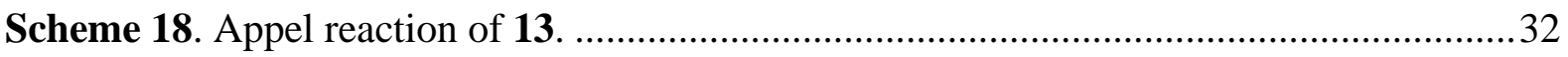

Scheme 19. Proposed Appel reaction mechanism.............................................................. 33

Scheme 20. Alkylation reaction of 15 with ethyl acetoacetate to give 17 ............................34

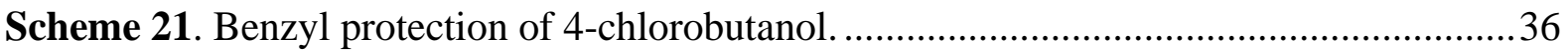

Scheme 22. Proposed mechanism of benzyl protection of 4-chlorobutanol. ...........................36

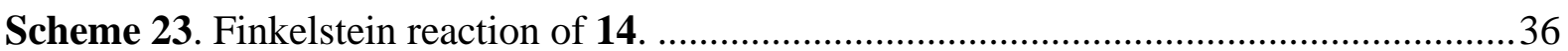

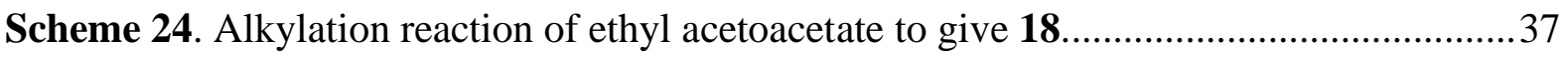

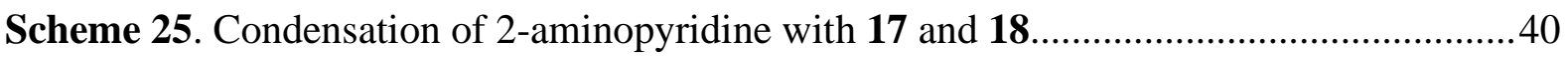

Scheme 26. Possible mechanisms of the condensation of $\mathbf{1 7}$ and $\mathbf{1 8}$ with 2-aminopyridine. .41

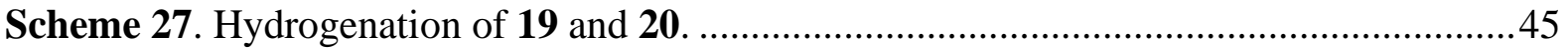

Scheme 28. Mechanism of palladium catalysed hydrogenative $O$-debenzylation.................49

Scheme 29. Proposed mechanism of $\mathrm{TiCl}_{4}$-mediated deprotection. …..................................53

Scheme 30. $\mathrm{TiCl}_{4}$-mediated benzyl-deprotection of pyridopyrimidones 19, 20, 21 and 22 ...54

Scheme 31. Proposed synthesis of analogues 8, 9, 28 and 29 via Appel reactions yielding iodides 25, 26, 31 and 32 . 
Scheme 32. Synthesis of analogue 9.

Scheme 33. Synthesis of analogues 8 and 29.

Scheme 34. Possible products of an alcohol (27) and iodide (31) mixture in the final condensation reaction. .63

Scheme 35. Synthesis of analogue 28. .64

Scheme 36. Synthesis of analogues 8, 9, 28 and 29. .65

Scheme 37. Overall synthetic route for risperidone analogues 8, 9, 28 and 29. .77 


\section{List of Tables}

Table 1. Cytokines and their related pathways. 7

Table 2. Tabulated NMR spectroscopic data $\left(500 \mathrm{MHz}, \mathrm{CDCl}_{3}\right)$ for benzisoxazole 3........29

Table 3. Tabulated NMR spectroscopic data $\left(500 \mathrm{MHz}, \mathrm{CDCl}_{3}\right)$ for alkylation product 18..38

Table 4. Reaction conditions investigated by Durrant toward the condensation of $\mathbf{1 7}$ and 2aminopyridine to form $19 .{ }^{98}$

Table 5. Tabulated NMR spectroscopic data $\left(500 \mathrm{MHz}, \mathrm{CDCl}_{3}\right)$ for pyridopyrimidone 19. .43

Table 6. Comparison of terminal triplet shifts and $J$-couplings of Appel starting materials and products. .64

Table 7. NMR parameters and settings for quantification experiments. 103 


\section{List of Abbreviations}

\begin{tabular}{|c|c|}
\hline$\alpha 1$ & Alpha-1 \\
\hline $\boldsymbol{\delta}$ & NMR chemical shift (ppm) \\
\hline${ }^{13} \mathrm{C}$ NMR & Carbon nuclear magnetic resonance \\
\hline${ }^{1} \mathbf{H}$ NMR & Proton nuclear magnetic resonance \\
\hline 5HT & 5-Hydroxytryptamine \\
\hline ABCB1 & ATP-binding cassette sub-family B member 1 \\
\hline $\mathrm{Ac}_{2} \mathrm{O}$ & Acetic anhydride \\
\hline $\mathrm{AcOH}$ & Acetic acid \\
\hline Ar & Aromatic \\
\hline Asp & Aspartic Acid \\
\hline atm. & Atmosphere \\
\hline BG-12 & Dimethyl fumarate \\
\hline ВММФ & Bone marrow derived macrophages \\
\hline Bn & Benzyl \\
\hline CNS & Central nervous system \\
\hline COSY & Correlation spectroscopy \\
\hline СТСМ & Complete T-cell media \\
\hline CYP2D6 & Cytochrome P450 2D6 \\
\hline CYP3A4 & Cytochrome P450 3A4 \\
\hline d & Doublet \\
\hline D2 & Dopamine-2 \\
\hline dd & Doublet of doublets \\
\hline ddd & Doublet of doublet of doublets \\
\hline DDQ & 2,3-Dichloro-5,6-dicyano-1,4-benzoquinone \\
\hline $\mathrm{dH}_{2} \mathrm{O}$ & Distilled water \\
\hline DMF & Dimethylformamide \\
\hline DMSO & Dimethyl sulfoxide \\
\hline dPBS & Dulbecco's phosphate-buffered saline \\
\hline dtd & doublet of triplet of doublets \\
\hline EAE & Experimental autoimmune encephalomyelitis \\
\hline ELISA & Enzyme-Linked Immunosorbent Assay \\
\hline
\end{tabular}




\begin{tabular}{|c|c|}
\hline EPS & Extrapyramidal Symptoms \\
\hline eq. & Equivalents \\
\hline $\mathbf{E t}_{2} \mathbf{O}$ & Diethyl ether \\
\hline EtOAc & Ethyl acetate \\
\hline EtOH & Ethanol \\
\hline FCS & Fetal calf serum \\
\hline GHB & Gamma-hydroxybutyrate \\
\hline HEPES & 4-(2-hydroxyethyl)-1-piperazineethanesulfonic acid \\
\hline HMBC & Heteronuclear multi-bond correlation \\
\hline HRMS & High resolution mass spectrometry \\
\hline HSQC & heteronuclear single quantum correlation \\
\hline $\mathbf{H z}$ & Hertz \\
\hline IFN- $\gamma$ & Interferon-gamma \\
\hline IL- & Interleukin \\
\hline IR & Infrared \\
\hline $\mathrm{K}_{2} \mathrm{CO}_{3}$ & Potassium carbonate \\
\hline kg & Kilogram \\
\hline $\mathbf{K}_{\mathbf{i}}$ & Inhibitory constant \\
\hline LPS & Lipopolysaccharide \\
\hline $\mathbf{m}$ & Multiplet \\
\hline$m / z$ & Mass to charge ratio \\
\hline МАРК & Mitogen-activated protein kinase \\
\hline MBn & para-Methylbenzyl \\
\hline МCP-1 & Monocyte chemo-attractant protein 1 \\
\hline МeOH & Methanol \\
\hline mg & Milligram \\
\hline $\mathrm{MgSO}_{4}$ & Magnesium sulfate \\
\hline MHz & Megahertz \\
\hline MS & Multiple sclerosis \\
\hline MTT & 3-(4,5-Dimethylthiazol-2-yl)-2,5-diphenyl-2H-tetrazol-3-ium \\
\hline mult. & Multiplicity \\
\hline NAAA & $\mathrm{N}$-acylethanolamine acid amidase \\
\hline NF-кB & Nuclear factor kappa-light-chain-enhancer of activated B cells \\
\hline
\end{tabular}


NMR

Nrf2

OD

$\mathbf{P d} / \mathrm{C}$

Ph

Phe

PMB

ppm

$p$-TsOH

qd

$\boldsymbol{R}_{f}$

RT

SA-HRP

$\mathbf{t}$

TfOH

TGF- $\beta$

Thr

TLC

TMB

TNF- $\alpha$

Trp

$\mathbf{U}$

UV

VUW

$\mathbf{w} / \mathbf{w}$
Nuclear magnetic resonance

Nuclear factor erythroid 2-related factor 2

Optical density

Palladium on carbon

Phenyl

Phenylalanine

para-Methoxylbenzyl

Parts per million

para-Toluenesulfonic acid

quartet of doublets

Retention factor

Room temperature

Streptavidin-horseradish peroxidase

triplet

Triflic acid

Transforming growth factor- $\beta$

Threonine

Thin layer chromatography

Tetramethyl benzidine

Tumour necrosis factor- $\alpha$

Tryptophan

Units

Ultraviolet

Victoria University of Wellington

weight per weight 


\title{
1 Introduction
}

\author{
1.1 Risperidone
}

\subsubsection{Background}

Risperidone is an atypical antipsychotic drug, originally developed by Janssen Pharmaceuticals in 1986 as a treatment for psychiatric disorders associated with schizophrenia. ${ }^{1}$ Its use has since expanded to the management of bipolar disorder ${ }^{2}$ and irritability associated with autism. ${ }^{3}$ As an atypical or second-generation antipsychotic, risperidone improved on the first generation of antipsychotics by reducing adverse effects associated with treatment, particularly extrapyramidal symptoms (EPS) like dyskinesia, akathisia, dystonia and parkinsonism. ${ }^{4}$ First generation antipsychotics, such as Haloperidol, competitively block post synaptic type-2 dopamine $\left(\mathrm{D}_{2}\right)$ receptors, resulting in their anti-hallucinogenic and anti-delusionary effects. ${ }^{5}$ However, this strong antagonism of the $\mathrm{D}_{2}$ receptor combined with a narrow therapeutic window was found to be the cause of EPS associated with treatment. ${ }^{6}$ Second generation antipsychotics target a wider range of receptors including $\mathrm{D}_{1}-\mathrm{D}_{5}$ receptors, type-2 serotonin $\left(5 \mathrm{HT}_{2}\right)$ receptors and $\alpha_{1}$ adrenergic receptors with varying affinities. This broader range of receptor affinities as well as a greater $5-\mathrm{HT}_{2} / \mathrm{D}_{2}$ binding ratio is thought to be the reason for the reduction in EPS associated with risperidone treatment. ${ }^{7}$

Structurally risperidone consists of a fluorinated benzisoxazole linked to a pyridopyrimidone moiety by a piperidine ring and a two-carbon alkyl spacer. Risperidone shares some structural features with other atypical antipsychotics (Figure 1). ${ }^{8}$ Paliperidone, a metabolite of risperidone, has a high structural similarity to its parent molecule, the difference being a 9hydroxy moiety. This has also been developed by Janssen as a schizophrenia treatment. ${ }^{9}$ In other antipsychotics, benzisoxazole or benzisothiazole structures are commonly linked to another moiety by a piperidine or piperazine ring. Alkyl spacers of varying lengths are frequently used to link these rings to another bulky group which have a large range of structural variance. 


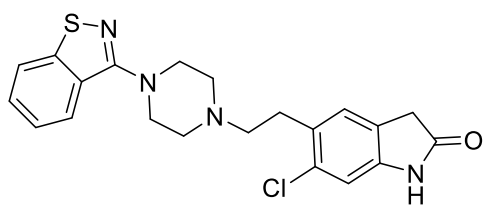

Ziprasidone

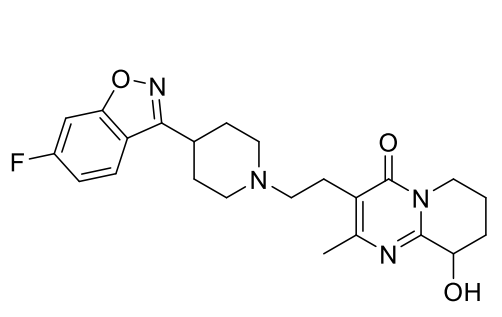

Paliperidone

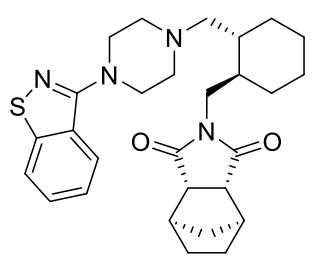

Lurasidone

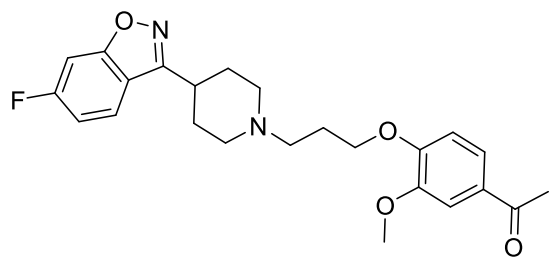

lloperidone
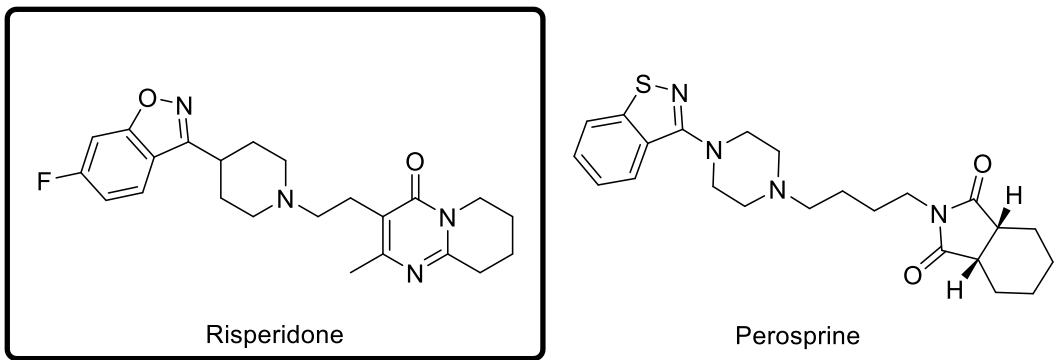

Perosprine

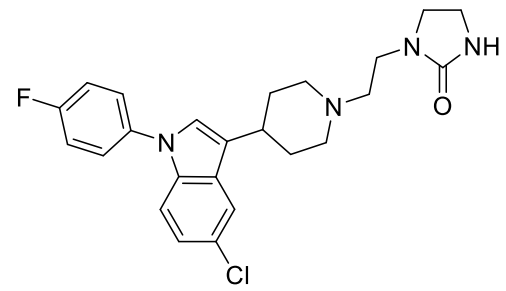

Sertindole

Figure 1. Risperidone and structurally related atypical antipsychotics.

Recently the crystal structures of risperidone bound to the $\mathrm{D}_{2}$ and 5- $\mathrm{HT}_{2 \mathrm{~A}}$ receptors have been elucidated. ${ }^{10-11}$ When bound to the $\mathrm{D}_{2}$ receptor, the benzisoxazole moiety of risperidone sits in a deep hydrophobic binding pocket created by the side chains of transmembrane helices III, V and VI (Figure 2). Of particular importance for binding are residues Thr119, Phe198, Phe382 and Trp386. When these residues were replaced individually by alanine, at least a ten-fold reduction in binding affinity was observed. Another hydrophobic pocket is found to enclose the pyridopyrimidone ring nearer to the entrance of the pocket. A salt bridge is also found to form between Asp114 and the nitrogen of the piperidine ring, further stabilising binding. The orientation of the pyridopyrimidone moiety in its unbound state significantly changes when bound to the $\mathrm{D}_{2}$ receptor in order to make a hydrophobic contact with Trp100. 


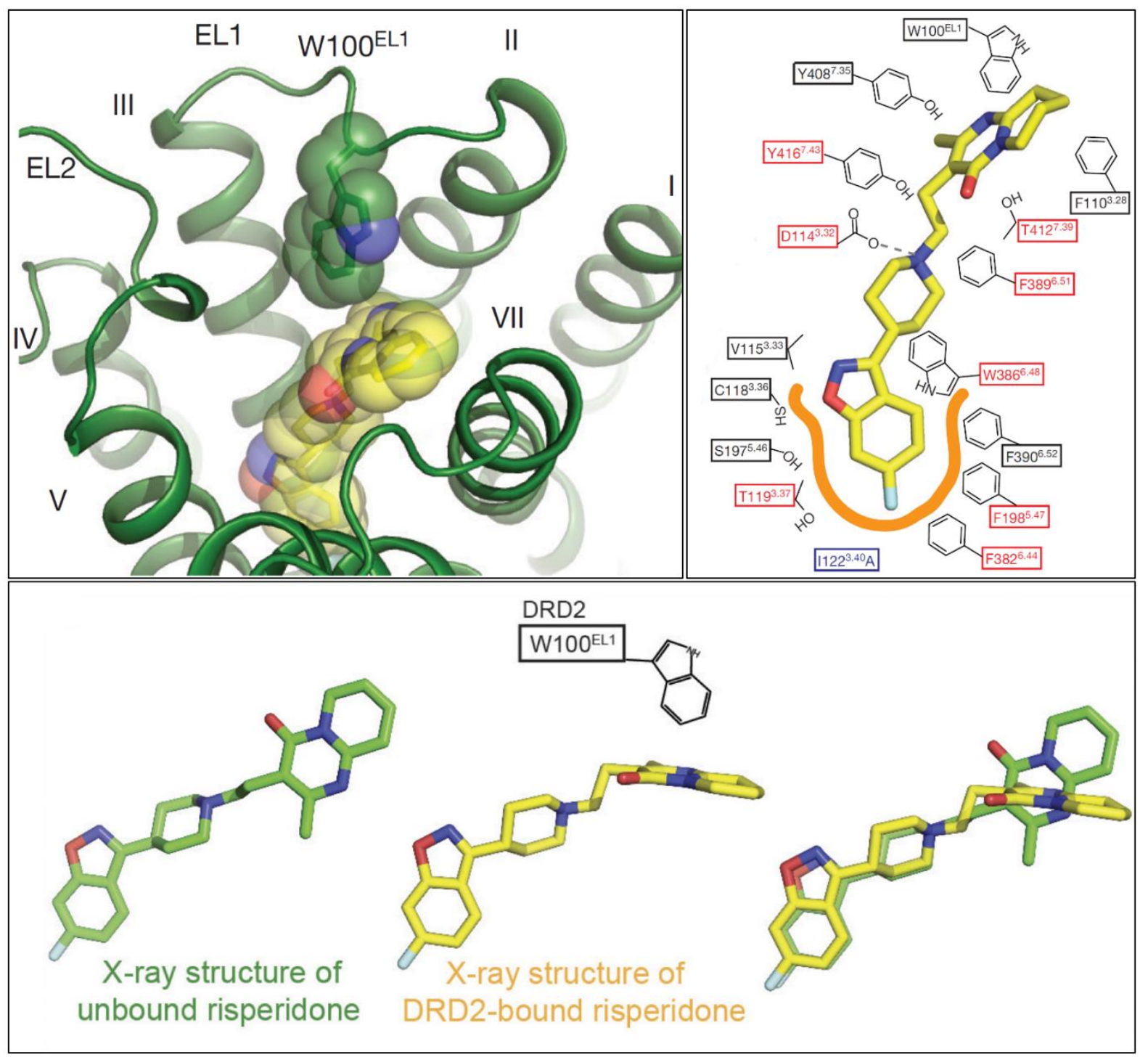

Figure 2. Top left, top down view of risperidone (yellow) bound in the pocket created by transmembrane helices III, V and VI (not shown). Top right, risperidone bound to $\mathrm{D}_{2}$ receptor. Bottom, risperidone orientation when unbound vs bound to $\mathrm{D}_{2}$ receptor. Bottom right, overlaid unbound (green) and bound (yellow). Adapted from Wang et al. Structure of the $D_{2}$ dopamine receptor bound to the atypical antipsychotic drug risperidone. Nature $\mathbf{5 5 5}$, $269 .^{10}$

Similar interactions are found when risperidone is bound to the $5-\mathrm{HT}_{2 \mathrm{~A}}$ receptor due to the conservation of many residues between the two aminergic receptors. ${ }^{12}$ This is indicated by the residues highlighted in green in Figure 3. As with the $D_{2}$ receptor, alanine mutagenesis of interacting residues in the benzisoxazole binding pocket results in a significantly reduced binding affinity, noted by residues in red. Mutation of Trp336 in particular caused a 1000-fold 
reduction in risperidone binding affinity. A salt bridge is also observed between an Asp residue and the piperidine ring. This is expected as it is a conserved residue among aminergic receptors. $^{12}$
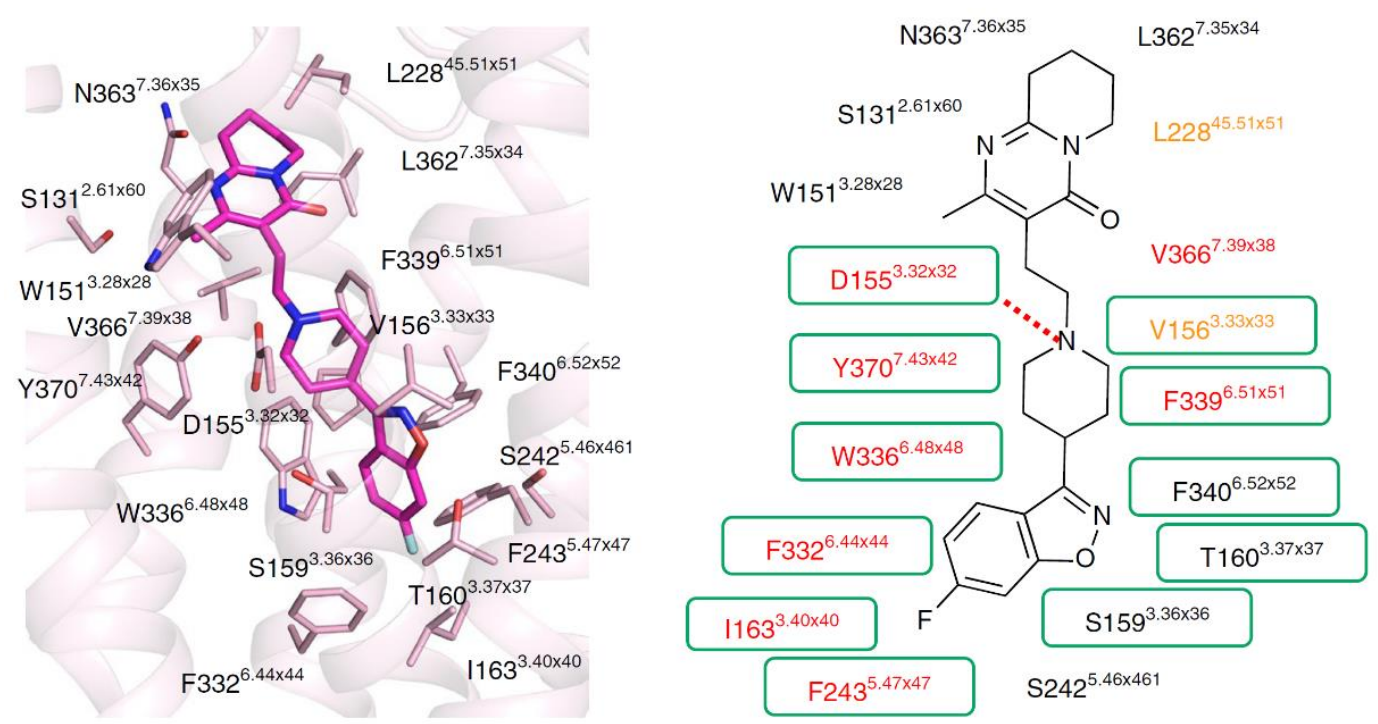

Figure 3. Left, 3-dimensional structure of risperidone bound to $5-\mathrm{HT}_{2 \mathrm{~A}}$ receptor. Right, interactions between risperidone and 5-HT2A. Adapted from Kimura et al. Structures of the 5$H T_{2 A}$ receptor in complex with the antipsychotics risperidone and zotepine. Nature Structural \& Molecular Biology 26, $121 .{ }^{11}$

\subsubsection{Pharmacokinetics and Receptor Affinities}

Risperidone is most commonly taken orally as a tablet with dosages ranging from 0.5 to 6 $\mathrm{mg} /$ day for schizophrenia patients. ${ }^{13}$ It is also provided as a depot injection, a slow-release, long-lasting form of administration. ${ }^{14}$ Following oral administration, bioavailability is approximately $68 \%$ and maximal plasma concentrations are achieved after approximately 1 hour. ${ }^{3,15}$ Plasma protein binding of risperidone to albumin and $\alpha$-acid glycoprotein is $90 \% .^{3}$ Risperidone is primarily metabolised in the liver by CYP2D6, and to a lesser extent CYP3A4, to give 9-hydroxyrisperidone (Paliperidone), an active metabolite. ${ }^{16-17}$ 9-Hydroxyrisperidone has a slightly reduced maximum plasma protein binding of $77 \% .{ }^{3}$ Risperidone has a mean halflife of approximately 3 hours while 9-hydroxyrisperidone has a substantially longer mean half- 
life of 24 hours. ${ }^{15}$ Efflux from cells is mediated by the ABCB 1 transporter ${ }^{18}$ and excretion of risperidone and its metabolites is primarily in the urine. ${ }^{3}$

Risperidone demonstrates very strong antagonistic affinity for 5- $\mathrm{HT}_{2 \mathrm{~A}}$ receptors $\left(\mathrm{K}_{\mathrm{i}}<1 \mathrm{nM}\right.$ in vitro) and a strong affinity for $\mathrm{D}_{2}$ and $\alpha_{1}$ receptors $(\mathrm{Ki}<10 \mathrm{nM}$ in vitro $) .{ }^{19-20}$ Antagonistic activity has also been observed for dopamine type-1, 3, $4\left(\mathrm{D}_{1}, \mathrm{D}_{3}, \mathrm{D}_{4},\right)$ serotonin type 1A, 1C, 7 (5- $\left.\mathrm{HT}_{1 \mathrm{~A}}, 5-\mathrm{HT}_{1 \mathrm{C}}, 5-\mathrm{HT}_{7}\right), \alpha 2$ adrenergic and $\mathrm{H}_{1}$ histaminergic receptors both in vivo and in vitro. ${ }^{21-22}$ Risperidone has also been shown act as an inverse agonist towards $\mathrm{D}_{2}, 5-\mathrm{HT}_{2 \mathrm{~A}}, 5$ $\mathrm{HT}_{2 \mathrm{C}}$ and $\mathrm{H}_{1}$ receptors. $^{23-24}$

Binding to $D_{2}$ and $D_{3}$ receptors in the limbic and cortical regions of the brain is thought to be the source of risperidone's therapeutic effects while binding to $\mathrm{D}_{2}$ receptors in the striatum may be the cause of motor side effects. ${ }^{25}$ Studies in schizophrenic patients show that a $1 \mathrm{mg} / \mathrm{day}$ oral dose results in a maximum $\mathrm{D}_{2}$ receptor occupancy of $50 \%{ }^{26}$ while larger doses of 3 and 6 $\mathrm{mg} /$ day result in $72 \%$ and $82 \% \mathrm{D}_{2}$ receptor occupancy respectively. ${ }^{27}$ 5- $\mathrm{HT}_{2 \mathrm{~A}}$ receptor occupancy was found to be greater, with 3 and $6 \mathrm{mg} /$ day dosing regimens resulting in $83 \%$ and $95 \%$ receptor occupancy, respectively. ${ }^{27}$

Atypical antipsychotics in general have a greater $5-\mathrm{HT}_{2 \mathrm{~A}} / \mathrm{D}_{2}$ binding ratio compared to first generation antipsychotics. ${ }^{28}$ Risperidone has a high $5-\mathrm{HT}_{2 \mathrm{~A}} / \mathrm{D}_{2}$ ratio of 21 , while only ziprasidone (31) and clozapine (45) are higher. ${ }^{29}$ In contrast, the majority of first generation antipsychotics have a $5-\mathrm{HT}_{2 \mathrm{~A}} / \mathrm{D}_{2}$ binding ratio less than one. Greater $5-\mathrm{HT}_{2 \mathrm{~A}}$ antagonism has been associated with an atypical drug profile and is required for treatment of the negative symptoms of schizophrenia. ${ }^{22}$ Nonetheless, $\mathrm{D}_{2}$ antagonism is required for antipsychotic activity and is responsible for treatment of the positive symptoms of schizophrenia. It has been hypothesised that strong antagonism of 5- $\mathrm{HT}_{2} \mathrm{~A}$ receptors alongside weaker antagonism of $\mathrm{D}_{2}$ receptors observed with atypical antipsychotics is responsible for the reduced incidence of EPS.

\subsubsection{Side Effects}

Risperidone produces a range of side effects when used in the treatment of schizophrenia. The most commonly observed major side effects in clinical trials and Phase IV monitoring were EPS-related events including tremor, dyskinesia and hyperkinesia. ${ }^{30-31}$ These side effects are also common in patients being treated for bipolar mania. ${ }^{32} \mathrm{~A}$ common relationship observed with antipsychotics is as $\mathrm{D}_{2}$ receptor occupancy increases, so does the likelihood of EPS. This 
correlation is particularly strong when $\mathrm{D}_{2}$ receptor occupancy increases past $80 \% .{ }^{33}$ This increase in EPS occurs most commonly in patients taking larger doses of risperidone (6 $\mathrm{mg} /$ day) despite the near complete $5-\mathrm{HT}_{2 \mathrm{~A}}$ receptor occupancy associated with treatment. ${ }^{34}$

Minor side effects frequently reported include sleepiness and moderate weight gain. ${ }^{35}$ Risperidone is a strong binder of 5- $\mathrm{HT}_{2 \mathrm{~A}}$ and $\mathrm{H}_{1}$ and antagonism of these receptors has been associated with deep sleep and sedation respectively. ${ }^{36}$ Weight gain is also associated with $\mathrm{H}_{1}$ antagonism as well as $5-\mathrm{HT}_{2 \mathrm{C}}$ binding. ${ }^{36}$ Risperidone-associated weight gain has also been correlated with altered levels of inflammatory factors when used in the treatment of schizophrenia. ${ }^{37}$

\subsection{Multiple Sclerosis and Cytokines}

\subsubsection{Multiple Sclerosis}

Multiple sclerosis (MS) is the most common chronic inflammatory, demyelinating and neurodegenerative disease in people under 40 with over 2.2 million cases reported worldwide in 2016. ${ }^{38-39}$ It is an autoimmune disease caused by demyelinating lesions that accumulate along the spinal cord and in the brain. This damage is caused by immune system attack on the myelin sheath surrounding neurons. As over 200 alleles are associated with this multifactorial disease it is not a simple condition. ${ }^{40}$ Demyelination causes relapses, reversible periods of neurological deficits that affects a person's movement and bladder and bowel function and can last for days or weeks. The disease can be classified as relapsing, characterised by relapses at irregular intervals with complete or incomplete recovery. ${ }^{41}$ In a minority of cases disease is progressive. ${ }^{41}$ This is characterised by symptoms worsening over time with acute periods of relapse, sometimes without full clinical recovery.

\subsubsection{Current Treatments}

Current treatments, such as Natalizumab and BG-12, aim to reduce the rate of these relapses and the growth of new lesions. Natalizumab works by reducing T-cell trafficking to the central nervous system, one of the possible causes of inflammation. ${ }^{42}$ However, after public release it was found to increase the chances of patients developing progressive multifocal 
leukoencephalopathy and now carries a black box warning. ${ }^{43-44}$ BG-12 reduces the rate of disease progression by activating the Nrf2 antioxidant response pathway, ${ }^{45}$ as well as potentially suppressing pro-inflammatory cytokine production or associated downstream pathways. ${ }^{46}$ It is currently used to treat relapsing forms of MS. Vitamin D has even been suggested to lower the risk of MS although there is some disagreement over its efficacy. ${ }^{47-50}$

\subsubsection{Cytokines and Multiple Sclerosis}

Cytokines are a broad category of small proteins important for cell signalling. They are unable to cross lipid bilayers so rely on interactions with cell surface receptors to initiate intracellular signalling cascades. They are predominantly produced by $\mathrm{T}$ helper cells and macrophages. ${ }^{51}$ Many cytokines are associated with pro- and anti-inflammatory pathways, or both, as listed in Table 1. T helper cells produce interleukin (IL)-2, IL-4, IL-5, IL-10, IL-13, tumour necrosis factor- $\alpha$ (TNF- $\alpha)$, IFN- $\gamma$ and transforming growth factor- $\beta$ (TGF- $\beta) .{ }^{52-53}$ As well as some of the previously mentioned cytokines, macrophages also produce IL-1 $\beta$, IL- 6 and IL-23. ${ }^{54}$

Table 1. Cytokines and their related pathways.

\begin{tabular}{|c|c|c|}
\hline $\begin{array}{c}\text { Associated } \\
\text { Pathways }\end{array}$ & Cytokine & Refs. \\
\hline Pro-inflammatory & TNF- $\alpha$, IFN- $\gamma$, IL-1 $\beta$, IL-2, IL-6, IL-12 IL-15, IL-17, IL-18 & $51,55-58$ \\
\hline Anti-inflammatory & TGF- $\beta$, IFN- $\alpha$, IL-2, IL-4, IL-6, IL-10, IL-11, IL-13 & $51,55,58-59$ \\
\hline
\end{tabular}

Uncontrolled production and secretion of pro-inflammatory cytokines has been widely observed in cases of MS and is suspected to be one of the causes of inflammation associated with the disease. In particular, dysregulation of IFN- $\gamma$, TNF- $\alpha$, IL-12 and IL-6 has been demonstrated to be important in the progression and severity of disease. To study these effects, experimental autoimmune encephalomyelitis (EAE) is often used as an animal model for MS. ${ }^{60}$ EAE is commonly used in mice or rats where the condition is artificially induced by immunisation with myelin-derived antigens. ${ }^{61}$ 
IFN- $\gamma$ can be considered a pro-inflammatory cytokine because of its regulatory activity towards TNF- $\alpha$ and nitric oxide. IFN- $\gamma$ expression has been shown to begin at the onset of central nervous system (CNS) inflammation, increase at the peak of disease in EAE and subside during remission. ${ }^{62}$ Overexpression of IFN- $\gamma$ results in demyelination throughout the CNS. ${ }^{63}$ Surprisingly, IFN- $\gamma$ knockout mice were also found to be susceptible to EAE induction. ${ }^{64}$ These knockout mice exhibited large amounts of CNS inflammation and a further progressed form of EAE. This led to the suggestion that IFN- $\gamma$ is not vital for induction or continuation of EAE. In humans, increased levels of IFN- $\gamma$ have been observed in patients with progressive forms of MS. ${ }^{65}$ This dysregulation of IFN- $\gamma$ production is suspected to be important in the transition of MS from a relapsing to a progressive form of the disease.

TNF- $\alpha$ is a pro-inflammatory cytokine produced by immune cells as well as astrocytes and neurons. Artificially increased TNF- $\alpha$ levels in mice results in a prolonged disease period for EAE and more severe infiltration of the spinal cord by immune cells. ${ }^{66}$ Injection with antiTNF- $\alpha$ antibodies prior to TNF- $\alpha$ treatment resulted in a dose-dependent reduction in disease severity suggesting a direct correlation between TNF- $\alpha$ levels and EAE severity. In transgenic mice, induced TNF- $\alpha$ expression resulted in a chronic inflammatory, demyelinating disease in $100 \%$ of subjects. ${ }^{67}$ Extensive T-cell infiltration was observed particularly in the meninges of the brain and the parenchyma of the CNS. Again, this was preventable by introduction of TNF$\alpha$ antibodies. In humans, MS lesions have been associated with significantly increased levels of TNF- $\alpha$ which is expressed by macrophages and microglia found in chronic lesions. ${ }^{68-69}$ High cerebrospinal fluid levels of TNF- $\alpha$ have also been associated with severity and progression of MS, particularly in patients with a chronic progressive form of the disease. ${ }^{70}$

IL-12 is involved in the differentiation and proliferation of $\mathrm{T}$ cells and produced primarily by monocytes and dendritic cells. In rat models that had recovered from induced EAE, administration of IL-12 was able to induce a relapse in disease. ${ }^{71}$ This was observed as an increase in CNS lesions, which coincided with increased macrophages peripheral to the surrounding blood vessels. Nitric oxide synthase, catalyst of nitric oxide production, was also upregulated in macrophages. Increased levels of nitric oxide and its metabolites have since been associated with progression of MS. ${ }^{72}$ In humans, IL-12 is found to be upregulated in the lesions and not in other areas of the brain of MS patients. ${ }^{73}$ Inhibitors of IL-12 production are now used for treatment of relapsing forms of MS. ${ }^{74-75}$ 
IL-6 can act as a pro- and anti-inflammatory cytokine whose production in monocytes and macrophages is stimulated by IL- $1 .{ }^{76}$ Upregulation of IL-6 in the CNS coincides with the induction phase of EAE in murine and rat models. ${ }^{77-78}$ Elevated plasma levels of IL-6 have also been observed in MS patients. ${ }^{79}$ In the brain of MS patients, IL-6 levels are found to be elevated. ${ }^{80-81}$ This is localised to macrophages and astrocytes found within lesions. Schönrock et $a l .{ }^{80}$ noted that the number of IL-6 expressing cells was greatest in inactive demyelinated lesions with large numbers of oligodendrocytes, suggesting that IL-6 may also play a role in remyelination.

\subsection{Risperidone, Inflammation and Cytokines}

Multiple studies show that some of the psychosis related symptoms observed in schizophrenia cases develop from neuroinflammation and immune system dysregulation. Risperidone treatment has been shown to have anti-inflammatory effects by modulation of cytokine profiles and cellular immune responses.

Atypical antipsychotics including risperidone have been shown to suppress production of proinflammatory cytokines while also upregulating production of the anti-inflammatory cytokine IL-10 in LPS-treated mice. ${ }^{82}$ Further research in rats shows risperidone also decreases LPS-induced production of pro-inflammatory cytokines IL-1 $\beta$ and TNF- $\alpha$, as well as MAPK and NF- $\mathrm{NB} .{ }^{83}$ Risperidone treatment also restored activity of anti-inflammatory pathways usually suppressed by LPS treatment.

A small-scale study in schizophrenia patients treated with risperidone showed changes in cytokine levels after 3 months of treatment. ${ }^{84}$ Most notably, IL-10 levels increased while IFN$\gamma$ levels decreased. As IL-10 is a suppressor of IFN- $\gamma$, this was an unsurprising connection, but it is unclear if IFN- $\gamma$ suppression was directly caused by the upregulation of IL-10 or other unspecified mechanisms. These modifications in cytokine levels were also seen in nonresponders to risperidone treatment, indicating the effect was unlikely to be entirely related to a specific psychopathological state.

Cytokine levels were also found to be altered in children with autism who were prescribed risperidone to manage irritability associated with their condition. ${ }^{85}$ Changes in plasma proinflammatory cytokine levels were more pronounced in responders to treatment vs nonresponders. This indicates a relationship between a patient's psychopathological state and the 
effect risperidone treatment has on their cytokine levels. This is contrary to the study previously described in schizophrenia patients. ${ }^{84}$

In patients with first episode paranoid schizophrenia, serum levels of IL-2, IL-6, IL-18 and TNF- $\alpha$ were found to be significantly reduced after 1 to 6 months, demonstrating an immunosuppressive effect in schizophrenia patients involving pro- and anti-inflammatory cytokines. ${ }^{86}$ Another study showed an initial anti-inflammatory effect where levels of IL-1 $\beta$, IL-6, and TNF- $\alpha$ decreased in the first month but reverted to baseline levels at the end of a 6month risperidone treatment period. ${ }^{37}$ However, baseline levels of these pro-inflammatory cytokines were greater in schizophrenia patients vs the control group. Juncal-Ruiz et al. ${ }^{87}$ suggested that the difference in baseline levels of these cytokines may be as a result of prior exposure to antipsychotic drugs because their study showed no difference in baseline levels of IL-1 $\beta$, IL-6 and TNF- $\alpha$ between healthy volunteers and drug naïve schizophrenia patients.

Risperidone has been shown to inhibit the IFN- $\gamma$ induced production of nitric oxide and proinflammatory cytokines in microglia. ${ }^{88}$ Haloperidol showed a much lesser inhibition of these pathways, leading to the suggestion that risperidone's wider aminergic receptor binding profile could be responsible for its improved inhibitory activity.

\subsection{Alkyl Spacer Effects in Drug Molecules}

A common structural motif in drug molecules, particularly those targeting the dopamine and serotonin receptors, is an extended alkyl spacer connecting two different moieties. Often in the development of a drug, structure-activity relationship studies will modify the length of alkyl spacers as this can drastically alter receptor binding profiles. This can be as a result of the increased flexibility afforded by a longer chain.

For example the $\mathrm{N}$-acylethanolamine acid amidase (NAAA) inhibitory potency of pyrrolidine amide derivatives synthesised by Zhou et al. ${ }^{89}$ increased with chain length and flexibility. However, the increased length also reduced their selectivity for NAAA when compared to analogues with more restricted linkers. ${ }^{89}$

More specifically in neurotropic drugs targeting the various dopamine and serotonin receptors, the distance between two different moieties, linked by an alkyl chain and often with a nitrogencontaining 6-membered ring, has been shown to have large effects on receptor binding profiles. 
Multiple studies investigating the structure-activity relationships of compounds targeting 5$\mathrm{HT}_{7}$ have found that longer alkyl linkers correlate to an improved binding affinity for $5-\mathrm{HT}_{7}$. Development of selectivity over other serotonin and dopaminergic receptors has also been possible from the introduction of these modifications. Volk et al. ${ }^{90}$ found that a four-carbon alkyl spacer was optimal for 5-HT 7 binding with minimal off target binding to 5-HT $1 \mathrm{~A}$ (Figure 4). Three- and five-carbon spacers were also investigated but exhibited strong off-target binding and reduced $5-\mathrm{HT}_{7}$ binding respectively. The efficacy of the four-carbon compound was confirmed in vivo. This was also consistent with prior work on structurally similar compounds where a four-carbon alkyl spacer was found to be superior in terms of 5-HT 7 affinity and specificity. ${ }^{91}$ Further study of $5-\mathrm{HT}_{2 \mathrm{~A}}, 5-\mathrm{HT}_{6}$ and $5-\mathrm{HT}_{7}$ antagonists showed a fourcarbon alkyl spacer to provide an improved binding affinity for these receptors compared to a three-carbon spacer compound (Figure 5). ${ }^{92}$ Interestingly, introducing a semi-rigid fouralkylene spacer into the compound further improved the molecule's binding affinity for $5-\mathrm{HT}_{7}$. This is likely because adding rigidity to the molecule will lock it into a more bioactive conformation. Upon interaction with $5-\mathrm{HT}_{7}$, less conformational rearrangement is then required for it to bind.

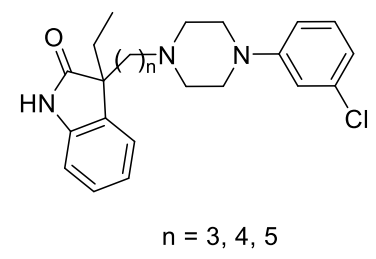

Figure 4. Oxindoles targeting 5-HT7 synthesised by Volk et al..$^{90}$

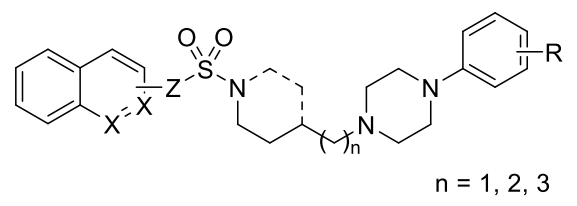

Figure 5. Quinoline- and isoquinoline-sulfonamides synthesised by Zajdel et al. ${ }^{92}$

The flexibility afforded by an extended alkyl linker when compared to more conformationally restricted linkers has also been investigated. Bojarski et al. ${ }^{93}$ found a tetramethylene linker to 
be optimal for $5-\mathrm{HT}_{7}$ binding and specificity when compared to more conformationally restricted linkers such as alkenes and cyclohexanes (Figure 6).
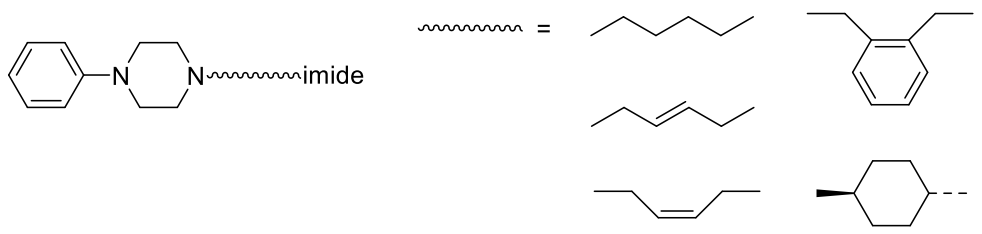

Figure 6. Arylpiperazines synthesised by Bojarski et al. ${ }^{93}$

Smid et al. ${ }^{94}$ investigated the effects of altering the alkyl linker length while optimising a molecule for $\mathrm{D}_{2}$ receptor binding (Figure 7). Compounds were tested for $\mathrm{D}_{2}$ receptor binding and serotonin reuptake inhibition in vitro and in vivo. In vitro experiments show the threecarbon compound to have a superior binding profile for the $\mathrm{D}_{2}$ and serotonin reuptake inhibition. The four- and five-carbon variants had a slightly increased binding affinity for $\mathrm{D}_{2}$ but also significantly reduced serotonin reuptake inhibitory activity.

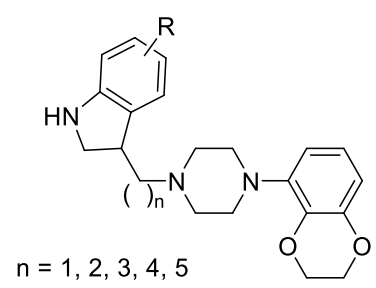

Figure 7. Piperazines synthesised by Smid et al. ${ }^{94}$

\subsection{Previous Studies at Victoria University of Wellington}

\subsubsection{Risperidone Reduces Disease Severity in EAE}

Researchers at VUW examined the effects of risperidone treatment on EAE on mice. ${ }^{95}$ Following induction of EAE, mice were treated with risperidone orally at either 1 or 3 $\mathrm{mg} / \mathrm{kg} /$ day via their drinking water. No obvious adverse effects were observed except for moderate weight gain as previously reported. 
Severity of disease was found to be reduced in a dose-dependent manner as measured by a reduction in the size and number of spinal cord lesions, which decreased with treatment compared to control. ${ }^{95}$ However, the incidence of disease was similar between treated and untreated subjects.

Risperidone treatment altered the production of specific cytokines measured in the peripheral lymphoid organs. ${ }^{95}$ Significantly decreased levels of IL-2, IL-4, IL-13 and IL-17a were observed while IFN- $\gamma$ production was unaffected, indicating that risperidone modulates antigen-specific T-cell responses.

In vitro testing with IFN- $\gamma$-primed bone marrow derived macrophages (BMMФ) showed that risperidone altered their ability to bias naïve T-cells. ${ }^{95}$ Risperidone had a direct immunomodulatory effect on BMMФ. A reduction in pro-inflammatory cytokine levels and an altered ability for BMMФ to bias naïve T-cells was observed. Little effect was observed on activation of macrophages in vivo during EAE. Risperidone reduced the activation of microglia and macrophages in the CNS.

Use of $\mathrm{D}_{1}$ and $\mathrm{D}_{2}$ antagonists did not cause inhibition of pro-inflammatory cytokines. ${ }^{95}$ This lead the authors to suggest that risperidone's immunomodulatory activity is achieved through a unique and yet to be described mechanism, independent of $\mathrm{D}_{1}$ and $\mathrm{D}_{2}$ antagonism. As the concentration of doses administered were physiologically comparable to those used for schizophrenia treatment, it was suggested that they could have a therapeutic use for inflammatory diseases like MS. The safety, toxicity and side effects of risperidone are well understood which would also make further investigation in humans more straight forward. Risperidone and clozapine have since been used in Phase Ib/IIa trials to assess the possibility of their being repurposed to treat MS. ${ }^{96}$

\subsubsection{Immunomodulatory Activity of Risperidone Analogues in Macrophages}

To further investigate the immunomodulatory activity of risperidone, VUW researchers synthesised truncated analogues of risperidone and used them in structure-activity relationship studies. ${ }^{97}$ Their aim was to discern what components of the molecule were responsible for the immunomodulatory effects of risperidone. 
Analogues investigated were the truncated benzisoxazole (3) and the ring-open variant oxime (4), unsaturated pyridopyrimidone (2) and truncated pyridopyrimidone analogues $(\mathbf{5 , 6 , 7})$ (Figure 8). ${ }^{97}$ These were synthesised using known methodologies and their ability to modify the production of pro-inflammatory cytokines IL-6, IL-12, TNF- $\alpha$ and monocyte chemoattractant protein 1 (MCP-1) in primed macrophages was assessed. Their activity was compared to unmodified risperidone (1). Cytokine assays showed that only the unsaturated risperidone (2) and ring closed benzisoxazole (3) modified cytokine levels in RAW 264.7 macrophages and ВMMФ.

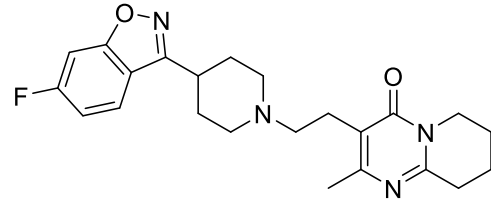

Risperidone (1)

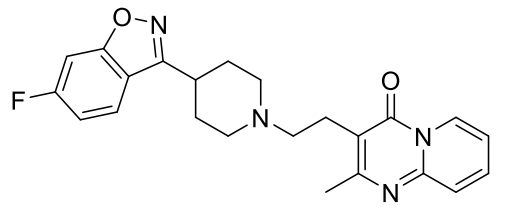

2

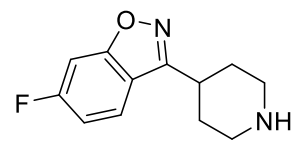

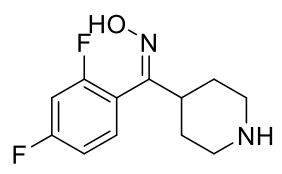

4<smiles>Cc1nc2n(c(=O)c1CCO)CCCC2</smiles><smiles>Cc1nc2ccccn2c(=O)c1CCO</smiles><smiles>Cc1cc(=O)n2ccccc2n1</smiles>

7

Figure 8. Risperidone analogues synthesised by VUW researchers. ${ }^{97}$

Risperidone was shown to upregulate production of IL-10 and suppress production of IL-12 and MCP-1. ${ }^{97}$ The unsaturated analogue 2 reduced production of IL-12 and MCP-1 to a lesser extent and had no measurable effect on IL-10 production. The truncated benzisoxazole 3 was more effective at suppressing production of IL-12 and MCP-1 compared to 2 but also showed no effect on IL-10 production. MTT assays showed that the unsaturated analogue 2 was less toxic than risperidone, with no change in macrophage cell viability at concentrations of up to $100 \mu \mathrm{M}$. At similar concentrations, risperidone treated cell viability was approximately $30 \%$ 
less than control. The truncated benzisoxazole $\mathbf{3}$ was more toxic than risperidone in macrophages, particularly at lower concentrations $(20 \mu \mathrm{M})$. This increase in toxicity observed with 3 and the subsequent reduction in cell number may be the cause of the reduction in cytokine production. As the oxime $\mathbf{4}$ did not have any effect on cell viability or cytokine production, it is likely the benzisoxazole moiety is required for immunomodulatory activity. The truncated pyridopyrimidone analogues $(\mathbf{5 , 6 , 7 )}$ had no observable effect on cytokine production or macrophage viability, however the pyridopyrimidone moiety appears to be important for immunomodulatory activity as demonstrated by risperidone $\mathbf{1}$ and the unsaturated analogue $\mathbf{2}$ compared to the truncated benzisoxazole $\mathbf{3}$.

\subsection{Project Aims}

The aim of this project is to synthesis two extended linker analogues of risperidone (Figure 9). Analogues 8 and 9 have three- and four-carbon alkyl spacers, respectively. RAW 264.7 cells will then be treated with analogues $\mathbf{8}$ and $\mathbf{9}$ and the cytotoxicity and pro-and anti-inflammatory cytokine production associated with treatment will be assessed. This will allow for the mechanism of action responsible for the anti-inflammatory activity of risperidone to be explored.

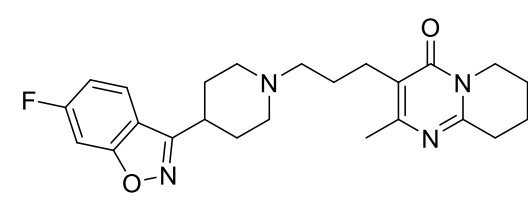

8

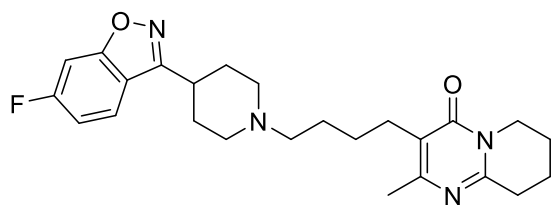

9

Figure 9. Three- and four-carbon linker analogues of risperidone.

\subsubsection{Synthetic Chemistry}

Synthesis of two extended-linker analogues of risperidone (8 and 9) will require the use of commercially available starting materials. This builds on earlier work by Durrant who generated three- and four-carbon linker benzyl-protected pyridopyrimidones as precursors for 
these analogues. ${ }^{98}$ Durrant's research explored catalytic hydrogenation for benzyl deprotection but was found to be unsuccessful after multiple attempts. This project aims to utilise the methodology developed by Durrant to synthesise the protected pyridopyrimidones, establish a suitable method for $O$-debenzylation and complete the synthesis of risperidone analogues $\mathbf{8}$ and 9.

In the synthesis of truncated and unsaturated analogues of risperidone, Zareie et al. ${ }^{97}$ employed known methodology for the synthesis of the benzisoxazole fragment (Scheme 1). Acetylation of the amine starting material was followed by a Friedel-Crafts acylation. This was followed by generation of an oxime (4) that was used in a nucleophilic aromatic substitution reaction to afford benzisoxazole 3. This chemistry is well established and was used in the synthesis of risperidone itself so was expected to be straight-forward.
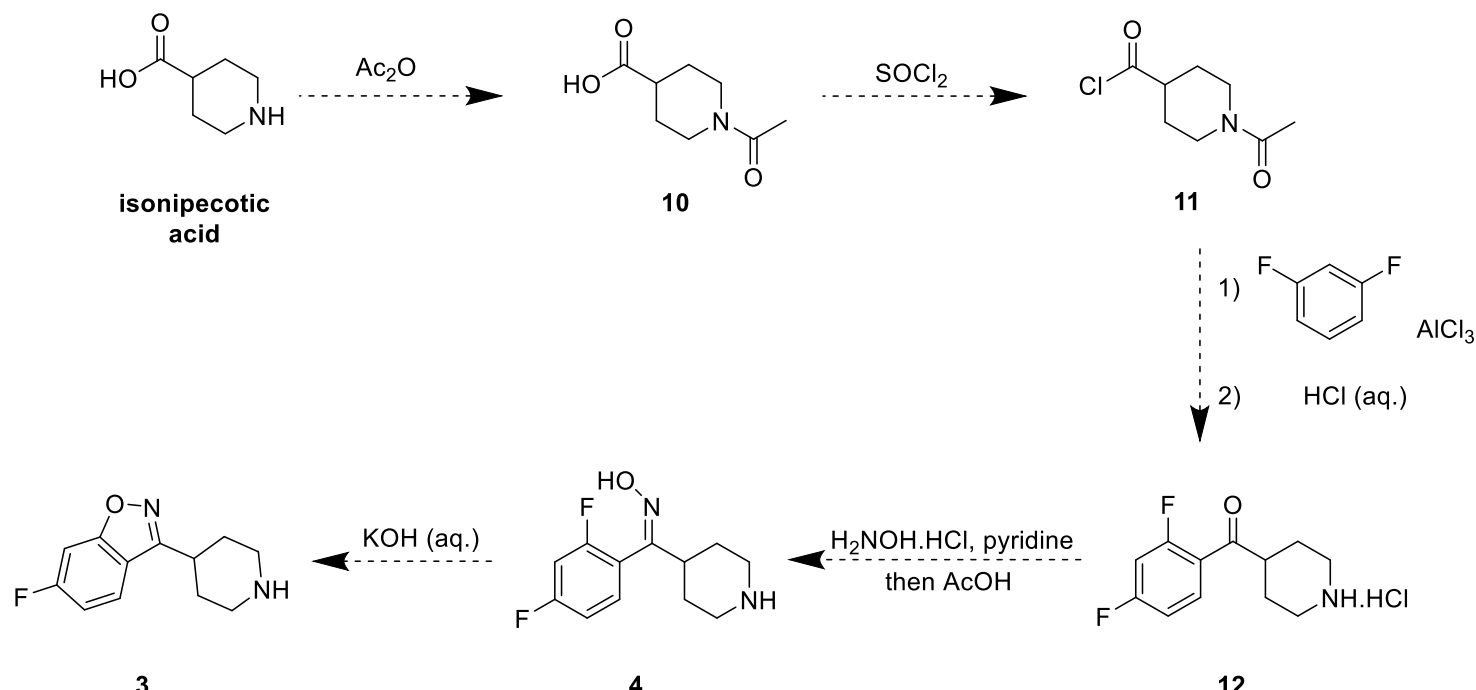

Scheme 1. Proposed synthesis of benzisoxazole 3.

Durrant's synthesis of extended linker coupled benzyl protected pyridopyrimidones differs from methodology used in the commercial production of risperidone which employs a cyclic starting material that does not require protecting groups for pyridopyrimidone synthesis. ${ }^{98}$ The synthetic route developed by Durrant for the extended-linker analogues involved benzyl monoprotection of alcohol functionality in the first step. Two different starting materials were required: 1,3-propanediol for the three-carbon analogue and 4-chlorobutanol for the four- 
carbon analogue. The choice of the latter is due to the unavailability of 1,4-butanediol, which is a controlled substance in New Zealand as it is a prodrug for the class B narcotic GHB. ${ }^{99}$

Benzyl protection of these starting materials required two different methods. A silver oxide mediated method was used for selective monoprotection of 1,3-propanediol and while an acidcatalysed method was used for benzyl protection of 4-chlorobutanol (Scheme 2). Appel and Finkelstein reactions were then required to yield iodoalkanes $\mathbf{1 5}$ and 16, respectively, in preparation for subsequent alkylation reactions with ethyl acetoacetate. The alkylated products 17 and 18 afforded from these reactions were then subject to condensation with 2aminopyridine. These reactions yield extended linker coupled pyridopyrimidones $\mathbf{1 9}$ and 20.

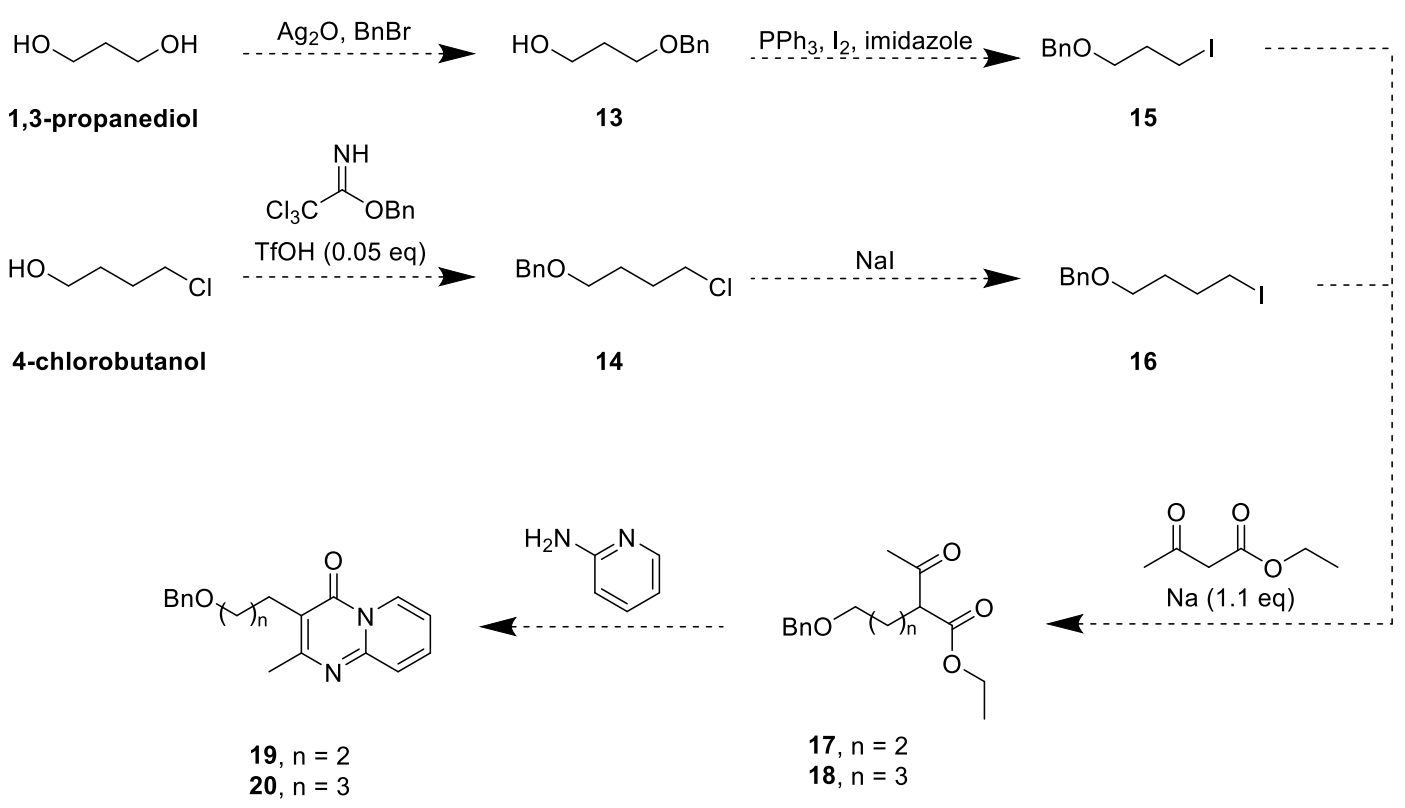

Scheme 2. Proposed synthesis of extended linker coupled pyridopyrimidones $\mathbf{1 9}$ and $\mathbf{2 0 .}$

Palladium-catalysed hydrogenation was then required to afford saturated pyridopyrimidones 21 and 22. Durrant ${ }^{98}$ suggested the use of catalytic hydrogenation for saturation of the pyridine ring could simultaneously remove the benzyl protecting group and afford alcohols $\mathbf{2 3}$ and $\mathbf{2 4}$. Unfortunately, this method only hydrogenated the pyridine ring, delivering 21 and 22 (Scheme 3). Therefore, debenzylation is required in a separate step. 


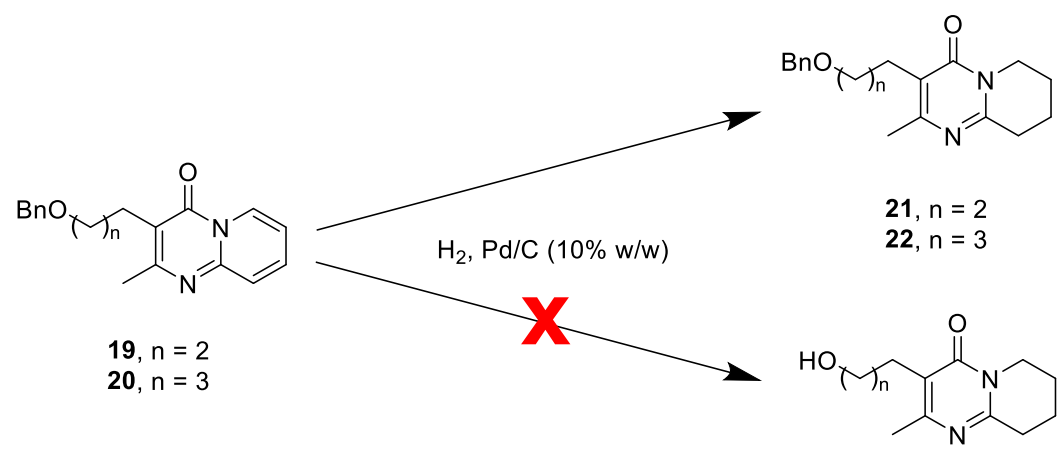

23, $n=2$

$24, n=3$

Scheme 3. Outcome of Durrant's Pd-catalysed hydrogenation reactions. ${ }^{98}$

Multiple methods have been employed for the cleavage of benzyl ethers in the literature. $\mathrm{TiCl}_{4}$ facilitates Lewis acid-mediated deprotection under mild conditions and can provide good selectivity, particularly in the total synthesis of natural products. ${ }^{100-102}$ Hydrogenolysis by transfer hydrogenation may also be suitable as reactions can be carried out in $\mathrm{MeOH}$, a solvent that 21 and 22 are soluble in. ${ }^{103-104}$ Oxidative cleavage of benzyl ethers can be achieved with DDQ, as this reagent has been applied to debenzylation in the synthesis of a range of substrates, including steroids, heterocycles and highly functionalised natural product. ${ }^{105-107}$ The use of photoirradiation at $365 \mathrm{~nm}$ has also been demonstrated to aid in $O$-debenzylation of simple substrates. ${ }^{108}$ In the current work, DDQ, $\mathrm{TiCl}_{4}$ and $\mathrm{Pd} / \mathrm{C}$ catalysed hydrogenolysis under more forcing conditions were explored for deprotection of $\mathbf{2 1}$ and $\mathbf{2 2}$ as these methods were expected to be compatible with the functional groups present in the molecules and will afford $\mathbf{2 3}$ and $\mathbf{2 4}$ (Scheme 4).

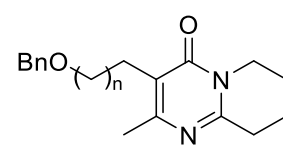

21, $n=2$

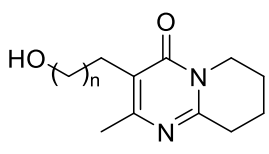

23, $n=2$

Scheme 4. Proposed DDQ-mediated deprotection of 21 and 22. 
Following deprotection, alcohols $\mathbf{2 3}$ and $\mathbf{2 4}$ will be subject to Appel reactions similar to those previously described (Scheme 5). ${ }^{97}$ This will provide iodides $\mathbf{2 5}$ and $\mathbf{2 6}$ which will then be coupled with benzisoxazole 3 using procedures established for the synthesis of risperidone, yielding the required three- and four-carbon extended linker analogues of risperidone $(\mathbf{8}, \mathbf{9})$.
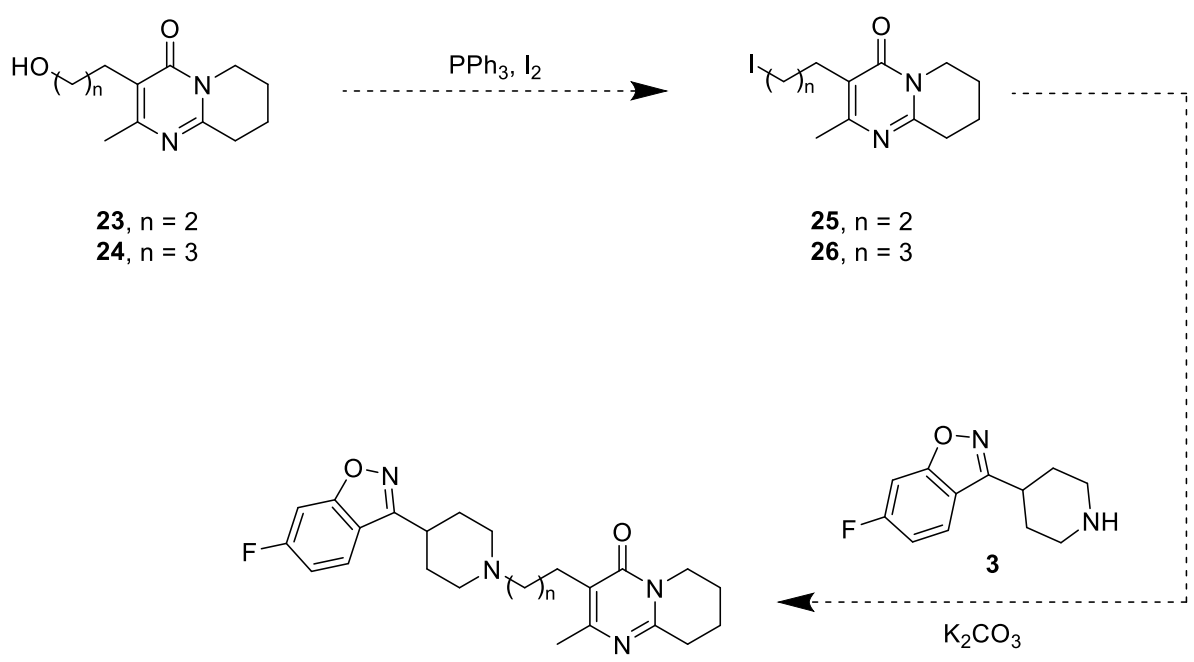

$8, n=2$

$9, n=3$

Scheme 5. Proposed synthesis of analogues 8 and 9.

\subsubsection{In Vitro Assays}

The cytotoxicity of analogues $\mathbf{8}$ and $\mathbf{9}$ will be explored using MTT assays according to methodology described by VUW researchers. ${ }^{97}$ Flow cytometry can also be utilised to assess cell viability. IL-6 and IL-12p40 from cell culture supernatants will be measured using sandwich ELISA (Enzyme-Linked Immunosorbent Assay) according to previously established methodology. ${ }^{97}$ IFN- $\gamma$, TNF- $\alpha$, MCP-1 and IL-10 will be measured using a cytokine bead array mouse inflammatory kit according to previously established methodology. ${ }^{97}$

RAW 264.7 cells were chosen for assessment of cell viability, as well as pro- and antiinflammatory cytokine production. Prior research has shown this cell type to give comparable results to $\mathrm{BMM} \Phi$ when used in studies on risperidone and truncated analogues. ${ }^{97}$ Macrophages are known to drive inflammatory processes that cause damage in this disease and ВMMФ have been used in MS studies. ${ }^{109}$ Furthermore, some MS treatments are effective due to the way in 
which they modulate macrophage responses in the CNS, thus making BMMФ a good in vitro model. ${ }^{110-111}$ Therefore, the related RAW 264.7 cells, readily available in our lab, are expected to provide a reasonable model for obtaining preliminary results. 


\section{Synthesis of Risperidone Analogues}

\subsection{Retrosynthesis}

Synthesis of the extended linker analogues 8 and 9 relies on $S_{N} 2$ coupling of the benzisoxazole fragment (3) and the extended linker coupled pyridopyrimidones 25 and 26 (Scheme 6). Synthesis of $\mathbf{3}$ will require a Friedel-Crafts acylation, formation of an oxime and ring closure through a nucleophilic aromatic substitution. Integration of the extended linkers will be required at the beginning of the synthesis with an alkylation to ethyl acetoacetate, the product of which will be subject to a condensation reaction with 2-aminopyridine. Generation of the desired analogues $\mathbf{8}$ and $\mathbf{9}$ will couple the benzisoxazole with a pyridopyrimidone in a basemediated $\mathrm{S}_{\mathrm{N}} 2$ reaction.

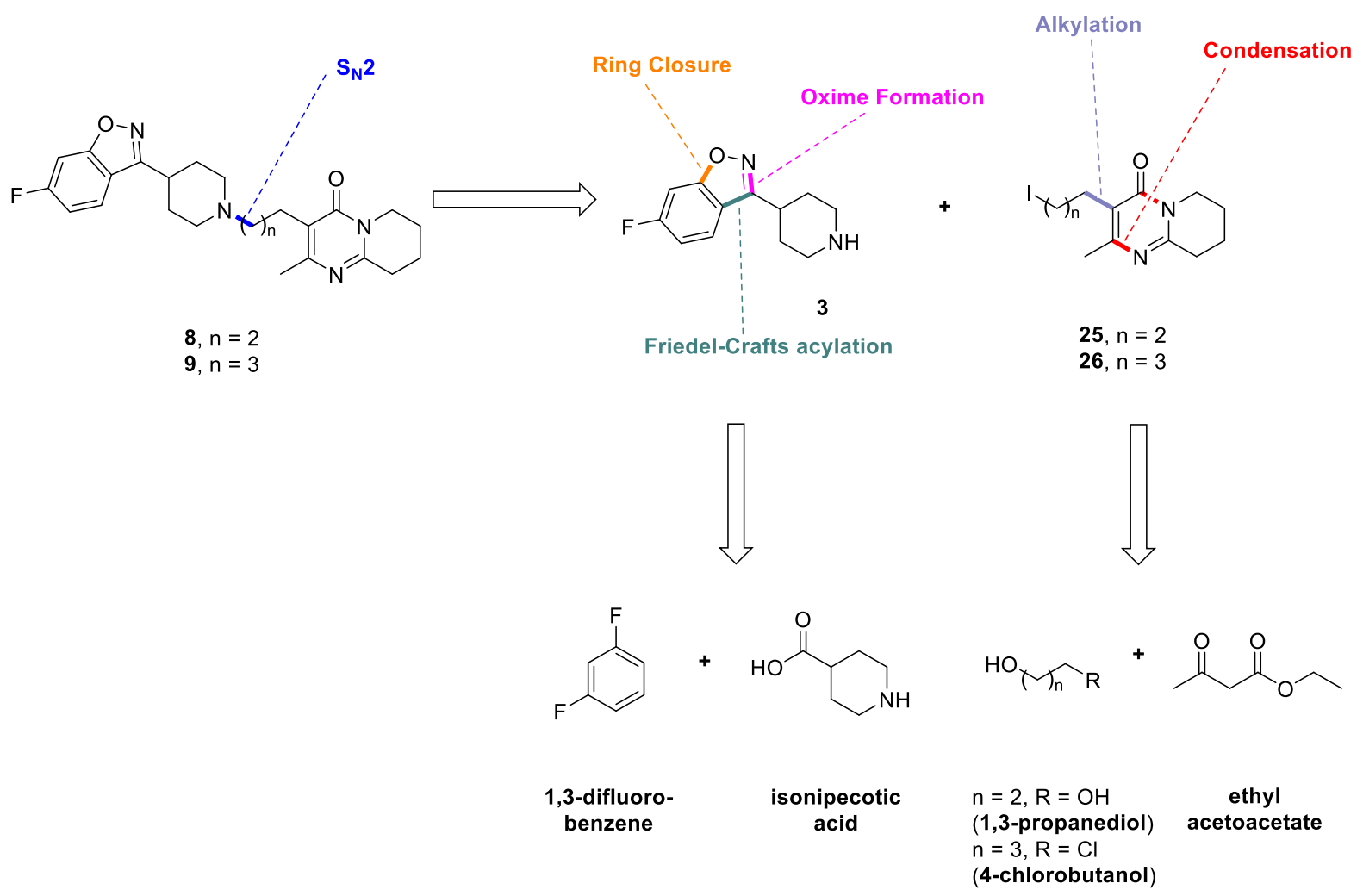

Scheme 6. Retrosynthesis of extended linker analogues of risperidone.

The first disconnection at the amine, as well as the three disconnections of benzisoxazole $\mathbf{3}$, should be applicable in the synthesis of analogues $\mathbf{8}$ and $\mathbf{9}$ as they have been applied to the 
commercial synthesis of risperidone. Furthermore, the addition of one and two methylenes in analogues $\mathbf{8}$ and $\mathbf{9}$, respectively, does not introduce new functionality so should not hinder these reactions. The disconnections described for the extended linker coupled pyridopyrimidones $\mathbf{2 5}$ and 26 have been established as viable routes and have the possibility of being applied to synthesis of analogues with longer alkyl spacers.

\subsection{Synthesis of the Benzisoxazole Fragment}

To begin, attention was centred on the synthesis of benzisoxazole $\mathbf{3}$ following established methodology. ${ }^{97}$ This route begins with acetylation of the amine starting material, followed by conversion of the carboxylic acid to an acyl chloride, a Friedel-Crafts acylation, formation of an oxime, and concludes with a ring closure through nucleophilic aromatic substitution (Scheme 7). This route will be described in detail below.
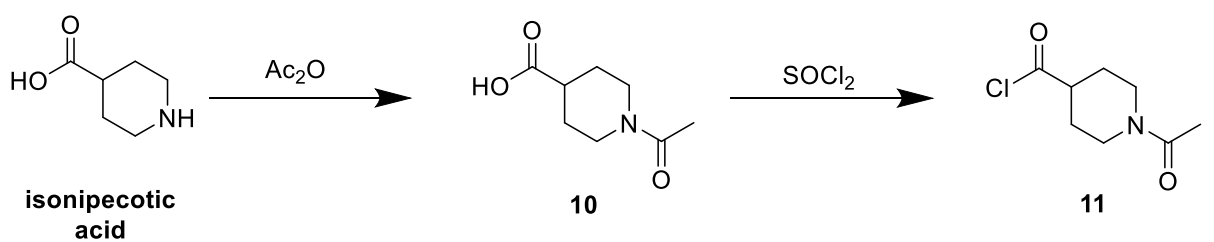

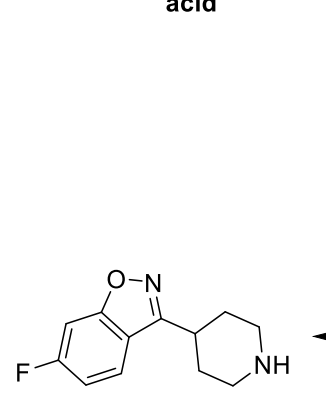

3
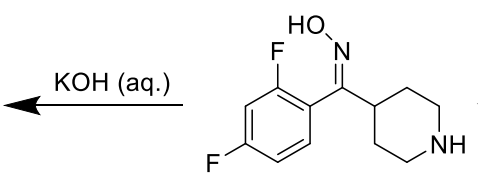

4
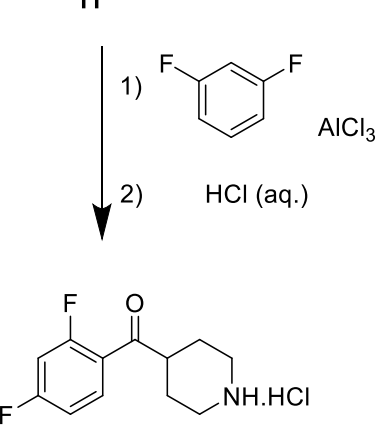

12

Scheme 7. Synthetic route to yield benzisoxazole 3.

\subsubsection{Isonipecotic Acid Acetylation}

Commercially available isonipecotic acid was used as a starting material and was acetylated using acetic anhydride (Scheme 8). Formation of the $N$-acetylated product (10) was confirmed by the ${ }^{1} \mathrm{H}$ and ${ }^{13} \mathrm{C}$ NMR spectra which were consistent with those previously reported. ${ }^{97}$ 
Interestingly, in the ${ }^{1} \mathrm{H}$ NMR spectrum, eight different shifts (one integrating for two protons) are observed for the nine protons in the piperidine ring although only five might be expected due to the apparent symmetry of the molecule. This is likely due to the product being present as a mixture of nitrogen rotamers (Figure 10). The piperidine ring is likely to adopt an energy minimised chair conformation with the $-\mathrm{CO}_{2} \mathrm{H}$ group found equatorial to reduce 1,3-diaxial interactions. In this conformation, two rotamer structures are possible at the amide where the oxygen will be oriented perpendicular relative to the ring system. These two conformers, or rotamers, ${ }^{112}$ appear to be present in equal amounts in solution which would account for the ${ }^{1} \mathrm{H}$ spectrum observed.

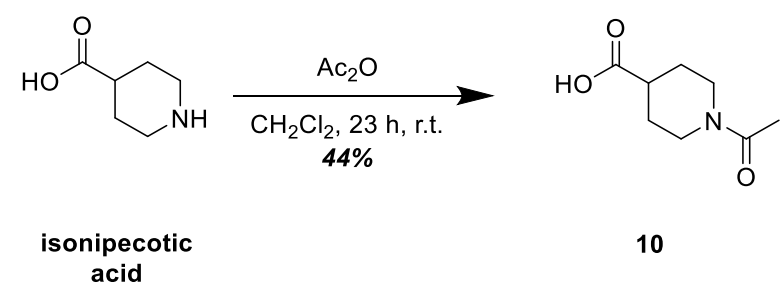

Scheme 8. Acetylation of isonipecotic acid.

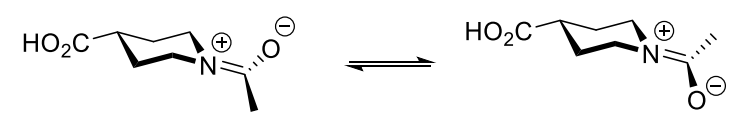

Figure 10. Possible nitrogen rotamers of $\mathbf{1 0 .}$

\subsubsection{Friedel-Crafts Acylation of $\mathbf{1 0}$}

The $\mathrm{N}$-acetylated product was then reacted with neat thionyl chloride to provide the corresponding acid chloride (11) (Scheme 9). This activated the acid for the subsequent Friedel-Crafts acylation. To avoid hydrolysis, the acid chloride intermediate was immediately subjected to the Friedel-Crafts acylation with 1,3-difluorobenzene using $\mathrm{AlCl}_{3}$ as the Lewis acid. The fluorine atoms of 1,3-difluorobenzene stabilise the ring by resonance and act as ortho/para directors for the reaction while the steric hindrance caused by the fluorine atoms prevents formation of the ortho/ortho regioisomer, resulting in the observed formation of only the desired product. The Friedel-Crafts acylation product was immediately treated with $6 \mathrm{M}$ 
$\mathrm{HCl}$ to cleave the acetate group which provided the desired amine $\mathrm{HCl}$ salt (12), with ${ }^{1} \mathrm{H}$ and ${ }^{13} \mathrm{C}$ NMR data consistent with those previously reported. ${ }^{97}$<smiles>CC(=O)N1CCC(C(=O)O)CC1</smiles>

10<smiles>CC(=O)N1CCC(C(=O)Cl)CC1</smiles>

11<smiles>Fc1cccc(F)c1</smiles>

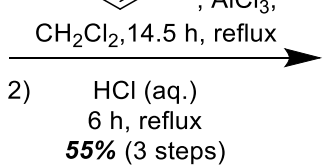<smiles>O=C(c1ccc(F)cc1F)C1CCNCC1</smiles>

12

Scheme 9. Friedel-Crafts acylation of $\mathbf{1 0 .}$

Analysis of the ${ }^{1} \mathrm{H}$ NMR spectrum clearly showed the introduction of aromatic protons with a triplet of doublets at $7.88 \mathrm{ppm}(1 \mathrm{H})$ and a multiplet at $7.10 \mathrm{ppm}(2 \mathrm{H})$. Cleavage of the acetate group was also confirmed by the loss of the methyl shift at $2.10 \mathrm{ppm}$. The loss of the molecules rotameric properties was also observed in the ${ }^{1} \mathrm{H}$ NMR spectrum, where the axial and equatorial protons at the 9- and 10-positions of the piperidine ring now have four shifts instead of seven distinct signals (Figure 11). A significant downfield shift of the proton at C-8 from $2.69 \mathrm{ppm}$ to $3.62 \mathrm{ppm}$ was noted, caused by the deshielding of the aromatic ring.

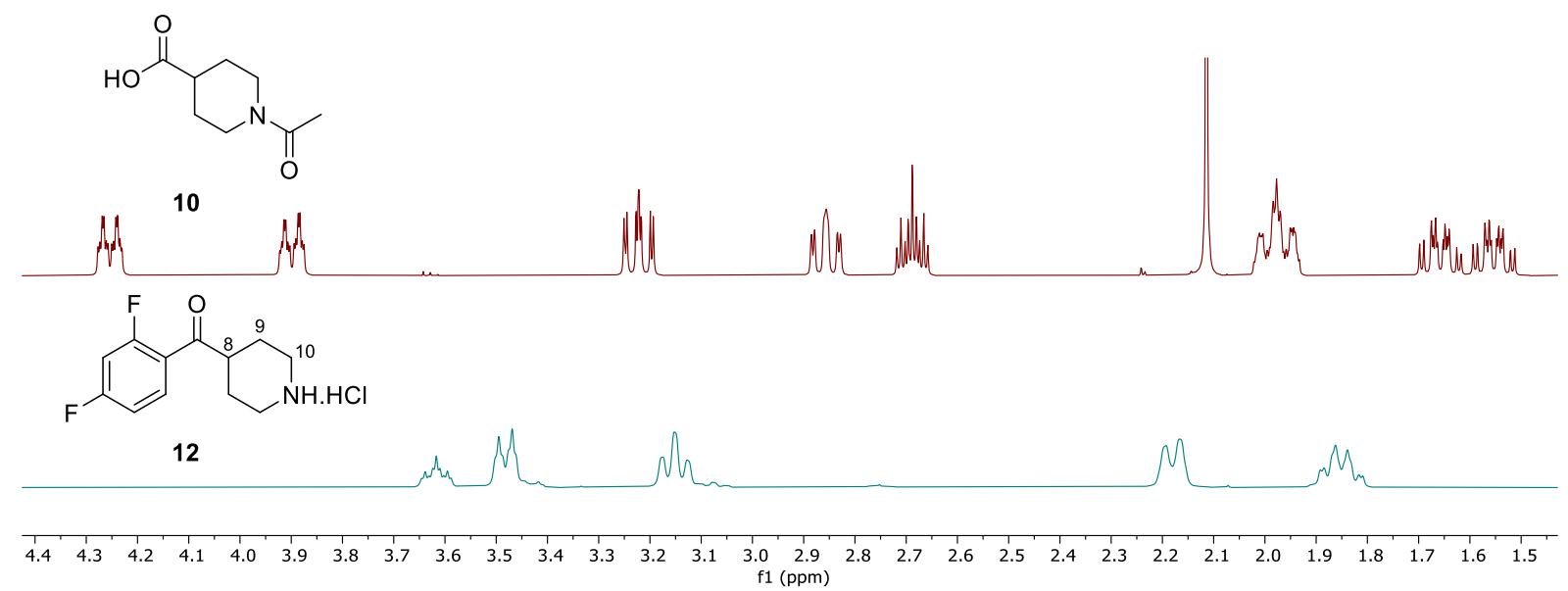

Figure 11. Comparison of ${ }^{1} \mathrm{H}$ NMR spectra of $\mathrm{N}$-acetylated acid $\mathbf{1 0}$ and Friedel-Crafts product 12 . 
The ${ }^{13} \mathrm{C}$ NMR spectrum showed the loss of the carboxylic acid functionality at $179.4 \mathrm{ppm}$ and the presence of a ketone further downfield at $201.7 \mathrm{ppm}$. The aromatic carbons are seen to couple to the two fluorines, causing splitting of the ${ }^{13} \mathrm{C}$ NMR signals similar to what is observed in ${ }^{1} \mathrm{H}$ NMR with neighbouring protons. Standard ${ }^{13} \mathrm{C}$ NMR pulse sequences utilise $\mathrm{C}-\mathrm{H}$ decoupling to prevent this peak splitting. C-F decoupling is not usually employed, thus splitting due to carbon-fluorine coupling is observed in the ${ }^{13} \mathrm{C}$ spectrum. In the case of 12 , each carbon covalently bonded to a fluorine exhibits splitting into a doublet of doublets at $166.1 \mathrm{ppm}$ and $162.1 \mathrm{ppm}$, both of which have one large $J$-coupling of approximately $255 \mathrm{~Hz}$ and a smaller $J$ coupling of approximately $14 \mathrm{~Hz}$ (Figure 12). The larger coupling being between the carbon and the attached fluorine while the finer splitting is likely a three-bond coupling to the fluorine on the meta-position.

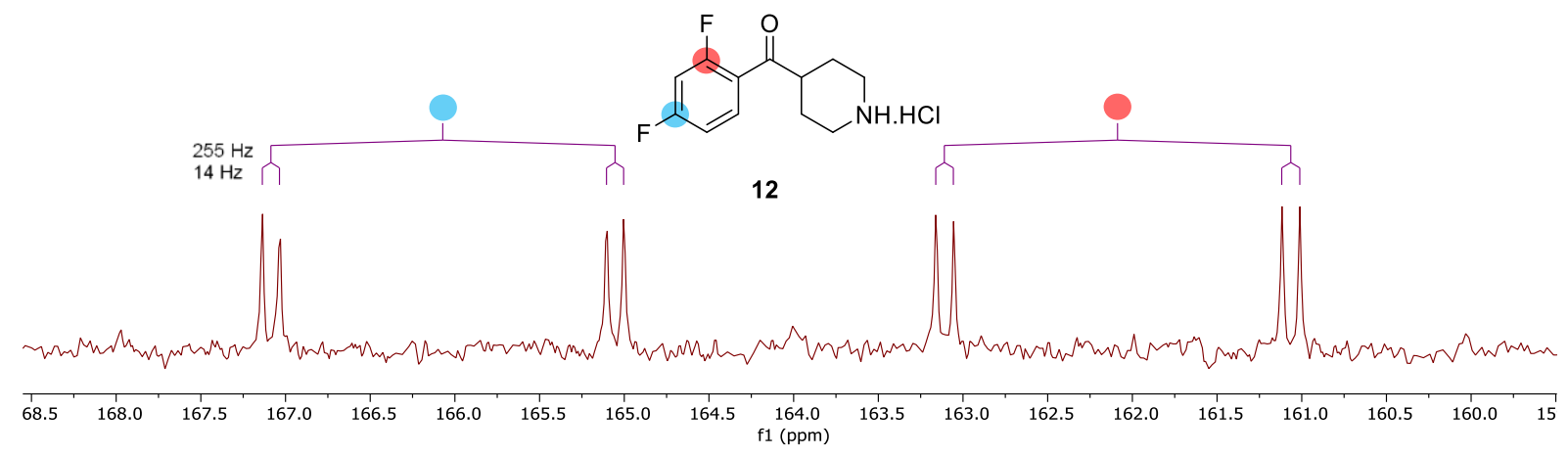

Figure 12. Splitting of ${ }^{13} \mathrm{C}$ peaks caused by fluorine coupling to neighbouring carbons in product $\mathbf{1 2}$.

\subsubsection{Oxime Formation}

Synthesis of oxime $\mathbf{4}$ from ketone 12 utilised hydroxylamine hydrochloride with excess pyridine and methanol as solvents (Scheme 10). The Z-oxime (4) was obtained as a mixture with its $E$-isomer (27) (0.35:1 Z:E ratio) based on comparison of the integrals of the aromatic peaks in the ${ }^{1} \mathrm{H}$ NMR spectrum. This ratio varied but was always in favour of the formation of the $E$-oxime. Recrystallisation from $\mathrm{MeOH}$ enabled isolation of the desired $\mathrm{Z}$-oxime $\mathbf{4}$ as white needle-like crystals. The supernatant was treated with acetic acid in $t$-butanol to convert the remaining $E$-isomer to further $Z$-isomer. A 4:1 mixture of $Z: E$ isomers was found in the crude reaction mixture. The $E$-isomer is essentially unreactive in the subsequent aromatic substitution 
step due to the hydroxyl group being positioned away from the fluorinated carbon. Recycling of the $E$-isomer is desirable synthetically as it maximises the amount of $Z$-isomer obtained, improving the overall yield. This $E$ to $Z$ conversion reaction was only repeated once as the yield acquired was sufficient for the following steps.

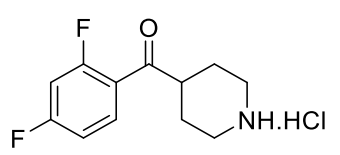

12

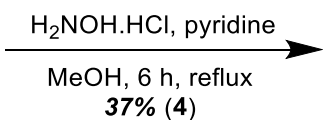

$37 \%(4)$

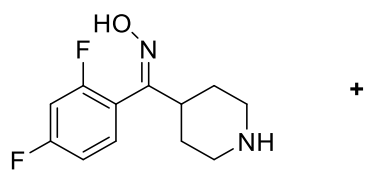

4

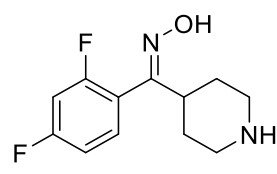

E-4

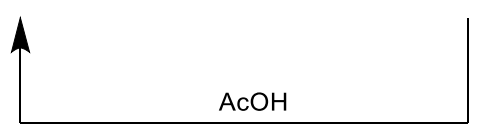

${ }^{\mathrm{t}} \mathrm{BuOH}, 16 \mathrm{~h}$, reflux

$16 \%(4)$

Scheme 10. Synthesis of Z-oxime 4.

The most notable change in the ${ }^{1} \mathrm{H}$ NMR spectrum upon oxime formation was an upfield shift of the proton of C-8 from $3.62 \mathrm{ppm}$ to $2.91 \mathrm{ppm}$, likely due to reduction in deshielding with conversion from a ketone to an oxime. The NMR data were consistent with those previously reported. ${ }^{97}$ HRMS also supported this assignment.

Mechanistically, formation of the oxime begins with attack of $\mathrm{NH}_{2} \mathrm{OH}$ at the carbonyl (Scheme 11). Proton transfer, followed by the loss of water results in the formation of both $E$ - and $Z$ isomers, with a preference for the $E$-isomer based on sterics. After separation, treatment of the $E$-isomer with a weak acid causes isomerisation (Scheme 12). This proceeds via protonation of the oxime, leading to a resonance structure with a single $\mathrm{C}-\mathrm{N}$ bond that is rotatable. In this way, rotation about the $\mathrm{C}-\mathrm{N}$ bond, followed by deprotonation of the amine triggering reformation of the $\mathrm{C}=\mathrm{N}$ bond, will yield a mixture of $E$ - and $Z$-isomers. Preferential formation of the Z-oxime under acidic conditions may be as a result of hydrogen bonding to the fluorine, stabilising this conformation before reformation of the $\mathrm{C}=\mathrm{N}$ bond. 


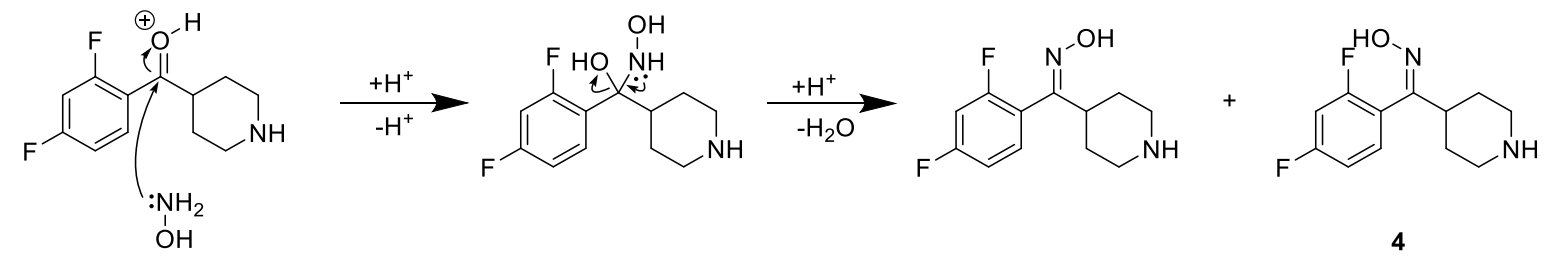

Scheme 11. Proposed mechanism of oxime formation.

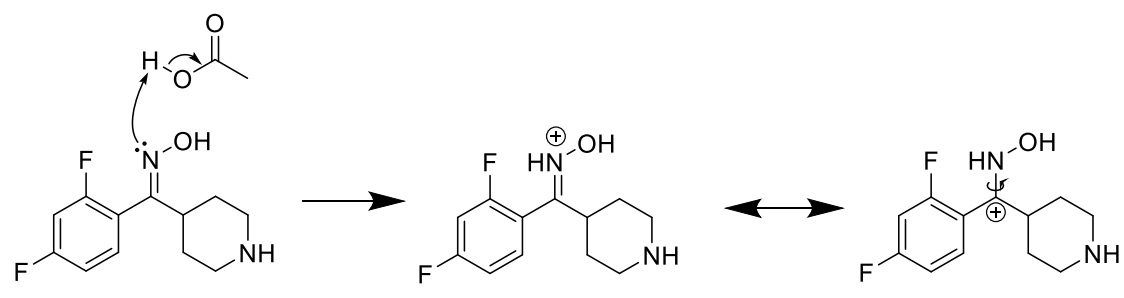

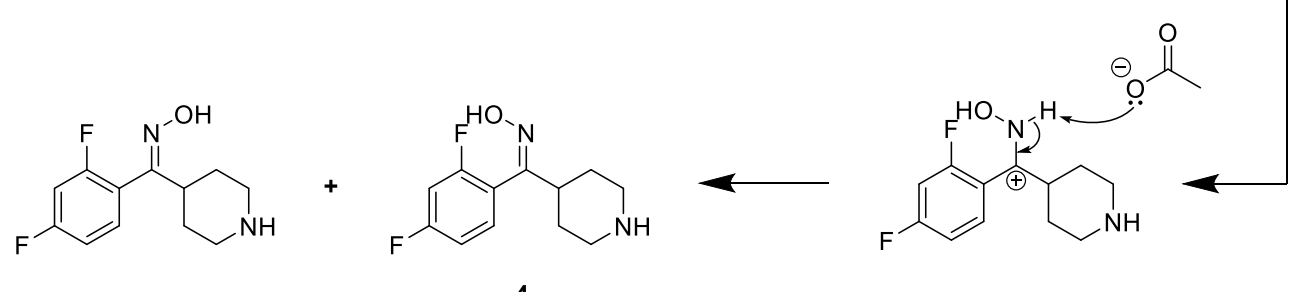

Scheme 12. Proposed mechanism of oxime isomeric conversion.

\subsubsection{Benzisoxazole Ring Closing}

Completion of the benzisoxazole fragment utilised aqueous $\mathrm{KOH}$ to deprotonate the oxime, inducing a nucleophilic aromatic substitution (Schemes 13 and 14) Any residual $E$-oxime will likely be unreactive due to the unfavourable orientation of the hydroxyl group.

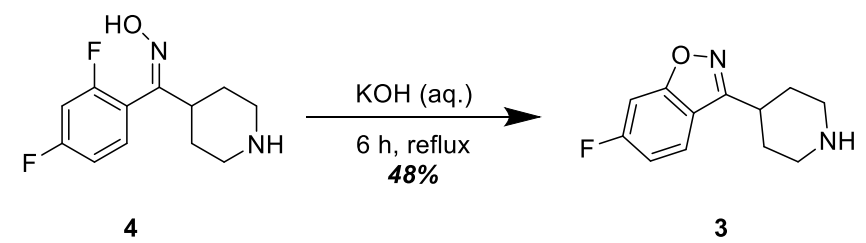

Scheme 13. Synthesis of benzisoxazole 3. 


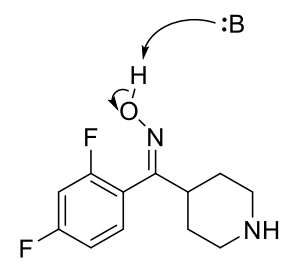

4

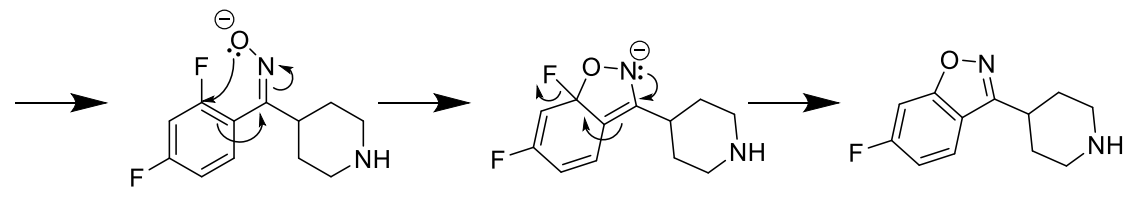

3

Scheme 14. Proposed mechanism of benzisoxazole formation.

Benzisoxazole 3 was fully characterised using ${ }^{1} \mathrm{H},{ }^{13} \mathrm{C}$, COSY, HSQC and HMBC NMR spectroscopy as full NMR assignment is not available in the literature (Table 2). Structural determination will also aid in characterisation of the final risperidone analogues and help define key HMBC correlations that are required to confirm the final condensation reactions have been successful. 


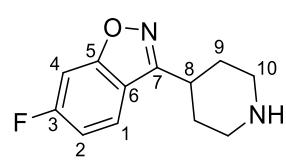

3

Table 2. Tabulated NMR spectroscopic data $\left(500 \mathrm{MHz}, \mathrm{CDCl}_{3}\right)$ for benzisoxazole 3 .

\begin{tabular}{|c|c|c|c|c|c|c|c|c|}
\hline \multirow[b]{2}{*}{ Position } & \multicolumn{3}{|c|}{${ }^{13} \mathrm{C}$} & \multicolumn{3}{|c|}{${ }^{1} \mathbf{H}$} & \multirow[b]{2}{*}{ COSY } & \multirow[b]{2}{*}{ HМBC } \\
\hline & $\begin{array}{c}\delta \\
(\mathbf{p p m})\end{array}$ & mult. & $\begin{array}{l}J_{\mathrm{CF}} \\
(\mathrm{Hz})\end{array}$ & $\begin{array}{c}\delta \\
(\mathbf{p p m})\end{array}$ & mult. & $\begin{array}{l}{ }^{3} J_{\mathrm{HH}} \\
(\mathrm{Hz})\end{array}$ & & \\
\hline $\mathrm{C}-1$ & 122.7 & $\mathrm{CH}$ & $\mathrm{d}, 11.1$ & 7.68 & $\mathrm{dd}$ & $8.6,5.1$ & 2 & $3,4,5,6,7$ \\
\hline C-2 & 112.4 & $\mathrm{CH}$ & $\mathrm{d}, 25.2$ & 7.04 & $\mathrm{td}$ & $8.9,2.3$ & 1 & $3,4,5,6$ \\
\hline C-3 & 164.1 & $\mathrm{C}$ & $\mathrm{d}, 250.4$ & - & - & - & - & - \\
\hline C-4 & 97.6 & $\mathrm{CH}$ & $\mathrm{d}, 26.8$ & 7.23 & dd & $8.6,2.3$ & - & $2,3,5,6$ \\
\hline$C-5$ & 164.0 & $\mathrm{C}$ & $\mathrm{d}, 13.5$ & - & - & - & - & - \\
\hline C-6 & 117.4 & $\mathrm{C}$ & - & - & - & - & - & - \\
\hline C-7 & 161.4 & $\mathrm{C}$ & - & - & - & - & - & - \\
\hline C-8 & 35.1 & $\mathrm{CH}$ & - & 3.19 & $\mathrm{tt}$ & $11.7,3.7$ & $9 a, 9 b$ & 7,9 \\
\hline \multirow[t]{2}{*}{ C-9 } & 31.7 & $\mathrm{CH}_{2}$ & - & a) 2.04 & $\mathrm{dd}$ & $12.9,3.3$ & $8,9 b$ & $8,9,10$ \\
\hline & & & - & b) 1.93 & qd & $11.8,4.0$ & $8,9 \mathrm{a}, 10 \mathrm{a}$ & $8,9,10$ \\
\hline \multirow[t]{2}{*}{ C-10 } & 46.6 & $\mathrm{CH}_{2}$ & - & a) 3.23 & $\mathrm{dt}$ & $12.4,3.6$ & $9 b, 10 b$ & $8,9,10$ \\
\hline & & & - & b) 2.81 & td & $12.1,2.8$ & $10 \mathrm{~b}$ & $8,9,10$ \\
\hline
\end{tabular}

The first peak assigned was the ${ }^{13} \mathrm{C}$ shift at $164.1 \mathrm{ppm}$. This has a large $J_{\mathrm{CF}}$-coupling (250.4 $\mathrm{Hz})$, typical of a fluorinated aromatic carbon, ${ }^{113-114}$ therefore it was designated as C-3. The aromatic peaks observed in the ${ }^{1} \mathrm{H}$ NMR spectrum at $7.23 \mathrm{ppm}$ and $7.04 \mathrm{ppm}$ were identified as the protons at positions neighbouring C-3 based on the two-bond $J_{\mathrm{CF}}$-couplings $(26.8 \mathrm{~Hz}$ and $25.2 \mathrm{~Hz}$, respectively) observed in the ${ }^{13} \mathrm{C}$ spectrum. The ${ }^{1} \mathrm{H}$ shift at $7.23 \mathrm{ppm}$ has no COSY correlations so can be assigned as the proton at C-4. COSY correlations are observed between the ${ }^{1} \mathrm{H}$ shifts at $7.68 \mathrm{ppm}$ and $7.04 \mathrm{ppm}$ which can be assigned as $\mathrm{C}-1$ and $\mathrm{C}-2$, respectively. The ${ }^{13} \mathrm{C}$ shift that represents $\mathrm{C}-1$ has a small $J_{\mathrm{CF}-\text {-coupling }}(11.1 \mathrm{~Hz})$, likely due to a three-bond coupling to the fluorine. A similar small $J_{\mathrm{CF}}$-coupling $(13.5 \mathrm{~Hz})$ is observed for the ${ }^{13} \mathrm{C}$ shift at $164.0 \mathrm{ppm}$ so can be assigned to C-5. The HSQC shows this position is unprotonated, providing further evidence for its assignment. 
The triplet of triplets at $3.19 \mathrm{ppm}$ in the ${ }^{1} \mathrm{H}$ NMR spectrum can be assigned to the proton on $\mathrm{C}$ 8 , as the splitting observed would be caused by separate coupling to the neighbouring axial and equatorial protons. The ${ }^{1} \mathrm{H}$ shift at 3.19 ppm exhibits HMBC correlations to the ${ }^{13} \mathrm{C}$ shift found at $161.4 \mathrm{ppm}$. The proton at position $\mathrm{C}-1$ also has an $\mathrm{HMBC}$ correlation to this ${ }^{13} \mathrm{C}$ shift. Due to these correlations, this carbon can likely be assigned as C-7. Strong deshielding from the neighbouring nitrogen would also account for the downfield shift observed. The protons of C1, C-2 and C-4 all exhibit HMBC correlations to the ${ }^{13} \mathrm{C}$ shift at $117.4 \mathrm{ppm}$. This aromatic shift is found further upfield when compared to carbons C-5 and C-7. As all other aromatic shifts have been assigned, this shift can be assigned to C-6.

The piperidine ring is likely to adopt a low energy chair conformation, resulting in different environments for the axial and equatorial protons at positions C-9 and C-10. This is seen in the HSQC spectrum where the ${ }^{13} \mathrm{C}$ shifts at $46.6 \mathrm{ppm}$ and $31.7 \mathrm{ppm}$ both have two hydrogens bonded, each with distinct environments. The COSY spectrum shows the proton of C-8 to have a correlation to the ${ }^{1} \mathrm{H}$ shifts at $2.04 \mathrm{ppm}$ and $1.93 \mathrm{ppm}$, both bound to the ${ }^{13} \mathrm{C}$ methylene at $31.7 \mathrm{ppm}$. Therefore it can be assigned as C-9. The ${ }^{1} \mathrm{H}$ shift at $1.93 \mathrm{ppm}$ exhibits a COSY correlation to the protons at $3.23 \mathrm{ppm}$. The HSQC spectrum shows these protons to be attached to the carbon at $31.7 \mathrm{ppm}$ in the ${ }^{13} \mathrm{C}$ NMR spectrum which can therefore be assigned as $\mathrm{C}-10$. The ${ }^{1} \mathrm{H}$ shift at $2.81 \mathrm{ppm}$ is assigned as the other proton of the $\mathrm{C}-10$ methylene based on the HSQC spectrum.

\subsection{Synthesis of Extended Linker Pyridopyrimidones}

Synthesis of the extended linker pyridopyrimidones required the use of two different starting materials, 1,3-propanediol and 4-chlorobutanol, for synthesis of the three- and four-carbon analogues, respectively (Scheme 15). Benzyl protection of the alcohol functionality was to be followed by Appel and Finkelstein reactions, respectively, in preparation for alkylation with ethyl acetoacetate. The alkylated ethyl acetoacetates $\mathbf{1 7}$ and $\mathbf{1 8}$ would then be subjected to condensation reactions with 2-aminopyridine to give unsaturated extended linker coupled pyridopyrimidones 19 and 20. $\mathrm{Pd} / \mathrm{C}$ catalysed hydrogenation can then be used to saturate the pyridine ring. As previous work also unsuccessfully attempted to use $\mathrm{Pd} / \mathrm{C}$ for $O$ debenzylation, an alternative method was required. ${ }^{98} \mathrm{DDQ}, \mathrm{TiCl}_{4}$ and $\mathrm{Pd} / \mathrm{C}$ catalysed 
hydrogenolysis under more forcing conditions was planned to be used to facilitate this deprotection as it should be compatible with the functionality of the pyridopyrimidones.
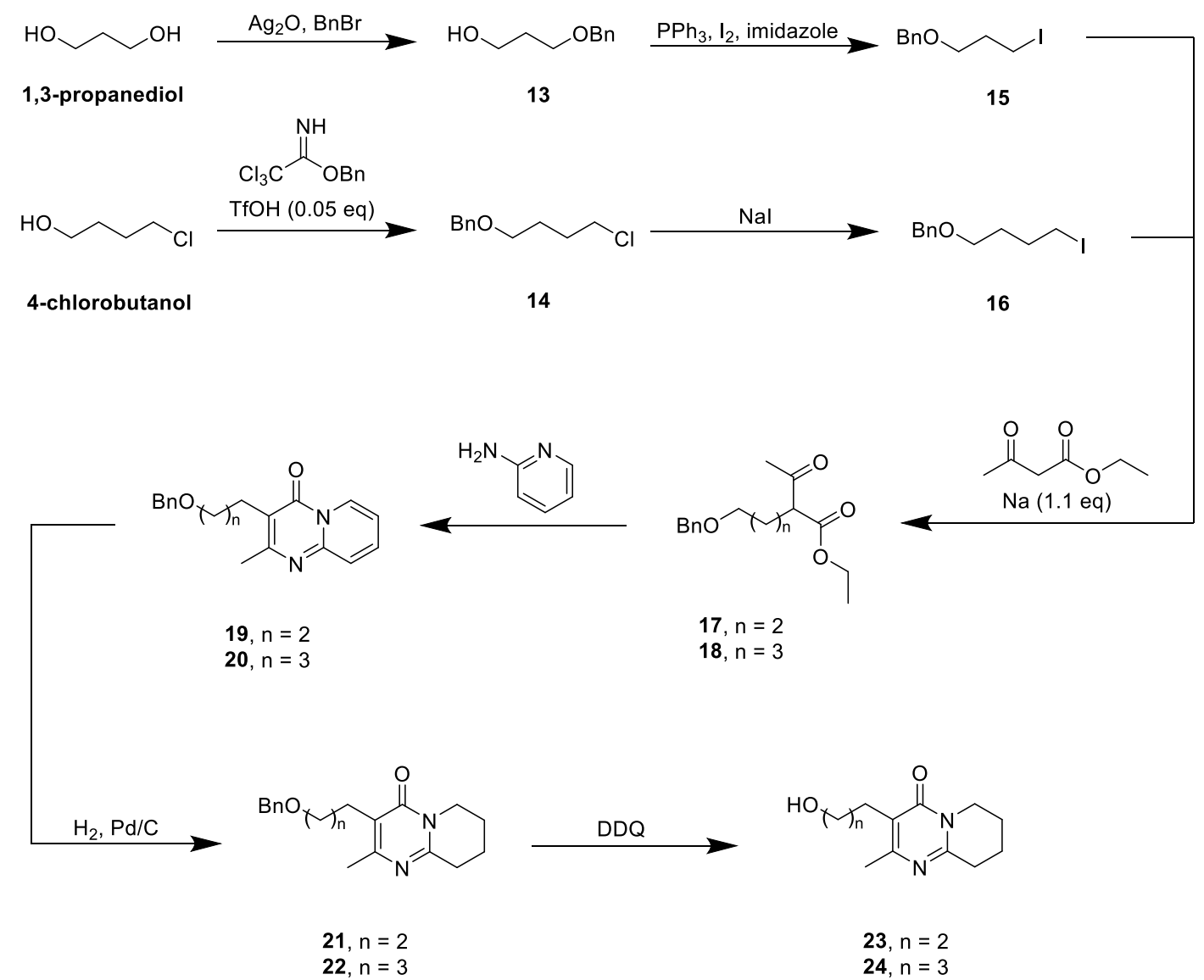

Scheme 15. Proposed synthetic route tetrahydropyridopyrimidones $\mathbf{2 3}$ and $\mathbf{2 4}$.

\subsubsection{Preparation of the Three-Carbon Alkylated Ethyl Acetoacetate}

Synthesis of the three-carbon analogue $(\mathbf{8})$ began with monoprotection of 1,3-propanediol using benzyl bromide and $\mathrm{Ag}_{2} \mathrm{O}$ as per the methodology employed by Durrant (Scheme 16). ${ }^{98}$, 115 Synthesis of $\mathbf{1 3}$ was successful with a quantitative yield and high ratio of mono:diprotected product (1:0.07), calculated by comparison of the integrals of the benzylic peaks in the ${ }^{1} \mathrm{H}$ NMR spectrum. It is proposed that high selectivity for monoprotection is achieved by coordination of the two oxygen atoms with the silver atom (Scheme 17). ${ }^{115}$ Internal hydrogen bonding increases the acidity of only one of the hydroxyl protons, allowing for its deprotonation, thus creating a good nucleophile for attack on benzyl bromide. 


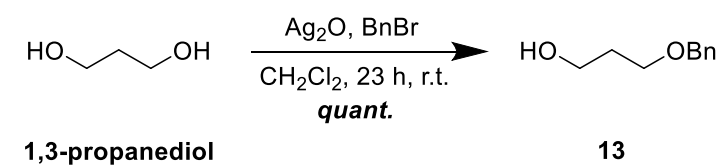

Scheme 16. Benzyl protection of 1,3-propanediol.

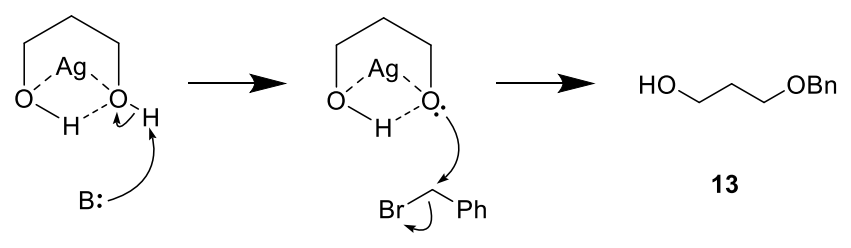

Scheme 17. Proposed mechanism of $\mathrm{Ag}_{2} \mathrm{O}$ mediated 1,3-propanediol.

The presence of a benzylic $\mathrm{CH}_{2}$ singlet at $4.53 \mathrm{ppm}$ in the ${ }^{1} \mathrm{H}$ NMR spectrum alongside the appearance of a complex multiplet at 7.40-7.27 ppm confirmed the benzyl protection was successful. Shifts in the alkyl chain protons were also consistent with literature data. ${ }^{116}$ This product was able to be used without further purification as the dual-protected alcohol should be unreactive in the subsequent step.

An Appel reaction was then utilised to convert the protected diol $\mathbf{1 3}$ to the iodoalkane $\mathbf{1 5}$ in preparation for the following alkylation reaction (Scheme 18). Applying the methodology reported separately by Muñoz and Durrant, alcohol 13 was treated with $\mathrm{PPh}_{3}$ and imidazole in $\mathrm{Et}_{2} \mathrm{O} .{ }^{98,117}$ Subsequent addition of $\mathrm{CH}_{3} \mathrm{CN}$ aided in solubilisation of the $\mathrm{PPh}_{3}$. Iodine was added at $0{ }^{\circ} \mathrm{C}$, then the reaction allowed to warm to room temperature and stir for 6 hours. Following workup, the desired iodide $\mathbf{1 5}$ was obtained in a $74 \%$ yield and was used without further purification in the subsequent step.

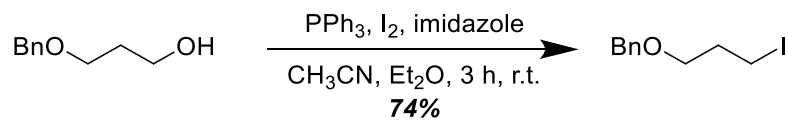

Scheme 18. Appel reaction of $\mathbf{1 3 .}$ 
The Appel reaction begins mechanistically by the attack of $\mathrm{PPh}_{3}$ on iodine, forming a phosphonium salt while the imidazole is able to deprotonate the alcohol (Scheme 19). The resulting alkoxide can then displace the iodine of the phosphonium salt. The free iodide can break the carbon-oxygen bond via an $\mathrm{S}_{\mathrm{N}} 2$ reaction, yielding the desired haloalkane product $\mathbf{1 5}$, driven by the favourable formation of a phosphine-oxygen double bond. As this method stated that iodine be added last, the phosphonium salt will only form upon $\mathrm{I}_{2}$ addition.
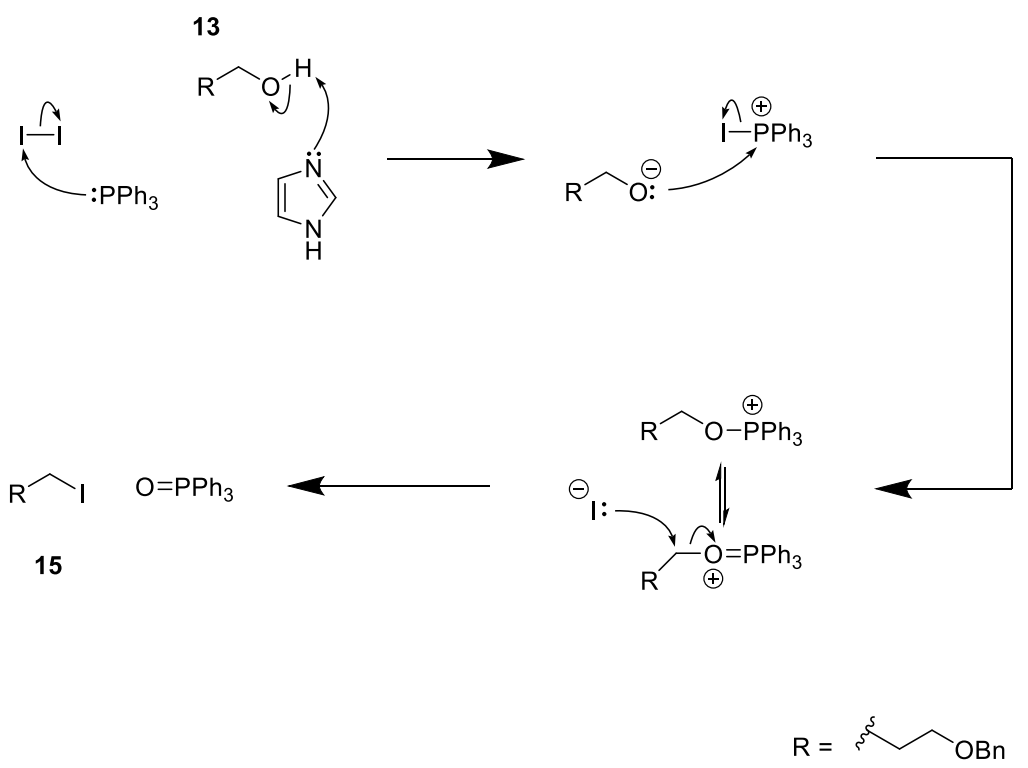

Scheme 19. Proposed Appel reaction mechanism.

Analysis of the ${ }^{1} \mathrm{H}$ NMR spectrum of $\mathbf{1 5}$ showed the peak at $3.79 \mathrm{ppm}$ of alcohol 13, representing the protons neighbouring the unprotected hydroxyl, exhibited an upfield shift to $3.31 \mathrm{ppm}$ in the product due to a reduction in deshielding afforded by the less electronegative iodine. In the ${ }^{13} \mathrm{C}$ NMR spectrum, the shift representing the substituted carbon moves from $62.2 \mathrm{ppm}$ in alcohol $\mathbf{1 3}$ to $3.6 \mathrm{ppm}$ in the iodide product 15 (Figure 13). These data are consistent with those previously reported. ${ }^{117}$ 


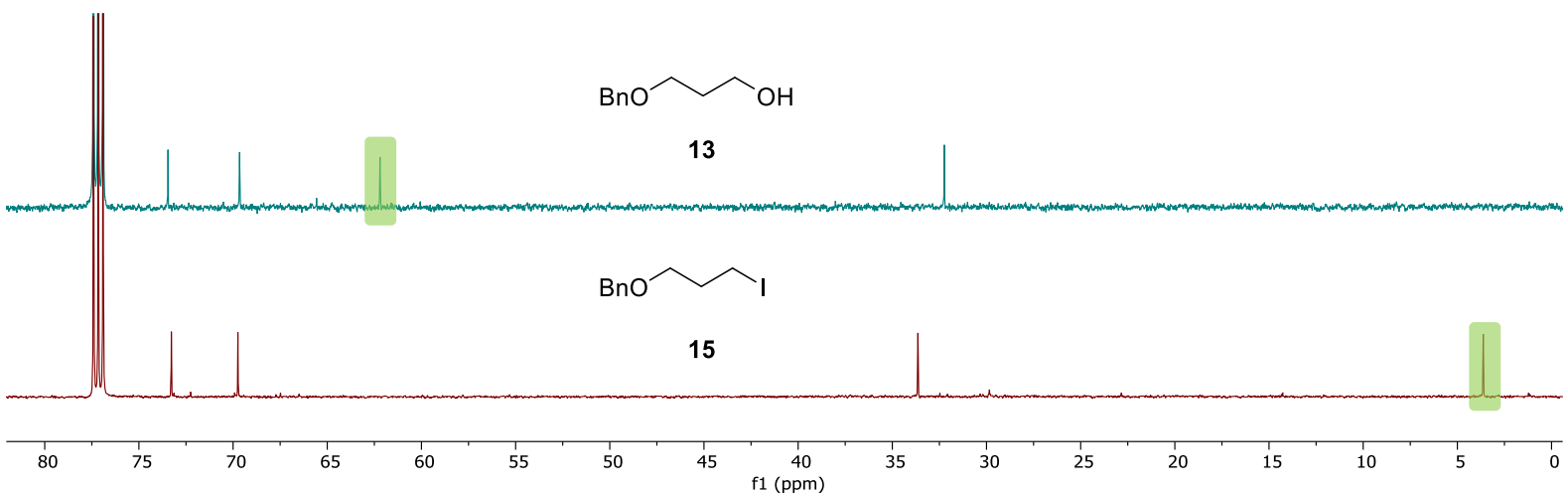

Figure 13. Comparison of ${ }^{13} \mathrm{C}$ NMR spectra of alcohol 13 and iodide 15. Highlighted in green are the terminal carbon shifts.

Following the methodology reported separately by Hasserodt and Durrant, the substituted ethyl acetoacetate $\mathbf{1 7}$ was synthesised from iodoalkane $\mathbf{1 5}$ (Scheme 20). ${ }^{98,118}$ This method required addition of freshly cut sodium to anhydrous ethanol. Subsequent refluxing was followed by the addition of ethyl acetoacetate, then iodoalkane 15. After 2.5 hours the reaction was cooled, filtered through a silica plug twice then purified by column chromatography. A 40:1 $\mathrm{CH}_{2} \mathrm{Cl}_{2}$ :EtOAc solvent system was employed following the methodology of Durrant. ${ }^{98}$ Compound 17 was isolated with a respectable 57\% yield although some co-eluting impurities were found in the ${ }^{1} \mathrm{H}$ NMR spectrum, attributed to streaking caused by the combination of $\mathrm{CH}_{2} \mathrm{Cl}_{2}$ as the mobile phase, the stationary phase and compound $\mathbf{1 7}$.

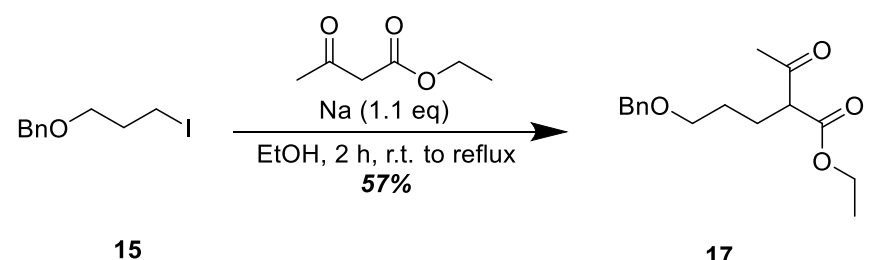

Scheme 20. Alkylation reaction of $\mathbf{1 5}$ with ethyl acetoacetate to give $\mathbf{1 7}$.

Mechanistically, the addition of sodium to anhydrous ethanol was required first to form sodium ethoxide. Subsequent addition of ethyl acetoacetate leads to the formation of the enolate via deprotonation at the $\alpha$-position. Addition of the iodoalkanes allows for nucleophilic attack in an $\mathrm{S}_{\mathrm{N}} 2$ type reaction to afford the desired alkylated products. 
Formation of the three-carbon alkylated product 17 was confirmed by NMR spectroscopy and HRMS analysis, the data of which were consistent with those previously reported. ${ }^{118}$ Notably, the appearance of ${ }^{13} \mathrm{C}$ shifts at $203.4 \mathrm{ppm}$ and $169.9 \mathrm{ppm}$ was indicative of a ketone and ester, respectively (Figure 14). The triplet at $3.31 \mathrm{ppm}$ in the ${ }^{1} \mathrm{H}$ NMR spectrum in iodoalkane 15 was replaced with a quartet at $1.95 \mathrm{ppm}$ in $\mathbf{1 7}$, indicative of a loss of iodine and the formation of a new covalent $\mathrm{C}-\mathrm{C}$ bond to a methine. The presence of two methyl peaks in the ${ }^{1} \mathrm{H}$ NMR spectrum, a singlet at $2.21 \mathrm{ppm}$ and a triplet at $1.26 \mathrm{ppm}$, provide further evidence that the alkylation was successful. These data are consistent with those previously reported. ${ }^{98,118}$

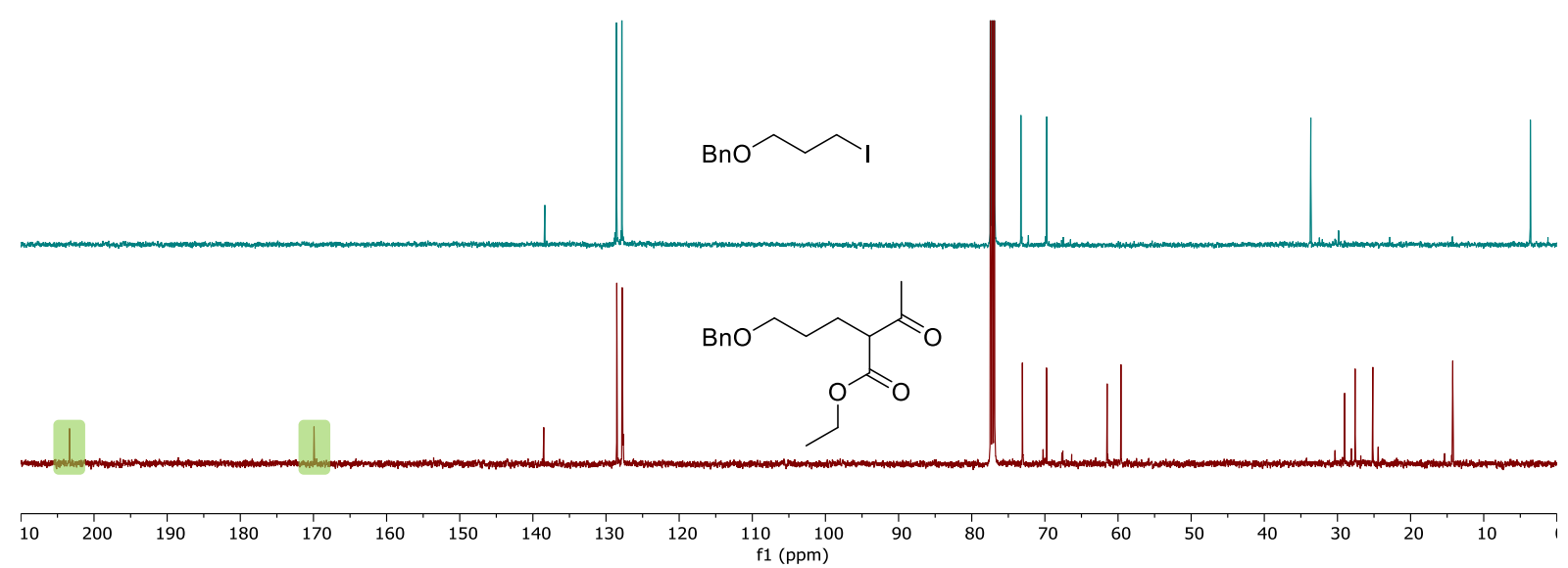

Figure 14. Comparison of ${ }^{13} \mathrm{C}$ NMR spectra of iodide $\mathbf{1 5}$ and alkylated product 17.

Highlighted in green are shifts indicative of ketone (left) and ester (right) functionalities.

\subsubsection{Preparation of the Four-Carbon Alkylated Ethyl Acetoacetate}

Due to the unavailability of 1,4-butanediol, 4-chlorobutanol was used and an alternative Bnprotection method was employed for protection of the four-carbon linker analogue. Following Durrant's methodology, the alcohol functionality of 4-chlorobutanol was protected using benzyl trichloroacetimidate and catalytic triflic acid (Scheme 21) ${ }^{98}$ A 4:1 ratio of 14:alcohol was obtained following silica plug filtration of the base-quenched reaction mixture. The product was contaminated with a small amount of residual trichloroacetimidate based on the integration $(8 \mathrm{H})$ of the aromatic region of the ${ }^{1} \mathrm{H}$ NMR spectrum. The presence of the benzyl protecting group was confirmed by the appearance of a benzylic $\mathrm{CH}_{2}$ singlet at $4.51 \mathrm{ppm}$ in the ${ }^{1} \mathrm{H}$ NMR spectrum. Shifts in the alkyl chain protons matched those previously reported. ${ }^{119}$ This 
process likely begins mechanistically with protonation of the imine, giving an electrophilic cation (Scheme 22). This charged species will readily react with the alcohol, yielding a benzyl ether (14) and trichloroacetamide as a byproduct.

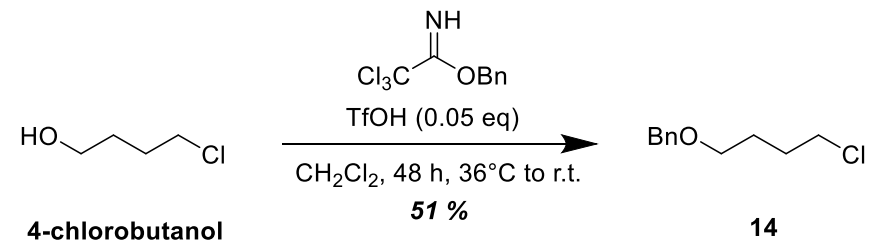

Scheme 21. Benzyl protection of 4-chlorobutanol.

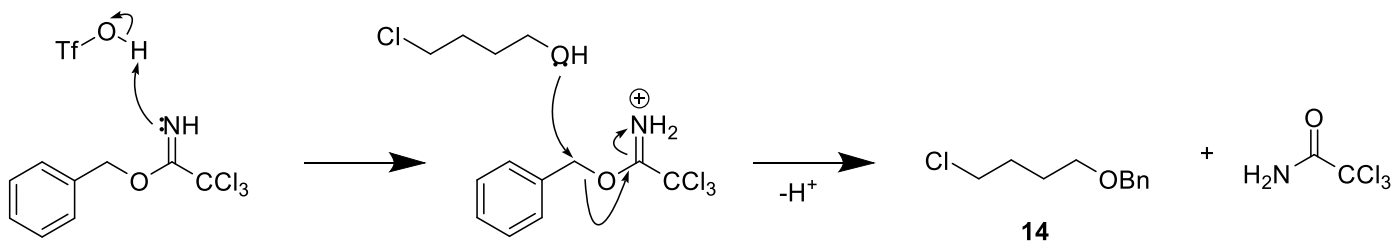

Scheme 22. Proposed mechanism of benzyl protection of 4-chlorobutanol.

A Finkelstein reaction was then employed for halide substitution of $\mathbf{1 4}$ in anticipation of the subsequent alkylation step as the iodine is a superior leaving group to chlorine (Scheme 23). Compound 14 was taken up in dry acetone with $\mathrm{NaI}$ and refluxed for 27 hours to provide the desired iodoalkane $\mathbf{1 6}$ as an orange oil. Similar to the synthesis of $\mathbf{1 5}$, an upfield shift in the protons attached to the halogen bonded carbon was observed in the ${ }^{1} \mathrm{H}$ NMR spectrum, from $3.57 \mathrm{ppm}$ in chloroalkane $\mathbf{1 4}$ to $3.21 \mathrm{ppm}$ in the iodide product 16. This change was again expected due to the reduced deshielding afforded by the less electronegative iodine. These data are consistent with those previously reported. ${ }^{119}$

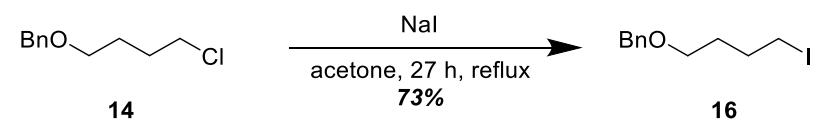

Scheme 23. Finkelstein reaction of 14. 
The methodology utilised for the synthesis of $\mathbf{1 7}$ was applied to the synthesis of the four-carbon linked ethyl acetoacetate 18 (Scheme 24). Chromatographic isolation of the four-carbon product 18 employed 9:1 hexanes:EtOAc which proved to be more successful in separation of a pure product. Despite a crude yield of $80 \%$, a disappointing $11 \%$ yield was achieved following purification. Surprisingly, after several hours under high vacuum, a large portion of 18 was lost with no change in the intensity of the yellow colour of the oil. This loss of volume could be attributed to possible volatility of the product.

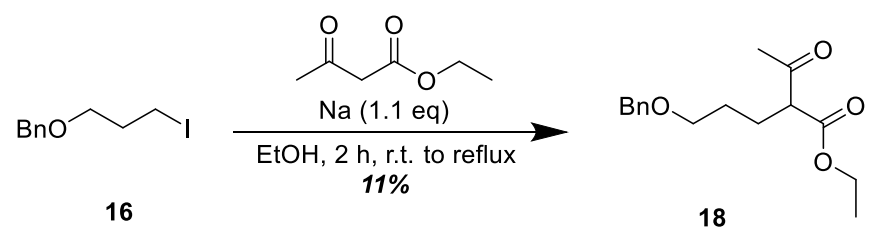

Scheme 24. Alkylation reaction of ethyl acetoacetate to give $\mathbf{1 8 .}$

The four-carbon alkylated product $\mathbf{1 8}$ was first synthesised by Durrant but full structural assignment remained ambiguous. ${ }^{98}$ Therefore the structure of $\mathbf{1 8}$ was fully assigned based on the NMR data as follows. These data are also available in Table $\mathbf{3}$ alongside the numbering system used for position assignments. 


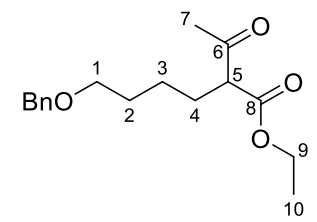

Table 3. Tabulated NMR spectroscopic data $\left(500 \mathrm{MHz}, \mathrm{CDCl}_{3}\right)$ for alkylation product 18.

\begin{tabular}{|c|c|c|c|c|c|c|c|}
\hline \multirow[b]{2}{*}{ Position } & \multicolumn{2}{|c|}{${ }^{13} \mathrm{C}$} & \multicolumn{3}{|c|}{${ }^{1} \mathbf{H}$} & \multirow[b]{2}{*}{ COSY } & \multirow[b]{2}{*}{ HМBC } \\
\hline & $\begin{array}{c}\delta \\
(\mathbf{p p m})\end{array}$ & mult. & $\delta(\mathbf{p p m})$ & mult. & $\begin{array}{l}{ }^{3} J_{\mathrm{HH}} \\
(\mathrm{Hz})\end{array}$ & & \\
\hline $\mathrm{C}-1$ & 70.0 & $\mathrm{CH}_{2}$ & 3.46 & $\mathrm{t}$ & 6.4 & 2 & $2,3, \mathrm{PhCH}_{2}$ \\
\hline $\mathrm{C}-2$ & 29.6 & $\mathrm{CH}_{2}$ & 1.63 & $\mathrm{~m}$ & - & 1,3 & $1,3,4$ \\
\hline $\mathrm{C}-3$ & 24.3 & $\mathrm{CH}_{2}$ & 1.38 & $\mathrm{~m}$ & - & 2,4 & 4,10 \\
\hline C-4 & 28.1 & $\mathrm{CH}_{2}$ & 1.86 & $\mathrm{~m}$ & - & 3,5 (weak) & $2,3,5,6,8$ \\
\hline C-5 & 60.0 & $\mathrm{CH}$ & 3.40 & $\mathrm{t}$ & 7.4 & 4 & $3,4,6,8$ \\
\hline C-6 & 203.4 & $\mathrm{C}$ & - & - & - & - & - \\
\hline C-7 & 28.9 & $\mathrm{CH}_{3}$ & 2.21 & $\mathrm{~s}$ & - & - & 5,6 \\
\hline C-8 & 169.9 & $\mathrm{C}$ & - & - & - & - & - \\
\hline C-9 & 61.4 & $\mathrm{CH}_{2}$ & 4.19 & qd & $7.1,0.9$ & 10 & 8,10 \\
\hline $\mathrm{C}-10$ & 14.2 & $\mathrm{CH}_{3}$ & 1.26 & $\mathrm{t}$ & 7.1 & 9 & 9 \\
\hline $\mathrm{Ar}$ & 138.6 & $\mathrm{C}$ & - & - & - & - & - \\
\hline $\mathrm{Ar}$ & 128.5 & $\mathrm{CH}$ & $7.36-7.26$ & $\mathrm{~m}$ & - & $\mathrm{Ar}$ & $\mathrm{Ar}$ \\
\hline $\mathrm{Ar}$ & 127.8 & $\mathrm{CH}$ & $7.36-7.26$ & $\mathrm{~m}$ & - & $\mathrm{Ar}$ & $\mathrm{Ar}$ \\
\hline $\mathrm{Ar}$ & 127.7 & $\mathrm{CH}$ & $7.36-7.26$ & $\mathrm{~m}$ & - & $\mathrm{Ar}$ & $\mathrm{Ar}$ \\
\hline $\mathrm{PhCH}_{2}$ & 73.0 & $\mathrm{CH}_{2}$ & 4.48 & $\mathrm{~s}$ & - & - & 1, Ar \\
\hline
\end{tabular}

The COSY spectrum confirms a four-carbon chain with methylene peaks found at $3.46 \mathrm{ppm}$, $1.86 \mathrm{ppm}, 1.63 \mathrm{ppm}$ and $1.38 \mathrm{ppm}$ in the ${ }^{1} \mathrm{H}$ NMR spectrum (Figure 15). The triplet at 3.46 ppm in the ${ }^{1} \mathrm{H}$ NMR spectrum is likely at position $\mathrm{C}-1$ due the increased deshielding of the neighbouring oxygen atom and splitting caused by coupling to the two protons at $\mathrm{C}-2$. The ${ }^{1} \mathrm{H}$ shift at $1.63 \mathrm{ppm}$ exhibits COSY correlations to the protons at C-1 and the shift at $1.38 \mathrm{ppm}$. This would place these shifts at positions C-2 and C-3, respectively. The protons at C-3 also have a COSY correlation to methylene protons at $1.86 \mathrm{ppm}$ in the ${ }^{1} \mathrm{H}$ NMR spectrum, therefore assigning it at C-4. The $\mathrm{C}-4$ protons have a COSY correlation to a single proton at $3.40 \mathrm{ppm}$ in the ${ }^{1} \mathrm{H}$ NMR spectrum, placing it at $\mathrm{C}-5$ and the internal end of the chain. The ${ }^{1} \mathrm{H}$ NMR 
spectrum shows two methyl groups present at $2.21 \mathrm{ppm}$, as a singlet, and $1.26 \mathrm{ppm}$, as a triplet. Based on these multiplicities, they can be assigned to C-7 and C-10, respectively. The protons of C-10 also exhibit a COSY correlation to two protons at $4.19 \mathrm{ppm}$ in the ${ }^{1} \mathrm{H}$ NMR spectrum which can be assigned to C-9. The two most downfield shifts in the ${ }^{13} \mathrm{C}$ NMR spectrum at 203.4 ppm and 169.9 ppm are typical of a ketone and an ester, respectively. An HMBC correlation from the protons of $\mathrm{C}-9$ to the ${ }^{13} \mathrm{C}$ peak at $169.9 \mathrm{ppm}$ allows it to be assigned as $\mathrm{C}-8$. Therefore, the ${ }^{13} \mathrm{C}$ peak at $203.4 \mathrm{ppm}$ must be the carbonyl at C-6. The methyl of $\mathrm{C}-7$ also has a strong HMBC correlation to C-6, providing further evidence for this assignment. The $\mathrm{CH}_{2}$ singlet at $4.48 \mathrm{ppm}$ in the ${ }^{1} \mathrm{H}$ NMR spectrum is typical of benzylic protons and also exhibits a three-bond HMBC correlation to $\mathrm{C}-1$, confirming the benzyl protecting group remained intact. A complex multiplet integrating for five protons in the aromatic region provide further evidence for this assignment.

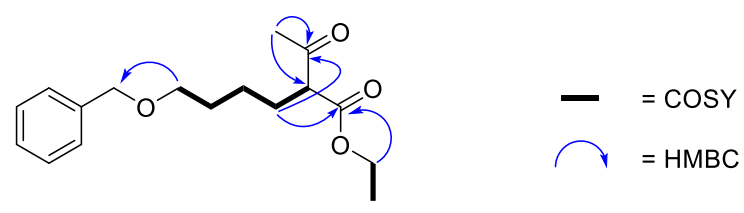

Figure 15. Key COSY and HMBC correlations of $\mathbf{1 8 .}$

\subsubsection{Condensation of $\mathbf{1 7}$ and $\mathbf{1 8}$ with 2-aminopyridine}

Prior work by Durrant found that methodology for condensation of a linker with 2aminopyridine in the synthesis of risperidone was not transferable to condensation reactions with the alkylated ethyl acetoacetates 17 and 18. ${ }^{98}$ Durrant trialled a range of reaction conditions and reagents, ultimately finding ammonium acetate to be an effective reagent for the reaction that was performed neat (Table 4). This method proved to be very simple and reproducible (Scheme 25). 
Table 4. Reaction conditions investigated by Durrant toward the condensation of $\mathbf{1 7}$ and 2aminopyridine to form $19 .{ }^{98}$

\begin{tabular}{|c|c|c|c|c|}
\hline Entry & Method & Time & Temp. ${ }^{\circ} \mathrm{C}$ & Outcome (Yield) \\
\hline 1 & $\mathrm{P}_{2} \mathrm{O}_{5}$ & Overnight & 160 & 17 \\
\hline 2 & $p$-TsOH / Toluene & $48 \mathrm{Hrs}$ & Reflux & 17 and 19 \\
\hline 3 & $\mathrm{P}_{2} \mathrm{O}_{5}$ & Overnight & 170 & By-product and 17 \\
\hline 4 & $p$-TsOH / Xylene & Overnight & Reflux & 17 and 19 \\
\hline 5 & $\mathrm{NH}_{4} \mathrm{O}_{2} \mathrm{CCH}_{3}$ & $2 \mathrm{Hrs}$ & 120 & 17 \\
\hline 6 & $\mathrm{H}_{3} \mathrm{PO}_{4} 85 \%$ & $4 \mathrm{Hrs}$ & 120 & 17 \\
\hline 7 & $\mathrm{H}_{3} \mathrm{PO}_{4} 100 \%$ & $4 \mathrm{Hrs}$ & 120 & 17 \\
\hline 8 & $p$-TsOH / Xylene & Overnight & Reflux & $19(57 \%)$ \\
\hline 9 & $\mathrm{P}_{2} \mathrm{O}_{5}$ & Overnight & 180 & By-product and 17 \\
\hline 10 & $\mathrm{NH}_{4} \mathrm{O}_{2} \mathrm{CCH}_{3}$ & Overnight & 180 & $19(85 \%)$ \\
\hline 11 & $\mathrm{NH}_{4} \mathrm{O}_{2} \mathrm{CCH}_{3}$ & 3.5 Hrs & 180 & $19(74 \%)$ \\
\hline 12 & $p$-TsOH / Xylene & Overnight & Reflux & $19(42 \%)$ \\
\hline 13 & $\mathrm{NH}_{4} \mathrm{O}_{2} \mathrm{CCH}_{3}$ & $2.5 \mathrm{Hrs}$ & 250 & $19(63 \%)$ \\
\hline
\end{tabular}

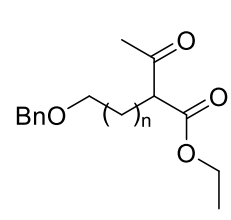

$17, \mathrm{n}=2$

$18, n=3$

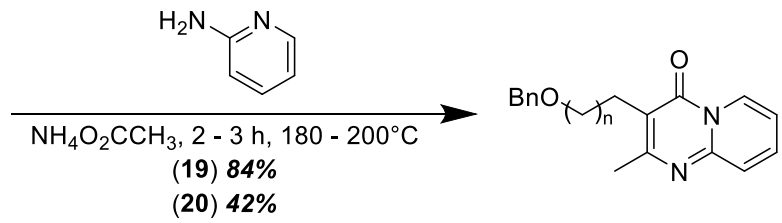

(20) $42 \%$

$19, \mathrm{n}=2$

$20, n=3$

Scheme 25. Condensation of 2-aminopyridine with 17 and 18.

Synthesis of the three-carbon pyridopyrimidone 19 using this method was simple, timeefficient and high yielding, affording a product without additional purification steps required. A plausible mechanism for formation of pyridopyrimidones 19 and 20 begins with attack of the primary amine at the carbonyl (Scheme 26). Subsequent formation of an imine leads to cyclisation by nucleophilic attack, resulting in the loss of ethanol. Deprotonation at the $\alpha$ position causes aromatisation via the loss of water, yielding 19 and 20. Alternatively, this process may begin with attack of the pyridine at the carbonyl of the ester, leading to a 
favourable loss of ethanol. Cyclisation by nucleophilic attack of the amine at the carbonyl, followed by proton transfer results in the loss of water and the formation of an imine. Aromatisation can then proceed to afford the desired product. It is also possible that imine formation could proceed first, followed by formation of the $\alpha, \beta$-unsaturated ketone and again, the desired product attained after cyclisation.
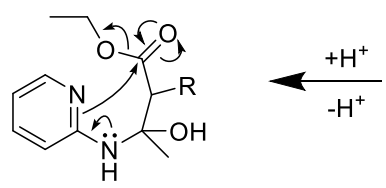

$\downarrow^{-E t O H}$

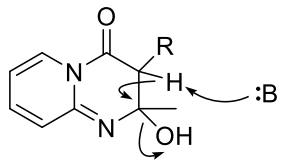

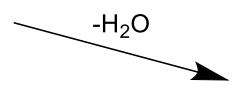

$\mathrm{R}=\mathrm{BnO} \widehat{\mathrm{Mn}_{\mathrm{n}}} \boldsymbol{\xi}^{\mathrm{s}}$

19, $\mathrm{n}=1$ $20, n=2$
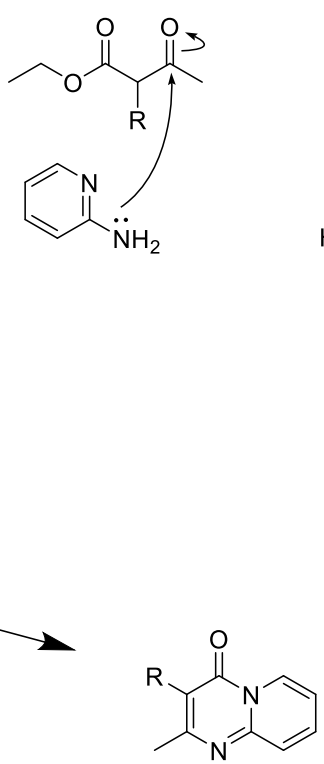<smiles>[R]c1c(C)nc2ccccn2c1=O</smiles>
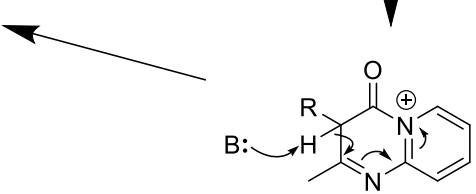

Scheme 26. Possible mechanisms of the condensation of $\mathbf{1 7}$ and $\mathbf{1 8}$ with 2-aminopyridine.

Small and impure samples of these condensation products were found to have unusual NMR behaviour, possibly due to the $\mathrm{pH}$ of the sample or salt impurities present. Following workup of the condensation reaction, the ${ }^{1} \mathrm{H}$ NMR spectrum of the crude product showed only one of the four pyridine ring protons to be fully resolved while the three remaining pyridine ring protons were not observed as distinct peaks (Figure 16). The shifts representing the alkyl chain and methyl group were present in their expected positions. Nonetheless, HRMS analysis showed the desired product 19 to be present, prompting chromatographic purification. 


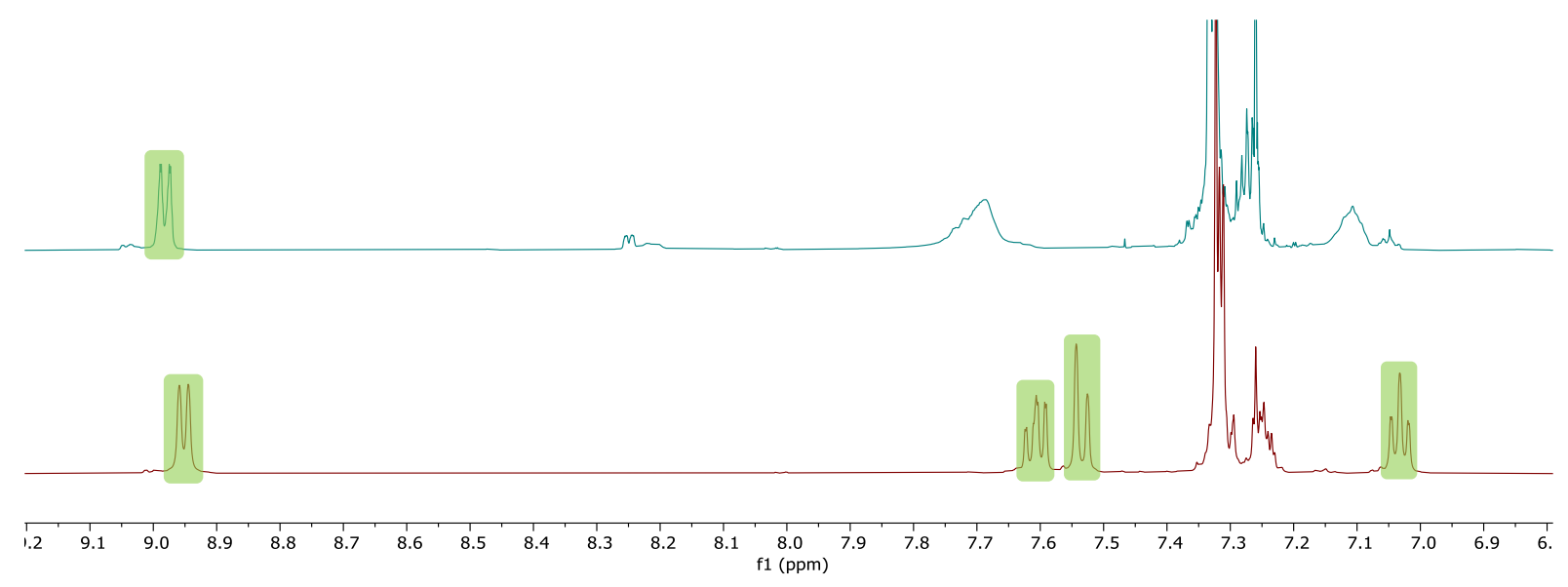

Figure 16. Comparison of ${ }^{1} \mathrm{H}$ NMR spectra of 2-aminopyridine condensation crude reaction mixture (top) and purified (bottom) 19. Pyridine ring shifts are highlighted in green

TLC analysis of the crude product showed a distinctly bright purple spot under $254 \mathrm{~nm} \mathrm{UV}$ light, a likely property of the product $\mathbf{1 9}$ due to its extensive conjugation. This spot was quite broad in 9:1 EtOAc:acetone, therefore 0.5\% triethylamine was added to the solvent system, giving a more compact band. Purification by flash chromatography employing the aforementioned solvent system yielded 19 with NMR spectroscopic data that agreed with those previously reported. ${ }^{98}$ This time a larger sample (>10 mg) was submitted for ${ }^{1} \mathrm{H}$ NMR analysis and all of the expected peaks were clearly resolved. This suggests that accurate NMR analysis of these pyridopyrimidones is sensitive to concentration or purity. Full structural assignment of $\mathbf{1 9}$ and $\mathbf{2 0}$ was ambiguous in the literature. ${ }^{98}$ Therefore, the structure of $\mathbf{1 9}$ was fully assigned based on the NMR spectroscopic data in Table 5. 


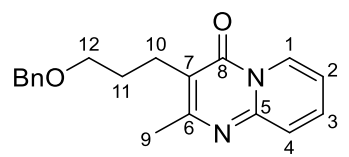

Table 5. Tabulated NMR spectroscopic data $\left(500 \mathrm{MHz}, \mathrm{CDCl}_{3}\right)$ for pyridopyrimidone 19.

\begin{tabular}{|c|c|c|c|c|c|c|c|}
\hline \multirow[b]{2}{*}{ Position } & \multicolumn{2}{|c|}{${ }^{13} \mathrm{C}$} & \multicolumn{3}{|c|}{${ }^{1} \mathbf{H}$} & \multirow[b]{2}{*}{ COSY } & \multirow[b]{2}{*}{ HМBC } \\
\hline & $\delta(\mathrm{ppm})$ & mult. & $\delta(\mathbf{p p m})$ & mult. & $\begin{array}{l}{ }^{3} \boldsymbol{J}_{\mathrm{HH}} \\
(\mathrm{Hz})\end{array}$ & & \\
\hline C-1 & 127.1 & $\mathrm{CH}$ & 8.95 & $\mathrm{~d}$ & 7.0 & 2 & $2,3,5,8$ \\
\hline $\mathrm{C}-2$ & 114.8 & $\mathrm{CH}$ & 7.03 & $\mathrm{t}$ & 6.8 & 1,3 & 1,4 \\
\hline C-3 & 134.9 & $\mathrm{CH}$ & 7.61 & ddd & $9.0,6.5,1.4$ & 2,4 & 1,5 \\
\hline C-4 & 125.7 & $\mathrm{CH}$ & 7.53 & $\mathrm{~d}$ & 8.8 & 3 & 2,5 \\
\hline $\mathrm{C}-5$ & 148.5 & $\mathrm{C}$ & - & - & - & - & - \\
\hline C-6 & 161.5 & $\mathrm{C}$ & - & - & - & - & - \\
\hline $\mathrm{C}-7$ & 115.7 & $\mathrm{C}$ & - & - & - & - & - \\
\hline C-8 & 158.0 & $\mathrm{C}$ & - & - & - & - & - \\
\hline C-9 & 22.4 & $\mathrm{CH}_{3}$ & 2.51 & $\mathrm{~s}$ & - & - & 6,7 \\
\hline $\mathrm{C}-10$ & 23.7 & $\mathrm{CH}_{2}$ & 2.81 & $\mathrm{t}$ & 7.5 & 10 & $6,7,8,11,12$ \\
\hline $\mathrm{C}-11$ & 28.4 & $\mathrm{CH}_{2}$ & 1.91 & $\mathrm{~m}$ & & 11,12 & $7,10,12$ \\
\hline $\mathrm{C}-12$ & 70.0 & $\mathrm{CH}_{2}$ & 3.55 & $\mathrm{t}$ & 6.3 & 11 & $10,11, \mathrm{PhCH}_{2}$ \\
\hline $\mathrm{Ar}$ & 138.7 & $\mathrm{C}$ & - & - & - & - & - \\
\hline $\mathrm{Ar}$ & 128.4 & $\mathrm{CH}$ & $7.35-7.22$ & $\mathrm{~m}$ & - & $\mathrm{Ar}$ & $\mathrm{Ar}$ \\
\hline Ar & 127.7 & $\mathrm{CH}$ & $7.35-7.22$ & $\mathrm{~m}$ & - & $\mathrm{Ar}$ & $\mathrm{Ar}$ \\
\hline $\mathrm{Ar}$ & 127.6 & $\mathrm{CH}$ & $7.35-7.22$ & $\mathrm{~m}$ & - & $\mathrm{Ar}$ & $\mathrm{Ar}$ \\
\hline $\mathrm{PhCH}_{2}$ & 72.9 & $\mathrm{CH}_{2}$ & 4.50 & $\mathrm{~s}$ & - & - & $12, \mathrm{Ar}$ \\
\hline
\end{tabular}

Two pathways of COSY correlations are found, one for three shifts representing the alkyl chain, which is consistent with the starting material 17, and the other connecting four protons that would be present in the pyrimidine ring.

The aromatic protons found at $8.95 \mathrm{ppm}, 7.03 \mathrm{ppm}, 7.61 \mathrm{ppm}$ and $7.53 \mathrm{ppm}$ in the ${ }^{1} \mathrm{H}$ NMR are likely the protons of the pyrimidine based their downfield shifts and COSY correlations. The doublet at $8.95 \mathrm{ppm}$ in the ${ }^{1} \mathrm{H}$ NMR is likely at position $\mathrm{C}-1$ as it experiences strong deshielding from the neighbouring aromatic nitrogen and has only one COSY correlation. The 
${ }^{1} \mathrm{H}$ shift at $7.03 \mathrm{ppm}$ has a COSY correlation to the proton at C-1 as well as the proton found at $7.61 \mathrm{ppm}$, placing these shifts at C-2 and C-3, respectively. The proton of C-3 also has a COSY correlation to the doublet found at $7.53 \mathrm{ppm}$ in the ${ }^{1} \mathrm{H}$ NMR which would place this shift at C-4.

HMBC correlations from the protons of C-1, C-3 and C-4 are observed to the ${ }^{13} \mathrm{C}$ shift at 148.5 ppm, providing evidence for its assignment as C-5. No HMBC evidence is observed for the proton of C-2 to C-5, which is not unexpected as a four-bond correlation is less likely.

The methyl singlet at $2.51 \mathrm{ppm}$ in the ${ }^{1} \mathrm{H}$ NMR has no COSY correlations, therefore must be C-9. HMBC correlations from the protons of C-9 to ${ }^{13} \mathrm{C}$ shifts at $161.5 \mathrm{ppm}$ and $115.7 \mathrm{ppm}$ are likely three and two-bond correlations, respectively. The more downfield shift is likely C-6 which means the ${ }^{13} \mathrm{C}$ shift at $115.7 \mathrm{ppm}$ is likely $\mathrm{C}-7$. The protons of $\mathrm{C}-10$ and $\mathrm{C}-11$ also make three and two-bond HMBC correlations, respectively, to C-7, providing further evidence for its assignment. HMBC correlations are observed from the protons of $\mathrm{C}-10$ to the ${ }^{13} \mathrm{C}$ shift at $158.0 \mathrm{ppm}$, assigning it as the carbonyl at C-8. A weak HMBC correlation is found from the protons of $\mathrm{C}-1$ to this proposed carbonyl position, providing further evidence for its assignment.

Similar signals were observed for the four-carbon linked pyridopyrimidone $\mathbf{2 0}$ and thus the assignments were made accordingly (Figure 17). The main point of difference was two upfield multiplets in the ${ }^{1} \mathrm{H}$ NMR spectrum at $1.75 \mathrm{ppm}$ and $1.67 \mathrm{ppm}$ assigned to $\mathrm{C}-12$ and $\mathrm{C}-11$, respectively, based on COSY correlations through the alkyl chain.

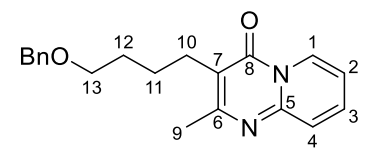

Figure 17. Numbered carbon environments for pyridopyrimidone 20.

\subsubsection{Pd/C Catalysed Hydrogenation of Pyridopyrimidones $\mathbf{1 9}$ and $\mathbf{2 0}$}

$\mathrm{Pd} / \mathrm{C}$ catalysed hydrogenation of heterocyclic substrates is a well studied area of medicinal chemistry due to the importance of these structures as pharmacophores. ${ }^{120-121}$ Hydrogenation of pyridine-based rings is possible under mild conditions. ${ }^{122}$ Selective hydrogenation of 
quinolones is achievable with the use of more specialised $\mathrm{Pd} / \mathrm{C}$-based catalyst supports. ${ }^{123}$ The use of catalytic $\mathrm{Pd} / \mathrm{C}$ under a hydrogen atmosphere can also be utilized for hydrogenative $O$ debenzylation in the synthesis of hydrogenated pyridopyrimidines. ${ }^{124}$ Extensive literature searches found the only application of $\mathrm{Pd} / \mathrm{C}$ catalysed hydrogenation on a pyridopyrimidone system was in the commercial synthesis of risperidone. ${ }^{125}$ This patent describes it to be a resource efficient and high yielding process forgoing the use of organic solvents.

Hydrogenation of the pyridine ring of $\mathbf{1 9}$ and $\mathbf{2 0}$ was required before deprotection. Prior work by Durrant planned to use $\mathrm{Pd} / \mathrm{C}$ catalysed hydrogenation to obtain hydrogenated and deprotected pyridopyrimidones $\mathbf{2 3}$ and $\mathbf{2 4}$ in one step. ${ }^{98}$ Unfortunately, this method only yielded hydrogenated products. These reactions required a Fischer-Porter vessel, allowing for high pressures ( 5 atm.) and relatively fast reaction times ( 24 hours). Regrettably, this apparatus was unavailable so a Schlenk tube with a hydrogen balloon attached was used in its place when first trialled on 19 (Scheme 27). This set up did not facilitate high pressures so a longer reaction time was expected, with periodic refilling of the $\mathrm{H}_{2}$ balloon required. After four days, TLC analysis showed a small amount of $\mathbf{1 9}$ remained and the formation of a slightly more polar, less UV active species. A reduction in UV activity was expected due to the reduction in conjugation of the anticipated product. Careful chromatography allowed for isolation of the required hydrogenated pyridopyrimidone 21. This procedure was repeated for hydrogenation of the four-carbon pyridopyrimidone 22, with similar observations of reduced polarity and UV activity upon TLC analysis.

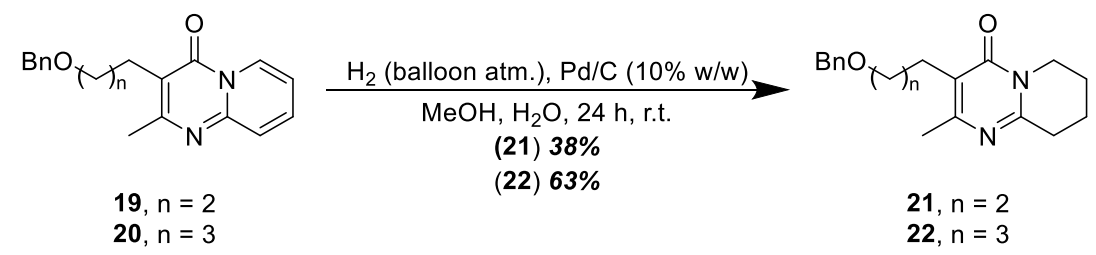

Scheme 27. Hydrogenation of 19 and 20.

Structural elucidation of 21 utilised 2D NMR spectroscopic data for assignment of all ${ }^{13} \mathrm{C}$ and ${ }^{1} \mathrm{H}$ shifts. The ${ }^{1} \mathrm{H}$ NMR spectrum showed a large upfield shift for the protons at positions $\mathrm{C}-1$ to $\mathrm{C}-4$, from > $7 \mathrm{ppm}$ in 19 to $3.90 \mathrm{ppm}, 1.94 \mathrm{ppm}, 1.84 \mathrm{ppm}$ and $2.86 \mathrm{ppm}$, respectively. These 
assignments are supported by the COSY and HSQC spectra. This change is expected to be an effect of the reduced conjugation of the system.

Interestingly, the relative ${ }^{13} \mathrm{C}$ shifts of C-6 and C-8 appear to switch (Figure 18). In the HMBC spectrum of 19, the proton of $\mathrm{C}-1$ has a three-bond correlation to $\mathrm{C}-8$ and the protons of $\mathrm{C}-9$ exhibit a two-bond correlation to C-6. Evidence in the HMBC spectrum of 21 suggests that C6 experiences a slight upfield shift to $158.1 \mathrm{ppm}$ while C-8 shifts downfield to $162.7 \mathrm{ppm}$ in the ${ }^{13} \mathrm{C}$ NMR spectrum. In the HMBC spectrum of 21, C-1 no longer has an HMBC correlation to C-8 while C-9 maintains its two-bond correlation to C-6 (Figure 19). C-10 maintains its HMBC correlation to $\mathrm{C}-8$, confirming these assignments.

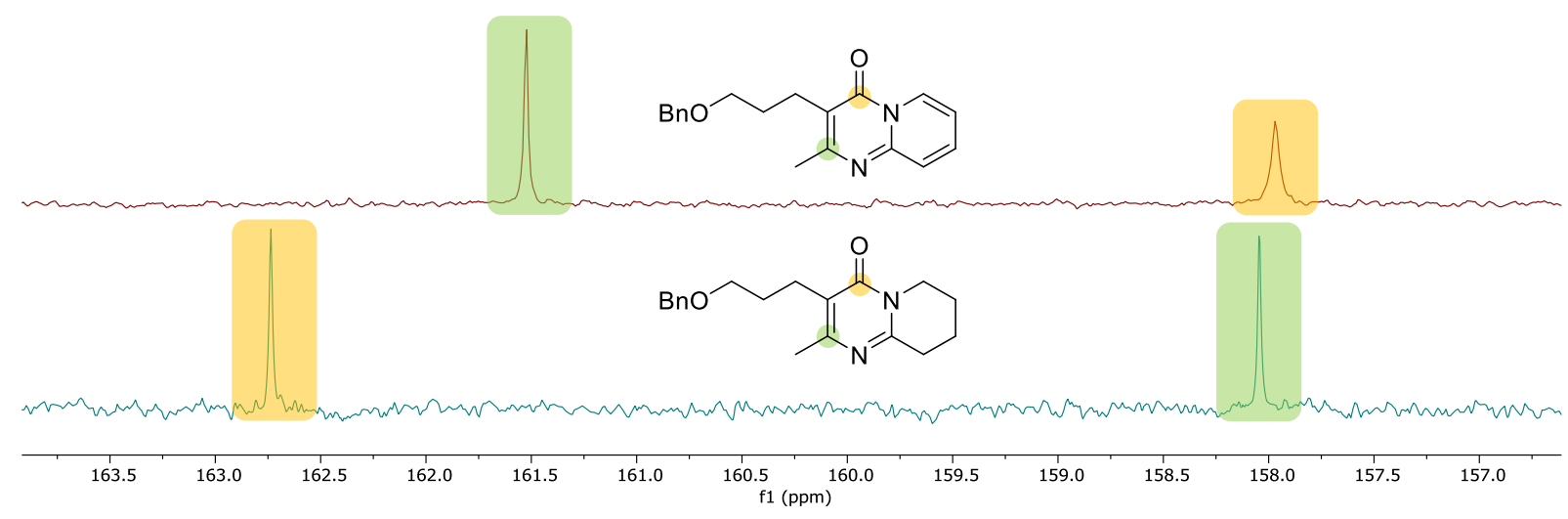

Figure 18. Comparison of ${ }^{13} \mathrm{C}$ shifts of C-6 and C-8 in $\mathbf{1 9}$ (top) and 21 (bottom).

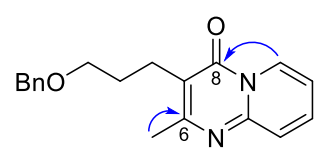

19

C-6, $\delta_{\mathrm{C}} 161.5$

$\mathrm{C}-8, \delta_{\mathrm{C}} 158.0$

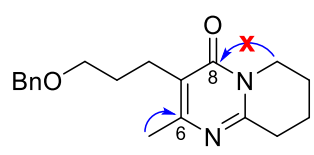

21

$\mathrm{C}-6, \delta_{\mathrm{C}} 158.1$

$\mathrm{C}-8, \delta_{\mathrm{C}} 162.7$

$$
\bigcap=\operatorname{HMBC}\left({ }^{1} \mathrm{H} \rightarrow{ }^{13} \mathrm{C}\right)
$$

Figure 19. Comparison of ${ }^{13} \mathrm{C}$ shifts of C-6 and C-8 in 19 and 21.

A study of non-alkylated pyridopyrimidones found that in unsaturated pyridopyrimidones like 19, the imine carbon (C-6) will have the furthest downfield ${ }^{13} \mathrm{C}$ shift, followed by the amide 
carbon. ${ }^{126}$ The structural assignment of non-alkylated pyridopyrimidones remains ambiguous in the literature. ${ }^{127-128}$ It is postulated the changes in chemical shifts observed in the ${ }^{13} \mathrm{C} N M R$ spectrum of $\mathbf{2 1}$ are caused by a resonance effect as the unsaturated pyridopyrimidone can exist in three resonance structures due to the extensive conjugation of the system (Figure 20). In a saturated substrate, such as $\mathbf{2 1}$, the electrons will be more localised as the system is less conjugated. The carbonyl carbon will be more deshielded than the imine as a result, causing the observed "switch" of chemical shifts.

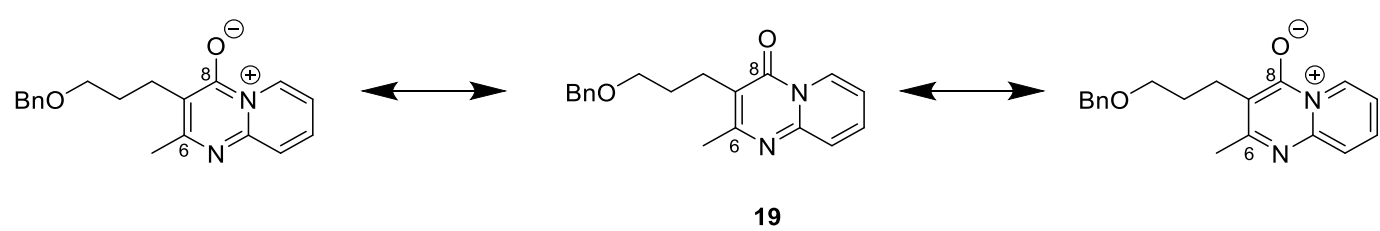

Figure 20. Possible resonance structures of 19.

Repetition of the hydrogenation of $\mathbf{1 9}$ employed different equipment due to the unavailability of the Schlenk tube at the time. A wider $50 \mathrm{~mL}$ round bottom flask with a hydrogen balloon attached was used instead (Figure 21). Compared to the Schlenk tube, the volume of the reaction mixture relative to the size of the flask was much smaller. It was expected that vigorous stirring would increase the surface area of the reaction mixture, allowing for more efficient incorporation of $\mathrm{H}_{2}$ gas into solution. After five days, TLC analysis showed the presence of the expected hydrogenated species, as well as a much more polar species $\left(\mathrm{R}_{f}=0.1,5: 1\right.$ EtOAc:acetone) only visible under $254 \mathrm{~nm}$ UV light. Purification of this mixture yielded the hydrogenated product 21 (12\%), as well as the hydrogenated and debenzylated pyridopyrimidone 23 (56\%). (Figure 22). NMR analysis showed 21 to be lacking the characteristic $\mathrm{CH}_{2}$ peak at $\sim 4.5 \mathrm{ppm}$ in the ${ }^{1} \mathrm{H}$ NMR spectrum as well as the complex multiplet at $\sim 7.3 \mathrm{ppm}$ found in previous Bn-protected pyridopyrimidones. Slight shifts were observed for peaks in the alkyl chain which was confirmed to remain intact by COSY correlations. Connectivity to the pyridopyrimidone was verified by HMBC correlations similar to those previously discussed. HRMS confirmed the presence of the deprotected tetrahydropyridopyrimidone $\mathbf{2 3}$. 

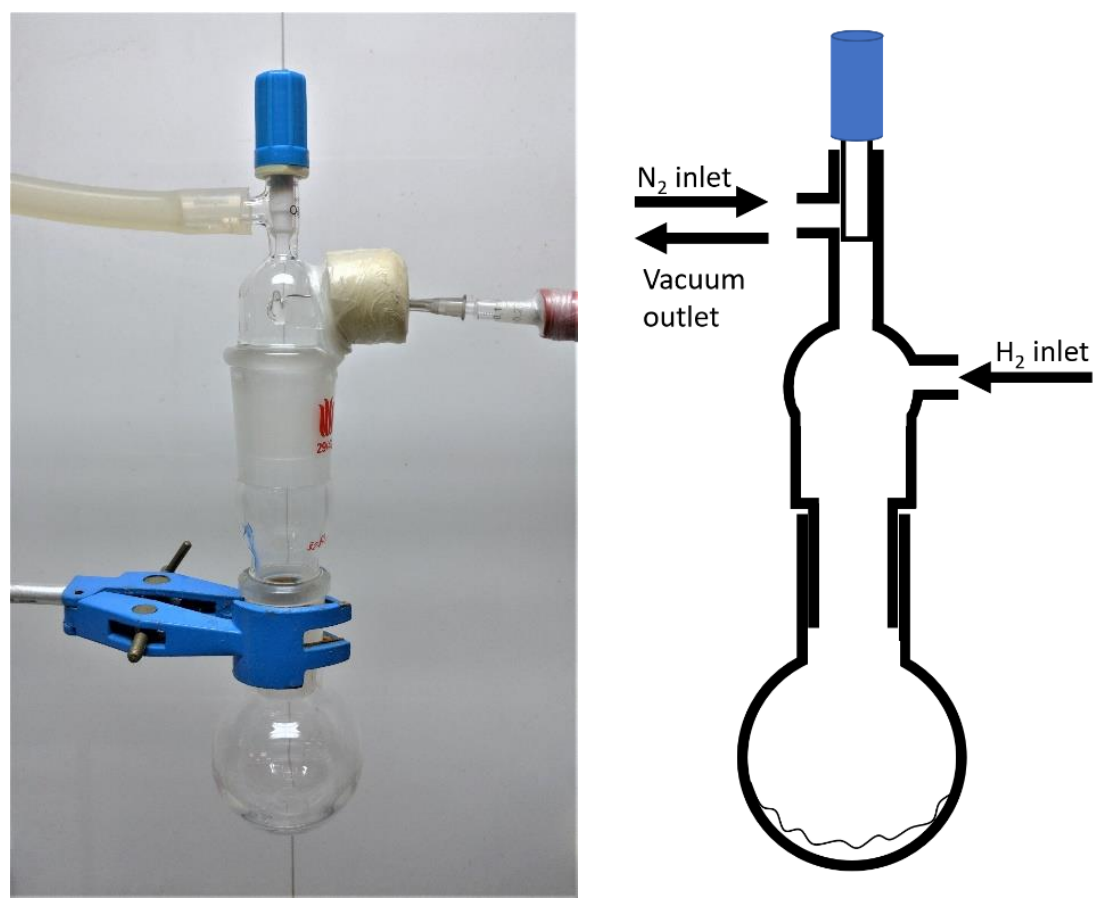

Figure 21. Photo (left) and schematic (right) of apparatus used for second hydrogenation attempt.

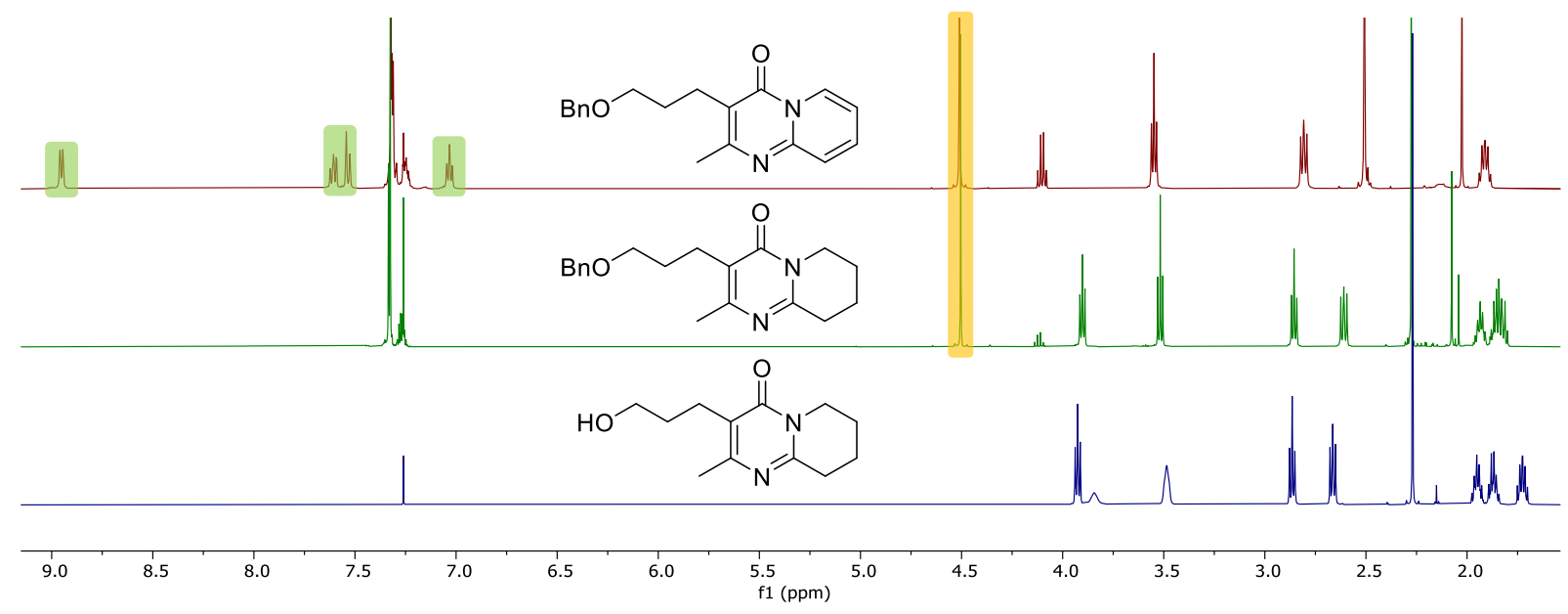

Figure 22. Comparison of ${ }^{1} \mathrm{H}$ NMR spectra of 19 (top), tetrahydropyridopyrimidone 21

(middle) and deprotected tetrahydropyridopyrimidone $\mathbf{2 3}$ (bottom). Highlighted are unsaturated pyridine shifts (green) and benzylic shifts (yellow).

This result was surprising as Durrant's experiments with higher $\mathrm{H}_{2}$ pressures did not yield any deprotected product. ${ }^{98}$ Interestingly, benzyl ether hydrogenolysis using $\mathrm{Pd} / \mathrm{C}$ can be inhibited 
in the presence of added ammonia, ammonium acetate or pyridine. ${ }^{129}$ However, It is unlikely that ammonium acetate is the reason for the lack of deprotection observed by Durrant as any residual ammonium acetate would have been removed during the aqueous workup of the previous step.

Mechanistically it is expected that the palladium catalysed hydrogenative debenzylation occurred via a catalytic cycle beginning with the aromatic ring $\pi$-stacking with the palladium catalyst (Scheme 28). $\mathrm{Pd}^{0}$ then inserts into the $\mathrm{C}-\mathrm{O}$ bond. Addition of $\mathrm{H}_{2}$ gas to the system allows for hydrogen transfer, releasing the debenzylated alcohol and toluene as a byproduct, thus reducing $\mathrm{Pd}^{\mathrm{II}}$ and resetting the cycle.

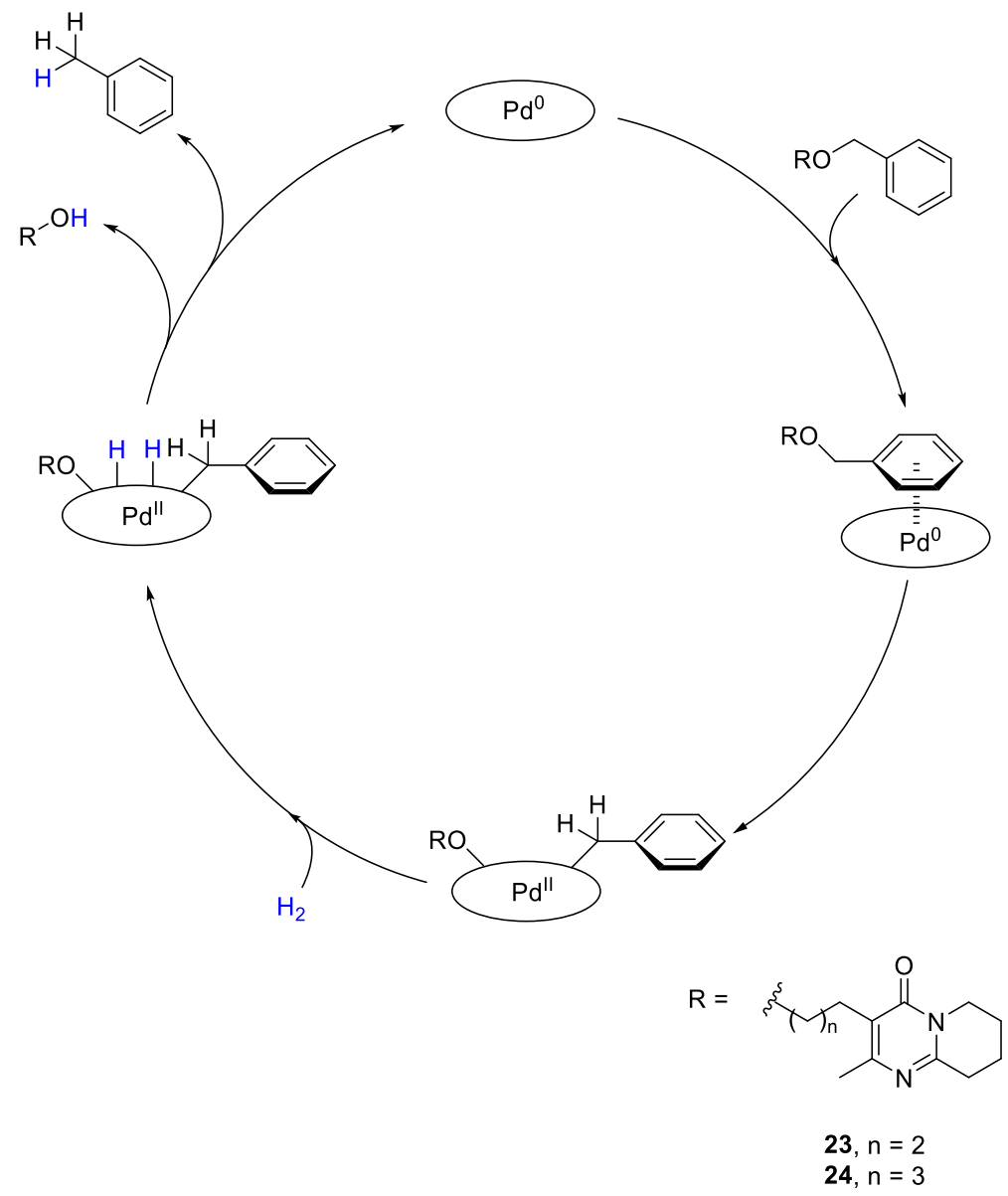

Scheme 28. Mechanism of palladium catalysed hydrogenative $O$-debenzylation. 


\subsection{Debenzylation Attempts}

An efficient route for $O$-debenzylation was required for synthesis of the two analogues. Early work by Durrant found that deprotection by means of catalytic hydrogenation was a dead end despite multiple attempts. ${ }^{98}$ However, hydrogenation of $\mathbf{1 9}$ in the current research found that the use of a larger reaction flask caused partial deprotection and afforded a mixture of $\mathbf{2 1}$ and 23. Unfortunately, the deprotection was slow and did not go to completion after five days, therefore a more efficient route was sought. Deprotections of 19 and 22 with DDQ and $\mathrm{TiCl}_{4}$ were attempted. These substrates were chosen because large stocks were available thanks to prior work by Durrant. ${ }^{98}$ This allowed for multiple small scale deprotection attempts without the pressure of limited material. Tests on substrates with varying conjugation and different alkyl chain lengths could also establish if the order of hydrogenation, then deprotection was strictly required.

\subsubsection{DDQ-mediated Deprotection Attempts}

DDQ was trialled first for debenzylation of 19. While DDQ is known to be an effective agent for oxidative cleavage of the more labile $p$-methoxylbenzyl (PMB) and $p$-methylbenzyl (MBn) protecting groups, ${ }^{130-132}$ DDQ-mediated $O$-debenzylation is often slower. ${ }^{107,}{ }^{133}$ The first deprotection attempt on 19 using 3 equivalents of DDQ was difficult to monitor by TLC due to the apparent formation of multiple byproducts. ${ }^{1} \mathrm{H}$ NMR analysis of the crude reaction mixture after 24 hours indicated only approximately 1:12 conversion based on the integration of the new benzaldehyde peak at $10.03 \mathrm{ppm}$, relative to the existing benzylic shift at $4.51 \mathrm{ppm}$. The appearance of shifted peaks with a similar splitting pattern to 19 suggested that DDQ was effective for $O$-debenzylation, albeit rather slowly.

This prompted another attempt, increasing the amount of DDQ to 20 equivalents. The solubility of DDQ was poor so it is unlikely the total quantity was dissolved in the reaction. ${ }^{1} \mathrm{H}$ NMR analysis after 24 hours showed an increase in benzaldehyde formation. The appearance of a triplet at $2.87 \mathrm{ppm}$ suggested transformation of $\mathbf{1 9}$ into a new species. Gradient flash chromatography (5:1 EtOAc:acetone then 1:1 EtOAc:acetone) was employed, yielding 19 (4 $\mathrm{mg}, 15 \%)$ as well as another far more polar product $(1 \mathrm{mg})$. The ${ }^{1} \mathrm{H}$ NMR spectrum of this polar species showed an apparently debenzylated product that was lacking the characteristic benzylic peak at $4.51 \mathrm{ppm}$ and the complex multiplet in the aromatic region. Surprisingly, only 
one of the protons (C-1) of the pyridine ring was observable (Figure 23). 2D NMR confirmed this observation as no COSY correlations were found in this region. These shifts should be retained in the product, suggesting that while deprotecting 19, DDQ was also interacting with the substrate in an undesired way and causing degradation.

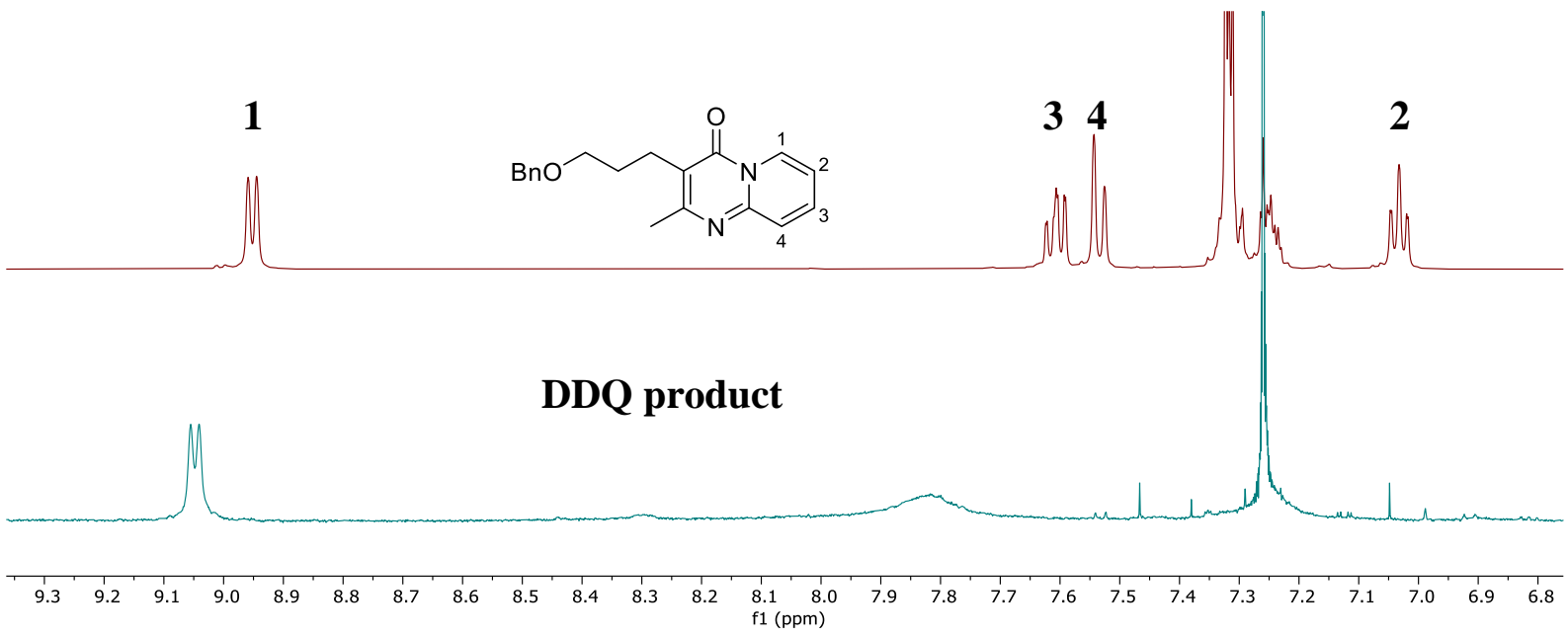

Figure 23. Stacked ${ }^{1} \mathrm{H}$ NMR of protected alcohol 19 (top) and unknown DDQ-mediated deprotection product (bottom).

These results demonstrate that DDQ was unlikely to be suitable for debenzylation of the pyridopyrimidone substrates. Long reaction times resulted in only partial deprotection, as well as formation of unidentifiable byproducts. Therefore, other methods of debenzylation were investigated.

\subsection{2 $\mathrm{TiCl}_{4}$-mediated Deprotection Attempts}

Attention was then turned toward the use of $\mathrm{TiCl}_{4}$ as an alternative method of deprotection. $\mathrm{TiCl}_{4}$ is known to be rapidly debenzylate benzyl ethers, making it an appealing alternative to DDQ. ${ }^{134} \mathrm{TiCl}_{4}$-mediated debenzylation has been used in the total synthesis of monocillin VII, a macrolactone containing a ketone and a pyran ring. ${ }^{135}$ Treatment with 10 equivalents of $\mathrm{TiCl}_{4}$ provided the expected product in an impressive $89 \%$ yield. Within the research group, $\mathrm{TiCl}_{4}$ was used for debenzylation in the final steps of syntheses of TAN-2483B analogues. ${ }^{136}$ These highly functionalised compounds were isolated in yields of $56-72 \%$ following ten minute 
reaction times. Interestingly, in the synthesis of leucascandrolide $\mathrm{A}, \mathrm{TiCl}_{4}$ was successfully used to facilitate allylation of an intermediate compound without deprotection of a benzyl ether. ${ }^{137}$ Unfortunately, no literature was available on the reactivity of pyridopyrimidones in the presence of $\mathrm{TiCl}_{4}$.

The first use of $\mathrm{TiCl}_{4}$ to debenzylate 19 using 5 equivalents of $\mathrm{TiCl}_{4}$ was difficult to monitor by TLC as the acid continued to react on the silica. Following aqueous workup, TLC analysis of the crude reaction mixture showed a broad, $254 \mathrm{~nm}$ UV active species at $\mathrm{R}_{f}=0.22(1: 1$ EtOAc:acetone), which was subsequently separated by column chromatography. Initial ${ }^{1} \mathrm{H}$ NMR analysis of one isolated fraction showed only one of the pyridine protons to be present, similar to what was found with the DDQ debenzylation attempt. Upon combination of all fractions containing the same pure compound, all of the expected proton shifts were present, signifying successful deprotection (Figure 24). This suggested that accurate NMR analysis of 27 is sensitive to concentration. Consequently, it also suggests the previous deprotection using DDQ may have been successful, but due to the small quantity isolated (1 mg), accurate NMR analysis was not possible.

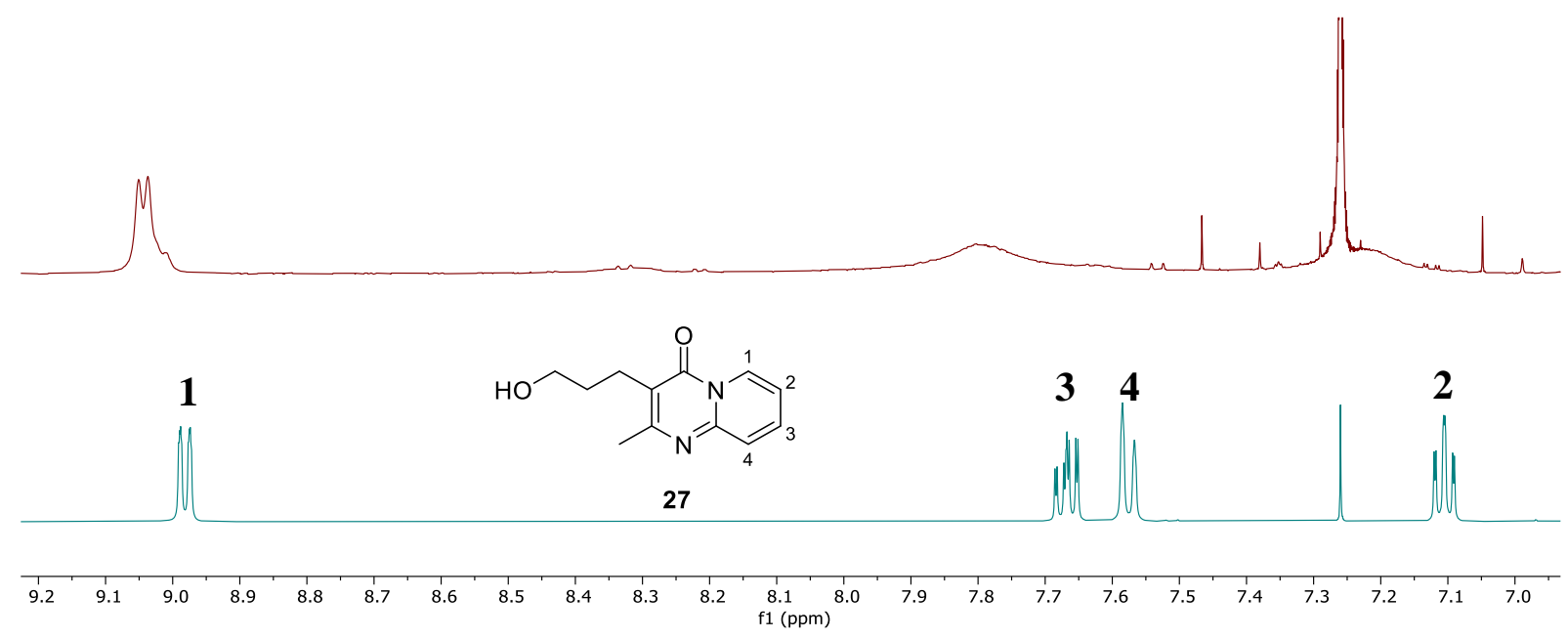

Figure 24. Stacked ${ }^{1} \mathrm{H}$ NMR spectra of one fraction of chromatographed $\mathrm{TiCl}_{4}$ reaction product (top) and combined fractions of $\mathrm{TiCl}_{4}$ reaction product (bottom).

The ${ }^{1} \mathrm{H}$ NMR spectrum of 27 showed the alkyl chain peaks to have shifted by up to $0.08 \mathrm{ppm}$ when compared to 19. The 2D NMR data confirmed the connectivity of the alkyl chain to the pyridopyrimidone remained unchanged. The ${ }^{13} \mathrm{C}$ NMR spectrum showed the loss of phenyl 
ring shifts and the shift characteristic of benzylic position at $72.9 \mathrm{ppm}$, indicative of successful deprotection. A broad $-\mathrm{OH}$ stretch at $3231 \mathrm{~cm}^{-1}$ was noted in the IR spectrum of 27 that was not present in the starting material. HRMS supported these observations, confirming the desired product had been isolated in a $49 \%$ yield.

Mechanistically it is proposed this reaction begins with attack of the oxygen on the titanium, leading to loss of a chlorine (Scheme 29). The free chlorine can then attack the benzylic position, breaking the $\mathrm{C}-\mathrm{O}$ bond and forming benzyl chloride as a result. Subsequent hydrolysis will provide the deprotected alcohol.

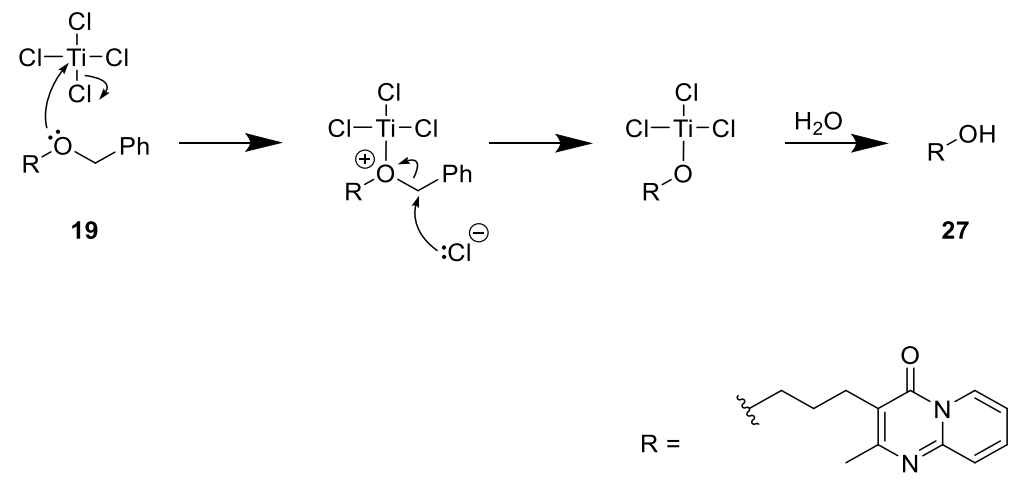

Scheme 29. Proposed mechanism of $\mathrm{TiCl}_{4}$-mediated deprotection.

The success of the deprotection of $\mathbf{1 9}$ prompted an attempt towards deprotection of $\mathbf{2 2}$. Employing the aforementioned procedure, chromatographic separation with a more polar solvent system (acetone $+0.5 \%$ triethylamine) yielded the anticipated alcohol $24(41 \%)$. The success of the $\mathrm{TiCl}_{4}$ deprotection method on both saturated and unsaturated substrates changed the aim of the project from synthesis of two analogues to four analogues. These four variants having three- and four-carbon alkyl linkers and the pyridopyrimidone being either saturated or unsaturated (Figure 25). The use of additional analogues in biological assays will hopefully provide more insight into the immunomodulatory mode of action of risperidone. 
<smiles>Cc1nc2n(c(=O)c1CCCN1CCC(c3noc4cc(F)ccc34)CC1)CCCC2</smiles>

8<smiles>Cc1nc2ccccn2c(=O)c1CCCN1CCC(c2noc3cc(F)ccc23)CC1</smiles>

28<smiles>Cc1nc2n(c(=O)c1CCCCN1CCC(c3noc4cc(F)ccc34)CC1)CCCC2</smiles>

9

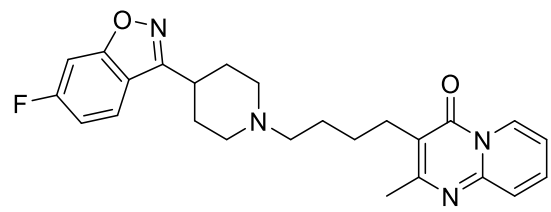

29

Figure 25. The four proposed risperidone analogues.

Deprotection of $\mathbf{1 9}$ was scaled up, with a more exhaustive extraction method providing a cleanly debenzylated product in a slightly improved yield (53\%). Scale up of the deprotection of 22 also had an improved yield (66\%). The aforementioned method was applied to the deprotection of 21 and 20 (Scheme 30). Observations in the NMR data similar to previous deprotected products confirmed the success of these debenzylation reactions.

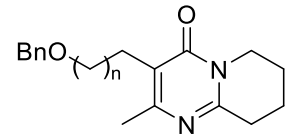

21, $\mathrm{n}=2$

22, $n=3$<smiles>Cc1nc2ccccn2c(=O)c1CCCOc1ccccc1</smiles>

$19, \mathrm{n}=2$

$20, n=3$

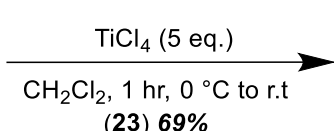

(24) $66 \%$

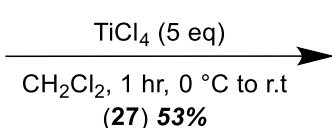

(30) $57 \%$

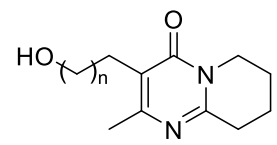

23, $\mathrm{n}=2$

$24, n=3$

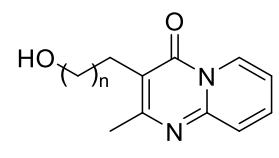

$27, \mathrm{n}=2$

$30, n=3$

Scheme 30. TiCl $_{4}$-mediated benzyl-deprotection of pyridopyrimidones 19, 20, 21 and 22. 
With the four deprotected pyridopyrimidones in hand, an Appel reaction was required to replace the hydroxyl with an iodide group in preparation for the final base-mediated coupling reactions (Scheme 31). Following the methodology of Zareie et al., approximately 2 equivalents of $\mathrm{PPh}_{3}$ and 1.5 equivalents of iodine were to be added to acetonitrile at $0{ }^{\circ} \mathrm{C} .{ }^{97}$ The pyridopyrimidone can then be added and the reaction heated at reflux overnight. Following workup, the iodide product was to be used immediately in the subsequent coupling with amine 3. Chromatographic purification of the Appel product would be avoided to prevent possible degradation on silica gel.<smiles>Cc1nc2n(c(=O)c1CCO)CCCC2</smiles>

23, $\mathrm{n}=2$ $24, n=3$<smiles>CC(C)=[Pb]</smiles><smiles>Cc1nc2n(c(=O)c1CCI)CCCC2</smiles>

$25, n=2$

26, $n=3$
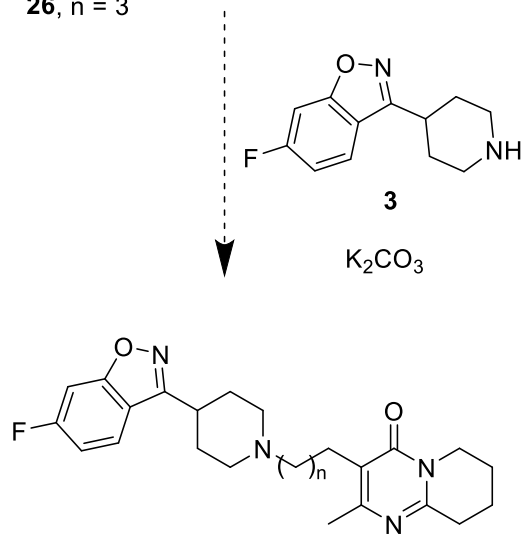

$8, n=2$

$9, \mathrm{n}=3$

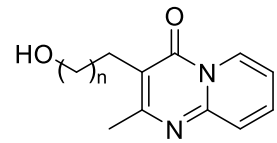

$27, \mathrm{n}=2$

$30, n=3$

$\mathrm{PPh}_{3}, \mathrm{I}_{2}$

$\dot{y}$

$31, \mathrm{n}=2$

$32, n=3$<smiles>Cc1nc2ccccn2c(=O)c1CCI</smiles>
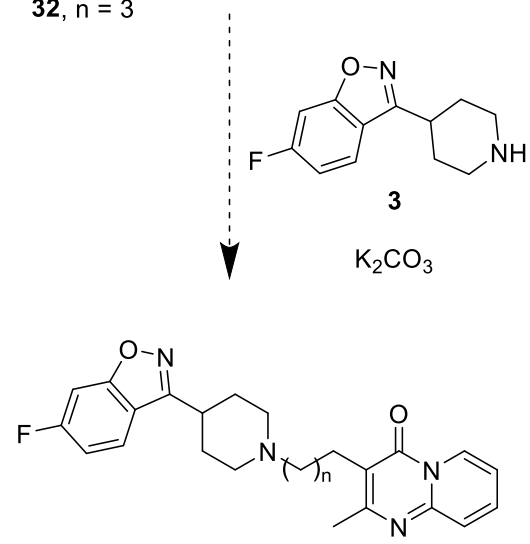

28, $n=2$

$29, n=3$

Scheme 31. Proposed synthesis of analogues 8, 9, 28 and 29 via Appel reactions yielding iodides 25, 26, 31 and 32. 


\subsubsection{Synthesis of Four-Carbon Saturated Analogue 9}

During the Appel reaction of $\mathbf{2 4}$ toward synthesis of $\mathbf{9}$, it was demonstrated that the addition of iodine to the dissolved $\mathrm{PPh}_{3}$ resulted in the formation of a precipitate (Scheme 32). This is likely a phosphonium salt formed via a similar mechanism to the earlier Appel reaction (see Section 2.3.1). The reaction was halted after 19 hours as reaction monitoring by TLC analysis was impossible due to streaking of the triphenylphosphine oxide byproduct (Figure 26). Addition of triethylamine to the mobile phase did not allow for resolution of individual species as it had in previous steps. Fortunately, the prescribed aqueous workup removed the $\mathrm{PPh}_{3} \mathrm{O}$ byproduct and afforded iodide $\mathbf{2 6}$ in a reasonable yield.

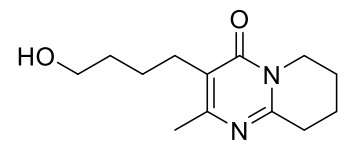

24

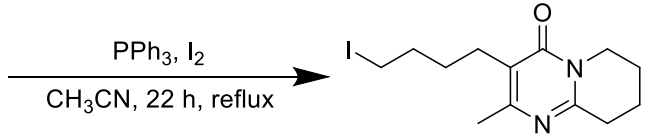

26

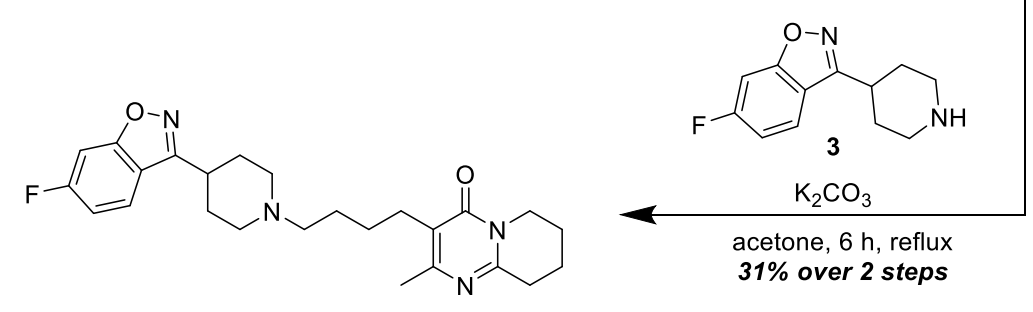

9

Scheme 32. Synthesis of analogue 9. 


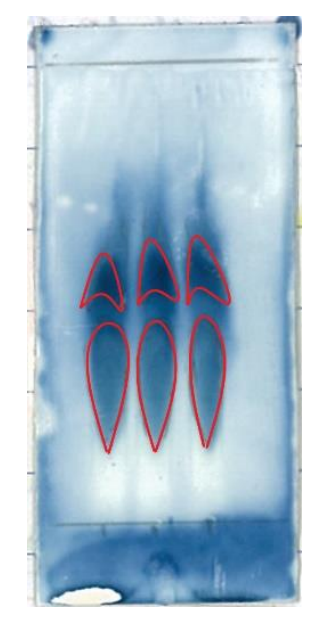

Figure 26. Triplicate TLC analysis (acetone $+0.5 \%$ triethylamine) of crude reaction mixture pre-workup for Appel reaction on 24. Stained with ceric ammonium molybdate. $254 \mathrm{~nm} \mathrm{UV}$ active spots are outlined in red.

The ${ }^{1} \mathrm{H}$ NMR spectrum of $\mathbf{2 6}$ showed the presence of a small amount of $\mathrm{PPh}_{3} \mathrm{O}$ (1:40) which was expected to be unreactive in the subsequent step. The biggest change when comparing the ${ }^{1} \mathrm{H}$ NMR spectra of alcohol $\mathbf{2 4}$ and iodide $\mathbf{2 6}$ was the moderate upfield shift of the halogen neighbouring protons. A shift from $3.71 \mathrm{ppm}$ in alcohol $\mathbf{2 4}$ to $3.21 \mathrm{ppm}$ in iodide 26 was observed with a small change in the $J$-couplings of these triplets $(6.2 \mathrm{~Hz}$ and $6.9 \mathrm{~Hz}$, respectively). These observations are similar to those noted in the synthesis of two-carbon linker pyridopyrimidones by Zareie et $a l .^{97}$

Iodide 26 was immediately subjected to a coupling reaction with the benzisoxazole-linked piperidine 3. Using approximately equimolar amounts of iodide 26, amine $\mathbf{3}$ and $\mathrm{K}_{2} \mathrm{CO}_{3}$, the mixture was heated at reflux. After six hours, TLC analysis was unconvincing due to the presence of multiple products. Four UV active species were present as well as two that stained with ceric ammonium molybdate dip (Figure 27). TLC analysis the following day showed that the addition of further $\mathrm{K}_{2} \mathrm{CO}_{3}$ ( 0.5 equivalents) had not pushed the reaction to completion. As a result, the reaction was halted, the aqueous workup followed and the crude reaction product analysed by NMR spectroscopy. Future syntheses withheld the addition of extra base due to its ineffectiveness. 


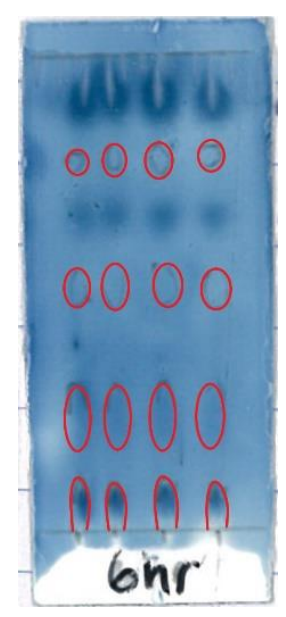

Figure 27. Quadruplicate TLC analysis (acetone $+0.5 \%$ triethylamine) of the crude reaction mixture of the coupling reaction towards 9. Stained with ceric ammonium molybdate. $254 \mathrm{~nm}$ UV active spots are outlined in red.

The ${ }^{1} \mathrm{H}$ NMR spectrum of the crude reaction mixture showed the presence of similar shifts to those of the two fragments $\mathbf{3}$ and 26, albeit slightly shifted. The largest change in chemical shifts were noted for protons located nearest to the point of coupling, the amine. In particular, the piperidine ring protons of $\mathbf{3}$ and the terminal protons of the alkyl chain of $\mathbf{2 6}$, exhibited the greatest change in shifts.

The peaks representative of the piperidine ring protons were found to be much less resolved than all other shifts found in the crude mixture. Comparing the ${ }^{1} \mathrm{H}$ NMR spectra of benzisoxazole 3 and analogue 9 showed the triplet of triplets and doublet of triplets, representing $\mathrm{H}-8^{\prime}$ and $\mathrm{H}-10^{\prime}$ a respectively, to be significantly less resolved in crude reaction mixture (Figure 28). This effect had been noted in the earlier 2-aminopyridine condensation step where some peaks did not resolve with impure samples. A slight upfield shift was also noted for protons $\mathrm{H}-8^{\prime}$ and $\mathrm{H}-10^{\prime} \mathrm{a}$ in the crude product. HRMS analysis confirmed the presence of the desired product 9 with a found mass of 439.2512 that matched the calculated value for $\mathrm{C}_{25} \mathrm{H}_{32} \mathrm{FN}_{4} \mathrm{O}_{2}{ }^{+}[\mathrm{M}+\mathrm{H}]^{+} 439.2504$ with $\Delta=1.9 \mathrm{ppm}$. 


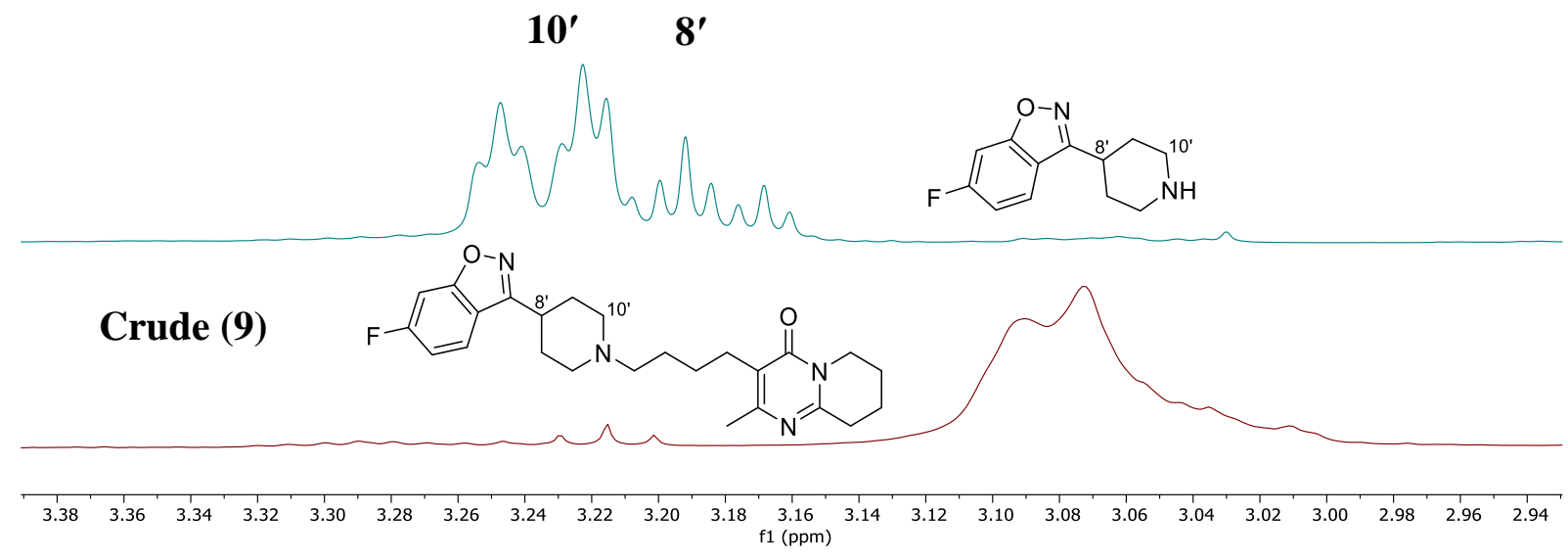

Figure 28. Stacked ${ }^{1} \mathrm{H}$ NMR spectra of benzisoxazole 3 (top) and crude condensation product 9 (bottom), focussed on shifts representative of positions C-8' and C-10'.

TLC analysis of the crude reaction mixture revealed a distinctly flat spot visible under $254 \mathrm{~nm}$ UV irradiation. Isolation of this species utilised diol-functionalised silica gel in a pipette column to avoid acid-mediated degradation associated with traditional silica gel. Fortunately, clean separation was achieved to afford the first analogue (9).

COSY NMR analysis demonstrated that connectivity was maintained throughout the alkyl chain, as well as in the pyridine ring of the pyridopyrimidone. HMBC correlations within the fused heterocycle were similar to those previously discussed (see Section 2.3.3). Connectivity of the piperidine ring to the benzisoxazole was confirmed by HMBC and COSY correlations as previously discussed (see Section 2.2.4). NMR analysis of the whole product confirmed that the coupling was successful, with an HMBC correlation from the protons of C-13 to C-10' (Figure 29). 


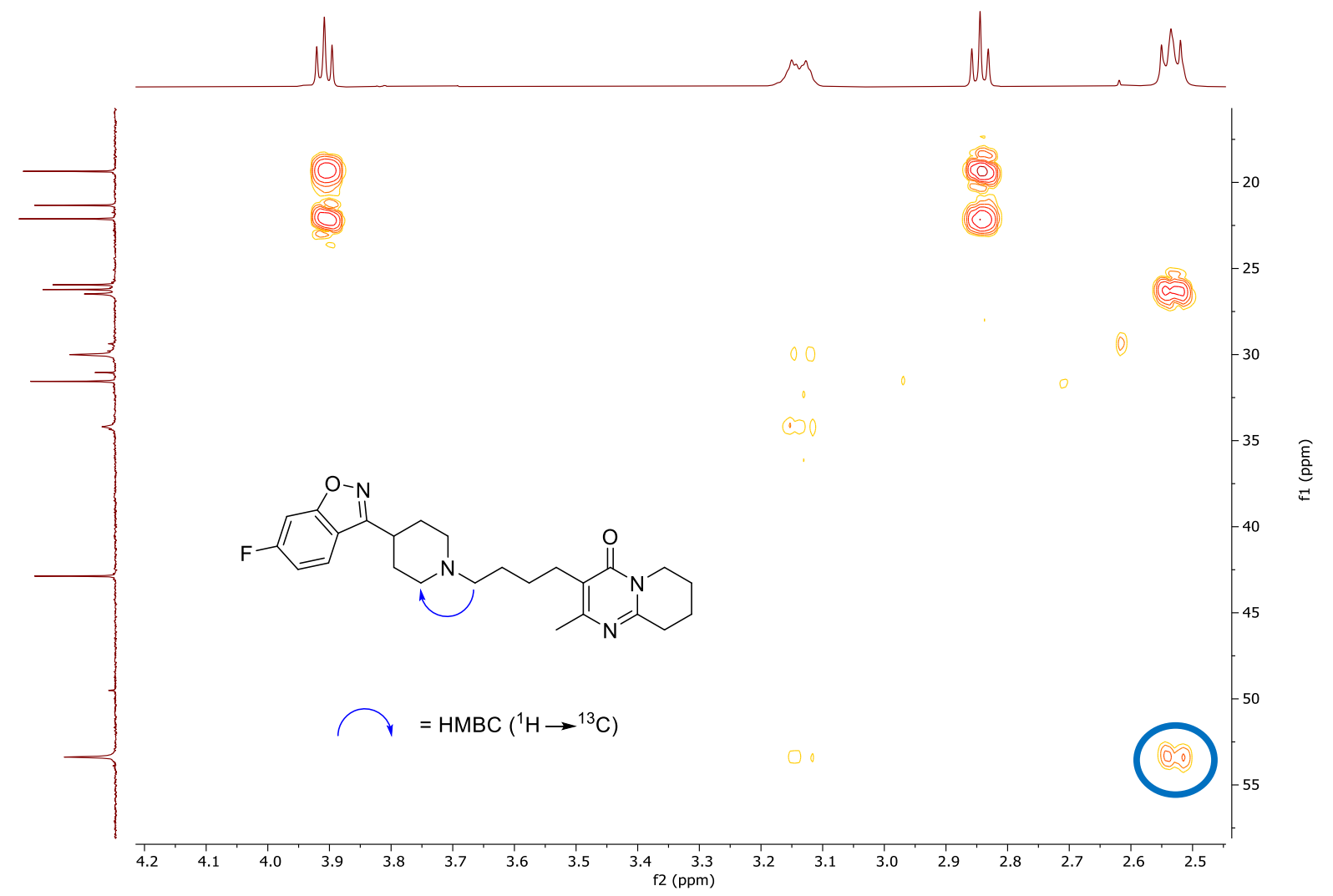

Figure 29. Expansion of HMBC spectrum of 9 with the key correlation circled.

Again, it was found that weakly concentrated NMR samples did not allow for adequate resolution of all peaks, similar to previous analyses of small quantities of 19 and 27. In an attempt to circumvent this issue the use of $\mathrm{D}_{2} \mathrm{O}$ was trialled in place of the usual $\mathrm{CDCl}_{3}$. Surprisingly, ${ }^{1} \mathrm{H}$ NMR analysis in $\mathrm{D}_{2} \mathrm{O}$ provided a more resolved spectrum (Figure 30), however poor solubility did not allow for collection of ${ }^{13} \mathrm{C}$ and $2 \mathrm{D}$ NMR spectra from this sample. Instead, larger quantities (> $10 \mathrm{mg}$ ) of analogue 9 were found to provide well-resolved spectra in $\mathrm{CDCl}_{3}$. 


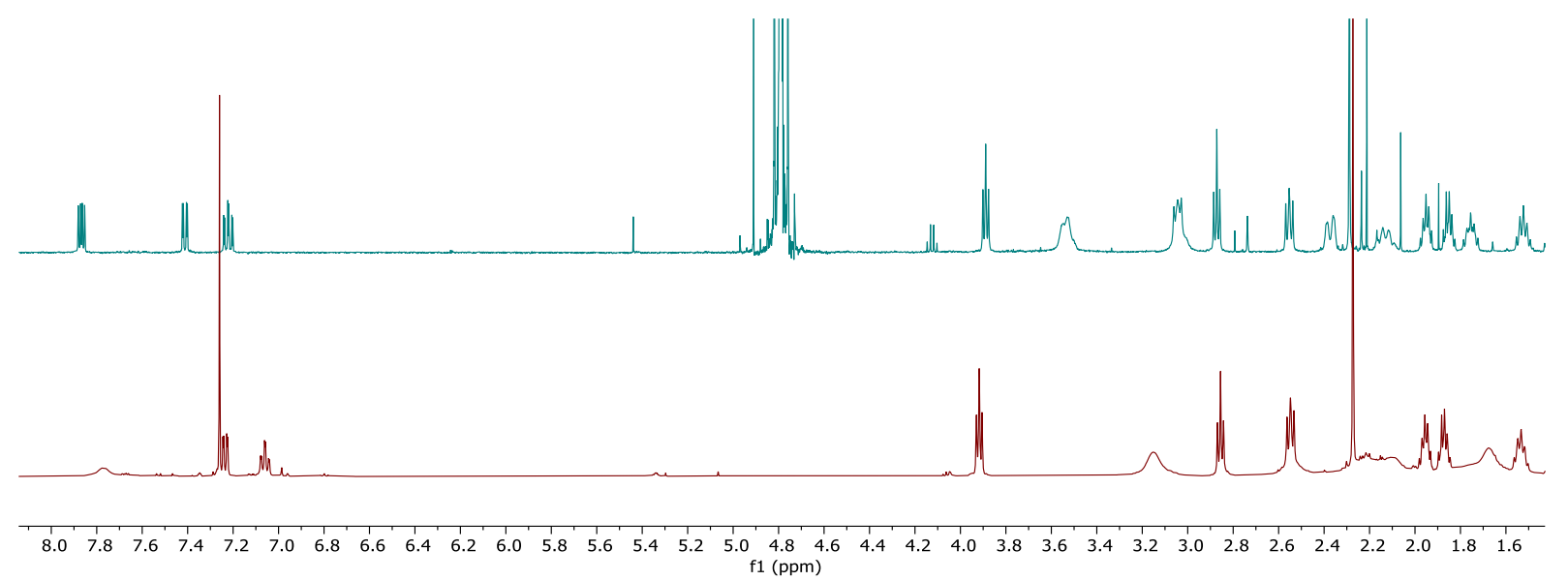

Figure 30. Comparison of ${ }^{1} \mathrm{H}$ NMR spectra of analogue 9 in $\mathrm{D}_{2} \mathrm{O}$ (top) and $\mathrm{CDCl}_{3}$ (bottom).

\subsubsection{Synthesis of Analogues $\mathbf{8}, \mathbf{2 8}$ and $\mathbf{2 9}$}

Synthesis of analogues $\mathbf{8}$ and $\mathbf{2 9}$ employed the same procedure as for synthesis of analogue $\mathbf{9}$ (Scheme 33). Appel reaction of $\mathbf{2 3}$ and $\mathbf{3 0}$ yielded iodides $\mathbf{2 5}$ and 32, the formation of which was confirmed by HRMS. These iodide products were used immediately in coupling reactions with 3. Chromatographic separation as previously described yielded the desired analogues $\mathbf{8}$ and 29. Fortunately, adequate quantities were synthesised for full structural elucidation by NMR spectroscopy. The ${ }^{1} \mathrm{H}$ NMR spectra of both $\mathbf{8}$ and 29 showed similar shifts in peaks to $\mathbf{9}$, when compared to the starting material (Figure 31). 
<smiles>Cc1nc2n(c(=O)c1CCCO)CCCC2</smiles>

23

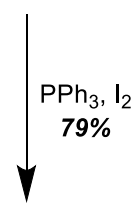<smiles>Cc1nc2n(c(=O)c1CCCI)CCCC2</smiles>

25

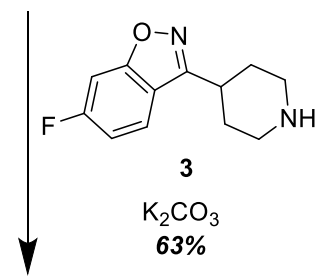<smiles>Cc1nc2n(c(=O)c1CCCN1CCC(c3noc4cc(F)ccc34)CC1)CCCC2</smiles><smiles>Cc1nc2ccccn2c(=O)c1CCCCO</smiles>

30 $\mathrm{PPh}_{3}, \mathrm{I}_{2}$ $\downarrow$<smiles>Cc1nc2ccccn2c(=O)c1CCCCI</smiles>

32
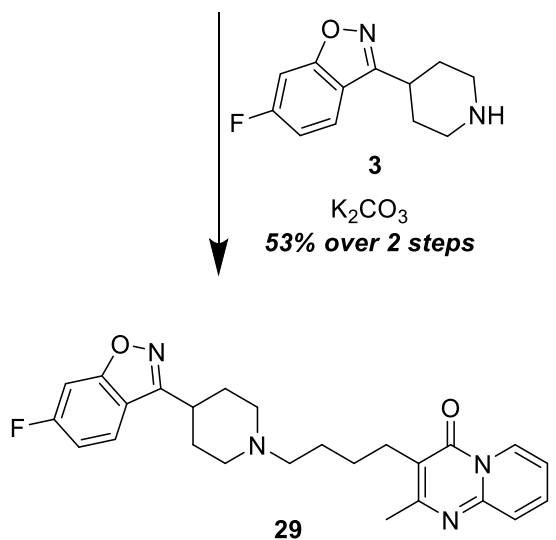

Scheme 33. Synthesis of analogues 8 and 29.

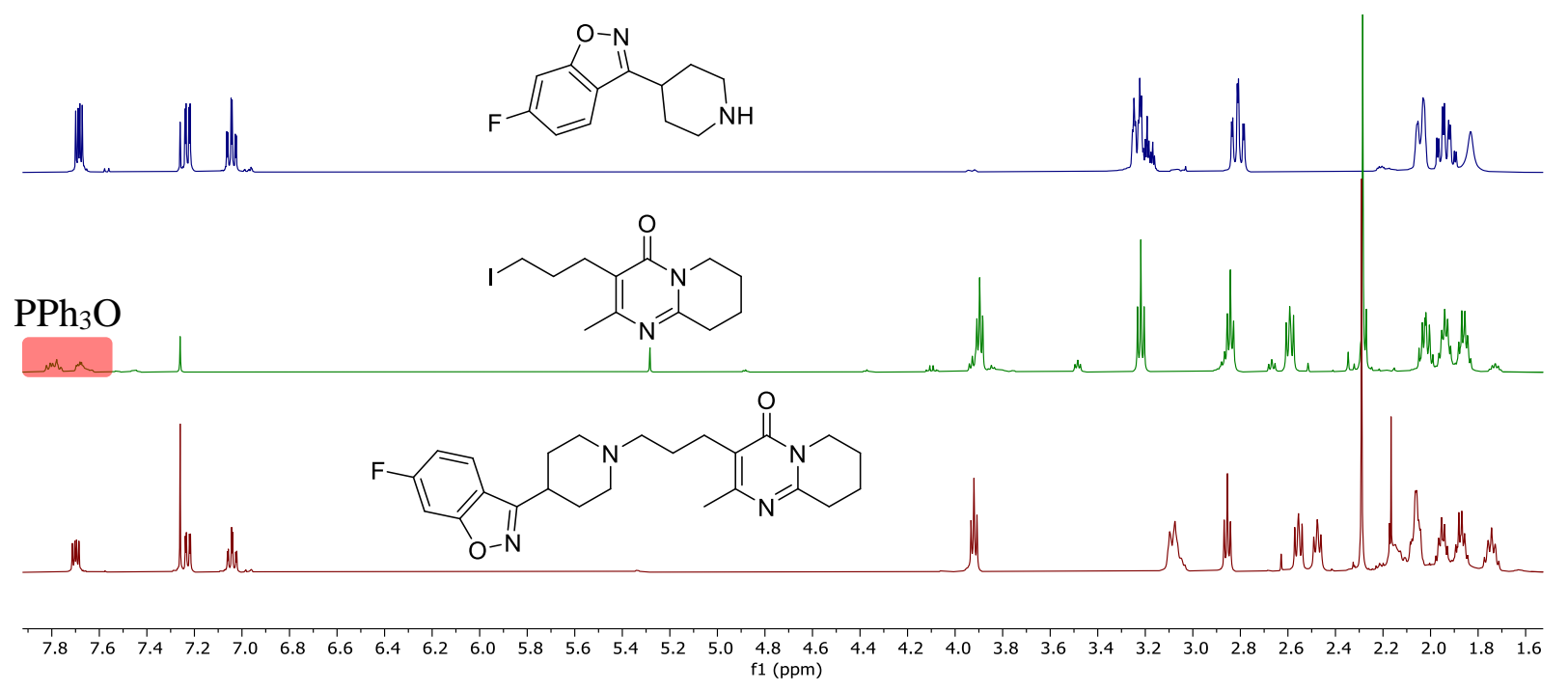

Figure 31. Stacked ${ }^{1} \mathrm{H}$ NMR spectra of benzisoxazole 3 (top), iodide 25 (middle) and analogue 8 (bottom). Residual $\mathrm{PPh}_{3} \mathrm{O}$ is highlighted in red. 
Synthesis of $\mathbf{2 8}$ was less efficient. Two attempts of the Appel reaction on this substrate resulted in only partial conversion of the alcohol to the iodide $\mathbf{3 1}$ (2:1 and 0.32:1 27:31 by comparison of integrals in the ${ }^{1} \mathrm{H}$ NMR spectrum). These mixtures were used in the subsequent coupling reaction without further purification as it was expected the alcohol would be unreactive. The hydroxyl proton would likely be less labile than the amine proton of benzisoxazole $\mathbf{3}$. However, if the alcohol were to react with the iodide, a dimeric product (33) could form (Scheme 34). Fortunately, the coupling with $\mathbf{3}$ proceeded smoothly and no dimeric product was identified (Scheme 35). The final analogue 28 was isolated in sufficient quantity (10.3 $\mathrm{mg}, 67 \%$ ) for definitive NMR analysis.

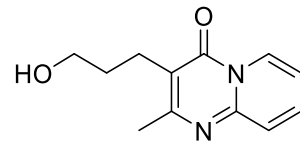

27

$+$

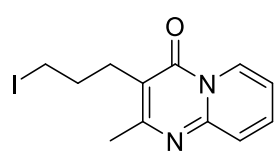

31

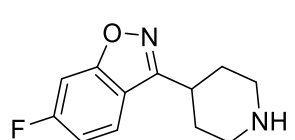

3

$\mathrm{K}_{2} \mathrm{CO}_{3}$
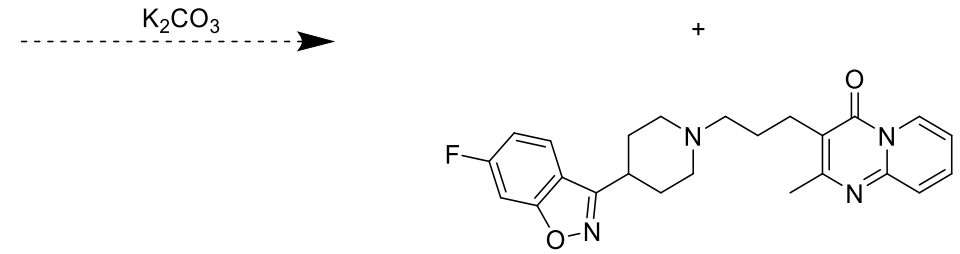

28

Scheme 34. Possible products of an alcohol (27) and iodide (31) mixture in the final condensation reaction. 
<smiles>Cc1nc2ccccn2c(=O)c1CCCO</smiles>

27

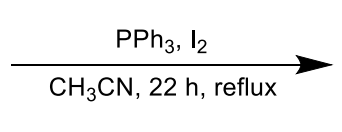

31

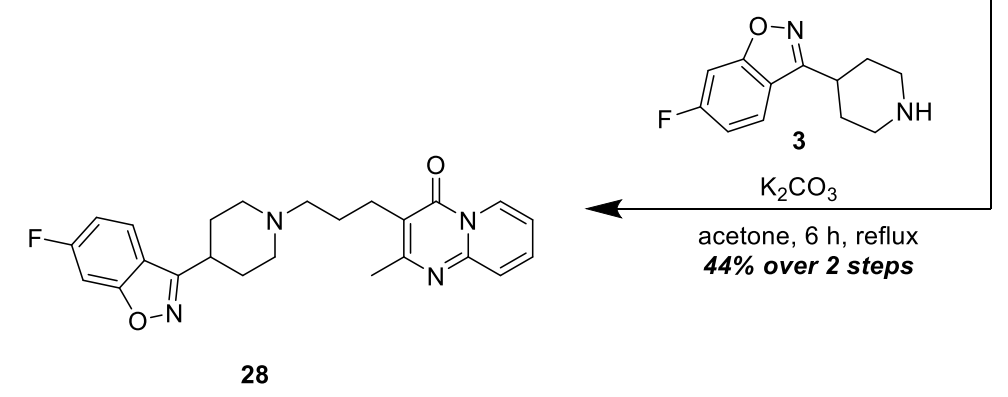

Scheme 35. Synthesis of analogue 28.

The transformation of all four substrates from an alcohol to an iodide showed some consistency in the observed ${ }^{1} \mathrm{H}$ NMR shifts (Table 6). The halogen-neighbouring protons of three-carbon iodides 25 and 31 experienced an upfield shift of $0.27 \mathrm{ppm}$ and $0.28 \mathrm{ppm}$, respectively. Similar protons in four-carbon iodides $\mathbf{2 6}$ and $\mathbf{3 2}$ experienced upfield shifts of $0.50 \mathrm{ppm}$ and $0.49 \mathrm{ppm}$, respectively. These protons in all four iodides were found to have $J$-couplings of $6.9 \mathrm{~Hz}$, larger than in the alcohol in all cases.

Table 6. Comparison of terminal triplet shifts and $J$-couplings of Appel starting materials and products.

\begin{tabular}{cccc}
\hline Analogue & $\begin{array}{c}\text { Alcohol } \boldsymbol{\delta}(\mathbf{p p m}) \\
\left({ }^{\mathbf{3}} \boldsymbol{J}_{\mathbf{H H}} \mathbf{H z}\right)\end{array}$ & $\begin{array}{c}\text { Iodide } \delta(\mathbf{p p m}) \\
\left({ }^{\mathbf{3}} \boldsymbol{J}_{\mathbf{H H}} \mathbf{H z}\right)\end{array}$ & $\begin{array}{c}\text { Difference } \delta(\mathbf{p p m}) \\
\left({ }^{\mathbf{3}} \boldsymbol{J}_{\mathbf{H H}} \mathbf{H z}\right)\end{array}$ \\
\hline 3-Carbon Saturated & $3.49(5.9)$ & $3.22(6.9)$ & $-0.27(+1.0)$ \\
3-Carbon Unsaturated & $3.54(5.8)$ & $3.26(6.9)$ & $-0.28(+1.1)$ \\
4-Carbon Saturated & $3.71(6.2)$ & $3.21(6.9)$ & $-0.50(+0.7)$ \\
4-Carbon Unsaturated & $3.72(6.3)$ & $3.23(6.9)$ & $-0.49(+0.6)$ \\
\hline
\end{tabular}


With the synthesis of analogue $\mathbf{2 8}$ complete, four risperidone analogues had successfully been generated (Scheme 36). According to the methodology of West, samples of analogues 8, 9, 28 and 29 were quantified by NMR using nitromethane as an internal standard. ${ }^{138} 10 \mathrm{mM}$ solutions of each analogue were made in DMSO in anticipation of the biological testing to follow.

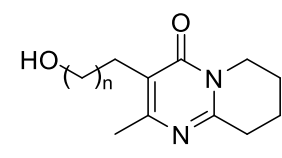

23, $\mathrm{n}=2$

24, $n=3$
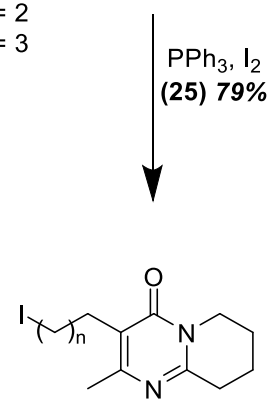

$25, n=2$

26, $n=3$
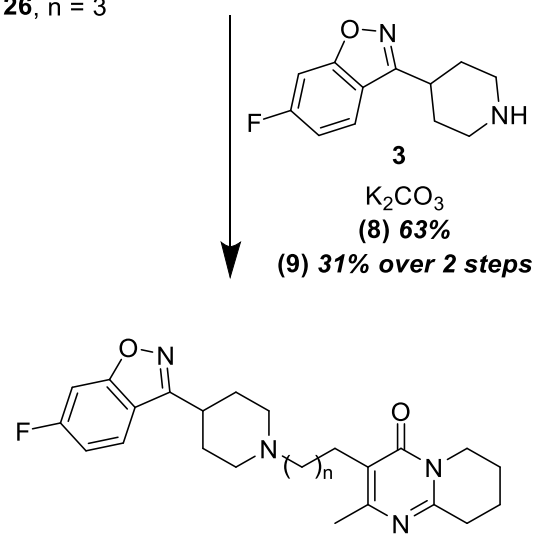

$8, n=2$

$9, \mathrm{n}=3$
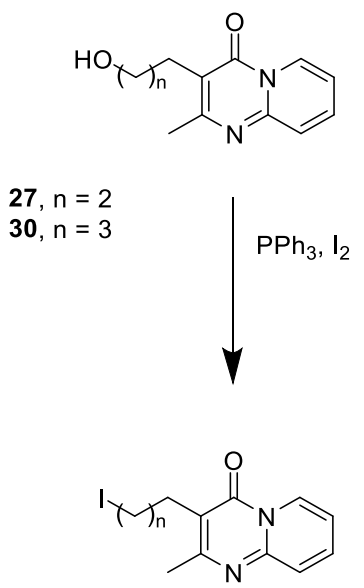

$31, \mathrm{n}=2$

32, $\mathrm{n}=3$
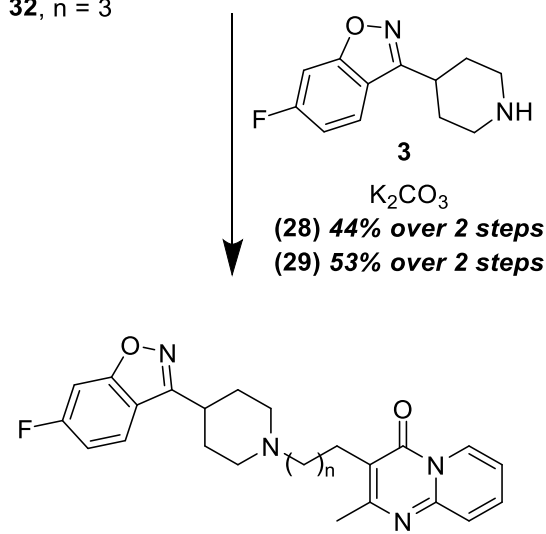

28, $n=2$

29, $n=3$

Scheme 36. Synthesis of analogues 8, 9, 28 and 29. 


\section{In Vitro Assays}

To investigate the in vitro activity of the four synthesised risperidone analogues, $\mathbf{8 , 9}, \mathbf{2 8}$ and 29 were added to the culture medium of LPS-stimulated RAW264.7 macrophages at increasing concentrations. Zareie et al. previously found risperidone to cause a modest decrease in MTT metabolism in RAW264.7 cells treated at concentrations of $80 \mu \mathrm{M}$ or greater. ${ }^{97}$ Cytokine levels of the supernatant were also measured by ELISA according to the methodology of Zareie et $a l .{ }^{97}$ Anti-inflammatory cytokine production was demonstrated to be significantly increased at risperidone concentrations of $60 \mu \mathrm{M}$ and above. Pro-inflammatory cytokine production was found to be significantly decreased at risperidone concentrations as low as $20 \mu \mathrm{M}$. The current research uses risperidone as a positive control for comparison of the results from assays of $\mathbf{8}$, 9, 28 and 29. In the MTT assay, risperidone results were comparable to the findings of Zareie et al. except for at concentrations of 80 and $100 \mu \mathrm{M}$ where the decrease in MTT metabolism was to a lesser degree than previously observed. This observed difference could be due to dilution of the stock risperidone solution with DMSO, instead of $0.1 \mathrm{M}$ acetic acid as previously used. ELISA results with risperidone treatment were comparable to previous work. ${ }^{97}$

\subsection{MTT and ELISA Assay Results}

\subsubsection{MTT Assay Results}

Treatment with three-carbon unsaturated analogue $\mathbf{2 8}$ resulted in similarly non-toxic activity to risperidone regarding its effect on MTT metabolism at concentrations up to $80 \mu \mathrm{M}$ (Figure 32). At $100 \mu \mathrm{M}$, treatment with $\mathbf{2 8}$ appeared to cause a small reduction in MTT metabolism compared to risperidone. 


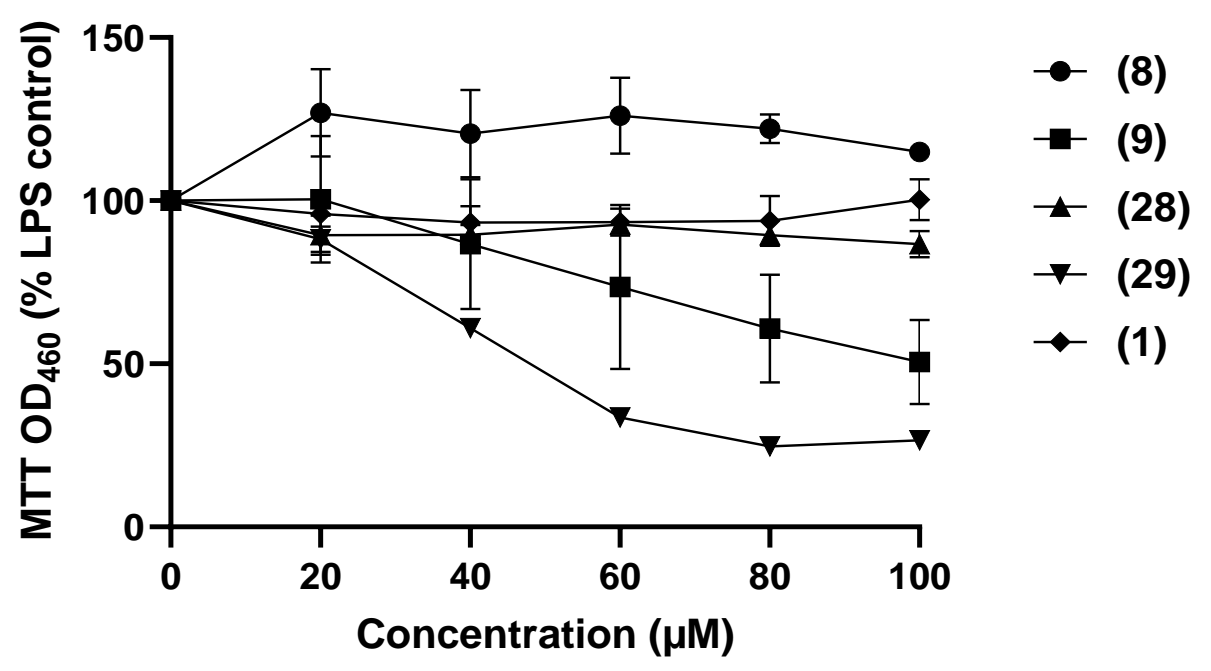

Figure 32. RAW264.7 cell viability measured by MTT assay. Presented as a percentage of vehicle control. RAW 264.7 cells were plated at 50,000 cells/well, primed with IFN- $\gamma$ (20 $\mathrm{U} / \mathrm{mL}$ ), and stimulated with LPS for 24 hours in increasing concentrations of analogues $\mathbf{8}, \mathbf{9}$, 28, 29 and risperidone at $1 \%$ DMSO. Shown are means and SEM of triplicate wells from one experiment.

Surprisingly, treatment with saturated three-carbon analogue $\mathbf{8}$ resulted in a significant increase in MTT metabolism at concentrations of $60 \mu \mathrm{M}$ and above when compared to the vehicle control. This apparent increase may be as a result of the readings lying outside the optimal range of the optical density reader. This may mean that MTT metabolism was not increased as a result of treatment with $\mathbf{8}$. However, it is unlikely that MTT metabolism is negatively affected by 8 .

Treatment with four-carbon saturated analogue $\mathbf{9}$ caused a large and significant decrease in MTT metabolism at concentrations of $80 \mu \mathrm{M}$ and above. Compound 29 was found to significantly inhibit MTT metabolism at concentrations of $40 \mu \mathrm{M}$ and greater.

In summary, varied effects on cell viability were seen with the four analogues 8, 9, 28 and 29 . The four-carbon linker analogues 9 and 29 led to decreased MTT metabolism, with the unsaturated analogue 29 shown to be the greatest inhibitor of MTT metabolism compared to all other treatments at concentrations of $40 \mu \mathrm{M}$ and above. The three-carbon linker analogues $\mathbf{8}$ and $\mathbf{2 8}$ behaved in a similar manner to risperidone itself, with little decrease in cell viability as seen by MTT metabolism. 


\subsubsection{IL-12 ELISA Results}

At concentrations of $40 \mu \mathrm{M}$ and greater, all analogues significantly inhibited production of proinflammatory cytokine IL-12 when compared to control (Figure 33). In comparison to risperidone treated cells at concentrations of $60 \mu \mathrm{M}$ and greater, analogue treatment resulted in significantly greater inhibition of IL-12 production. The attenuation of IL-12 production observed in the supernatant of $\mathbf{9}$ and $\mathbf{2 9}$ treated cells may be a result of the reduction in cell viability inferred from the MTT assay. Thus, fewer living cells are present to produce this inflammatory cytokine.

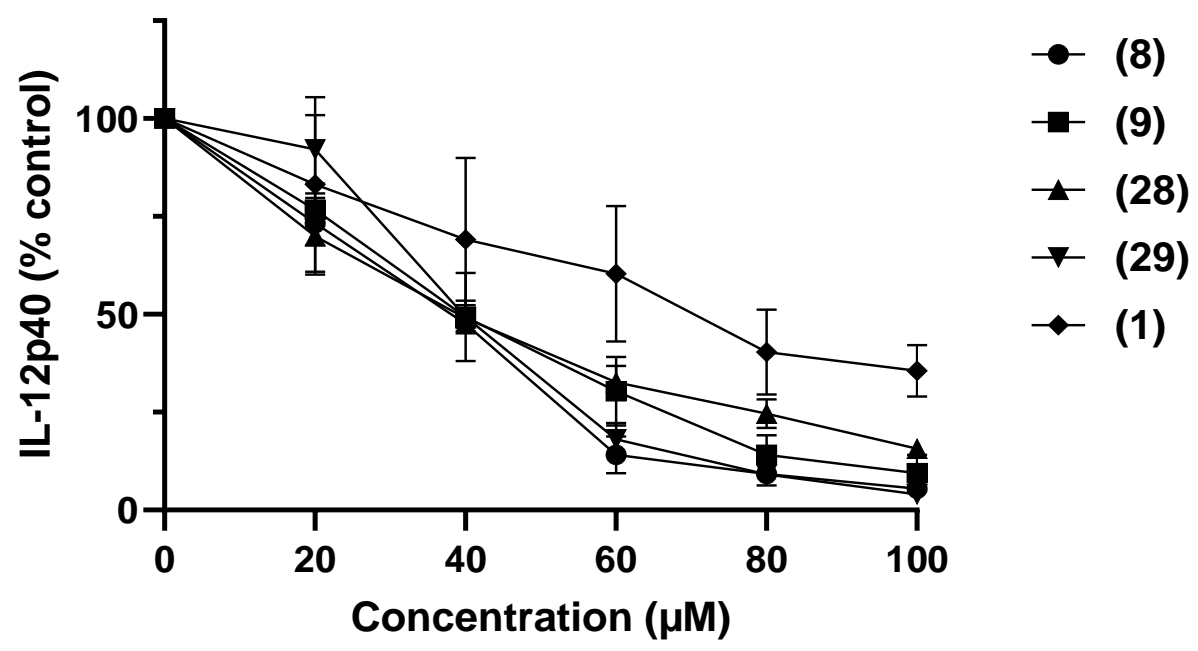

Figure 33. IL-12 in the supernatant measured by ELISA.

The results for risperidone treatment were comparable to those of Zareie et al. who demonstrated IL-12 production to be reduced linearly upon treatment with risperidone at concentrations of up to $60 \mu \mathrm{M} \cdot{ }^{97}$ At concentrations greater than $60 \mu \mathrm{M}$ no further change in IL-12 production was observed. Risperidone is proven to be a suitable positive control for this experiment. 


\subsubsection{IL-10 ELISA Results}

The ELISA results of treatment with the risperidone analogues on quantities of antiinflammatory cytokine IL-10 were varied (Figure 34). Treatment with three-carbon linker analogues 8 and 28 resulted in no significant change in IL-10 production when compared to vehicle control across all concentrations tested. Treatment with four-carbon analogues 9 and 29 treatment at $20 \mu \mathrm{M}$ and $40 \mu \mathrm{M}$ concentrations resulted in a significant increase in IL-10 production, greater than $200 \%$ of control. This was significantly more than the increase observed for risperidone (1). At $60 \mu \mathrm{M}$, the level of IL-10 production is comparable to risperidone treatment while concentrations of $80 \mu \mathrm{M}$ and greater resulted in levels of IL-10 comparable to vehicle control.

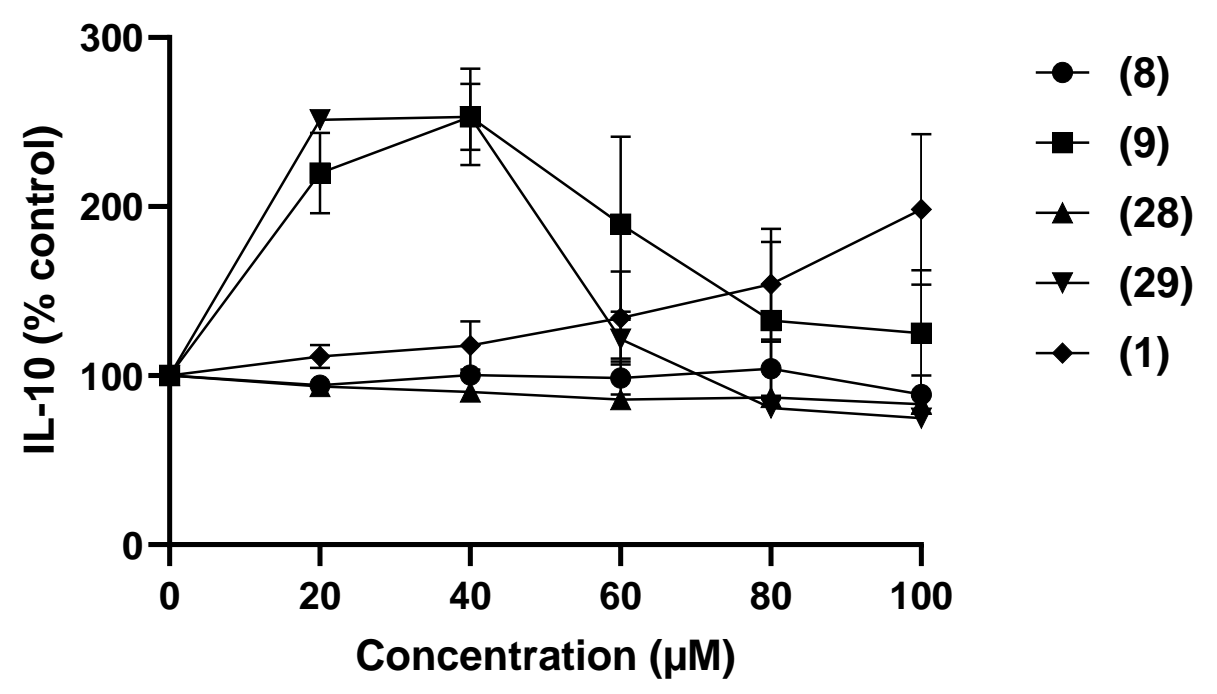

Figure 34. IL-10 in the supernatant measured by ELISA.

\subsection{Discussion}

\subsubsection{Cell Viability}

These results show that, like risperidone, neither of the three-carbon linker analogues inhibits MTT metabolism and therefore, have no negative effect on cell viability. Interestingly, fourcarbon linker analogues $\mathbf{9}$ and $\mathbf{2 9}$ were found to significantly reduce cell viability at 
concentrations of $80 \mu \mathrm{M}$ and $40 \mu \mathrm{M}$, respectively. These results will need to be verified by flow cytometry.

The suppression of MTT metabolism associated with 9 and 29 treatment is apparently due to the longer alkyl spacer in these compounds. These four-carbon linker analogues have two additional methylenes, compared to risperidone, separating the piperidine and the pyridopyrimidone moieties. This longer alkyl chain has more rotatable bonds which increases the flexibility of these molecules and expands the number of structural conformations these molecules can adopt. A greater number of conformations may increase the number of protein binding sites accessible to these molecules.

A flexible molecule can adopt different conformations, allowing it to access more than one dissimilar binding site. An example of this is acarbose, an antidiabetic drug that adopts different conformations to inhibit the activity of both glucoamylase and 4- $\alpha$-glucanotransferase (Figure 35). ${ }^{139-140}$ The binding affinity of acarbose for each protein is different due to the variations in the amino acids and their positions in the active site. Extending the linker of risperidone may have a similar effect and allow for off-target protein binding. This promiscuity could result in inhibition of multiple key metabolic pathways, thus explaining the reduction in cell viability associated with 9 and 29 treatment.

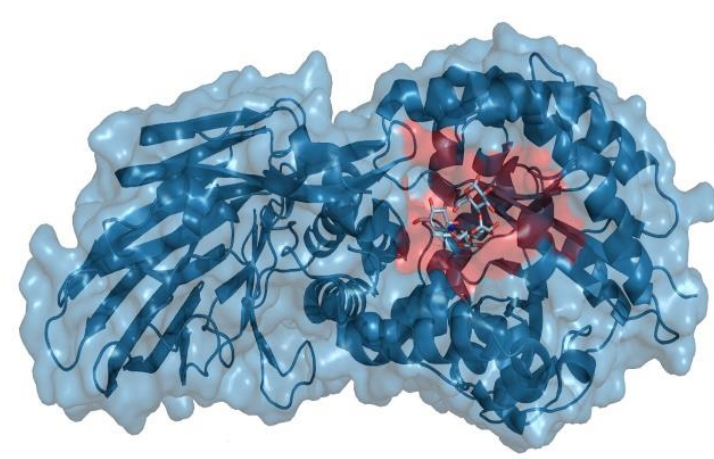

4- $\alpha$-glucanotransferase

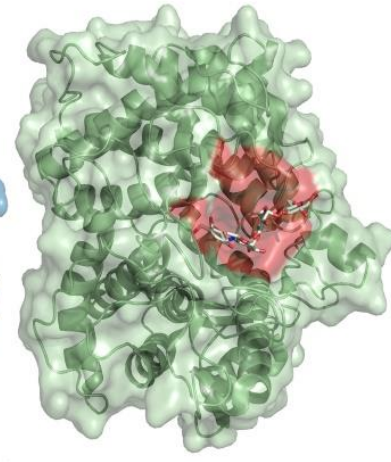

Glucoamylase

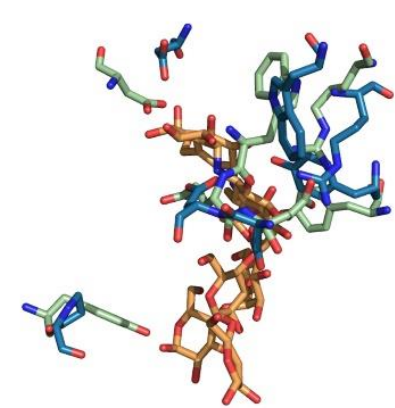

Aligned Binding Site Residues

Figure 35. Acarbose binding site alignments in 4- $\alpha$-glucanotransferase and glucoamylase. Binding sites are highlighted in red and ligands are presented in orange. Adapted from Haupt et al. Drug Promiscuity in PDB: Protein Binding Site Similarity Is Key. PLOS ONE 2013, 8

$$
\text { (6), e65894. }{ }^{141}
$$


Alternatively, a longer alkyl chain could make the ligand compatible with proteins that have similar binding sites and open up new therapeutic areas. For example, the antiviral drug brivudine inhibits virus replication by binding to thymidine kinase. ${ }^{142}$ Brivudine can also bind to human heat shock protein (HSP), conferring potential anticancer activity. ${ }^{143}$ The active sites of these proteins share five residues in similar positions, including two phenylalanines that are crucial for $\pi$-stacking interactions in the binding pocket.

It is plausible that the conformational flexibility of $\mathbf{9}$ and $\mathbf{2 9}$ may allow for binding to many proteins with structurally similar active sites, similar to brivudine. The increased toxicity of $\mathbf{2 9}$, compared to $\mathbf{9}$, at lower concentrations may be attributed to the increase in $\pi$-stacking interactions possible with the unsaturated pyridopyrimidone. Inhibition of multiple key metabolic pathways as a result of this promiscuity could explain the observed reduction in cell viability. Alternatively, reduced MTT metabolism may be due to direct inhibition of the enzymatic reduction of MTT to formazan.

\subsubsection{Immunomodulatory Activity}

Compounds 8 and 28 induced suppression of IL-12 production follows a similar concentrationdependent curve as risperidone treatment. This suggests a similar mode of action between $\mathbf{8}$, $\mathbf{2 8}$ and risperidone. Compounds $\mathbf{8}$ and $\mathbf{2 8}$ did not affect IL-10 production significantly while even at low concentrations, both four-carbon analogues 9 and $\mathbf{2 9}$ demonstrated significant IL10 amplification properties. Compared to control, a 200\% increase in IL-10 production was observed at sub-toxic concentrations.

Compared to risperidone, an IL-12 suppression response was associated with $\mathbf{8}$ and $\mathbf{2 8}$ while an increase in IL-10 production was associated with 9 and 29. These observations may be a result of enhanced binding of the analogues within the active site of a protein afforded by the extended linker. As the mode of action associated with the immunomodulatory activity of risperidone is unknown, the types of binding interactions possible can only be postulated.

A range of binding pocket interactions could be possible, including adjacent, shallow and deep pocket interactions. An adjacent pocket allows a bivalent ligand, such as risperidone, to bind in the main active site as well as an adjacent pocket simultaneously. ${ }^{10}$ A shallow pocket ligandprotein interaction is less likely as these are usually associated with protein-protein interactions. ${ }^{144}$ Deep, hydrophobic pockets in a protein are very common sites for small 
molecules to bind as the large amount of hydrophobic residues present favour interactions with organic molecules. ${ }^{145-147}$

The extended linker of an analogue may allow for a second pharmacophore to be favourably positioned to make an adjacent pocket interaction. For example, the benzisoxazole pharmacophore of risperidone binds in a deep hydrophobic pocket in the $\mathrm{D}_{2}$ receptor, and the pyridopyrimidone extends into an adjacent binding pocket. ${ }^{10}$ The benzisoxazole moiety of 9 was not modified so this would allow it to access the same hydrophobic pocket of the $\mathrm{D}_{2}$ receptor as risperidone. However, ligand-protein interactions in the extended binding pocket are likely to change due to the increased distance between the piperidine ring and the pyridopyrimidone moiety (Figure 36). Key stabilising interactions, such as those with Trp100, may be lost and result in a less stable binding interaction. Alternatively, the pyridopyrimidone moiety may extend into a different binding pocket that creates a more stable ligand-protein interaction. The potential $\pi$-stacking interactions of unsaturated analogues $\mathbf{2 8}$ and $\mathbf{2 9}$ would also alter the binding profile of these compounds in an adjacent pocket. 


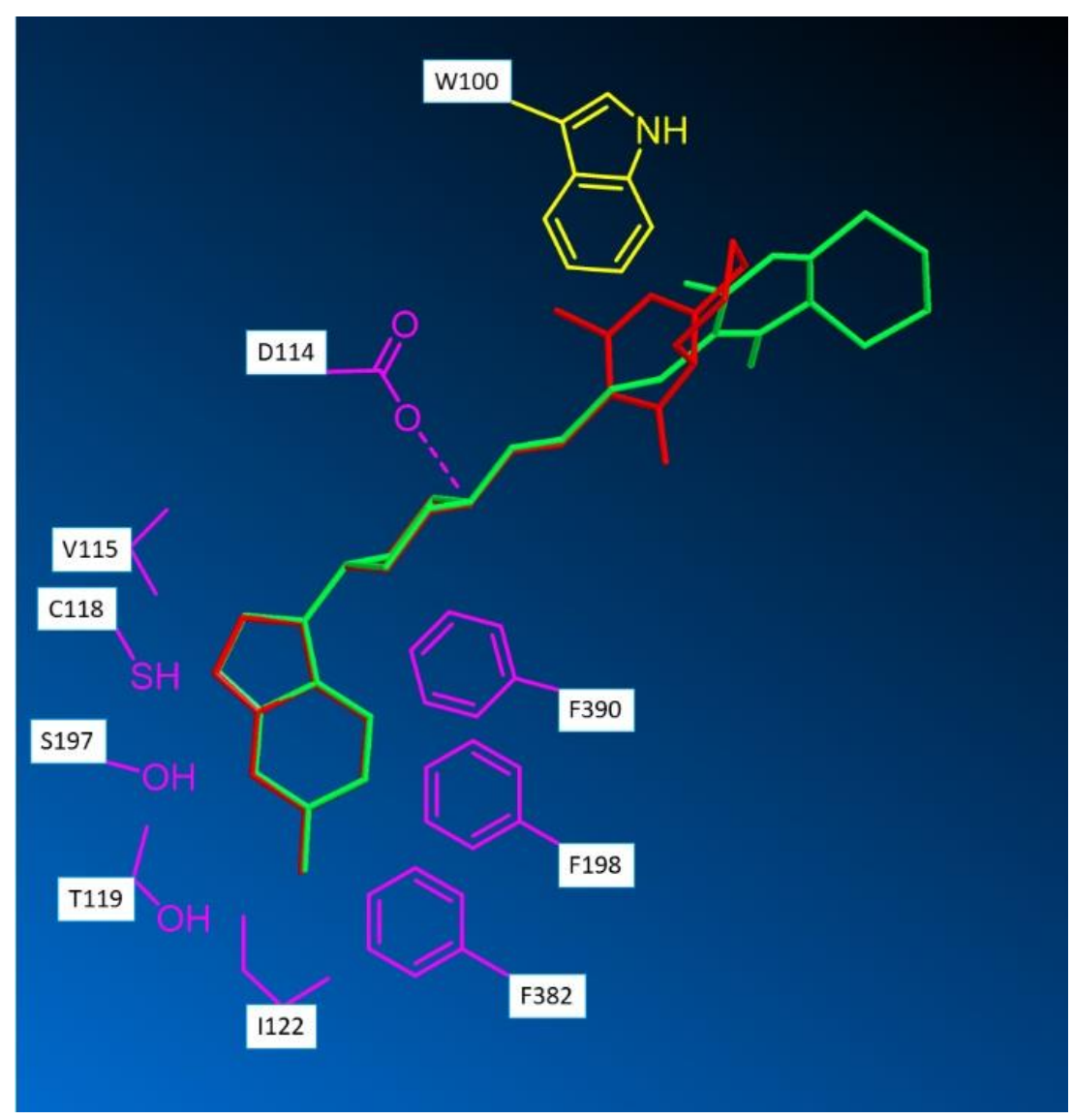

Figure 36. Overlay of 9 (green) and risperidone (red), demonstrating their proposed positions in relation to a tryptophan residue (yellow) in the $\mathrm{D}_{2}$ receptor.

If the pharmacophore were to bind in a deep hydrophobic pocket of an unknown protein, a longer alkyl spacer may reduce unfavourable drug-protein interactions if the unbound moiety resided outside the binding pocket (Figure 37). In this proposed situation, risperidone may have weaker ligand-protein interactions due to the steric hindrance caused by the non-binding moiety at the entrance of the pocket. This could explain the enhanced IL-12 suppression attributed to $\mathbf{8}$ and $\mathbf{2 8 .}$ 

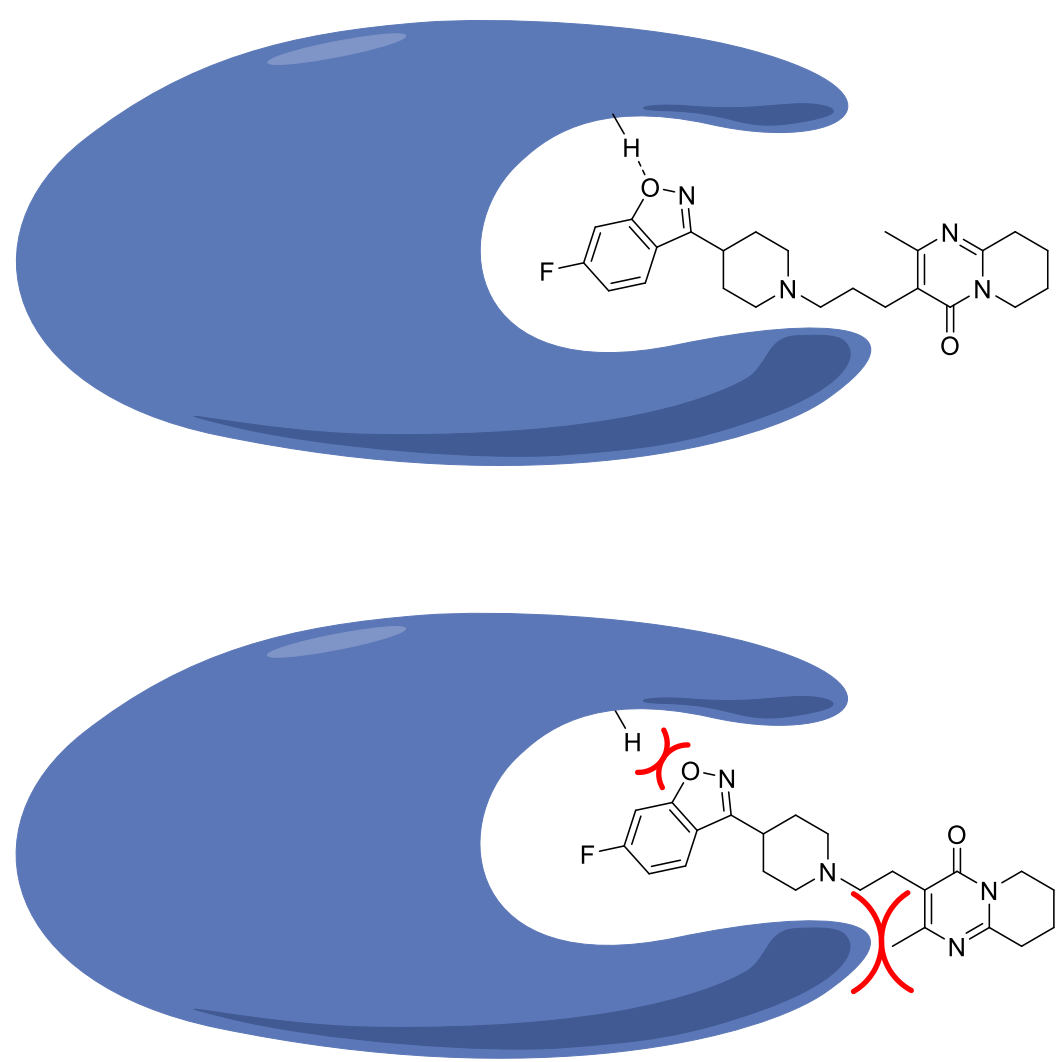

Figure 37. Proposed deep-pocket ligand-protein interactions of $\mathbf{8}$ (top) and risperidone (bottom).

A longer alkyl spacer may also prevent unfavourable intramolecular interactions within the ligand when binding to protein. A protein with a wide, shallow binding pocket could restrict the size of the molecule it is able to accommodate (Figure 38). Flexibility about the alkyl chain may be required for the pharmacophore to establish strong ligand-receptor interactions whilst minimising unfavourable intramolecular interactions. Analogues with longer alkyl spacers have an increased number of rotatable bonds. Therefore, a molecule like 9 would be more likely to have a strong binding interaction with a protein. If such a protein were part of the IL-10 pathway, this could explain the enhanced IL-10 production observed. 

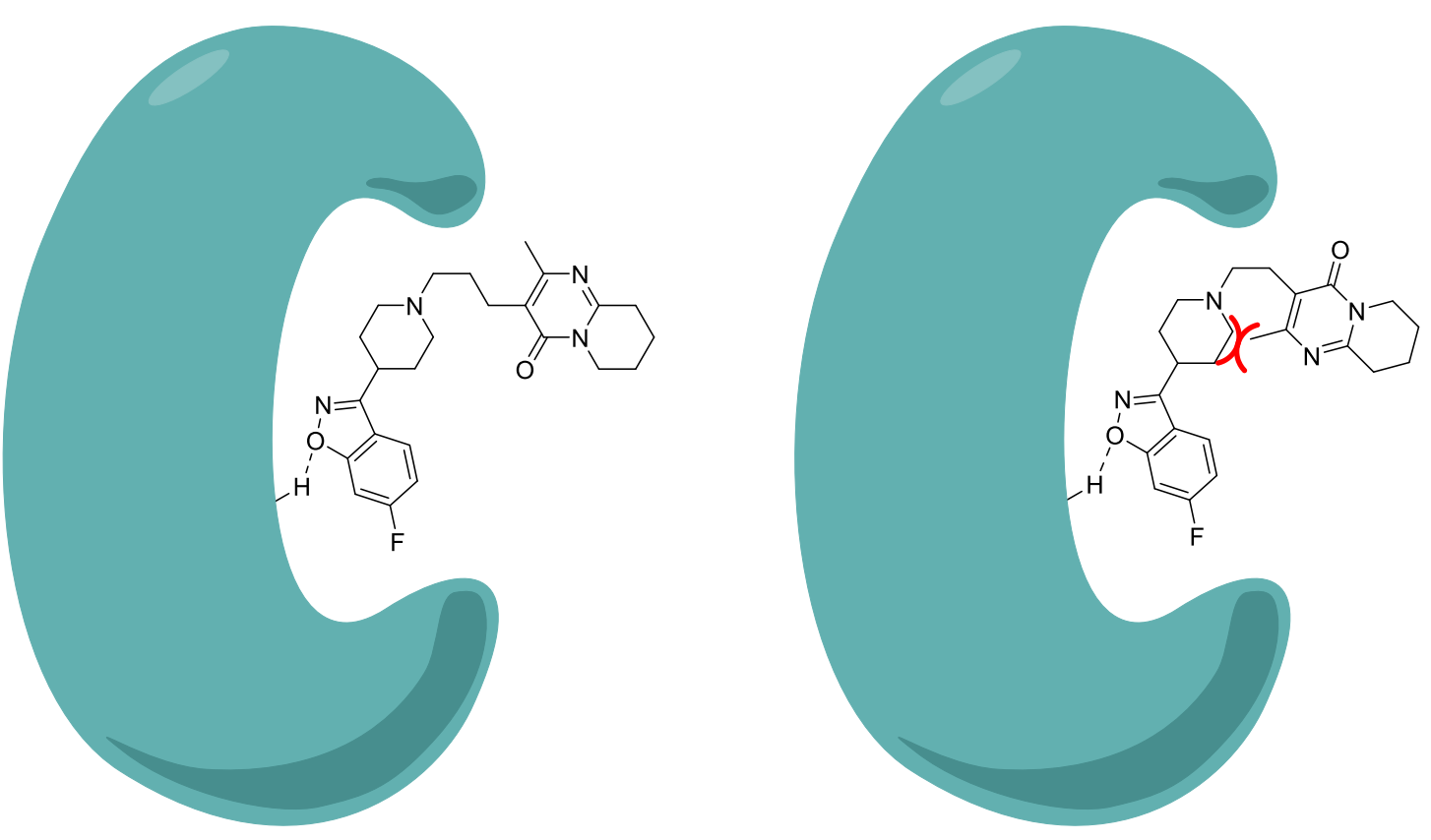

Figure 38. Proposed shallow-pocket ligand-protein interactions of 8 (left) and risperidone (right). 


\section{Summary and Future Work}

\subsection{Summary}

Four risperidone analogues $(\mathbf{8}, \mathbf{9}, \mathbf{2 8}, \mathbf{2 9})$ were successfully synthesised (Scheme 37), exceeding the initial aim of generating two analogues $(\mathbf{8}, \mathbf{9})$. This project was a continuation of Durrant's preliminary work, from which a method was required for deprotection of the benzylprotected hydrogenated pyridopyrimidones $\mathbf{2 1}$ and $\mathbf{2 2 .}{ }^{98}$ Interestingly, here, catalytic hydrogenation was found to be applicable for debenzylation, contrary to previous reports. This method was rather slow so, fortunately, $\mathrm{TiCl}_{4}$ was subsequently found to be a suitable reagent. $\mathrm{TiCl}_{4}$-mediated deprotection was also demonstrated to be applicable to formation of unsaturated pyridopyrimidones 27 and 30. This allowed for synthesis of four analogues, now including unsaturated variants 28 and 29. Fortunately, the Appel and coupling reactions to follow were straight-forward and all four analogues were generated. 

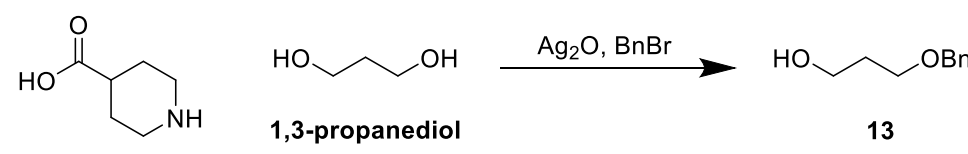

$\mathrm{PPh}_{3}, \mathrm{I}_{2}$,

1,3-propanediol

13

15<smiles>CC(=O)N1CCC(C(=O)O)CC1</smiles>

$\mathrm{Cl}_{3} \mathrm{C}_{\mathrm{OBn}}^{\mathrm{NH}}$

$\sim \mathrm{Cl} \stackrel{\mathrm{TfOH}(0.05 \mathrm{eq})}{\longrightarrow}$<smiles>ClCCCCO[Sn]</smiles><smiles>C=[14CH]</smiles>
$\mathrm{BnO}$

14

16

10<smiles>CC(=O)N1CCC(C(=O)Cl)CC1</smiles><smiles>O=C(c1ccc(F)cc1F)C1CCNCC1</smiles>

12<smiles>CCCCC(C)NOC(=O)Cl</smiles><smiles>O/N=C(/c1ccc(F)cc1F)C1CCNCC1</smiles>

4<smiles>CC(C)CC(C)O</smiles>

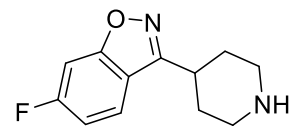

3<smiles>Cc1nc2ccccn2c(=O)c1CCCCOc1ccccc1</smiles>

19, $\mathrm{n}=2$

20, $n=3$<smiles>Nc1cccnc1I</smiles><smiles>CCOC(=O)C(CC(C)C)C(=O)OCC</smiles>

$17, \mathrm{n}=2$

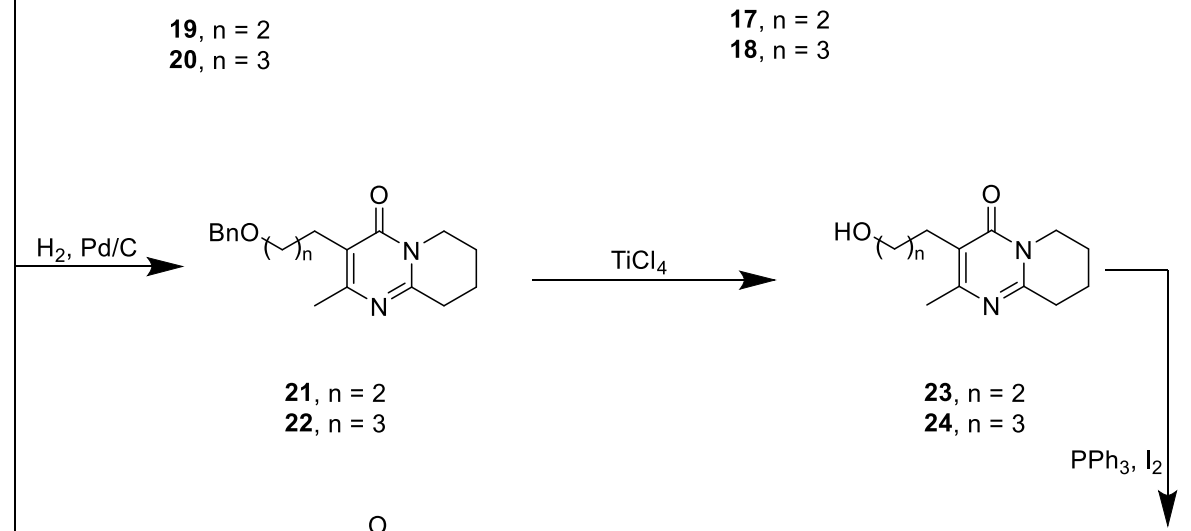

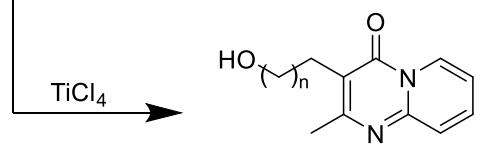

27, $\mathrm{n}=2$

$30, n=3$

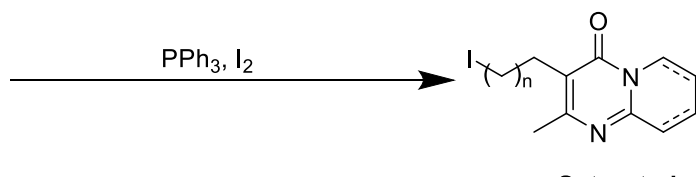

Saturated

$25, n=2$

Unsaturated

$31, n=2$

$32, n=3$

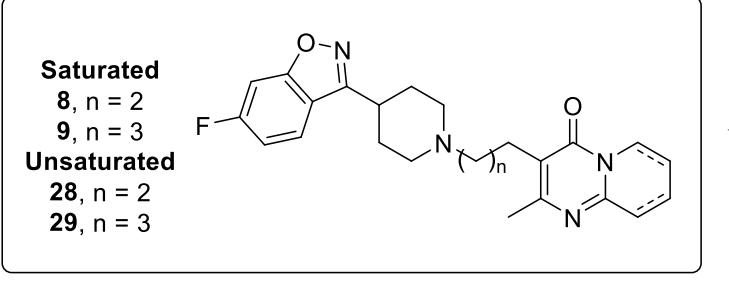

3, $\mathrm{K}_{2} \mathrm{CO}_{3}$

Scheme 37. Overall synthetic route for risperidone analogues 8, 9, 28 and 29.

Preliminary immunomodulatory studies were also performed. In vitro assays of analogues $\mathbf{8}$, 9, 28 and 29 in RAW264.7 cells found both four-carbon analogues $(\mathbf{9}, 29)$ to be cytotoxic while 8 and 28 had no observable effect on cell viability, similar to risperidone. Suppression of IL- 
12 production was observed with all four compounds, however for $\mathbf{9}$ and $\mathbf{2 9}$ this may be as a result of cytotoxicity. Analogues $\mathbf{8}$ and $\mathbf{2 8}$ suppressed IL-12 production to a greater extent than risperidone. Analogues 9 and 29 greatly amplified IL-10 production at low concentrations while $\mathbf{8}$ and $\mathbf{2 8}$ had no effect on IL-10 production at all concentrations tested. Unfortunately, time did not permit for further repetitions of these assays nor measurement of IFN- $\gamma$, TNF- $\alpha$, MCP-1 and IL-6 production in RAW264.7 cells and BMMФ. These will be followed up in the near future.

\subsection{Future Work}

The successful synthesis of four risperidone analogues and their in vitro assay results encourages further investigation into the potential of risperidone and these analogues as immunomodulatory agents.

Additional in vitro testing is required to corroborate the results observed in the current research. Due to time constraints the proposed ELISAs to detect IL-6, TNF- $\alpha$, IFN- $\gamma$ and MCP-1 were not completed. Assays revealing the effects of the synthesised analogues on the profiles of these signalling molecules in RAW264.7 and BMMФ cells will further reveal potential immunomodulatory activity. The strong increase in IL-10 production associated with low (subtoxic) concentrations of four-carbon analogues 9 and 29 is of particular interest due to their more potent anti-inflammatory effect when compared to risperidone. Similar experiments using lower concentrations of these analogues will provide more detailed information of the anti-inflammatory effect associated with $\mathbf{9}$ and $\mathbf{2 9}$ treatment.

Optimisation of the $\mathrm{TiCl}_{4}$ deprotection of the benzyl ether in the synthesis of the pyridopyrimidone fragment could improve the overall yield by modifying the reaction times and workup conditions. Alternatively, the DDQ debenzylation method could be trialled again, using larger quantities for NMR analysis to confirm whether this reagent is applicable to deprotection of a pyridopyrimidone system. The $\mathrm{Pd} / \mathrm{C}$ catalysed hydrogenation- $O$ debenzylation should be repeated to confirm the reproducibility of the deprotection and to optimise for higher yields. A dual hydrogenation and debenzylation step would prevent the need for a separate deprotection as well as the associated purification, reducing the number of steps and potentially increasing the overall yield. 
Alternative routes towards synthesis of the current analogues could be also more efficient stepwise and thus, improve the overall yield. A Stille reaction could be used for integration of the extended alkyl chain onto a pyridopyrimidone substrate, removing the need for protecting groups altogether. ${ }^{127}$ However, the use of tin reagents may be unfavourable due to the current trends towards green synthesis so a Suzuki reaction could be applied instead.

Synthesis and testing of higher homologues, such as those with five- and six-carbon linkers (34, 36 and 35, 37, respectively) would be informative (Figure 39). The methodology applied to the synthesis of three-carbon analogues $\mathbf{8}$ and $\mathbf{2 8}$ should be transferable due to the availability of diol starting materials for both proposed analogues and the lack of additional functionality.

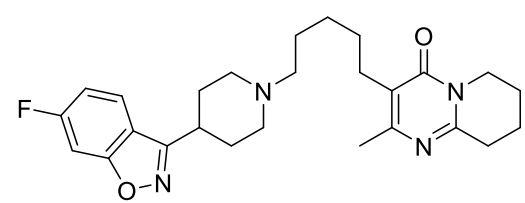

34

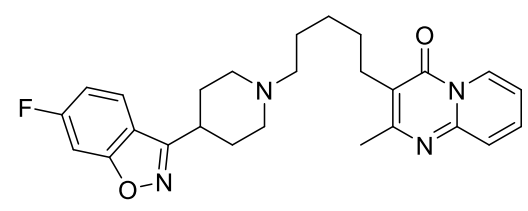

36

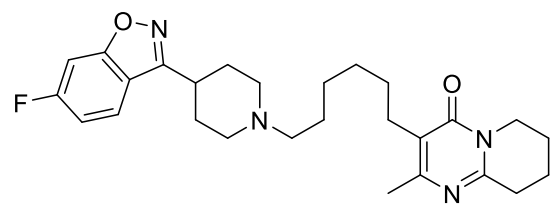

35

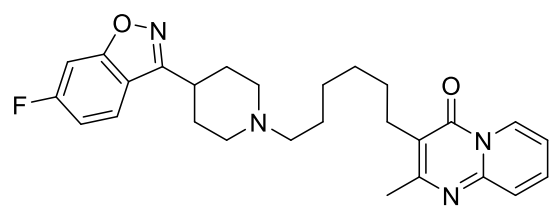

37

Figure 39. Proposed five- and six-carbon linker analogues of risperidone.

Structure rigidification is a common approach in the optimisation of drugs. ${ }^{148}$ Further modification of the current three- and four-carbon analogues with a more restricted linker would also provide more structure activity relationship data with in vitro testing. Differentially positioned $E$ - and $Z$-alkenes (38 - 41) could aid in the elucidation the mode of action of these compounds (Figure 40). 


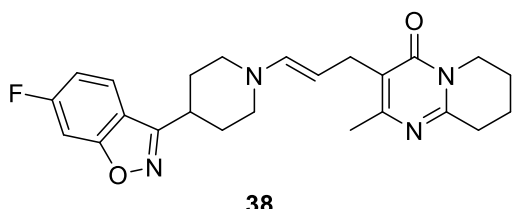

38

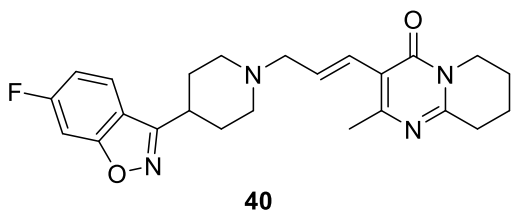

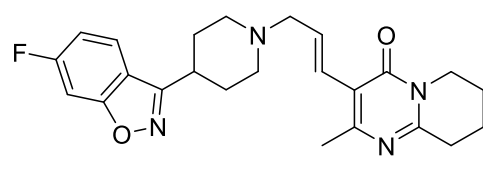

39

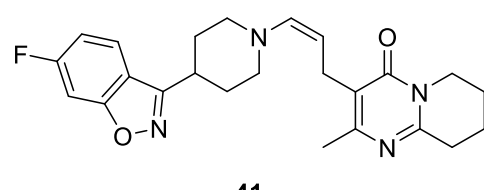

41

Figure 40. Proposed rigidified analogues of $\mathbf{8}$.

Furthermore, the synthesis of biotin-linked risperidone and analogues for use with affinity chromatography could aid in discovery of new ligand-protein interactions. Attachment of a biotin tag to the benzisoxazole and pyridopyrimidone moieties separately could help in identification of protein targets with varying affinities for these two potential pharmacophores. Molecular modelling could then be used to identify putative binding pockets for target proteins captured, furthering our understanding of the activity of risperidone and its analogues. 


\section{Experimental}

\subsection{Synthetic Chemistry Experimental}

\subsubsection{General Methods}

Unless otherwise noted, the following general conditions were applied. Reactions were performed under an atmosphere of dry argon using standard syringe techniques. Reaction solvents $\left(\mathrm{CH}_{2} \mathrm{Cl}_{2}, \mathrm{Et}_{2} \mathrm{O}\right)$ were dispensed from an Innovative Technologies Inc. PureSolv ${ }^{\mathrm{TM}}$ solvent purification system. Dry acetone was stored over activated $3 \AA$ molecular sieves for 24 hours before use. Molecular sieves were activated by drying under high-vacuum at $350 \quad{ }^{\circ} \mathrm{C}$ for $4 \mathrm{hrs}$. Workup solvents were used from the bottle as received from the supplier. All water was distilled and reaction glassware was oven dried at $130{ }^{\circ} \mathrm{C}$ overnight, assembled hot and cooled under vacuum. Reagents were purchased from Sigma-Aldrich unless otherwise specified. NMR spectra were collected on a JEOL JMTC-500/54/JJ NMR spectrometer at 22 $\pm 1{ }^{\circ} \mathrm{C}$ with a field strength of $11.74 \mathrm{~T}$. ${ }^{13} \mathrm{C}$ NMR were proton-decoupled. Chemical shift $(\delta)$ is reported in parts per million (ppm) to the nearest $0.01 \mathrm{ppm}$ for ${ }^{1} \mathrm{H}$ and $0.1 \mathrm{ppm}$ for ${ }^{13} \mathrm{C} .{ }^{1} \mathrm{H}$ and ${ }^{13} \mathrm{C}$ NMR spectra in $\mathrm{CDCl}_{3}$ were referenced to residual solvent peaks with ${ }^{1} \mathrm{H} \mathrm{NMR}\left(\mathrm{CHCl}_{3}\right) \delta$ $=7.26 \mathrm{ppm}$ and ${ }^{13} \mathrm{C} \mathrm{NMR}\left(\mathrm{CDCl}_{3}\right) \delta=77.16 \mathrm{ppm} .{ }^{1} \mathrm{H}$ spectra in $\mathrm{D}_{2} \mathrm{O}$ were referenced to the residual solvent peak $\left(\mathrm{D}_{2} \mathrm{O}\right) \delta=4.79 \mathrm{ppm} .{ }^{13} \mathrm{C}$ spectra in $\mathrm{D}_{2} \mathrm{O}$ were unreferenced. Multiplicities are described as d (doublet), t (triplet), q (quartet), quin. (quintet, m (multiplet), br. (broad) and apparent (app.). Where identifiable, impurity peaks are not reported. Full spectral data are available in the supplementary information. Atom numbering in this section is for the purposes of description only and does not necessarily reflect the IUPAC name. Mass spectra were collected on an Agilent 6530 LCMS QToF using ESI and were processed using Mestrelab ${ }^{\circledR}$ MestreNova (V. 14.0.0) and Agilent ${ }^{\circledR}$ MassHunter (V. B.06.01). Infrared spectra were collected using neat samples on a Bruker Alpha FTIR ATR spectrometer and are reported in $\mathrm{cm}^{-1}$. All chromatography was with hexanes b.p. $40-60{ }^{\circ} \mathrm{C}$, ethyl acetate, $\mathrm{CH}_{2} \mathrm{Cl}_{2}$ and acetone, with $0.5 \%$ triethylamine, on silica and TLC staining was with ceric ammonium molybdate unless otherwise noted. 


\section{1-Acetylpiperidine-4-carboxylic acid (10)}<smiles>CC(=O)N1CCC(C(=O)O)CC1</smiles>

To a solution of isonipecotic acid $(4.124 \mathrm{~g}, 31.9 \mathrm{mmol})$ and $\mathrm{CH}_{2} \mathrm{Cl}_{2}(65 \mathrm{~mL})$, acetic anhydride (3.40 mL, $36.0 \mathrm{mmol}$ ) dissolved in $\mathrm{CH}_{2} \mathrm{Cl}_{2}(6.5 \mathrm{~mL})$ was added dropwise. The reaction was stirred at room temperature for 23 hours, then concentrated in vacuo. The resulting white solid was recrystallised from ethanol to afford acid 10 as a white powder $(2.439 \mathrm{~g}, 14.2 \mathrm{mmol}, 45 \%)$.

m.p. $181.2-183.0{ }^{\circ} \mathrm{C}$

${ }^{1}$ H NMR (500 MHz, D2O) $\delta_{\mathrm{H}} 4.25(\mathrm{dtd}, J=13.3,3.9,1.8 \mathrm{~Hz}, 1 \mathrm{H}), 3.90(\mathrm{dtd}, J=13.9,4.0,1.8$ $\mathrm{Hz}, 1 \mathrm{H}), 3.22$ (ddd, $J=14.3,11.6,2.9 \mathrm{~Hz}, 1 \mathrm{H}), 2.86(\mathrm{ddd}, J=13.9,11.8,3.1 \mathrm{~Hz}, 1 \mathrm{H}), 2.69$ (tt, $J=11.4,4.0 \mathrm{~Hz}, 1 \mathrm{H}), 2.11(\mathrm{~s}, 3 \mathrm{H}), 2.04-1.91(\mathrm{~m}, 2 \mathrm{H}), 1.66(\mathrm{dtd}, J=13.4,11.5,4.2 \mathrm{~Hz}, 1 \mathrm{H})$, $1.55(\mathrm{dtd}, J=13.6,11.6,4.2 \mathrm{~Hz}, 1 \mathrm{H})$.

${ }^{13}$ C NMR (126 MHz, D2O) $\delta_{C} 179.4,172.2,46.0,41.3,40.4,27.8,27.4,20.4$.

HRMS: $m / z \mathrm{C}_{8} \mathrm{H}_{14} \mathrm{NO}_{3}{ }^{+}[\mathrm{M}+\mathrm{H}]^{+}$calcd. 172.0968, found 172.0963 ( $\left.\triangle 2.9 \mathrm{ppm}\right)$.

The experimental data obtained matches those previously reported. ${ }^{97}$

\section{4-(2',4'-Difluorobenzoyl)piperidine hydrochloride (12)}<smiles>O=C(c1ccc(F)cc1F)C1CCNCC1</smiles>

A solution of acid $10(499 \mathrm{mg}, 2.92 \mathrm{mmol})$ in thionyl chloride (neat, $5.0 \mathrm{~mL}, 69 \mathrm{mmol}$ ) was stirred at room temperature for 4.5 hours. $\mathrm{Et}_{2} \mathrm{O}(5 \mathrm{~mL})$ was added and the solution concentrated in vасио. The resulting red solid, acid chloride 11, was used without further purification. To a solution of acid chloride 11 in $\mathrm{CH}_{2} \mathrm{Cl}_{2}(5 \mathrm{~mL}), \mathrm{AlCl}_{3}(1.022 \mathrm{~g}, 9 \mathrm{mmol})$ and 1,3 difluorobenzene $(0.36 \mathrm{~mL}, 3.67 \mathrm{mmol})$ were added and heated at reflux for 14.5 hours. The resulting brown solution was cooled and poured into an ice/water mixture (32 g, 50\% w/w). This mixture was 
extracted with $\mathrm{CH}_{2} \mathrm{Cl}_{2}(3 \times 30 \mathrm{~mL})$, the organic fractions combined, dried $\left(\mathrm{MgSO}_{4}\right)$ and concentrated in vacuo to provide a viscous brown oil $(592 \mathrm{mg})$ which was used without further purification. This oil was dissolved in $6 \mathrm{M} \mathrm{HCl}(5 \mathrm{~mL})$ and heated at reflux for 6 hours. The reaction mixture was then cooled, extracted with $\mathrm{CH}_{2} \mathrm{Cl}_{2}(3 \times 30 \mathrm{~mL})$ and the aqueous portion was concentrated in vacuo to provide hydrochloride salt $\mathbf{1 2}$ as a beige powder (420 mg, 1.61 mmol, $55 \%$ over 3 steps).

${ }^{1} \mathbf{H}$ NMR $\left(500 \mathrm{MHz}, \mathbf{D}_{2} \mathrm{O}\right) \delta_{\mathrm{H}} 7.88(\mathrm{td}, J=8.8,6.5 \mathrm{~Hz}, 1 \mathrm{H}), 7.15-7.05(\mathrm{~m}, 2 \mathrm{H}), 3.62(\mathrm{tt}, J=$ 11.0, $3.6 \mathrm{~Hz}, 1 \mathrm{H}$ ), 3.48 (dt, $J=13.1,3.9 \mathrm{~Hz}, 2 \mathrm{H}), 3.15$ (br t, $J=12.6 \mathrm{~Hz}, 2 \mathrm{H}), 2.18$ (br d, $J=$ $14.7 \mathrm{~Hz} 2 \mathrm{H}), 1.86$ (m, 2H).

${ }^{13}$ C NMR (126 MHz, D2O) $\delta_{\mathrm{C}} 201.7,166.1(\mathrm{dd}, J=255.4,14.1 \mathrm{~Hz}), 162.1(\mathrm{dd}, J=256.0,14.0$ Hz) $132.7(\mathrm{~m}), 120.7$ (d, $J=11.0 \mathrm{~Hz}), 112.5$ (d, J = 21.2 Hz), 105.1 (t, $J=26.5 \mathrm{~Hz}), 44.1,43.2$, 24.4 .

HRMS: $m / z \mathrm{C}_{12} \mathrm{H}_{14} \mathrm{~F}_{2} \mathrm{NO}^{+}[\mathrm{M}+\mathrm{H}]^{+}$calcd. 226.1038, found 226.1047 ( $\left.\Delta 4.0 \mathrm{ppm}\right)$.

The experimental data obtained matches those previously reported. ${ }^{97}$

\section{(Z)-2,4-Difluorophenyl-(4-piperidinyl)methanone oxime (4)}<smiles>O/N=C(/c1ccc(F)cc1F)C1CCNCC1</smiles>

To a solution of pyridine $(0.72 \mathrm{~mL}, 8.94 \mathrm{mmol})$ and hydroxylamine hydrochloride $(129 \mathrm{mg}$, $1.86 \mathrm{mmol})$ in $\mathrm{MeOH}(9 \mathrm{~mL})$, ketone $12(201 \mathrm{mg}, 0.77 \mathrm{mmol})$ was added and heated at reflux for 7 hours. The reaction mixture was cooled and concentrated in vacuo to provide a 1:0.35 mixture of $E$ - and $Z$-isomers. This solid was recrystallised from methanol to provide $Z$-oxime 4 as white needle-like crystals $(68 \mathrm{mg}, 0.28 \mathrm{mmol}, 37 \%)$. The remaining supernatant was concentrated in vacuo, dissolved in $t$-butanol $(10 \mathrm{~mL})$ and glacial acetic acid $(2 \mathrm{~mL})$ and heated at reflux for 19 hours. The reaction mixture was cooled and concentrated in vacuo to provide a beige solid that was recrystallised from methanol to provide further $\mathbf{4}$ as white needle-like crystals (29.5 mg, $0.12 \mathrm{mmol}, 16 \%)$. Total combined yield of 4: $97.3 \mathrm{mg}, 0.40 \mathrm{mmol}, 53 \%$.

m.p. $233-239^{\circ} \mathrm{C}$ 
${ }^{1} \mathbf{H}$ NMR (500 MHz, D2O) $\delta_{\mathrm{H}} 7.29(\mathrm{~m}, 1 \mathrm{H}), 7.14$ - 7.05 (complex m, 2H), 3.45 (dt, $J=13.1$, $3.8 \mathrm{~Hz}, 2 \mathrm{H}), 3.04(\mathrm{td}, J=12.7,3.0 \mathrm{~Hz}, 2 \mathrm{H}), 2.91$ (tt, $J=11.3,3.5 \mathrm{~Hz}, 1 \mathrm{H}), 2.09$ (br d, 2H), $1.77(\mathrm{dtd}, J=15.6,11.8,4.0 \mathrm{~Hz}, 2 \mathrm{H})$.

${ }^{13}$ C NMR (126 MHz, D2O) $\delta_{\mathrm{C}} 163.4(\mathrm{dd}, J=248.9,12.1 \mathrm{~Hz}) 158.7(\mathrm{dd}, J=248.0,12.1 \mathrm{~Hz})$ $157.1,129.9(\mathrm{dd}, J=10.0,5.6 \mathrm{~Hz}) 116.3(\mathrm{dd}, J=18.5,4.0 \mathrm{~Hz}) 112.0(\mathrm{dd}, J=22.0,3.3 \mathrm{~Hz}$, $104.3(\mathrm{t}, J=26.0 \mathrm{~Hz}), 43.5,38.8,25.5$.

HRMS: $m / z, \mathrm{C}_{12} \mathrm{H}_{15} \mathrm{~F}_{2} \mathrm{~N}_{2} \mathrm{O}^{+}[\mathrm{M}+\mathrm{H}]^{+}$calcd. 241.1147 found 241.1156 ( $\left.\Delta 3.7 \mathrm{ppm}\right)$.

The experimental data obtained matches those previously reported. ${ }^{97}$

\section{6-Fluoro-3-(piperidin-4-yl)benzo[d]isoxazole (3)}<smiles>Fc1ccc2c(C3CCNCC3)noc2c1</smiles>

A solution of $\mathrm{KOH}(614 \mathrm{mg}, 11 \mathrm{mmol})$ dissolved in $\mathrm{H}_{2} \mathrm{O}(2.00 \mathrm{~mL})$ was added to oxime 4 (55.1 $\mathrm{mg}, 0.23 \mathrm{mmol}$ ) and heated at reflux for 6.5 hours. The solution was cooled and extracted with $\mathrm{CH}_{2} \mathrm{Cl}_{2}(3 \times 10 \mathrm{~mL})$. The organic fractions were combined, dried $\left(\mathrm{MgSO}_{4}\right)$ and concentrated in vacuo to provide benzisoxazole 3 as an off white powder (41.7 mg, $0.19 \mathrm{mmol}, 83 \%)$.

${ }^{1}$ H NMR (500 MHz, CDCl $) \delta_{\mathrm{H}} 7.68(\mathrm{dd}, J=8.6,5.1 \mathrm{~Hz}, 1 \mathrm{H}, \mathrm{H}-1), 7.23(\mathrm{dd}, J=8.6,2.1 \mathrm{~Hz}$, 1H, H-4), 7.04 (td, $J=8.9,2.3 \mathrm{~Hz}, 1 \mathrm{H}, \mathrm{H}-2), 3.23$ (dt, $J=12.4,3.6 \mathrm{~Hz}, 2 \mathrm{H}, \mathrm{H}-10 \mathrm{a}$ ), 3.19 (tt, $J$ $=11.7,3.7 \mathrm{~Hz}, 1 \mathrm{H}, \mathrm{H}-8) 2.81(\mathrm{td}, J=12.1,2.8 \mathrm{~Hz}, 2 \mathrm{H}, \mathrm{H}-10 \mathrm{~b}), 2.04(\mathrm{dd}, J=12.9,3.3 \mathrm{~Hz}, 2 \mathrm{H}$, H-9a), 1.93 (qd, $J=11.8,4.0 \mathrm{~Hz}, 2 \mathrm{H}, \mathrm{H}-9 \mathrm{~b}$ ).

${ }^{13}$ C NMR (126 MHz, CDCl $) \delta_{\mathrm{C}} 164.1$ (d, $\left.J=250.4 \mathrm{~Hz}, \mathrm{C}, \mathrm{C}-3\right), 164.0$ (d, $J=13.5 \mathrm{~Hz}, \mathrm{C}, \mathrm{C}-$ 5), 161.4 (C, C-7), 122.7 (d, J=11.1 Hz, CH, C-1), 117.4 (C, C-6), 112.4 (d, J = 25.2 Hz, CH, C-2), 97.6 (d, J = 26.8 Hz, CH, C-4), $46.6\left(\mathrm{CH}_{2}, \mathrm{C}-10\right), 35.1(\mathrm{CH}, \mathrm{C}-8), 31.7\left(\mathrm{CH}_{2}, \mathrm{C}-9\right)$.

HRMS: $m / z \mathrm{C}_{12} \mathrm{H}_{14} \mathrm{FN}_{2} \mathrm{O}^{+}[\mathrm{M}+\mathrm{H}]^{+}$calcd. 221.1085, found 221.1085 ( $\left.\Delta 0.0 \mathrm{ppm}\right)$.

The experimental data obtained matches those previously reported. ${ }^{97}$ 


\section{3-(Benzyloxy)propan-1-ol (13)}<smiles></smiles>

To a solution of $\mathrm{Ag}_{2} \mathrm{O}(1.672 \mathrm{~g}, 7.28 \mathrm{mmol})$ suspended in $\mathrm{CH}_{2} \mathrm{Cl}_{2}(18 \mathrm{~mL}), 1,3$-propanediol $(0.48 \mathrm{~mL}, 6.65 \mathrm{mmol})$ was added. The solution was stirred for 15 minutes until small clumps of $\mathrm{Ag}_{2} \mathrm{O}$ formed in the clear solution. The solution was then cooled in an ice-salt bath for 10 minutes. Benzyl bromide $(0.82 \mathrm{~mL}, 6.94 \mathrm{mmol})$ was added dropwise over 15 minutes. The ice bath was removed and the solution stirred for 23 hours, after which a precipitate was free flowing in solution. The solution was filtered through a silica plug and concentrated in vacuo to afford $\mathbf{1 3}$ as a yellow oil (1.106 g, $6.65 \mathrm{mmol}, 100 \%)$ containing 20:1 mono:dibenzylated product which was used without purification in the subsequent step.

${ }^{1}$ H NMR (500 MHz, CDCl3) $\delta_{\mathrm{H}}$ 7.40-7.27 (complex m, 5H), $4.53(\mathrm{~s}, 2 \mathrm{H}), 3.79$ (t, $J=5.7 \mathrm{~Hz}$, $2 \mathrm{H}$ ), 3.67 (t, $J=5.7 \mathrm{~Hz}, 2 \mathrm{H}), 1.88$ (quin, $J=5.7 \mathrm{~Hz}, 2 \mathrm{H}$ ).

${ }^{13}$ C NMR (126 MHz, CDCl 3$) \delta_{C} 128.6,127.9,127.8,73.5,69.7,62.2,32.2$.

HRMS: $m / z \mathrm{C}_{10} \mathrm{H}_{15} \mathrm{O}_{2}{ }^{+}[\mathrm{M}+\mathrm{H}]^{+}$calcd. 167.1067 , found 167.1065 ( $\left.\Delta 1.2 \mathrm{ppm}\right)$.

The experimental data obtained matches those previously reported. ${ }^{98,116}$

\section{3-Benzyloxy-1-iodopropane (15)}<smiles>[Sb]OCCCI</smiles>

To alcohol 13 (1.106 g, $6.65 \mathrm{mmol}), \mathrm{PPh}_{3}$ (2.645 g, $10.1 \mathrm{mmol}$ ), imidazole (1.111 g, 16.3 $\mathrm{mmol})$ and $\operatorname{dry} \mathrm{Et}_{2} \mathrm{O}(36 \mathrm{~mL})$ were added. The resulting solution was cooled in an ice bath and $\mathrm{CH}_{3} \mathrm{CN}$ (12 mL) added. Once the $\mathrm{PPh}_{3}$ had dissolved, a solution of $\mathrm{I}_{2}(2.494 \mathrm{~g}, 9.83 \mathrm{mmol})$ in $\mathrm{Et}_{2} \mathrm{O}(13 \mathrm{~mL})$ was added dropwise, causing the formation of a white precipitate. The solution was allowed to warm to room temperature and stir for 2.5 hours, after which further $\mathrm{I}_{2}(1.416$ $\mathrm{g}, 5.58 \mathrm{mmol}$ ) was added as a solid directly to the reaction mixture and stirring continued for a further 3.5 hours. The solution was then filtered through cotton wool and rinsed with $\mathrm{Et}_{2} \mathrm{O}$. Sat. aqueous $\mathrm{NaHCO}_{3}(20 \mathrm{~mL})$ was added to the filtered solution which was stirred vigorously and the phases separated. The organic layer was washed with sat. aqeuous $\mathrm{Na}_{2} \mathrm{~S}_{2} \mathrm{O}_{3}(3 \times 20 \mathrm{~mL})$, brine $(1 \times 20 \mathrm{~mL})$ and concentrated in vacuo to give a yellow oil. The oil was then taken up in 5:1 hexanes:EtOAc $(20 \mathrm{~mL})$ and shaken to produce a white precipitate in a clear solution. 
Filtration through a silica plug and concentration of the filtrate in vacuo afforded iodide $\mathbf{1 5}$ as a yellow oil (1.257 g, $4.92 \mathrm{mmol}, 74 \%)$. (74\% over 2 steps).

${ }^{1}$ H NMR (500 MHz, CDCl 3$) \delta_{\mathrm{H}} 7.40-7.27$ (complex m, 5H), 4.52 (s, 2H), 3.55 (t, $J=5.7$ $\mathrm{Hz}, 2 \mathrm{H}), 3.31,(\mathrm{t}, J=6.8 \mathrm{~Hz}, 2 \mathrm{H}), 2.10(\mathrm{tt}, J=6.8,5.8 \mathrm{~Hz}, 2 \mathrm{H})$.

${ }^{13}$ C NMR (126 MHz, CDCl 3$) \delta_{C} 138.4,128.6,127.8$ (2 overlapping peaks), 73.3, 69.7, 33.6, 3.6 .

The experimental data obtained matches those previously reported. ${ }^{98,117}$

Ethyl 2-acetyl-5-(benzyloxy)pentanoate (17)<smiles>CCOC(=O)C(CCCOc1ccccc1)C(C)=O</smiles>

To a solution of freshly cut sodium $(0.55 \mathrm{~g}, 2.4 \mathrm{mmol})$ dissolved in EtOH $(10 \mathrm{~mL}$, dried over $3 \AA$ sieves $)$ was added ethyl acetoacetate $(0.25 \mathrm{~mL}, 1.97 \mathrm{mmol})$ and the reaction heated at reflux. Once refluxing, a solution of iodide 15 (480 mg, $1.74 \mathrm{mmol})$ in EtOH (2 mL) was added dropwise. Reflux was continued for 2.5 hours after which the solution was cooled, filtered through a silica plug with ethanol $(3 \times 5 \mathrm{~mL})$ and concentrated in vacuo to give a yellow oil and white precipitate. This slurry was taken up in 5:1 PE:EtOAc, filtered through a silica plug and concentrated in vacuo to afford a yellow oil. Silica gel chromatography (40:1 $\mathrm{CH}_{2} \mathrm{Cl}_{2}$ :EtOAc) provided $\mathbf{1 7}$ as a slightly yellow oil that was used immediately ( $275 \mathrm{mg}, 0.99$ mmol, 57\%).

$\mathbf{R}_{f} 0.33\left(40: 1 \mathrm{CH}_{2} \mathrm{Cl}_{2}:\right.$ EtOAc)

${ }^{1}$ H NMR (500 MHz, CDCl3) $\delta_{\mathrm{H}} 7.36-7.27$ (complex m, 5H), 4.49 (s, 2H), 4.19 (qd, $J=6.9$, $2.3 \mathrm{~Hz}, 2 \mathrm{H}), 3.48(\mathrm{td}, J=6.3,1.5 \mathrm{~Hz}, 2 \mathrm{H}), 3.46(\mathrm{t}, J=7.6 \mathrm{~Hz}, 2 \mathrm{H}), 2.21(\mathrm{~s}, 3 \mathrm{H}), 1.95(\mathrm{q}, J=$ $7.7 \mathrm{~Hz}, 2 \mathrm{H}), 1.61(\mathrm{~m}, 2 \mathrm{H}), 1.26(\mathrm{t}, J=7.1 \mathrm{~Hz}, 3 \mathrm{H})$.

${ }^{13}$ C NMR (126 MHz, CDCl3) $\delta_{\mathrm{C}} 203.4,169.9,138.5,128.5,127.8,127.7,73.1,69.8,61.5$, 59.6, 29.0, 27.6, 25.2, 14.2 .

HRMS: $m / z \mathrm{C}_{16} \mathrm{H}_{23} \mathrm{O}_{4}{ }^{+}[\mathrm{M}+\mathrm{H}]^{+}$calcd. 279.1591, found 279.1591 ( $\left.\Delta 0.0 \mathrm{ppm}\right)$. 
The experimental data obtained matches those previously reported. ${ }^{98,118}$

\section{3-(3-(Benzyloxy)propyl)-2-methyl-4H-pyrido[1,2-a]pyrimidin-4-one (19)}<smiles>Cc1nc2ccccn2c(=O)c1CC=CCOc1ccccc1</smiles>

A mixture of pentanoate 17 (1.277 g, $4.56 \mathrm{mmol})$, 2-aminopyridine (434 $\mathrm{mg}, 4.6 \mathrm{mmol})$ and ammonium acetate $(12.484 \mathrm{~g}, 0.16 \mathrm{~mol})$ was set to stir vigorously at $180{ }^{\circ} \mathrm{C}$ for 3.5 hours. Upon reaching $120{ }^{\circ} \mathrm{C}$, the ammonium salt melted providing a viscous 2-phase solution which became a single brown phase at $180{ }^{\circ} \mathrm{C}$. The reaction mixture was then cooled, diluted with $\mathrm{H}_{2} \mathrm{O}(20 \mathrm{~mL})$ and extracted with $\mathrm{CH}_{2} \mathrm{Cl}_{2}(3 \times 20 \mathrm{~mL})$. The organic fractions were combined, washed with sat. aqueous $\mathrm{NaHCO}_{3}(20 \mathrm{~mL})$ and brine $(20 \mathrm{~mL})$, then dried $\left(\mathrm{MgSO}_{4}\right)$ and concentrated in vacuo to afford 19 as a viscous brown oil $(1.196 \mathrm{~g}, 3.88 \mathrm{mmol}, 85 \%$ crude yield). Silica gel chromatography (EtOAc $+0.5 \%$ triethylamine) provided the title compound (19) as a slightly yellow oil (901 mg, $2.92 \mathrm{mmol}, 64 \%)$.

$\mathbf{R}_{f} 0.25$ (EtOAc $+0.5 \%$ triethylamine $)$.

${ }^{1}$ H NMR $(500$ MHz, CDCl $) \delta_{\mathrm{H}} 8.95(\mathrm{~d}, J=7.0 \mathrm{~Hz}, 1 \mathrm{H}, \mathrm{H}-1), 7.61(\mathrm{ddd}, J=9.0,6.5,1.4 \mathrm{~Hz}$, 1H, H-3), 7.53 (d, $J=8.8 \mathrm{~Hz}, 1 \mathrm{H}, \mathrm{H}-4), 7.35-7.22$ (complex m, 5H, Bn), 7.03 (t, $J=6.8 \mathrm{~Hz}$, 1H, H-2), 4.51 (s, 2H, $\mathrm{PhCH}_{2}$ ), 3.55 (t, $\left.J=6.3 \mathrm{~Hz}, 2 \mathrm{H}, \mathrm{H}-12\right), 2.81$ (t, $\left.J=7.5 \mathrm{~Hz}, 2 \mathrm{H}, \mathrm{H}-10\right)$, 2.51 (s, 3H, H-9), $1.96-1.87$ (m, 2H, H-11).

${ }^{13}$ C NMR (126 MHz, CDCl 3$) \delta_{\mathrm{C}} 161.5$ (C, C-6), 158.0 (C, C-8), 148.5 (C, C-5), 138.7 (C, Bn), 134.9 (CH, C-3), 128.4 (CH, Bn), 127.7 (CH, Bn), 127.6 (CH, Bn), 127.1 (CH, C-1), 125.7 (CH, C-4), 115.7 (C, C-7), 114.8 (CH, C-2), $72.9\left(\mathrm{CH}_{2}, \mathrm{PhCH}_{2}\right), 70.0\left(\mathrm{CH}_{2}, \mathrm{C}-12\right), 28.4\left(\mathrm{CH}_{2}\right.$, $\mathrm{C}-11), 23.7\left(\mathrm{CH}_{2}, \mathrm{C}-10\right), 22.4\left(\mathrm{CH}_{3}, \mathrm{C}-9\right)$.

HRMS: $m / z \mathrm{C}_{19} \mathrm{H}_{21} \mathrm{~N}_{2} \mathrm{O}_{2}{ }^{+}[\mathrm{M}+\mathrm{H}]^{+}$calcd. 309.1598, found $309.1601(\Delta 1.0 \mathrm{ppm})$.

IR: (neat) $v_{\max } 2928,2856,1735,1665,1635,1531,1474,1427,1327,1095,1044,768,731$, $697 \mathrm{~cm}^{-1}$.

The experimental data obtained matches those previously reported. ${ }^{98}$ 


\section{3-(3-(Benzyloxy)propyl)-2-methyl-6,7,8,9-tetrahydro-4H-pyrido[1,2- $\alpha]$ pyrimidin-4-one}

(21)<smiles>Cc1nc2n(c(=O)c1CC=CCOc1ccccc1)CCCC2</smiles>

A Schlenk tube fitted with a Youngs tap was charged with 19 (112 mg, $0.36 \mathrm{mmol})$, palladium on activated carbon $(10 \% \mathrm{w} / \mathrm{w}, 11.2 \mathrm{mg}, 0.11 \mathrm{mmol}), \mathrm{MeOH}(0.8 \mathrm{~mL})$ and $\mathrm{H}_{2} \mathrm{O}(0.7 \mathrm{~mL})$. The tube was flushed with $\mathrm{N}_{2}$ and evacuated 5 times, then charged with $\mathrm{H}_{2}$ under balloon pressure. Stirring for 4 days provided a suspension that was filtered through Celite ${ }^{\circledR}$ to afford a clear solution that was concentrated in vacuo to provide a yellow oil. Silica gel chromatography $(5: 1$ EtOAc:Acetone $+0.5 \%$ triethylamine) provided the title compound (21) as a yellow oil (42.4 $\mathrm{mg}, 0.14 \mathrm{mmol}, 38 \%)$.

$\mathbf{R}_{f} 0.35$ (5:1 EtOAc: acetone).

${ }^{1} \mathbf{H}$ NMR $\left(500 \mathrm{MHz}, \mathbf{C D C l}_{3}\right) \delta_{\mathrm{H}} 7.35-7.26(\mathrm{~m}, 5 \mathrm{H}, \mathrm{Bn}), 4.50\left(\mathrm{~s}, 2 \mathrm{H}, \mathrm{PhCH}_{2}\right), 3.90(\mathrm{t}, J=6.2$ Hz, 2H, H-1), 3.52 (t, $J=6.3 \mathrm{~Hz}, 2 \mathrm{H}, \mathrm{H}-12), 2.86$ (t, $J=6.7 \mathrm{~Hz}, 2 \mathrm{H}, \mathrm{H}-4), 2.61$ (t, $J=7.8 \mathrm{~Hz}$, 2H, H-10), 2.28 (s, 3H, H-9), 1.97 - 1.90 (m, 2H, H-2), $1.89-1.79$ (m, 4H, H-3,11).

${ }^{13}$ C NMR (126 MHz, CDCl3) $\delta_{\mathrm{C}} 162.7$ (C, C-8), 158.1 (C, C-6), 155.9 (C, C-5), 138.8 (C, Bn) 128.5(CH, Bn), 127.7 (CH, Bn), 127.6 (CH, Bn), 121.2 (C, C-7), $72.9\left(\mathrm{CH}_{2}, \mathrm{PhCH}_{2}\right), 70.1$ $\left(\mathrm{CH}_{2}, \mathrm{C}-12\right), 42.8\left(\mathrm{CH}_{2}, \mathrm{C}-1\right), 31.4\left(\mathrm{CH}_{2}, \mathrm{C}-4\right), 28.2\left(\mathrm{CH}_{2}, \mathrm{C}-11\right), 23.1\left(\mathrm{CH}_{2}, \mathrm{C}-10\right), 22.1\left(\mathrm{CH}_{2}\right.$, C-2), $21.2\left(\mathrm{CH}_{3}, \mathrm{C}-9\right), 19.4\left(\mathrm{CH}_{2}, \mathrm{C}-3\right)$.

HRMS: $m / z \mathrm{C}_{19} \mathrm{H}_{25} \mathrm{~N}_{2} \mathrm{O}_{2}{ }^{+}[\mathrm{M}+\mathrm{H}]^{+}$calcd. 313.1911, found 313.1898 ( $\left.\Delta 4.2 \mathrm{ppm}\right)$.

IR: (neat) $v_{\max } 2947,2861,1652,1534,1192,1099,738,698 \mathrm{~cm}^{-1}$.

The experimental data obtained matches those previously reported..$^{98}$ 
<smiles>Cc1nc2n(c(=O)c1CC=CCO)CCCC2</smiles>

A solution of benzyl ether $21(34.7 \mathrm{mg}, 0.11 \mathrm{mmol})$ in $\mathrm{CH}_{2} \mathrm{Cl}_{2}(0.44 \mathrm{~mL})$ was cooled to $0{ }^{\circ} \mathrm{C}$ and $1 \mathrm{M} \mathrm{TiCl}_{4}$ in $\mathrm{CH}_{2} \mathrm{Cl}_{2}(0.56 \mathrm{~mL}, 0.56 \mathrm{mmol}, 5$ equiv. $)$ was added dropwise resulting in the formation of a yellow precipitate. The solution was then allowed to warm to room temperature and stir for 1 hour. The reaction mixture was then poured into ice cold sat. aqueous $\mathrm{NaHCO}_{3}$ $(20 \mathrm{~mL})$. This solution was extracted with $\mathrm{CH}_{2} \mathrm{Cl}_{2}(3 \times 10 \mathrm{~mL})$ and EtOAc $(10 \mathrm{~mL})$. The organic fractions were combined, dried $\left(\mathrm{MgSO}_{4}\right)$ and concentrated in vacuo to provide a yellow oil. Purification by silica gel chromatography (Acetone $+0.5 \%$ triethylamine) provided alcohol 23 as an off-white amorphous solid (17.1 $\mathrm{mg}, 0.77 \mathrm{mmol}, 69 \%)$.

$\mathbf{R}_{f} 0.28$ (acetone $+0.5 \%$ triethylamine) .

${ }^{1} \mathbf{H}$ NMR $\left(500 \mathrm{MHz}, \mathbf{C D C l}_{3}\right) \delta_{\mathrm{H}} 3.93(\mathrm{t}, J=6.2 \mathrm{~Hz}, 2 \mathrm{H}, \mathrm{H}-1), 3.49$ (br. t, $J=5.9 \mathrm{~Hz}, 2 \mathrm{H}, \mathrm{H}-$ 12), 2.86 (t, $J=6.6 \mathrm{~Hz}, 2 \mathrm{H}, \mathrm{H}-4), 2.66$ (t, $J=6.7 \mathrm{~Hz}, 2 \mathrm{H}, \mathrm{H}-10), 2.27$ (s, 3H, H-9), $1.98-1.92$ (m, 2H, H-2), $1.90-1.83$ (m, 2H, H-3), 1.73 (ddt, $J=7.9,6.6,5.7 \mathrm{~Hz}, 2 \mathrm{H}, \mathrm{H}-11$ ).

${ }^{13}$ C NMR (126 MHz, CDCl 3 ) $\delta_{\mathrm{C}} 164.1$ (C, C-8), 159.3 (C, C-6), 156.0 (C, C-5), 120.5 (C, C7), $60.4\left(\mathrm{CH}_{2}, \mathrm{C}-12\right), 43.2\left(\mathrm{CH}_{2}, \mathrm{C}-1\right), 31.5\left(\mathrm{CH}_{2}, \mathrm{C}-4\right), 31.1\left(\mathrm{CH}_{2}, \mathrm{C}-11\right), 22.1\left(\mathrm{CH}_{2}, \mathrm{C}-2\right)$, $21.4\left(\mathrm{CH}_{2}, \mathrm{C}-10\right), 21.2\left(\mathrm{CH}_{3}, \mathrm{C}-9\right), 19.3\left(\mathrm{CH}_{2}, \mathrm{C}-3\right)$.

HRMS: $m / z \mathrm{C}_{12} \mathrm{H}_{19} \mathrm{~N}_{2} \mathrm{O}_{2}{ }^{+}[\mathrm{M}+\mathrm{H}]^{+}$calcd. 223.1441, found $223.1442(\Delta 0.4 \mathrm{ppm})$.

IR: (neat) $v_{\max } 3407,2931,2868,1633,1528,1190,1057,1041,729,606 \mathrm{~cm}^{-1}$.

\section{3-(3-Iodopropyl)-2-methyl-6,7,8,9-tetrahydro-4H-pyrido[1,2- $\alpha]$ pyrimidin-4-one (25)}<smiles>Cc1nc2n(c(=O)c1CC=CCI)CCCC2</smiles>

$\mathrm{I}_{2}(32.3 \mathrm{mg}, 0.13 \mathrm{mmol})$ was added to a solution of $\mathrm{PPh}_{3}(44.9 \mathrm{mg}, 0.17 \mathrm{mmol})$ in $\mathrm{CH}_{3} \mathrm{CN}(1.20$ $\mathrm{mL}$ ) at $0{ }^{\circ} \mathrm{C}$ and stirred for 30 minutes to give an orange solution. A solution of alcohol $\mathbf{2 3}$ (18.3 mg, $0.08 \mathrm{mmol})$ in $\mathrm{CH}_{3} \mathrm{CN}(0.60 \mathrm{~mL})$ was added and the reaction mixture heated at reflux 
for 20 hours to give a dark orange solution. The reaction mixture was cooled and concentrated in vacuo, then taken up in EtOAc $(10 \mathrm{~mL})$ and $\mathrm{H}_{2} \mathrm{O}(10 \mathrm{~mL})$. The organic layer was washed with $\mathrm{H}_{2} \mathrm{O}(5 \mathrm{x} 10 \mathrm{~mL})$, then $1 \mathrm{M} \mathrm{HCl}(10 \mathrm{~mL})$. The aqueous layers were combined and extracted with EtOAc (20 mL). $\mathrm{CH}_{2} \mathrm{Cl}_{2}(20 \mathrm{~mL})$ was added to the aqueous phase and the $\mathrm{pH}$ adjusted to 7 by addition of sat. aqueous $\mathrm{NaHCO}_{3}$. The phases were separated and the aqueous layer extracted with $\mathrm{CH}_{2} \mathrm{Cl}_{2}(2 \times 20 \mathrm{~mL})$. The $\mathrm{CH}_{2} \mathrm{Cl}_{2}$ layers were combined, dried $\left(\mathrm{Na}_{2} \mathrm{SO}_{4}\right)$ and concentrated in vacuo to provide iodide 25 as a yellow solid (21.7 mg, $0.06 \mathrm{mmol}, 79 \%)$.

m.p. $96-100{ }^{\circ} \mathrm{C}$

${ }^{1}$ H NMR (500 MHz, CDCl3) $\delta_{\mathrm{H}} 3.90$ (t, $\left.J=6.2 \mathrm{~Hz}, 2 \mathrm{H}, \mathrm{H}-1\right), 3.22$ (t, $\left.J=6.9 \mathrm{~Hz}, 2 \mathrm{H}, \mathrm{H}-12\right)$, 2.84 (t, $J=6.6 \mathrm{~Hz}, 2 \mathrm{H}, \mathrm{H}-4), 2.59$ (t, $J=7.7 \mathrm{~Hz}, 2 \mathrm{H}, \mathrm{H}-10), 2.29$ (s, 3H, H-9), $2.06-1.98$ (m, 2H, H-11), 1.94 (quin, $J=6.1 \mathrm{~Hz}, 2 \mathrm{H}, \mathrm{H}-2), 1.89-1.83$ (m, 2H, H-3).

${ }^{13}$ C NMR (126 MHz, CDCl 3$) \delta_{\mathrm{C}} 162.7$ (C, C-8), 158.4 (C, C-6), 156.1 (C, C-5), 119.9 (C, C7), $42.8\left(\mathrm{CH}_{2}, \mathrm{C}-1\right), 32.2\left(\mathrm{CH}_{2}, \mathrm{C}-11\right), 31.5\left(\mathrm{CH}_{2}, \mathrm{C}-4\right), 27.4\left(\mathrm{CH}_{2}, \mathrm{C}-10\right), 22.1\left(\mathrm{CH}_{2}, \mathrm{C}-2\right)$, $21.4\left(\mathrm{CH}_{3}, \mathrm{C}-9\right), 19.3\left(\mathrm{CH}_{2}, \mathrm{C}-3\right), 6.8\left(\mathrm{CH}_{2}, \mathrm{C}-12\right)$.

HRMS: $m / z \mathrm{C}_{12} \mathrm{H}_{18} \mathrm{IN}_{2} \mathrm{O}^{+}[\mathrm{M}+\mathrm{H}]^{+}$calcd. 333.0458, found 333.0456 ( $\left.\Delta 0.6 \mathrm{ppm}\right)$

IR: (neat) $v_{\max } 3389,2952,2869,1651,1525,1436,1397,1231,1193,755,707,494 \mathrm{~cm}^{-1}$.

\section{3-(3-(4-(6-Fluorobenzo[d]isoxazol-3-yl)piperidin-1-yl)propyl)-2-methyl-6,7,8,9- tetrahydro-4H-pyrido[1,2- $\alpha]$ pyrimidin-4-one (8)}

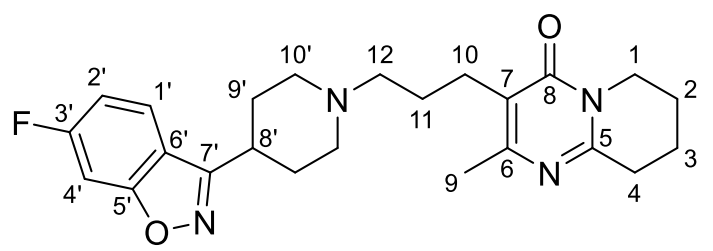

Iodide 25 (20.0 mg, $0.06 \mathrm{mmol})$ was dissolved in acetone (1.30 mL). Amine 3 (13.7 mg, 0.06 mmol) was added followed by $\mathrm{K}_{2} \mathrm{CO}_{3}(9.6 \mathrm{mg}, 0.07 \mathrm{mmol})$. The reaction mixture was heated at reflux for 6.5 hours resulting in a dark yellow solution that was cooled and concentrated in vacuo to afford a dark orange solid that was then suspended in $\mathrm{H}_{2} \mathrm{O}(5 \mathrm{~mL})$ and stirred for 1 hour. The water was filtered off, the remaining solid taken up in $\mathrm{CH}_{2} \mathrm{Cl}_{2}$ and concentrated in vacuo to afford a dark orange solid (22.0 mg, $0.05 \mathrm{mmol}, 86 \%$ crude yield). Purification by 
pipette column using diol (acetone) provided analogue $\mathbf{8}$ as a slightly yellow film (16.1 mg, $0.038 \mathrm{mmol}, 63 \%)$.

$\mathbf{R}_{f} 0.16$ (acetone $+0.5 \%$ triethylamine)

${ }^{1}$ H NMR $\left(500\right.$ MHz, CDCl3) $\delta_{\mathrm{H}} 7.70\left(\mathrm{dd}, J=8.7,5.1 \mathrm{~Hz}, 1 \mathrm{H}, \mathrm{H}-1^{\prime}\right), 7.23(\mathrm{dd}, J=8.5,2.1 \mathrm{~Hz}$, 1H, H-4'), 7.04 (td, $\left.J=8.9,2.2 \mathrm{~Hz}, 1 \mathrm{H}, \mathrm{H}-2^{\prime}\right), 3.92$ (t, $J=6.2 \mathrm{~Hz}, 2 \mathrm{H}, \mathrm{H}-1$ ), 3.09 (complex m, 3H, H-8',10'a), 2.85 (t, $J=6.7 \mathrm{~Hz}, 2 \mathrm{H}, \mathrm{H}-4), 2.55$ (t, $J=7.6 \mathrm{~Hz}, 2 \mathrm{H}, \mathrm{H}-10), 2.48$ (t, $J=7.5 \mathrm{~Hz}$, 2H, H-12), 2.29 (s, 3H, H-9), 2.21 - 2.13 (complex m, 2H, H-10'b), 2.10 - 2.04 (complex m, 4H, H-9'), 1.95 (m, 2H, H-2), 1.87 (m, 2H, H-3), 1.79 - 1.70 (m, 2H, H-11).

${ }^{13}$ C NMR (126 MHz, CDCl 3$) \delta_{\mathrm{C}} 164.1\left(\mathrm{~d}, J=251.2 \mathrm{~Hz}, \mathrm{C}, \mathrm{C}-3^{\prime}\right), 164.0(\mathrm{~d}, J=14.0 \mathrm{~Hz}, \mathrm{C}, \mathrm{C}-$ 5'), 162.8 (C, C-8), 161.3 (C, C-7'), 158.0 (C, C-6), 155.8 (C, C-5), 122.8 (d, J = 14.0 Hz, CH, C-1'), 121.2 (C, C-7), 117.4 (C, C-6'), 112.5 (d, $J=25.4$ Hz, CH, C-2'), 97.5 (d, $J=26.7 \mathrm{~Hz}$ $\left.\mathrm{CH}, \mathrm{C}-4^{\prime}\right), 58.5\left(\mathrm{CH}_{2}, \mathrm{C}-12\right), 53.6\left(\mathrm{CH}_{2}, \mathrm{C}-10^{\prime}\right), 42.8\left(\mathrm{CH}_{2}, \mathrm{C}-1\right), 34.7\left(\mathrm{CH}, \mathrm{C}-8^{\prime}\right), 31.6\left(\mathrm{CH}_{2}\right.$, C-4), $30.6\left(\mathrm{CH}_{2}, \mathrm{C}-9^{\prime}\right), 25.5\left(\mathrm{CH}_{2}, \mathrm{C}-11\right), 24.3\left(\mathrm{CH}_{2}, \mathrm{C}-10\right), 22.1\left(\mathrm{CH}_{2}, \mathrm{C}-2\right), 21.4\left(\mathrm{CH}_{3}, \mathrm{C}-9\right)$, $19.4\left(\mathrm{CH}_{2}, \mathrm{C}-3\right)$.

HRMS: $m / \mathrm{z} \mathrm{C}_{24} \mathrm{H}_{30} \mathrm{FN}_{4} \mathrm{O}_{2}{ }^{+}[\mathrm{M}+\mathrm{H}]^{+}$calcd. 425.2347 , found $425.2351(\Delta 0.9 \mathrm{ppm})$

IR: (neat) $v_{\max } 2926,2805,2765,1643,1613,1531,1447,1270,1120,955,835,730 \mathrm{~cm}^{-1}$.

\section{3-(3-hydroxypropyl)-2-methyl-4H-pyrido[1,2-a]pyrimidin-4-one (27)}

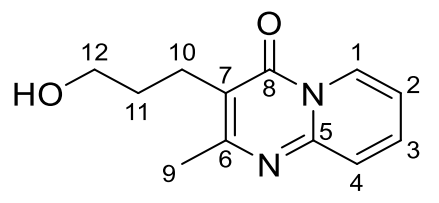

A solution of benzyl ether $19(99.2 \mathrm{mg}, 0.32 \mathrm{mmol})$ dissolved in $\mathrm{CH}_{2} \mathrm{Cl}_{2}(1.30 \mathrm{~mL})$ was cooled to $0{ }^{\circ} \mathrm{C}$ and $1 \mathrm{M} \mathrm{TiCl}_{4}$ in $\mathrm{CH}_{2} \mathrm{Cl}_{2}(1.60 \mathrm{~mL}, 1.6 \mathrm{mmol}, 5$ equiv. $)$ was added dropwise resulting in the formation of a yellow precipitate. The flask was then allowed to warm to room temperature and stir for 1 hour. The reaction mixture was then poured into ice cold sat. aqueous $\mathrm{NaHCO}_{3}(40 \mathrm{~mL})$. This solution was extracted with $\mathrm{CH}_{2} \mathrm{Cl}_{2}(3 \times 30 \mathrm{~mL})$ and EtOAc $(30 \mathrm{~mL})$. The organic fractions were combined, dried $\left(\mathrm{MgSO}_{4}\right)$ and concentrated in vacuo to provide a yellow oil. Purification by silica gel chromatography $(1: 1$ EtOAc:Acetone $+0.5 \%$ triethylamine) provided the alcohol 27 as a yellow solid (37.2 $\mathrm{mg}, 0.17 \mathrm{mmol}, 53 \%)$. 
$\mathbf{R}_{f} 0.26$ (1:1 EtOAc: acetone)

m.p. $85.6-89.0^{\circ} \mathrm{C}$

${ }^{1}$ H NMR (500 MHz, CDCl $) \delta_{\mathrm{H}} 8.98(\mathrm{~d}, J=7.2 \mathrm{~Hz}, 1 \mathrm{H}, \mathrm{H}-1), 7.67(\mathrm{ddd}, J=9.0,6.6,1.6 \mathrm{~Hz}$, 1H, H-3), 7.58 (br. dt, $J=9.0,1.2 \mathrm{~Hz}, 1 \mathrm{H}, \mathrm{H}-4$ ), 7.11 (ddd, $J=7.2,6.6,1.4 \mathrm{~Hz}, 1 \mathrm{H}, \mathrm{H}-2$ ), 3.54 (t, $J=5.8 \mathrm{~Hz}, 2 \mathrm{H}, \mathrm{H}-12), 2.87$ (t, $J=6.8 \mathrm{~Hz}, 2 \mathrm{H}, \mathrm{H}-10$ ), 2.52 (s, 3H, H-9), 1.83 (quin, $J=6.2$ $\mathrm{Hz}, 2 \mathrm{H}, \mathrm{H}-11)$.

${ }^{13}$ C NMR (126 MHz, CDCl 3 ) $\delta_{\mathrm{C}} 162.6$ (C, C-6), 159.2 (C, C-8), 148.4 (C, C-5), 135.2 (CH, C-3), $127.2(\mathrm{CH}, \mathrm{C}-1), 125.8(\mathrm{CH}, \mathrm{C}-4), 115.4(\mathrm{CH}, \mathrm{C}-2), 115.1(\mathrm{CH}, \mathrm{C}-7), 60.6\left(\mathrm{CH}_{2}, \mathrm{C}-12\right)$, $31.2\left(\mathrm{CH}_{2}, \mathrm{C}-11\right), 22.4\left(\mathrm{CH}_{3}, \mathrm{C}-9\right), 22.1\left(\mathrm{CH}_{2}, \mathrm{C}-10\right)$.

HRMS: $m / z \mathrm{C}_{12} \mathrm{H}_{15} \mathrm{~N}_{2} \mathrm{O}_{2}{ }^{+}[\mathrm{M}+\mathrm{H}]^{+}$calcd. 219.1128, found $219.1122(\Delta 2.7 \mathrm{ppm})$.

IR: (neat) $v_{\max } 3231,2923,2863,1655,1629,1527,1473,1419,1253,1228,1062,936,769$, $719,698,689,429 \mathrm{~cm}^{-1}$.

\section{3-(3-Iodopropyl)-2-methyl-4H-pyrido[1,2- $\alpha$ ]pyrimidin-4-one (31)}<smiles>Cc1nc2ccccn2c(=O)c1CCCI</smiles>

$\mathrm{I}_{2}(27.2 \mathrm{mg}, 0.107 \mathrm{mmol})$ was added to a solution of $\mathrm{PPh}_{3}(36.4 \mathrm{mg}, 0.139 \mathrm{mmol})$ in $\mathrm{CH}_{3} \mathrm{CN}$ $(1.20 \mathrm{~mL})$ at $0{ }^{\circ} \mathrm{C}$ and stirred for 30 minutes. A solution of alcohol $27(11.8 \mathrm{mg}, 0.054 \mathrm{mmol})$ in $\mathrm{CH}_{3} \mathrm{CN}(1.20 \mathrm{~mL})$ was added and the reaction mixture heated at reflux for 21 hours to give an orange solution. The reaction mixture was then cooled and concentrated in vacuo, then taken up in EtOAc $(10 \mathrm{~mL})$ and $\mathrm{H}_{2} \mathrm{O}(10 \mathrm{~mL})$. The organic layer was washed with $\mathrm{H}_{2} \mathrm{O}(5 \mathrm{x} 10 \mathrm{~mL})$, then $1 \mathrm{M} \mathrm{HCl}(10 \mathrm{~mL})$. The aqueous layers were combined and extracted with EtOAc $(20 \mathrm{~mL})$. $\mathrm{CH}_{2} \mathrm{Cl}_{2}(20 \mathrm{~mL})$ was added to the aqueous phase and the $\mathrm{pH}$ adjusted to 7 by addition of sat. aqueous $\mathrm{NaHCO}_{3}$. The phases were separated and the aqueous layer extracted with $\mathrm{CH}_{2} \mathrm{Cl}_{2}(3 \mathrm{x}$ $20 \mathrm{~mL})$. The $\mathrm{CH}_{2} \mathrm{Cl}_{2}$ layers were combined, dried $\left(\mathrm{Na}_{2} \mathrm{SO}_{4}\right)$ and concentrated in vacuo to provide a yellow oil that was determined to be a 1:0.32 mixture of 32:27 by ${ }^{1} \mathrm{H}$ NMR analysis (12.2 $\mathrm{mg}, 0.037 \mathrm{mmol}, 65 \%$ iodide yield). This was used in the next step without further purification. 
${ }^{1} \mathrm{H}$ NMR $\left(500 \mathrm{MHz}, \mathbf{C D C l}_{3}\right) \delta_{\mathrm{H}} 8.95(\mathrm{ddd}, J=7.3,1.6,0.8 \mathrm{~Hz}, 1 \mathrm{H}), 7.64-7.61(\mathrm{~m}, 1 \mathrm{H}), 7.53$ (br. dt, $J=8.9,1.1 \mathrm{~Hz}, 1 \mathrm{H}), 7.06(\mathrm{ddd}, J=7.2,6.5,1.4 \mathrm{~Hz}, 1 \mathrm{H}), 3.26(\mathrm{t}, J=6.9 \mathrm{~Hz}, 2 \mathrm{H}), 2.83$ $-2.76(\mathrm{~m}, 2 \mathrm{H}), 2.53(\mathrm{~s}, 3 \mathrm{H}), 2.15-2.06(\mathrm{~m}, 2 \mathrm{H})$.

HRMS: $m / z \mathrm{C}_{12} \mathrm{H}_{14} \mathrm{IN}_{2} \mathrm{O}^{+}[\mathrm{M}+\mathrm{H}]^{+}$calcd. 329.0145, found $329.0151(\Delta 1.8 \mathrm{ppm})$.

\section{3-(3-(4-(6-Fluorobenzo[d]isoxazol-3-yl)piperidin-1-yl)propyl)-2-methyl-4H-pyrido[1,2-} $\alpha]$ pyrimidin-4-one (28)<smiles>Cc1nc2ccccn2c(=O)c1CC=CCN1CCC(c2noc3cc(F)ccc23)CC1</smiles>

A 1:0.32 mixture of $\mathbf{3 2 : 2 7}(11.9 \mathrm{mg}, 0.036 \mathrm{mmol})$ was suspended in acetone (1.0 mL). Amine $3(9.1 \mathrm{mg}, 0.041 \mathrm{mmol})$ was added followed by $\mathrm{K}_{2} \mathrm{CO}_{3}(6.3 \mathrm{mg}, 0.046 \mathrm{mmol})$. The reaction mixture was heated at reflux for 6 hours resulting in a cloudy yellow solution that was cooled and concentrated in vacuo to afford a viscous yellow oil that was then suspended in $\mathrm{H}_{2} \mathrm{O}(5$ $\mathrm{mL}$ ) and stirred for 1 hour. The water was filtered off, the remaining solid concentrated in vacuo to afford a light brown solid (14.7 $\mathrm{mg}, 0.035 \mathrm{mmol}, 97 \%$ crude yield). Purification by pipette column using diol (acetone) provided analogue $\mathbf{2 8}$ as a yellow film (10.3 $\mathrm{mg}, 0.024$ mmol, $67 \%)$. (44\% over 2 steps).

$\mathbf{R}_{f} 0.12$ (acetone $+0.5 \%$ triethylamine)

${ }^{1}$ H NMR (500 MHz, CDCl3) $\delta_{\mathrm{H}} 8.97(\mathrm{ddd}, J=7.2,1.6,0.8 \mathrm{~Hz}, 1 \mathrm{H}, \mathrm{H}-1), 7.70(\mathrm{dd}, J=8.7$, $\left.5.1 \mathrm{~Hz}, 1 \mathrm{H}, \mathrm{H}-1^{\prime}\right), 7.63$ (ddd, $\left.J=9.0,6.6,1.6 \mathrm{~Hz}, 1 \mathrm{H}, \mathrm{H}-3\right), 7.53$ (dt, $J=8.9,1.2 \mathrm{~Hz}, 1 \mathrm{H}, \mathrm{H}-$ 4), 7.23 (dd, $\left.J=8.5,2.1 \mathrm{~Hz}, 1 \mathrm{H}, \mathrm{H}-4^{\prime}\right), 7.08$ - 7.02 (m, 2H, H-2,2'), 3.15 - 3.04 (complex m, 3H, H-8',10'a), 2.77 (t, $J=7.7 \mathrm{~Hz} 2 \mathrm{H}, \mathrm{H}-10$ ), 2.54 (complex m, 5H, H-9,12), $2.24-2.15$ (complex m, 2H, H-10'b), 2.14 - 2.04 (complex m, 4H, H-9'), $1.90-1.81$ (m, 2H, H-11).

${ }^{13}$ C NMR (126 MHz, CDCl 3$) \delta_{\mathrm{C}} 164.1\left(\mathrm{~d}, J=251.1 \mathrm{~Hz}, \mathrm{C}, \mathrm{C}-3^{\prime}\right), 164.0$ (d, $J=13.6 \mathrm{~Hz}, \mathrm{C}, \mathrm{C}-$ 5'), 161.6 (C, C-6), 161.2 (C, C-7'), 158.1 (C, C-8), 148.5 (C, C-5), 134.9 (CH, C-3), 127.1 (CH, C-1), 125.9 (CH, C-4), 122.8 (d, $\left.J=11.1 \mathrm{~Hz}, \mathrm{CH}, \mathrm{C}-1^{\prime}\right), 117.4$ (C, C-6'), 115.9 (C, C-7), $114.9(\mathrm{CH}, \mathrm{C}-2), 112.5$ (d, $\left.J=25.3 \mathrm{~Hz}, \mathrm{CH}, \mathrm{C}-2^{\prime}\right), 97.6$ (d, $\left.J=26.7 \mathrm{~Hz}, \mathrm{CH}, \mathrm{C}-4^{\prime}\right), 58.5\left(\mathrm{CH}_{2}\right.$, 
C-12), $53.6\left(\mathrm{CH}_{2}, \mathrm{C}-10^{\prime}\right), 34.7\left(\mathrm{CH}, \mathrm{C}-8^{\prime}\right), 30.6\left(\mathrm{CH}_{2}, \mathrm{C}-9^{\prime}\right), 25.6\left(\mathrm{CH}_{2}, \mathrm{C}-11\right), 25.0\left(\mathrm{CH}_{2}, \mathrm{C}-\right.$ 10), $22.7\left(\mathrm{CH}_{3}, \mathrm{C}-9\right)$.

HRMS: $m / z \mathrm{C}_{24} \mathrm{H}_{26} \mathrm{FN}_{4} \mathrm{O}_{2}{ }^{+}[\mathrm{M}+\mathrm{H}]^{+}$calcd. 421.2034 , found 421.2035 ( $\left.\Delta 0.2 \mathrm{ppm}\right)$.

IR: (neat) $v_{\max } 2927,2805,2766,1663,1635,1614,1530,1474,1416,1121,955,768,729$ $\mathrm{cm}^{-1}$.

\section{4-Benzyloxy-1-chlorobutane (14)}<smiles>ClCCCCOCc1ccccc1</smiles>

To a solution of 4-chlorobutanol $(0.23 \mathrm{~mL}, 2.3 \mathrm{mmol})$ in $\mathrm{CH}_{2} \mathrm{Cl}_{2}(11 \mathrm{~mL})$ at $36{ }^{\circ} \mathrm{C}$, benzyl trichloroacetimidate $(0.64 \mathrm{~mL}, 3.5 \mathrm{mmol})$ was added to give a cloudy yellow solution. Triflic acid $(0.02 \mathrm{~mL}, 0.12 \mathrm{mmol})$ was added dropwise and the solution stirred for 3 hours before heat was removed and stirring continued for 45 hours. The cloudy yellow mixture was quenched by dropwise addition of pyridine $(0.02 \mathrm{~mL}, 0.25 \mathrm{mmol})$. The solution was then concentrated in vacuo to provide a pink slurry. This was taken up in 14:1 PE:EtOAc and filtered through a silica plug. The filtrate was concentrated in vacuo to provide the title compound (14) as a colourless oil (234 mg, $1.18 \mathrm{mmol}, 51 \%$ ) containing a 4:1 ratio of 14:4-chlorobutanol by ${ }^{1} \mathrm{H}$ NMR analysis. This was used in the next step without further purification.

${ }^{1}$ H NMR (500 MHz, CDCl3) $\delta_{\mathrm{H}} 7.43-7.27(\mathrm{~m}, 5 \mathrm{H}), 4.51(\mathrm{~s}, 2 \mathrm{H}), 3.57(\mathrm{t}, J=6.5 \mathrm{~Hz}, 2 \mathrm{H})$, $3.51(\mathrm{t}, J=6.2 \mathrm{~Hz}, 2 \mathrm{H}), 1.93-1.83(\mathrm{~m}, 2 \mathrm{H}), 1.80-1.72(\mathrm{~m}, 2 \mathrm{H})$.

The experimental data obtained matches those previously reported. ${ }^{98,119}$

\section{4-Benzyloxy-1-iodobutane (16)}<smiles>ICCCCO[Bi]</smiles>

A solution of $\mathrm{NaI}(1.031 \mathrm{~g}, 3.5 \mathrm{mmol})$ dissolved in distilled acetone $(5 \mathrm{~mL})$ was added to $\mathbf{1 4}$ (234 mg, $1.79 \mathrm{mmol}$ ) giving a yellow solution that was heated at reflux for 27 hours. The resulting dark orange solution was concentrated in vacuo to provide a wet dark orange crystalline product that was taken up in $\mathrm{Et}_{2} \mathrm{O}(5 \mathrm{~mL})$, washed with water $(2 \times 5 \mathrm{~mL})$, brine ( 5 
$\mathrm{mL})$ and dried $\left(\mathrm{MgSO}_{4}\right)$. Concentration in vacuo afforded iodide $\mathbf{1 6}$ as an orange oil $(251 \mathrm{mg}$, $0.87 \mathrm{mmol}, 73 \%)$. This was used in the next step without further purification.

${ }^{1}$ H NMR (500 MHz, CDCl 3$) \delta_{\mathrm{H}} 7.40-7.27(\mathrm{~m}, 5 \mathrm{H}), 4.50(\mathrm{~s}, 2 \mathrm{H}), 3.50(\mathrm{t}, J=6.3 \mathrm{~Hz}, 2 \mathrm{H})$, 3.21 (t, $J=7.1 \mathrm{~Hz}, 2 \mathrm{H}), 1.98-1.91$ (app. quin, 2H), 1.73 (app quin, 2H).

The experimental data obtained matches those previously reported. ${ }^{98,119}$

\section{Ethyl 2-acetyl-6-(benzyloxy)hexanoate (18)}

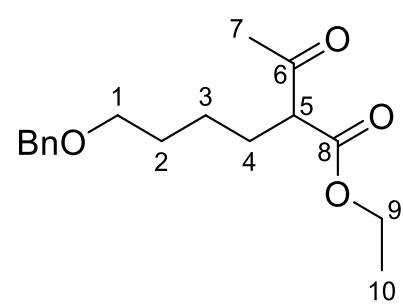

To a solution of sodium (22 $\mathrm{mg}, 0.96 \mathrm{mmol})$ dissolved in ethanol $(3 \mathrm{~mL})$, ethyl acetoacetate $(0.11 \mathrm{~mL}, 0.85 \mathrm{mmol})$ was added and the reaction heated at reflux. A solution of iodide $\mathbf{1 6}$ (227 $\mathrm{mg}, 0.78 \mathrm{mmol})$ dissolved in ethanol $(2 \mathrm{~mL})$ was then added dropwise, giving a brown solution. Reflux was continued for 2.5 hours, after which the reaction was cooled and concentrated in vacuo to give a brown slurry. The slurry was then taken up in 5:1 PE:EtOAc, filtered through a silica plug and concentrated in vacuo to provide a yellow oil $(183.5 \mathrm{mg}, 0.63 \mathrm{mmol}, 80 \%$ crude). Purification by silica gel chromatography (9:1 PE:EtOAc) provided hexanoate $\mathbf{1 8}$ as a yellow oil ( $25.7 \mathrm{mg}, 0.09 \mathrm{mmol}, 11 \%)$. (4\% over 3 steps).

$\mathbf{R}_{f} 0.18$ (9:1 hexanes: EtOAc)

${ }^{1}$ H NMR (500 MHz, CDCl 3$) \delta_{\mathrm{H}} 7.36$ - $7.26(\mathrm{~m}, 5 \mathrm{H}, \mathrm{Bn}), 4.48\left(\mathrm{~s}, 2 \mathrm{H}, \mathrm{PhCH}_{2}\right), 4.19$ (qd, $J=$ 7.1, 0.9 Hz, 2H, H-9), 3.46 (t, J=6.4 Hz, 2H, H-1), 3.40 (t, J=7.4 Hz, 1H, H-5), 2.21 (s, 3H, H-7), $1.90-1.82$ (m, 2H, H-4), $1.67-1.60$ (m, 2H, H-2), $1.42-1.33$ (m, 2H, H-3), 1.26 (t, J $=7.1 \mathrm{~Hz}, 3 \mathrm{H}, \mathrm{H}-10)$.

${ }^{13}$ C NMR (126 MHz, CDCl $)$ ) $\delta_{\mathrm{C}} 203.4$ (C, C-6), 169.9 (C, C-8), 138.6 (C, Bn), 128.5 (CH, Bn), $127.8(\mathrm{CH}, \mathrm{Bn}), 127.7(\mathrm{CH}, \mathrm{Bn}), 73.0\left(\mathrm{CH}_{2}, \mathrm{PhCH}_{2}\right), 70.0\left(\mathrm{CH}_{2}, \mathrm{C}-1\right), 61.4\left(\mathrm{CH}_{2}, \mathrm{C}-9\right)$, 60.0 (CH, C-5), $29.6\left(\mathrm{CH}_{2}, \mathrm{C}-2\right), 28.9\left(\mathrm{CH}_{3}, \mathrm{C}-7\right), 28.1\left(\mathrm{CH}_{2}, \mathrm{C}-4\right), 24.3\left(\mathrm{CH}_{2}, \mathrm{C}-3\right), 14.2\left(\mathrm{CH}_{3}\right.$, C-10).

HRMS: $m / z \mathrm{C}_{17} \mathrm{H}_{25} \mathrm{O}_{4}{ }^{+}[\mathrm{M}+\mathrm{H}]^{+}$calcd. 293.1747, found 293.1755 ( $\left.\Delta 2.7 \mathrm{ppm}\right)$. 
IR: (neat) $v_{\max } 2935,2862,1737,1713,1454,1360,1097,737,698 \mathrm{~cm}^{-1}$.

The experimental data obtained matches those previously reported. ${ }^{98}$

\section{3-(4-(Benzyloxy)butyl)-2-methyl-4H-pyrido[1,2- $\alpha$ ]pyrimidin-4-one (20)}

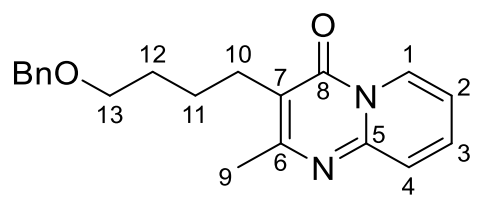

A mixture of hexanoate $18(20.7 \mathrm{mg}, 0.07 \mathrm{mmol}), 2$-aminopyridine $(7.5 \mathrm{mg}, 0.08 \mathrm{mmol})$ and ammonium acetate $(0.687 \mathrm{~g}, 8.9 \mathrm{mmol})$ was set to stir at $180{ }^{\circ} \mathrm{C}$. At $120^{\circ} \mathrm{C}$ the ammonium salt melted giving a viscous brown solution which became a clear brown mixture at $180{ }^{\circ} \mathrm{C}$. After 1 hour, more ammonium acetate $(1.106 \mathrm{~g}, 14.3 \mathrm{mmol})$ was added. After 3 hours, the reaction mixture was cooled and diluted with $\mathrm{H}_{2} \mathrm{O}(10 \mathrm{~mL})$. The aqueous solution was extracted with $\mathrm{CH}_{2} \mathrm{Cl}_{2}$ (4x $10 \mathrm{~mL}$ ), the organic fractions combined and washed with sat. aqueous $\mathrm{NaHCO}_{3}$ $(10 \mathrm{~mL})$ and brine $(10 \mathrm{~mL})$, then dried $\left(\mathrm{MgSO}_{4}\right)$ and concentrated in vacuo to provide a brown oil. Purification by silica gel chromatography (EtOAc $+0.5 \%$ triethylamine) provided the title compound (20) as a yellow oil (9.6 $\mathrm{mg}, 0.03 \mathrm{mmol}, 42 \%)$.

$\mathbf{R}_{f} 0.37$ (EtOAc $+0.5 \%$ triethylamine)

${ }^{1}$ H NMR (500 MHz, CDCl $) \delta_{\mathrm{H}} 8.97$ (ddd, $\left.J=7.2,1.6,0.8 \mathrm{~Hz}, 1 \mathrm{H}, \mathrm{H}-1\right), 7.62(\mathrm{ddd}, J=9.0$, 6.5, 1.6 Hz, 1H, H-3), 7.54 (d, $J=8.7 \mathrm{~Hz}, 1 \mathrm{H}, \mathrm{H}-4), 7.36-7.27$ (m, 5H, Bn), 7.05 (ddd, $J=$ 7.2, 6.5, $1.4 \mathrm{~Hz}, 1 \mathrm{H}, \mathrm{H}-2), 4.50$ (s, 2H, $\mathrm{PhCH}_{2}$ ), 3.52 (t, $\left.J=6.4 \mathrm{~Hz}, 2 \mathrm{H}, \mathrm{H}-13\right), 2.74$ (t, $J=7.8$ Hz, 2H, H-10), 2.50 (s, 3H, H-9), 1.74 (m, 2H, H-12), 1.67 (m, 2H, H-11).

${ }^{13}$ C NMR (126 MHz, CDCl 3$) \delta_{\mathrm{C}} 161.3$ (C, C-6), 158.1 (C, C-8), 148.5 (C, C-5), 138.8 (C, Bn), 134.9 (CH, C-3), 128.5 (CH, Bn), 127.8 (CH, Bn), 127.6 (CH, Bn), 127.2 (CH, C-1), 125.8 (CH, C-4), 116.2 (C, C-7), 114.9 (CH, C-2), $73.1\left(\mathrm{CH}_{2}, \mathrm{PhCH}_{2}\right), 70.4\left(\mathrm{CH}_{2}, \mathrm{C}-13\right), 29.9\left(\mathrm{CH}_{2}\right.$, C-12), $26.8\left(\mathrm{CH}_{2}, \mathrm{C}-10\right), 25.2\left(\mathrm{CH}_{2}, \mathrm{C}-11\right), 22.6\left(\mathrm{CH}_{3}, \mathrm{C}-9\right)$.

HRMS: $m / z, \mathrm{C}_{20} \mathrm{H}_{23} \mathrm{~N}_{2} \mathrm{O}_{2}{ }^{+}[\mathrm{M}+\mathrm{H}]^{+}$calcd. 323.1754 , found 323.1760 ( $\left.\Delta 1.9 \mathrm{ppm}\right)$.

IR: (neat) $v_{\max } 2926,2855,1663,1635,1530,1474,1426,1098,768,735,696,607 \mathrm{~cm}^{-1}$.

The experimental data obtained matches those previously reported. ${ }^{98}$ 


\section{3-(4-(Benzyloxy)butyl)-2-methyl-6,7,8,9-tetrahydro-4H-pyrido[1,2- $\alpha]$ pyrimidin-4-one}

(22)

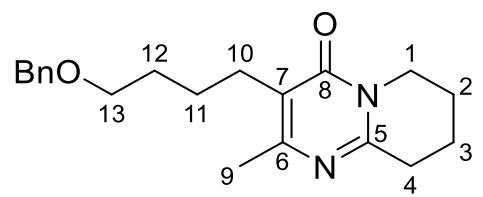

A Schlenk tube fitted with a Youngs tap was charged with 20 (35.6 mg, $0.11 \mathrm{mmol})$, palladium with $10 \%$ activated carbon $(4 \mathrm{mg}, 10 \% \mathrm{w} / \mathrm{w}), \mathrm{MeOH}(0.40 \mathrm{~mL})$ and $\mathrm{H}_{2} \mathrm{O}(0.35 \mathrm{~mL})$. The tube was flushed with $\mathrm{N}_{2}$ and evacuated 5 times, then charged with $\mathrm{H}_{2}$ under balloon pressure. Stirring for 5 days provided a suspension that was filtered through Celite ${ }^{\circledR}$ to afford a clear solution that was concentrated in vacuo to provide a brown oil. Silica gel chromatography $($ EtOAc $+0.5 \%$ triethylamine) provided the title compound (22) as a clear oil $(22.7 \mathrm{mg}, 0.07$ mmol, 63\%).

$\mathbf{R}_{f} 0.16($ EtOAc $+0.5 \%$ triethylamine $)$

${ }^{1} \mathbf{H}$ NMR $\left(\mathbf{5 0 0} \mathbf{M H z}, \mathbf{C D C l}_{3}\right) \delta_{\mathrm{H}} 7.35-7.26(\mathrm{~m}, 5 \mathrm{H}, \mathrm{Bn}), 4.49\left(\mathrm{~s}, 2 \mathrm{H}, \mathrm{PhCH}_{2}\right), 3.91(\mathrm{t}, J=6.2$ Hz, 2H, H-1), 3.50 (t, $J=6.6 \mathrm{~Hz}, 2 \mathrm{H}, \mathrm{H}-13), 2.84$ (t, $J=6.7 \mathrm{~Hz}, 2 \mathrm{H}, \mathrm{H}-4), 2.53$ (t, $J=7.7 \mathrm{~Hz}$ 2H, H-10), 2.25 (s, 3H, H-9), 1.98 - 1.91 (m, 2H, H-2), $1.89-1.83$ (m, 2H, H-3), $1.73-1.65$ (m, 2H, H-12), $1.61-1.53$ (m, 2H, H-11).

${ }^{13}$ C NMR (126 MHz, CDCl3) $\delta_{\mathrm{C}} 162.8$ (C, C-8), 157.9 (C, C-6), 155.7 (C, C-5), 138.8 (C, Bn), 128.5 (CH, Bn), 127.8 (CH, Bn), 127.6 (CH, Bn), 121.5 (C, C-7), $73.1\left(\mathrm{CH}_{2}, \mathrm{PhCH}_{2}\right), 70.5$ $\left(\mathrm{CH}_{2}, \mathrm{C}-13\right), 42.8\left(\mathrm{CH}_{2}, \mathrm{C}-1\right), 31.6\left(\mathrm{CH}_{2}, \mathrm{C}-4\right), 29.9\left(\mathrm{CH}_{2}, \mathrm{C}-12\right), 26.1\left(\mathrm{CH}_{2}, \mathrm{C}-10\right), 25.0\left(\mathrm{CH}_{2}\right.$, C-11), $22.2\left(\mathrm{CH}_{2}, \mathrm{C}-2\right), 21.3\left(\mathrm{CH}_{3}, \mathrm{C}-9\right), 19.4\left(\mathrm{CH}_{2}, \mathrm{C}-3\right)$.

HRMS: $m / z, \mathrm{C}_{20} \mathrm{H}_{27} \mathrm{~N}_{2} \mathrm{O}_{2}{ }^{+}[\mathrm{M}+\mathrm{H}]^{+}$calcd. 327.2067, found $327.2068(\Delta 0.3 \mathrm{ppm})$.

IR: (neat) $v_{\max } 2934,2860,1649,1531,1190,1096,734,698,607 \mathrm{~cm}^{-1}$.

The experimental data obtained matches those previously reported..$^{98}$ 
<smiles>Cc1nc2n(c(=O)c1CC=CCO)CCCC2</smiles>

A solution of $22(209 \mathrm{mg}, 0.64 \mathrm{mmol})$ dissolved in $\mathrm{CH}_{2} \mathrm{Cl}_{2}(2.5 \mathrm{~mL})$ was cooled to $0{ }^{\circ} \mathrm{C}$ and $1 \mathrm{M} \mathrm{TiCl}_{4}$ in $\mathrm{CH}_{2} \mathrm{Cl}_{2}(3.2 \mathrm{~mL}, 3.2 \mathrm{mmol}, 5$ equiv.) was added dropwise resulting in the formation of a yellow precipitate. The flask was then allowed to warm to room temperature and stir for 1 hour. The reaction mixture was then poured into ice cold sat. aqueous $\mathrm{NaHCO}_{3}$ (80 mL). This solution was extracted with $\mathrm{CH}_{2} \mathrm{Cl}_{2}(3 \times 60 \mathrm{~mL})$ and EtOAc $(60 \mathrm{~mL})$. The organic fractions were combined, dried $\left(\mathrm{MgSO}_{4}\right)$ and concentrated in vacuo to provide a yellow oil. Silica gel chromatography (Acetone $+0.5 \%$ triethylamine) provided alcohol 24 as a yellow oil (99.3 mg, $0.42 \mathrm{mmol}, 66 \%)$.

$\mathbf{R}_{f} 0.39$ (acetone $+0.5 \%$ triethylamine)

${ }^{1} \mathbf{H}$ NMR (500 MHz, CDCl$) \delta_{\mathrm{H}} 3.92(\mathrm{t}, J=6.2 \mathrm{~Hz}, 2 \mathrm{H}, \mathrm{H}-1), 3.71(\mathrm{t}, J=6.2 \mathrm{~Hz}, 2 \mathrm{H}, \mathrm{H}-13)$, 2.89 (t, $J=6.6 \mathrm{~Hz}, 2 \mathrm{H}, \mathrm{H}-4), 2.54$ (t, $J=7.7 \mathrm{~Hz}, 2 \mathrm{H}, \mathrm{H}-10), 2.29$ (s, 3H, H-9) $1.99-1.92$ (m, 2H, H-2), 1.91 - 1.84 (m, 2H, H-3), 1.67 - 1.53 (complex m, 4H, H-11,12).

${ }^{13}$ C NMR (126 MHz, CDCl3) $\delta_{\mathrm{C}} 162.8$ (C, C-8), 157.8 (C, C-6), 155.8 (C, C-5), 121.6 (C, C5), $62.5\left(\mathrm{CH}_{2}, \mathrm{C}-13\right), 42.9\left(\mathrm{CH}_{2}, \mathrm{C}-1\right), 32.3\left(\mathrm{CH}_{2}, \mathrm{C}-12\right), 31.4\left(\mathrm{CH}_{2}, \mathrm{C}-4\right), 25.6\left(\mathrm{CH}_{2}, \mathrm{C}-10\right)$, $24.5\left(\mathrm{CH}_{2}, \mathrm{C}-11\right), 22.1\left(\mathrm{CH}_{2}, \mathrm{C}-2\right), 21.2\left(\mathrm{CH}_{3}, \mathrm{C}-9\right), 19.3\left(\mathrm{CH}_{2}, \mathrm{C}-3\right)$.

HRMS: $m / z \mathrm{C}_{13} \mathrm{H}_{21} \mathrm{~N}_{2} \mathrm{O}_{2}{ }^{+}[\mathrm{M}+\mathrm{H}]^{+}$calcd. 237.1598, found $237.1596(\Delta 0.8 \mathrm{ppm})$.

IR: (neat) $v_{\max } 3284,2925,2859,1637,1529,1414,1191,1096,709 \mathrm{~cm}^{-1}$.

\section{3-(4-Iodobutyl)-2-methyl-6,7,8,9-tetrahydro-4H-pyrido[1,2- $\alpha]$ pyrimidin-4-one (26)}<smiles>Cc1nc2n(c(=O)c1CCCCI)CCCC2</smiles>

$\mathrm{I}_{2}(51 \mathrm{mg}, 0.20 \mathrm{mmol})$ was added to a solution of $\mathrm{PPh}_{3}(67.1 \mathrm{mg}, 0.26 \mathrm{mmol})$ in $\mathrm{CH}_{3} \mathrm{CN}(1.80$ $\mathrm{mL}$ ) at $0{ }^{\circ} \mathrm{C}$ and stirred for 30 minutes to give an orange solution. A solution of alcohol $\mathbf{2 4}$ (29.3 mg, $0.12 \mathrm{mmol})$ in $\mathrm{CH}_{3} \mathrm{CN}(0.5 \mathrm{~mL})$ was added and the reaction mixture heated at reflux 
for 22 hours to give a yellow solution. The reaction mixture was cooled and concentrated in vacuo, then taken up in EtOAc $(15 \mathrm{~mL})$ and $\mathrm{H}_{2} \mathrm{O}(15 \mathrm{~mL})$. The organic layer was washed with $\mathrm{H}_{2} \mathrm{O}(5 \mathrm{x} 10 \mathrm{~mL})$, then $1 \mathrm{M} \mathrm{HCl}(10 \mathrm{~mL})$. The aqueous layers were combined and extracted with EtOAc (20 mL). $\mathrm{CH}_{2} \mathrm{Cl}_{2}(20 \mathrm{~mL})$ was added to the aqueous phase and the $\mathrm{pH}$ adjusted to 7 by addition of sat. aqeuous $\mathrm{NaHCO}_{3}$. The phases were separated and the aqueous layer extracted with $\mathrm{CH}_{2} \mathrm{Cl}_{2}$ (2x $\left.20 \mathrm{~mL}\right)$. The $\mathrm{CH}_{2} \mathrm{Cl}_{2}$ layers were combined, dried $\left(\mathrm{Na}_{2} \mathrm{SO}_{4}\right)$ and concentrated in vacuo to provide iodide 26 as a yellow oil (38.5 $\mathrm{mg}, 0.11 \mathrm{mmol}, 90 \%)$. This was used in the next step without further purification.

${ }^{1}$ H NMR (500 MHz, CDCl $) \delta_{\mathrm{H}} 3.93(\mathrm{t}, J=6.1 \mathrm{~Hz}, 2 \mathrm{H}), 3.21(\mathrm{t}, J=6.9 \mathrm{~Hz}, 2 \mathrm{H}), 3.06(\mathrm{t}, J=$ $6.6 \mathrm{~Hz}, 2 \mathrm{H}), 2.52(\mathrm{t}, J=7.8 \mathrm{~Hz}, 2 \mathrm{H}), 2.37(\mathrm{~s}, 3 \mathrm{H}), 2.02-1.95(\mathrm{~m}, 2 \mathrm{H}), 1.93-1.85(\mathrm{~m}, 4 \mathrm{H})$, $1.62-1.55(\mathrm{~m}, 2 \mathrm{H})$.

HRMS: $m / z, \mathrm{C}_{13} \mathrm{H}_{20} \mathrm{IN}_{2} \mathrm{O}^{+}[\mathrm{M}+\mathrm{H}]^{+}$calcd. 347.0615, found 347.0605 ( $\left.\Delta 2.9 \mathrm{ppm}\right)$.

\section{3-(4-(4-(6-Fluorobenzo[d]isoxazol-3-yl)piperidin-1-yl)butyl)-2-methyl-6,7,8,9- tetrahydro-4H-pyrido[1,2- $\alpha]$ pyrimidin-4-one (9)}<smiles>Cc1nc2n(c(=O)c1CC=CCN1CCC(c3noc4cc(F)ccc34)CC1)CCCC2</smiles>

Iodide 26 (35.1 mg, $0.101 \mathrm{mmol})$ was suspended in acetone $(2.00 \mathrm{~mL})$. Amine $3(23.1 \mathrm{mg}$, $0.105 \mathrm{mmol})$ was added followed by $\mathrm{K}_{2} \mathrm{CO}_{3}(16.5 \mathrm{mg}, 0.119 \mathrm{mmol})$. The reaction mixture was heated at reflux for 6 hours resulting in a cloudy grey solution that was cooled and concentrated in vacuo to afford a sticky grey solid that was then suspended in $\mathrm{H}_{2} \mathrm{O}(5 \mathrm{~mL})$ and stirred for 1 hour. The water was filtered off and the remaining solid purified by pipette column using diol (Acetone) provided analogue 9 as a clear film (16.1 mg, $0.037 \mathrm{mmol}, 36 \%$ ). (31\% over 2 steps). $\mathbf{R}_{f} 0.10$ (acetone $+0.5 \%$ triethylamine)

${ }^{1} \mathbf{H}$ NMR $\left(\mathbf{5 0 0} \mathbf{M H z}, \mathbf{D}_{2} \mathrm{O}\right) \delta_{\mathrm{H}} 7.87(\mathrm{dd}, J=8.9,4.9 \mathrm{~Hz}, 1 \mathrm{H}), 7.42(\mathrm{~d}, J=8.9,2.2 \mathrm{~Hz}, 1 \mathrm{H}), 7.22$ $(\mathrm{td}, J=9.2,2.3 \mathrm{~Hz}, 1 \mathrm{H}), 3.89(\mathrm{t}, J=6.3 \mathrm{~Hz}, 2 \mathrm{H}), 3.61-3.45$ (complex m, 3H), $3.10-2.98$ (complex m, 4H), $2.87(\mathrm{t}, J=6.6 \mathrm{~Hz}, 2 \mathrm{H}), 2.55(\mathrm{t}, J=7.8 \mathrm{~Hz}, 2 \mathrm{H}), 2.37$ (br. d, $J=14.7 \mathrm{~Hz}$ 
2H), 2.29 (s, 3H), 2.17 - 2.09 (complex m, 2H), 1.99 - 1.92 (m, 2H), $1.88-1.82(\mathrm{~m}, 2 \mathrm{H}), 1.79$ $-1.72(\mathrm{~m}, 2 \mathrm{H}), 1.53$ (quin, $J=7.6 \mathrm{~Hz}, 2 \mathrm{H}$ ).

${ }^{1}$ H NMR $\left(500 \mathrm{MHz}, \mathbf{C D C l}_{3}\right) \delta_{\mathrm{H}} 7.75\left(\mathrm{dd}, J=8.7,5.1 \mathrm{~Hz}, 1 \mathrm{H}, \mathrm{H}-1^{\prime}\right), 7.22(\mathrm{dd}, J=8.5,2.2 \mathrm{~Hz}$, 1H, H-4'), 7.04 (td, $\left.J=8.8,2.1 \mathrm{~Hz}, 1 \mathrm{H}, \mathrm{H}-2^{\prime}\right), 3.91$ (t, $\left.J=6.2 \mathrm{~Hz}, 2 \mathrm{H}, \mathrm{H}-1\right), 3.14$ (m, 3H, H8',10'a), 2.84 (t, $J=6.7 \mathrm{~Hz}, 2 \mathrm{H}, \mathrm{H}-4), 2.58-2.51$ (m, 4H, H-11,12), 2.34 - 2.25 (complex m, 5H, H-9,10'b), 2.22 - 2.16 (complex, 2H, H-9'a), 2.14 - 2.07 (complex m, 2H, H-9'b), 1.98 1.91 (m, 2H, H-2), $1.89-1.83$ (m, 2H, H-3), 1.70 - 1.62 (m, 2H, H-12), 1.56 - 1.49 (m, 2H, H-11).

${ }^{13}$ C NMR (126 MHz, CDCl3) $\delta_{\mathrm{C}} 164.1,\left(\mathrm{~d}, J=250.8 \mathrm{~Hz}, \mathrm{C}, \mathrm{C}-3^{\prime}\right) 164.0$ (d, $J=13.7 \mathrm{~Hz}, \mathrm{C}, \mathrm{C}-$ 5), 162.8 (C, C-8), 161.0 (C, C-7'), 158.0 (C, C-6), 155.8 (C, C-5), 122.9 (d, J = 11.0 Hz, CH, C-1'), 121.3 (C, C-7), 117.3 (C, C-6'), 112.6 (d, J = 25.3 Hz, CH, C-2'), 97.5 (d, J = 26.8 Hz, $\left.\mathrm{CH}, \mathrm{C}-4^{\prime}\right), 58.7\left(\mathrm{CH}_{2}, \mathrm{C}-13\right), 53.4\left(\mathrm{CH}_{2}, \mathrm{C}-10^{\prime}\right), 42.9\left(\mathrm{CH}_{2}, \mathrm{C}-1\right), 34.2\left(\mathrm{CH}, \mathrm{C}-8^{\prime}\right), 31.6\left(\mathrm{CH}_{2}\right.$, C-4), $\left.30.0\left(\mathrm{CH}_{2}, \mathrm{C}-9\right)^{\prime}\right), 26.5\left(\mathrm{CH}_{2}, \mathrm{C}-12\right), 26.2\left(\mathrm{CH}_{2}, \mathrm{C}-11\right), 25.9\left(\mathrm{CH}_{2}, \mathrm{C}-10\right), 22.1\left(\mathrm{CH}_{2}, \mathrm{C}-\right.$ 2) $21.3\left(\mathrm{CH}_{3}, \mathrm{C}-9\right), 19.4\left(\mathrm{CH}_{2}, \mathrm{C}-3\right)$.

HRMS: $m / z \mathrm{C}_{25} \mathrm{H}_{32} \mathrm{FN}_{4} \mathrm{O}_{2}{ }^{+}[\mathrm{M}+\mathrm{H}]^{+}$calcd. 439.2504, found 439.2514 ( $\left.\Delta 2.3 \mathrm{ppm}\right)$.

IR: (neat) $v_{\max } 2931,2807,2768,1641,1613,1530,1447,1271,1189,955,836,815,728 \mathrm{~cm}^{-}$ 1 .

\section{3-(4-Hydroxybutyl)-2-methyl-4H-pyrido[1,2- $\alpha]$ pyrimidin-4-one (30)}<smiles>Cc1nc2ccccn2c(=O)c1CC=CCO</smiles>

A solution of $20(66.7 \mathrm{mg}, 0.21 \mathrm{mmol})$ dissolved in $\mathrm{CH}_{2} \mathrm{Cl}_{2}(0.96 \mathrm{~mL})$ was cooled to $0{ }^{\circ} \mathrm{C}$ and $1 \mathrm{M} \mathrm{TiCl}_{4}$ in $\mathrm{CH}_{2} \mathrm{Cl}_{2}$ (1.04 mL, $1.04 \mathrm{mmol}, 5$ equiv.) was added dropwise resulting in the formation of a dark red precipitate. The flask was then allowed to warm to room temperature and stir for 1 hour. The reaction mixture was then poured into ice cold sat. aqueous $\mathrm{NaHCO}_{3}$ (30 mL). This solution was extracted with $\mathrm{CH}_{2} \mathrm{Cl}_{2}(3 \times 20 \mathrm{~mL})$ and EtOAc $(20 \mathrm{~mL})$. The organic fractions were combined, dried $\left(\mathrm{MgSO}_{4}\right)$ and concentrated in vacuo to provide a yellow oil. Silica gel chromatography (Acetone $+0.5 \%$ triethylamine) provided alcohol $\mathbf{3 0}$ as a yellow oil (27.3 mg, $0.12 \mathrm{mmol}, 57 \%)$. 
$\mathbf{R}_{f} 0.42$ (acetone $+0.5 \%$ triethylamine)

${ }^{1}$ H NMR (500 MHz, CDCl $) \delta_{\mathrm{H}} 8.96(\mathrm{ddd}, J=7.2,1.6,0.8 \mathrm{~Hz}, 1 \mathrm{H}, \mathrm{H}-1), 7.62(\mathrm{ddd}, J=9.0$, 6.6, 1.6 Hz, 1H, H-3), 7.53 (ddd, $J=9.0,1.4,0.9 \mathrm{~Hz}, 1 \mathrm{H}, \mathrm{H}-4$ ), 7.06 (ddd, $J=7.2,6.5,1.4 \mathrm{~Hz}$, 1H, H-2), 3.72 (br. t, $J=6.3 \mathrm{~Hz}, 2 \mathrm{H}, \mathrm{H}-13$ ), 2.75 (t, $J=7.5 \mathrm{~Hz}, 2 \mathrm{H}, \mathrm{H}-10), 2.51$ (s, 3H, H-9), $1.73-1.61$ (m, 4H, H-11,12).

${ }^{13}$ C NMR (126 MHz, CDCl 3 ) $\delta_{\mathrm{C}} 161.5$ (C, C-6), 158.2 (C, C-8), 148.5 (C, C-5), 134.9 (CH, C-3), 127.1 (CH, C-1), 125.9 (CH, C-4), 116.2 (C, C-7), 114.9 (CH, C-2), $62.7\left(\mathrm{CH}_{2}, \mathrm{C}-13\right)$, $32.4\left(\mathrm{CH}_{2}, \mathrm{C}-12\right), 26.3\left(\mathrm{CH}_{2}, \mathrm{C}-10\right), 24.7\left(\mathrm{CH}_{2}, \mathrm{C}-11\right), 22.6\left(\mathrm{CH}_{3}, \mathrm{C}-9\right)$.

HRMS: $m / z \mathrm{C}_{13} \mathrm{H}_{17} \mathrm{~N}_{2} \mathrm{O}_{2}{ }^{+}[\mathrm{M}+\mathrm{H}]^{+}$calcd. 233.1285, found 233.1286 ( $\left.\Delta 0.4 \mathrm{ppm}\right)$.

IR: (neat) $v_{\max } 3448,2945,2928,2856,1657,1631,1527,1471,1368,1219,1134,770,572$, $432 \mathrm{~cm}^{-1}$.

\section{3-(4-Iodobutyl)-2-methyl-4H-pyrido[1,2- $\alpha]$ pyrimidin-4-one (32)}<smiles>Cc1nc2ccccn2c(=O)c1CCCCI</smiles>

$\mathrm{I}_{2}\left(30.5 \mathrm{mg}, 0.12 \mathrm{mmol}\right.$ ) was added to a solution of $\mathrm{PPh}_{3}(39.4 \mathrm{mg}, 0.15 \mathrm{mmol})$ in $\mathrm{CH}_{3} \mathrm{CN}(1.20$ $\mathrm{mL}$ ) at $0{ }^{\circ} \mathrm{C}$ and stirred for 30 minutes to give a yellow solution. A solution of alcohol $\mathbf{3 0}$ (17.0 $\mathrm{mg}, 0.07 \mathrm{mmol})$ in $\mathrm{CH}_{3} \mathrm{CN}(0.7 \mathrm{~mL})$ was added and the reaction mixture heated at reflux for 21 hours to give a transparent orange solution. The reaction mixture was cooled and concentrated in vacuo, then taken up in EtOAc $(10 \mathrm{~mL})$ and $\mathrm{H}_{2} \mathrm{O}(10 \mathrm{~mL})$. The organic layer was washed with $\mathrm{H}_{2} \mathrm{O}(5 \times 10 \mathrm{~mL})$, then $1 \mathrm{M} \mathrm{HCl}(10 \mathrm{~mL})$. The aqueous layers were combined and extracted with EtOAc $(20 \mathrm{~mL}) . \mathrm{CH}_{2} \mathrm{Cl}_{2}(20 \mathrm{~mL})$ was added to the aqueous phase and the $\mathrm{pH}$ adjusted to 7 by addition of sat. aqueous $\mathrm{NaHCO}_{3}$. The phases were separated and the aqueous layer extracted with $\mathrm{CH}_{2} \mathrm{Cl}_{2}(2 \times 20 \mathrm{~mL})$. The $\mathrm{CH}_{2} \mathrm{Cl}_{2}$ layers were combined, dried $\left(\mathrm{Na}_{2} \mathrm{SO}_{4}\right)$ and concentrated in vacuo to provide iodide 32 as a yellow oil (15.0 mg, $0.04 \mathrm{mmol}$, $60 \%$ ). This was used in the next step without further purification.

${ }^{1}$ H NMR (500 MHz, CDCl $) \delta_{\mathrm{H}} 8.95$ (br. d, $\left.J=6.8 \mathrm{~Hz}, 1 \mathrm{H}\right), 7.64-7.60$ (m, 1H), 7.52 (br. d, $J=9.0 \mathrm{~Hz}, 1 \mathrm{H}), 7.05(\mathrm{td}, J=7.0,1.7 \mathrm{~Hz}, 1 \mathrm{H}), 3.23(\mathrm{t}, J=6.9 \mathrm{~Hz}, 2 \mathrm{H}), 2.72(\mathrm{t}, J=7.6 \mathrm{~Hz}, 2 \mathrm{H})$, 2.50 (s, 3H), 1.93 (quin, $J=7.5 \mathrm{~Hz}, 2 \mathrm{H}), 1.73-1.63(\mathrm{~m}, 2 \mathrm{H})$. 
HRMS: $m / z \mathrm{C}_{13} \mathrm{H}_{16} \mathrm{IN}_{2} \mathrm{O}^{+}[\mathrm{M}+\mathrm{H}]^{+}$calcd. 343.0302, found 343.0306 ( $\left.\Delta 1.2 \mathrm{ppm}\right)$.

\section{3-(4-(4-(6-Fluorobenzo[d]isoxazol-3-yl)piperidin-1-yl)butyl)-2-methyl-4H-pyrido[1,2-} a]pyrimidin-4-one (29)<smiles>Cc1nc2ccccn2c(=O)c1CC=CCN1CCC(c2noc3cc(F)ccc23)CC1</smiles>

Iodide 32 (14.5 mg, $0.042 \mathrm{mmol}$ ) was suspended in acetone (1 mL). Amine 3 (9.7 mg, 0.044 mmol) was added followed by $\mathrm{K}_{2} \mathrm{CO}_{3}(7.7 \mathrm{mg}, 0.052 \mathrm{mmol})$. The reaction mixture was heated at reflux for 6.5 hours resulting in a cloudy grey solution that was cooled and concentrated in vacuo to afford a slightly yellow solid that was then suspended in $\mathrm{H}_{2} \mathrm{O}(5 \mathrm{~mL})$ and stirred for 1 hour. The water was filtered off, the remaining solid taken up in $\mathrm{CH}_{2} \mathrm{Cl}_{2}$ and concentrated in vacuo to afford a yellow film $(17.1 \mathrm{mg}, 0.039 \mathrm{mmol}, 94 \%$ crude yield). Purification by pipette column using diol (acetone) provided analogue 29 as a yellow film (16.0 mg, $0.037 \mathrm{mmol}$, $88 \%)$. (53\% over 2 steps).

$\mathbf{R}_{f} 0.15$ (acetone)

${ }^{1}$ H NMR (500 MHz, CDCl3) $\delta_{\mathrm{H}} 8.97(\mathrm{ddd}, J=7.3,1.6,0.9 \mathrm{~Hz}, 1 \mathrm{H}, \mathrm{H}-1), 7.74(\mathrm{dd}, J=8.7$, $\left.5.1 \mathrm{~Hz}, 1 \mathrm{H}, \mathrm{H}-1^{\prime}\right), 7.63$ (ddd, $\left.J=9.0,6.6,1.6 \mathrm{~Hz}, 1 \mathrm{H}, \mathrm{H}-3\right), 7.53$ (dt, $J=9.0,1.2 \mathrm{~Hz}, 1 \mathrm{H}, \mathrm{H}-$ 4), 7.23 (dd, $\left.J=8.5,2.1 \mathrm{~Hz}, 1 \mathrm{H}, \mathrm{H}-4^{\prime}\right), 7.08-7.02$ (m, 2H, H-2,2'), $3.10-3.02$ (m, 3H, H8',10'a), 2.76 (t, J=7.5 Hz, 2H, H-10), 2.52 (s, 2H, H-9), 2.44 (t, J=7.4 Hz 2H, H-13), 2.30 2.04 (complex m, 6H, H-9',10'b), 1.69 (m, 2H, H-12), 1.63 (m, 2H, H-11).

${ }^{13}$ C NMR (126 MHz, CDCl3) $\delta_{\mathrm{C}} 164.1\left(\mathrm{~d}, J=251.5 \mathrm{~Hz}, \mathrm{C}, \mathrm{C}-3^{\prime}\right), 164.0$ (d, $J=13.5 \mathrm{~Hz}, \mathrm{C}, \mathrm{C}-$ 5'), 161.5 (C, C-7'), 161.2 (C, C-6), 158.1 (C, C-8), 148.5 (C, C-5), 134.9 (CH, C-3), 127.2 (CH, C-1), 125.9 (CH, C-4), 122.9 (d, $J=11.6$ Hz, CH, C-1'), 117.4 (C, C-6'), 116.1 (C, C-7), $114.9(\mathrm{CH}, \mathrm{C}-2), 112.5$ (d, $\left.J=25.3 \mathrm{~Hz}, \mathrm{CH}, \mathrm{C}-2^{\prime}\right), 97.6$ (d, $\left.J=26.5 \mathrm{~Hz}, \mathrm{CH}, \mathrm{C}-4^{\prime}\right), 58.8\left(\mathrm{CH}_{2}\right.$, C-13), $53.6\left(\mathrm{CH}_{2}, \mathrm{C}-10^{\prime}\right), 34.5\left(\mathrm{CH}, \mathrm{C}-8^{\prime}\right), 30.3\left(\mathrm{CH}_{2}, \mathrm{C}-9^{\prime}\right), 26.8\left(\mathrm{CH}_{2}, \mathrm{C}-12\right), 26.8\left(\mathrm{CH}_{2}, \mathrm{C}-\right.$ 10), $26.5\left(\mathrm{CH}_{2}, \mathrm{C}-11\right), 22.6\left(\mathrm{CH}_{3}, \mathrm{C}-9\right)$.

HRMS: $m / z \mathrm{C}_{25} \mathrm{H}_{28} \mathrm{FN}_{4} \mathrm{O}_{2}{ }^{+}[\mathrm{M}+\mathrm{H}]^{+}$calcd. 435.2191, found 435.2199 ( $\left.\Delta 1.8 \mathrm{ppm}\right)$. 
IR: (neat) $v_{\max } 3067,2807,2767,1662,1635,1613,1530,1474,1426,1249,1121,955,768$. $729 \mathrm{~cm}^{-1}$.

\subsection{In Vitro Assay Experimental}

\subsubsection{Cell Culture and In Vitro Experiments}

\subsubsection{Quantification of Analogues}

Compounds to be quantified were 8, 9, 28 and 29. Following the methodology of West, ${ }^{138}$ the compound to be quantified was dissolved in $\mathrm{CDCl}_{3}(500 \mu \mathrm{L})$ and an approximately equimolar amount of $\mathrm{CH}_{3} \mathrm{NH}_{2}$, also dissolved in $\mathrm{CDCl}_{3}$, was added. The solutions were sonicated, transferred to $5 \mathrm{~mm}$ NMR tubes and sealed with parafilm. ${ }^{1} \mathrm{H}$ NMR spectra for quantification were collected on a JEOL JNM-ECZ600R NMR spectrometer with the settings described in Table 7 applied.

Table 7. NMR parameters and settings for quantification experiments.

\begin{tabular}{|c|c|}
\hline Parameter & Setting \\
\hline Temperature & $25^{\circ} \mathrm{C}$ \\
\hline Relaxation Delay & $15.0 \mathrm{~s}$ \\
\hline Pulse Angle & $90.0^{\circ}$ \\
\hline Repetitions & 64 \\
\hline
\end{tabular}

\subsubsection{Compounds for In Vitro Use}

Analogues synthesised were dissolved in DMSO at a concentration of $10 \mathrm{mM}$ and stored at room temperature until required. Risperidone (Kindly provided by Douglas Pharmaceuticals, Auckland, New Zealand) was dissolved in $0.1 \mathrm{M} \mathrm{AcOH}$ (Sigma-Aldrich, MO) at a concentration of $25 \mathrm{mM}$ and stored at $-80{ }^{\circ} \mathrm{C}$ until required. All stock compounds were stored in single use aliquots to prevent repeated freeze/thaw cycles. Compounds were diluted to the desired concentration in 1\% DMSO and complete T-cell media (CTCM) for in vitro assays. 


\subsubsection{Culture and Maintenance of RAW 264.7 Macrophage Cell Line}

RAW 264.7 cells were a kind gift from Dr. Helen Woolner. According to the methodology of Zareie, ${ }^{149} 2 \times 10^{6}$ RAW264.7 cells were stored long term by re-suspending cells in cryopreservation medium (see Appendix 6.2) and kept in a liquid phase liquid nitrogen storage tank until required. Low passage numbers $(<20)$ RAW264.7 cells were cultured from storage by first thawing the cryovial in a $37^{\circ} \mathrm{C}$ water bath, after which its contents were immediately transferred into $9 \mathrm{~mL}$ of $37{ }^{\circ} \mathrm{C} \mathrm{CTCM}$ and centrifuged at $400 \mathrm{x} \mathrm{g}$ for 5 minutes to remove the cryopreservation medium. The cell pellet was then re-suspended in $10 \mathrm{~mL}$ of $37^{\circ} \mathrm{C} \mathrm{CTCM}$ and transferred to a T25 tissue culture flask and incubated in a humidified incubator at $37{ }^{\circ} \mathrm{C}$ and $5 \% \mathrm{CO}_{2}$ until confluent. At $80 \%$ confluency, RAW264.7 cells were passaged by first removing culture medium and adding $5 \mathrm{~mL}$ of warm dPBS to wash non-adherent cells/debris to be discarded. $5 \mathrm{~mL}$ of cold dPBS is then added to the flask and adherent cells were lifted from the flask by using a cell scraper. The cell suspension was then aspirated and transferred to a $15 \mathrm{~mL}$ conical tube and centrifuged at $400 \mathrm{x}$ g for 5 mins and re-suspended in $1 \mathrm{~mL}$ of dPBS. Live cells are counted by trypan blue exclusion. $1 \times 10^{6}$ cells are added to $15 \mathrm{~mL}$ of CTCM in a T75 culture flask and cultured until $80 \%$ confluent.

\subsubsection{MTT Reduction Assay}

Following completion of an experiment, $170 \mu \mathrm{L} /$ well of supernatant was transferred to a sterile flat bottom 96 well plate and stored at $-20^{\circ} \mathrm{C}$ or used immediately. $50 \mu \mathrm{L} /$ well of fresh CTCM warmed to $37{ }^{\circ} \mathrm{C}$ was added before adding $20 \mu \mathrm{L} /$ well of MTT solution (see Appendix 6.2) was added to each well. Plates were incubated for a further 2 hours at $37{ }^{\circ} \mathrm{C}$ and $5 \% \mathrm{CO}_{2}$. After incubation, the reaction was stopped by adding $100 \mu \mathrm{L} /$ well of MTT stop solution (see Appendix 6.2) and left overnight at $37{ }^{\circ} \mathrm{C}$ to solubilize formazan products. Absorbance was measured at $570 \mathrm{~nm}$ in a multi-well Enspire 2300 Multilabel plate reader (PerkinElmer, Wellesley, MA). Cell metabolism was calculated as percentage absorbance of indicated control wells.

\subsubsection{Cytokine Assays}

\subsubsection{General ELISA Protocol}

Enzyme linked immunosorbent assays (ELISA) were performed by coating 96-well Nunc 
MaxiSorp plates (Thermo Fisher Scientific, MA) with a primary capture antibody in ELISA capture buffer and incubated overnight at $4{ }^{\circ} \mathrm{C}$. Capture antibody solution was removed and plates were washed in wash buffer containing PBS with 0.01\% Tween-20 (Sigma-Aldrich, MO) 4 times. Plates were blocked with $10 \%$ fetal calf serum (FCS) in dPBS for 2 hours at room temperature, then washed 3 times with wash buffer. $50 \mu \mathrm{L} /$ well of cytokine standards and samples were then added to each well and incubated for 2 hours RT. The standard curve was prepared by serially diluting in the top two rows of the plate. Plates were then washed 4 times in wash buffer and $50 \mu \mathrm{L} /$ well of the matched biotinylated secondary antibody was added and incubated RT. After 1 hour plates were washed 6 times in wash buffer and $50 \mu \mathrm{L} /$ well of streptavidin-horseradish peroxidase (SA-HRP) was added and incubated for a further 1-hour room temperature protected from light. After incubation, plates are washed 8 times and tetramethyl benzidine (TMB) substrates A and B (BD Biosciences, $\mathrm{NJ}$ ) were brought to room temperature and mixed to equal volumes. $100 \mu \mathrm{L} /$ well of TMB reagent was added and the reaction was stopped with $100 \mu \mathrm{L} /$ well $0.18 \mathrm{M} \mathrm{H}_{2} \mathrm{SO}_{4}$. Details for specific ELISA's can be found in Appendix 6.2. 


\section{Appendix}

6.1 NMR Spectra 
${ }^{1} \mathrm{H}$ NMR spectrum of 1-Acetylpiperidine-4-carboxylic acid (10) $\left(500 \mathrm{MHz}, \mathrm{D}_{2} \mathrm{O}\right)$

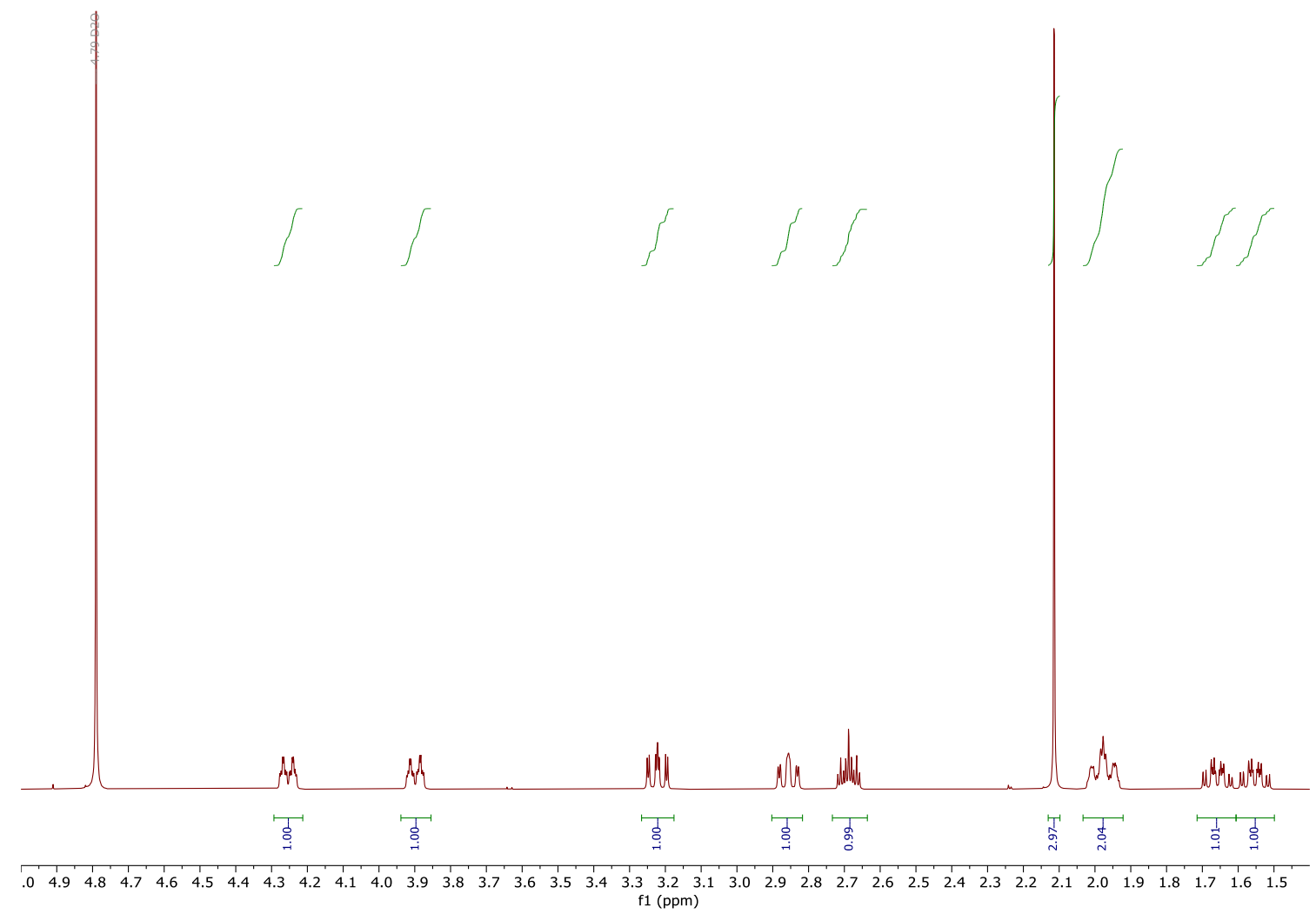

${ }^{13} \mathrm{C}$ NMR spectrum of 1-Acetylpiperidine-4-carboxylic acid (10) $\left(126 \mathrm{MHz}, \mathrm{D}_{2} \mathrm{O}\right)$
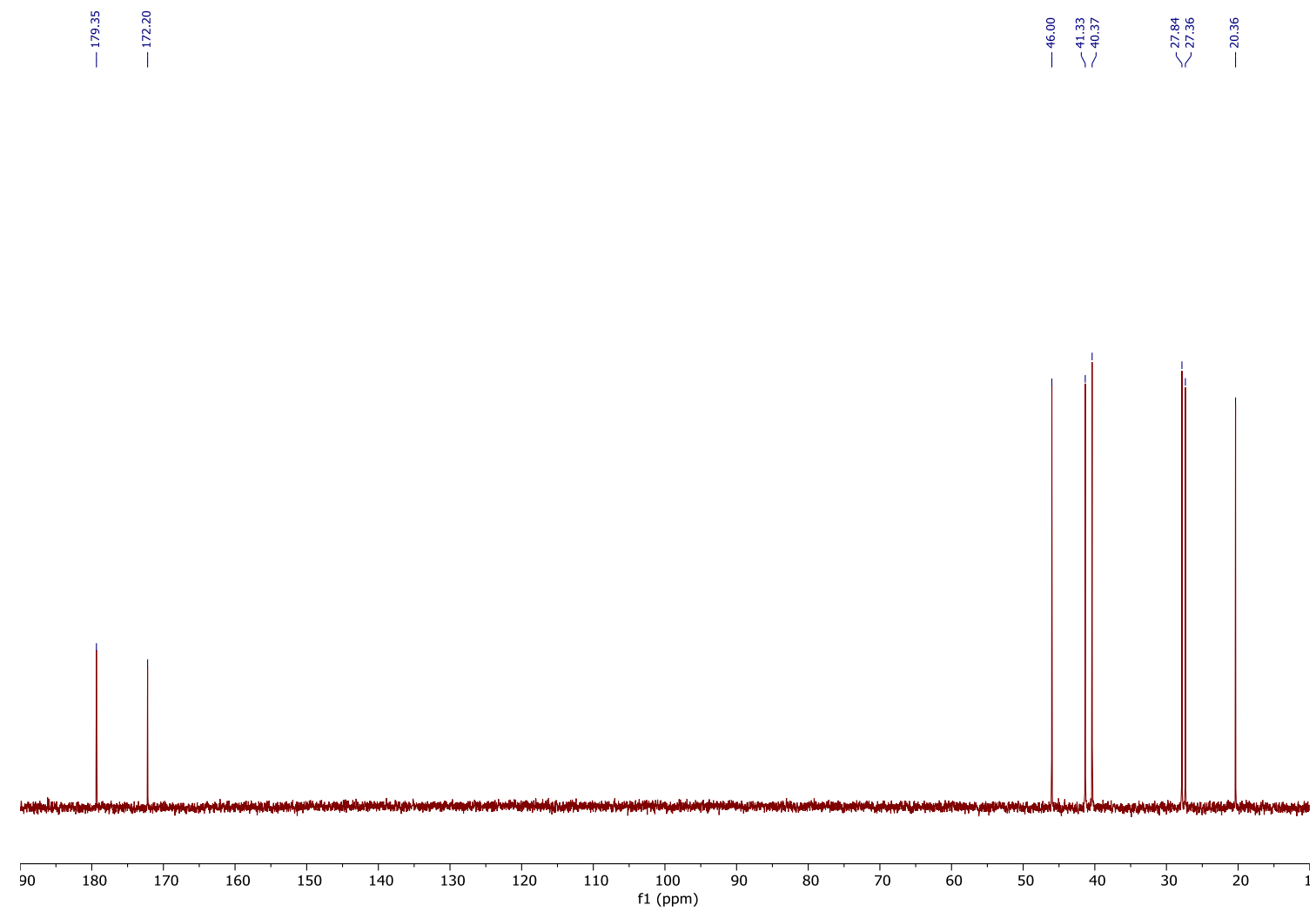
${ }^{1} \mathrm{H}$ NMR spectrum of 4-(2',4'-Difluorobenzoyl)piperidine hydrochloride (12) (500 MHz, $\mathrm{D}_{2} \mathrm{O}$ )

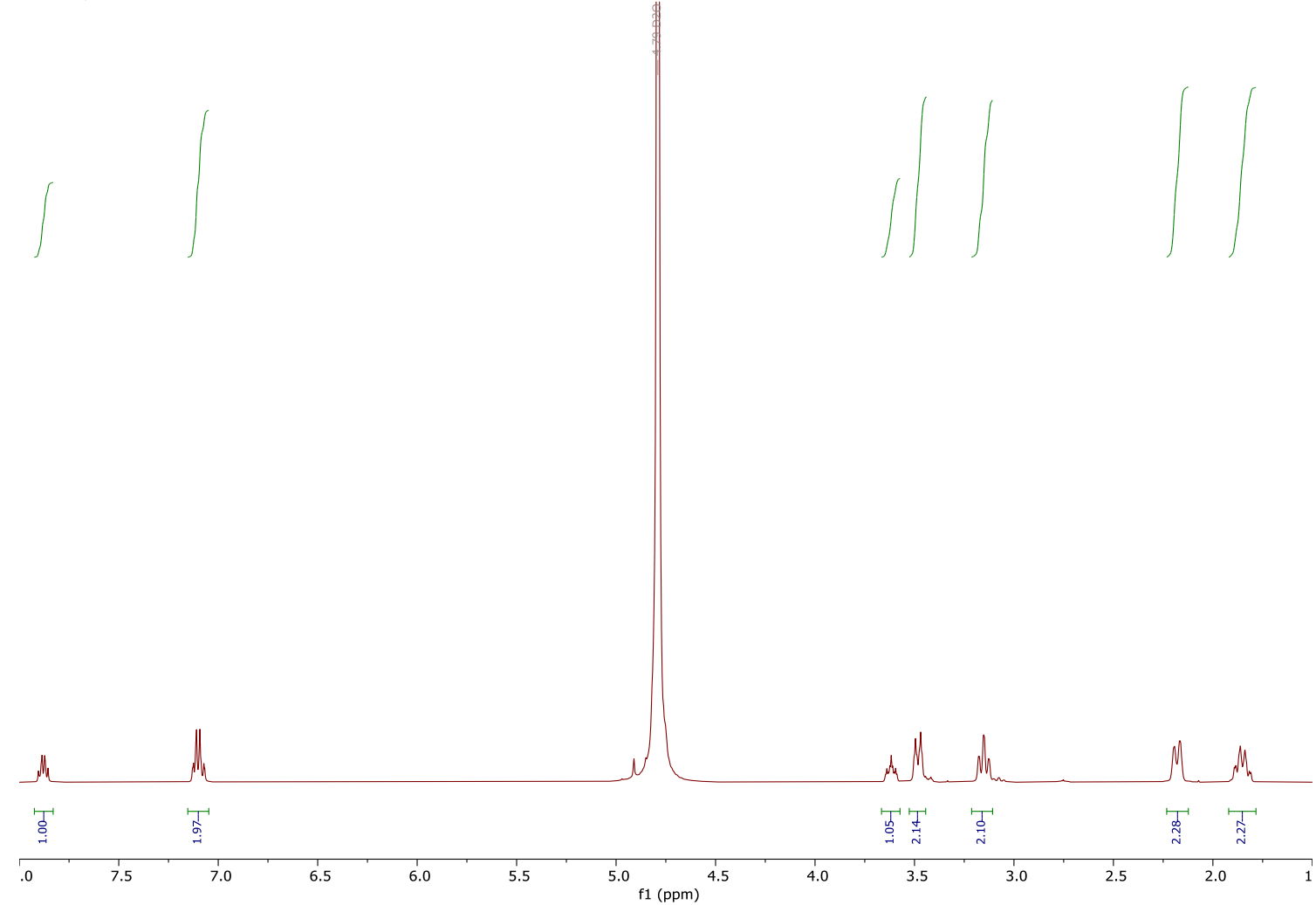

${ }^{13} \mathrm{C}$ NMR spectrum of 4-(2',4'-Difluorobenzoyl)piperidine hydrochloride (12) $(126 \mathrm{MHz}$, $\mathrm{D}_{2} \mathrm{O}$ )

至

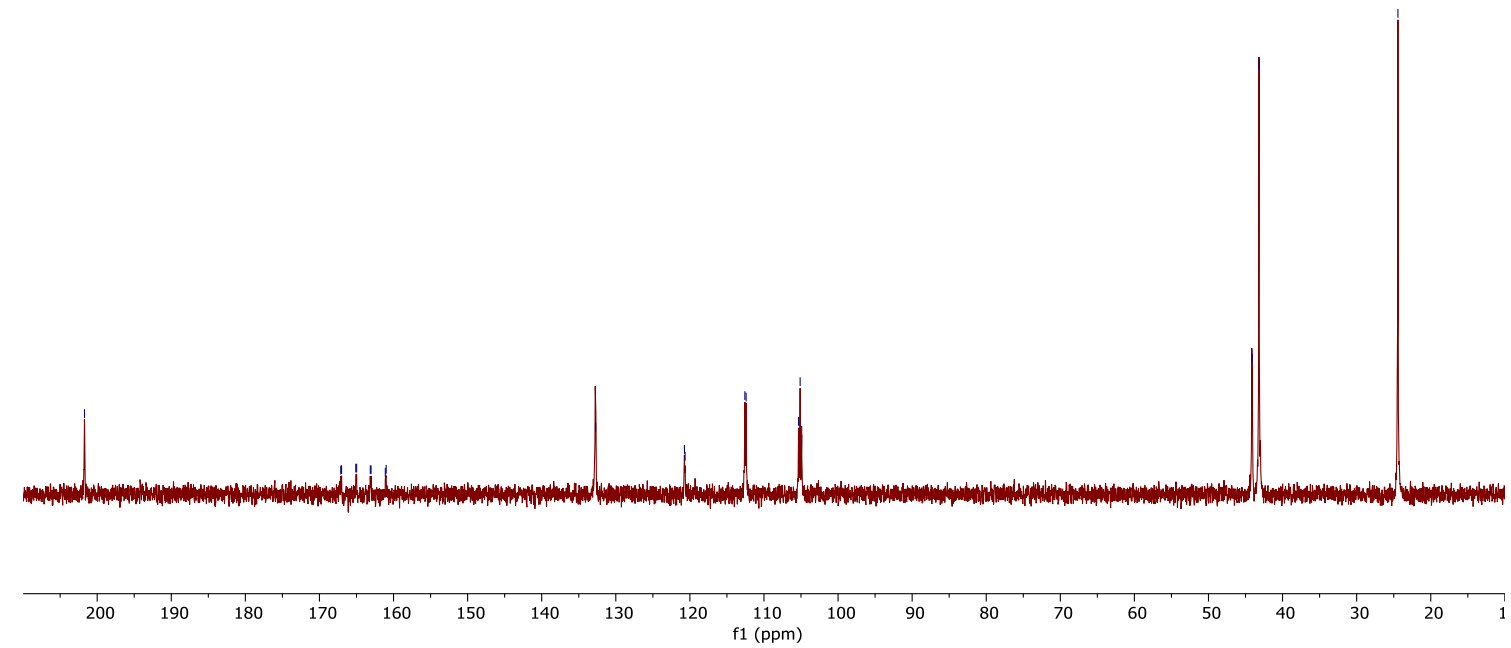


${ }^{1} \mathrm{H}$ NMR spectrum of (Z)-2,4-Difluorophenyl-(4-piperidinyl)methanone oxime (4) $\left(\mathrm{D}_{2} \mathrm{O}, 500\right.$ $\mathrm{MHz})$

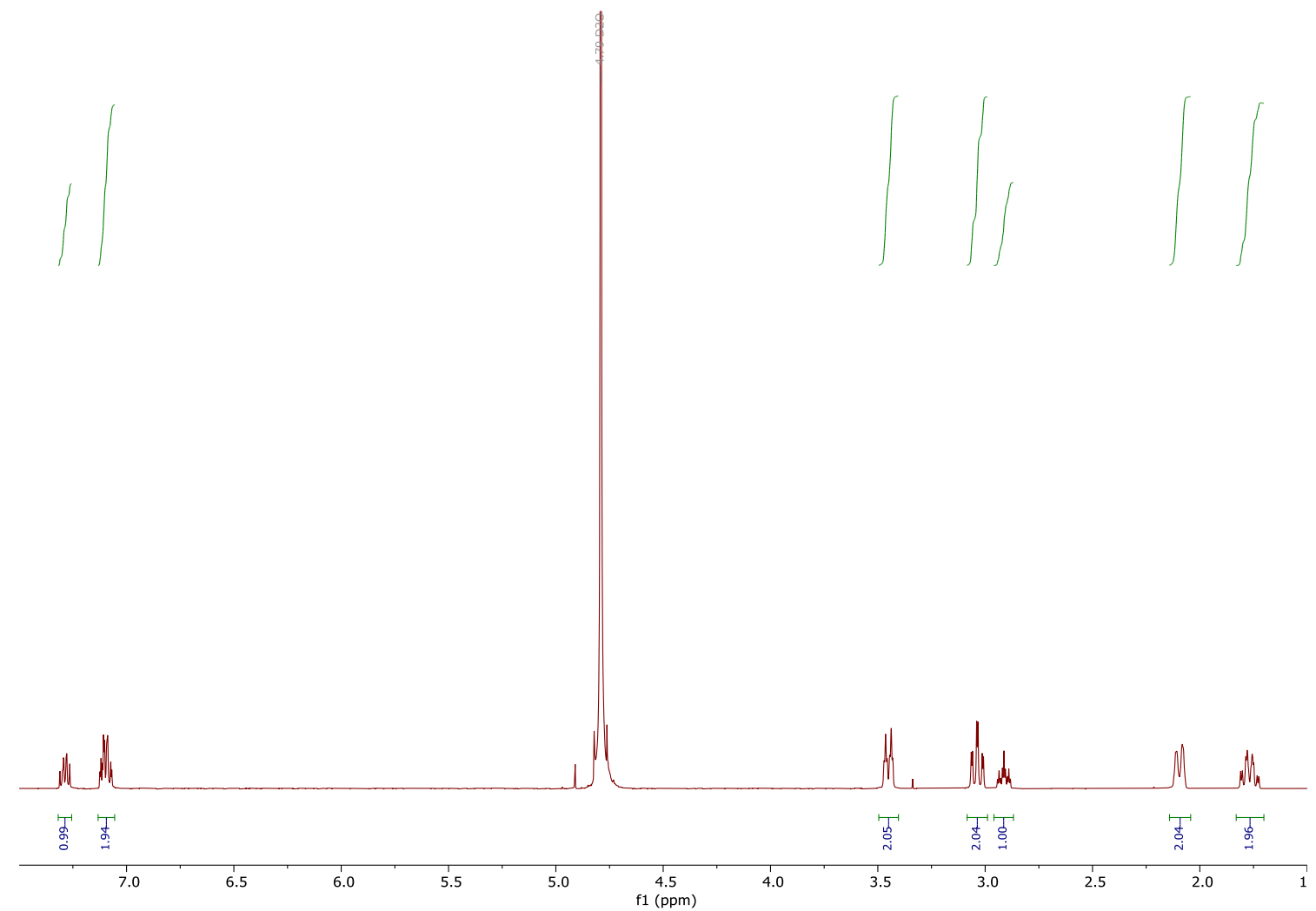

${ }^{13} \mathrm{C}$ NMR spectrum of (Z)-2,4-Difluorophenyl-(4-piperidinyl)methanone oxime (4) $\left(\mathrm{D}_{2} \mathrm{O}, 126\right.$ $\mathrm{MHz}$ )

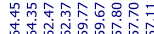

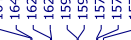

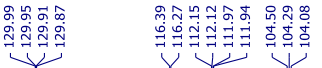

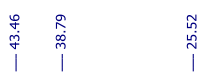

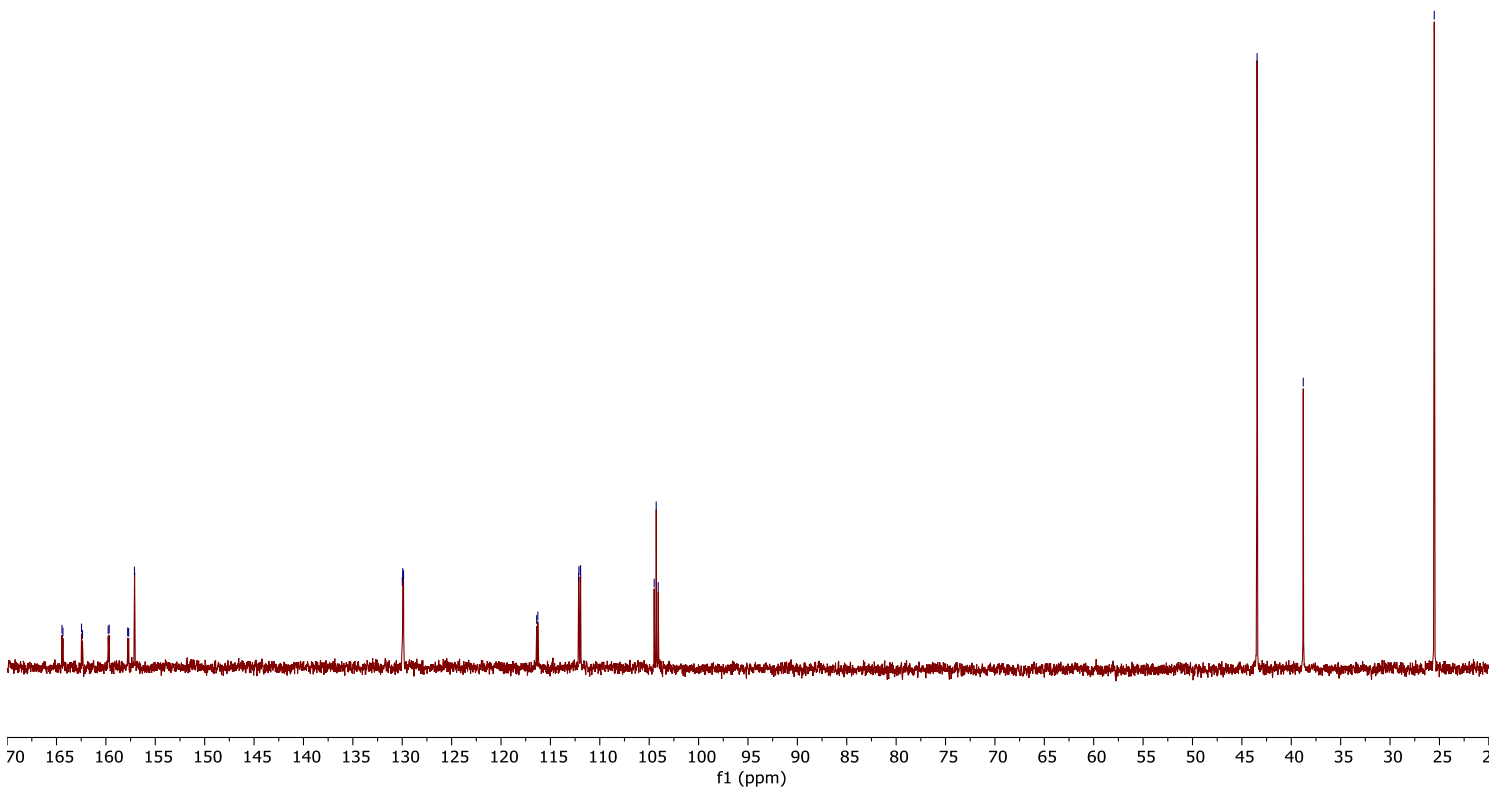


${ }^{1} \mathrm{H}$ NMR spectrum of 6-Fluoro-3-(piperidin-4-yl)benzo[d]isoxazole (3) $\left(\mathrm{CDCl}_{3}, 500 \mathrm{MHz}\right)$

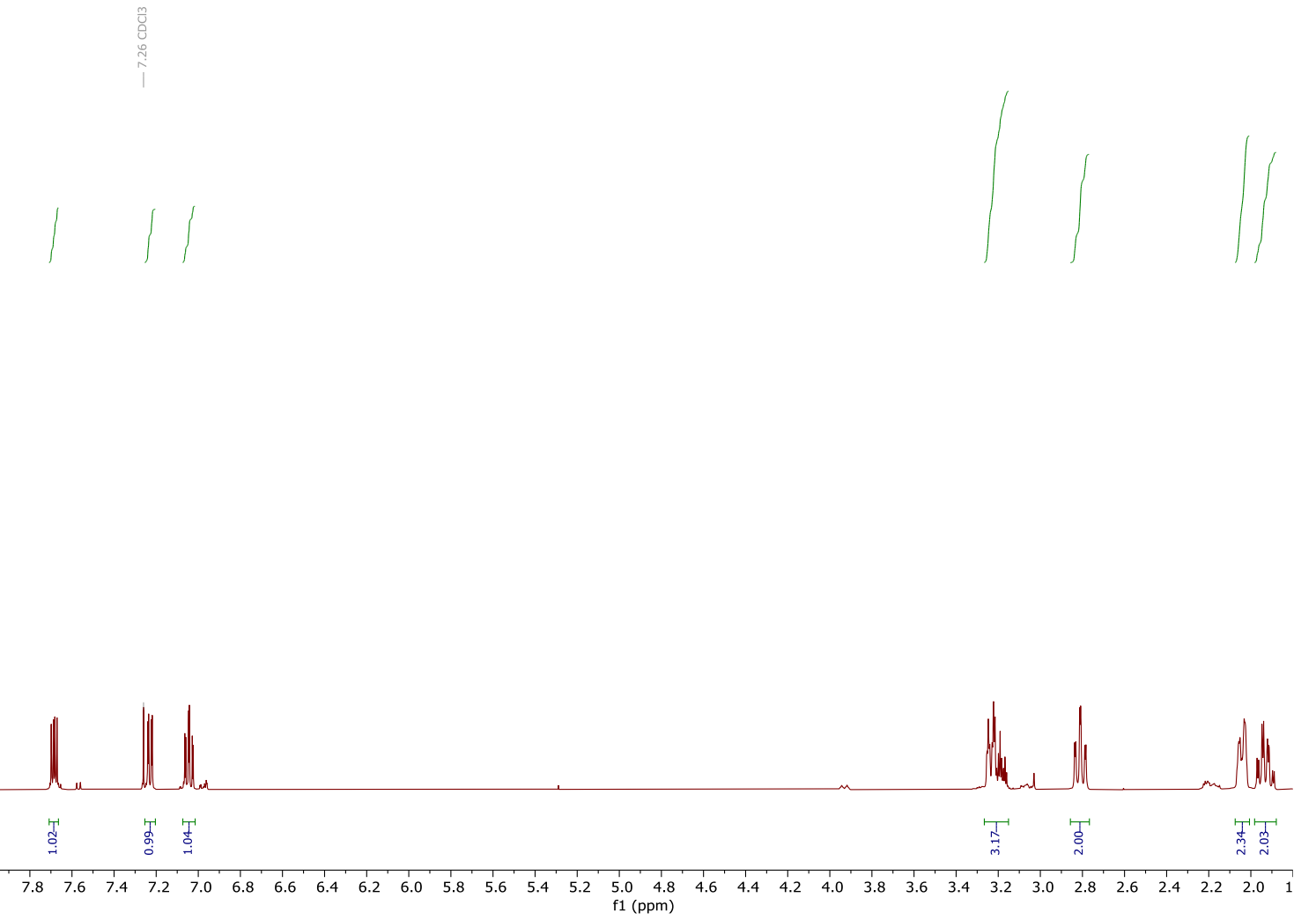

${ }^{13} \mathrm{C}$ NMR spectrum of 6-Fluoro-3-(piperidin-4-yl)benzo[d]isoxazole (3) $\left(\mathrm{CDCl}_{3}, 126 \mathrm{MHz}\right)$
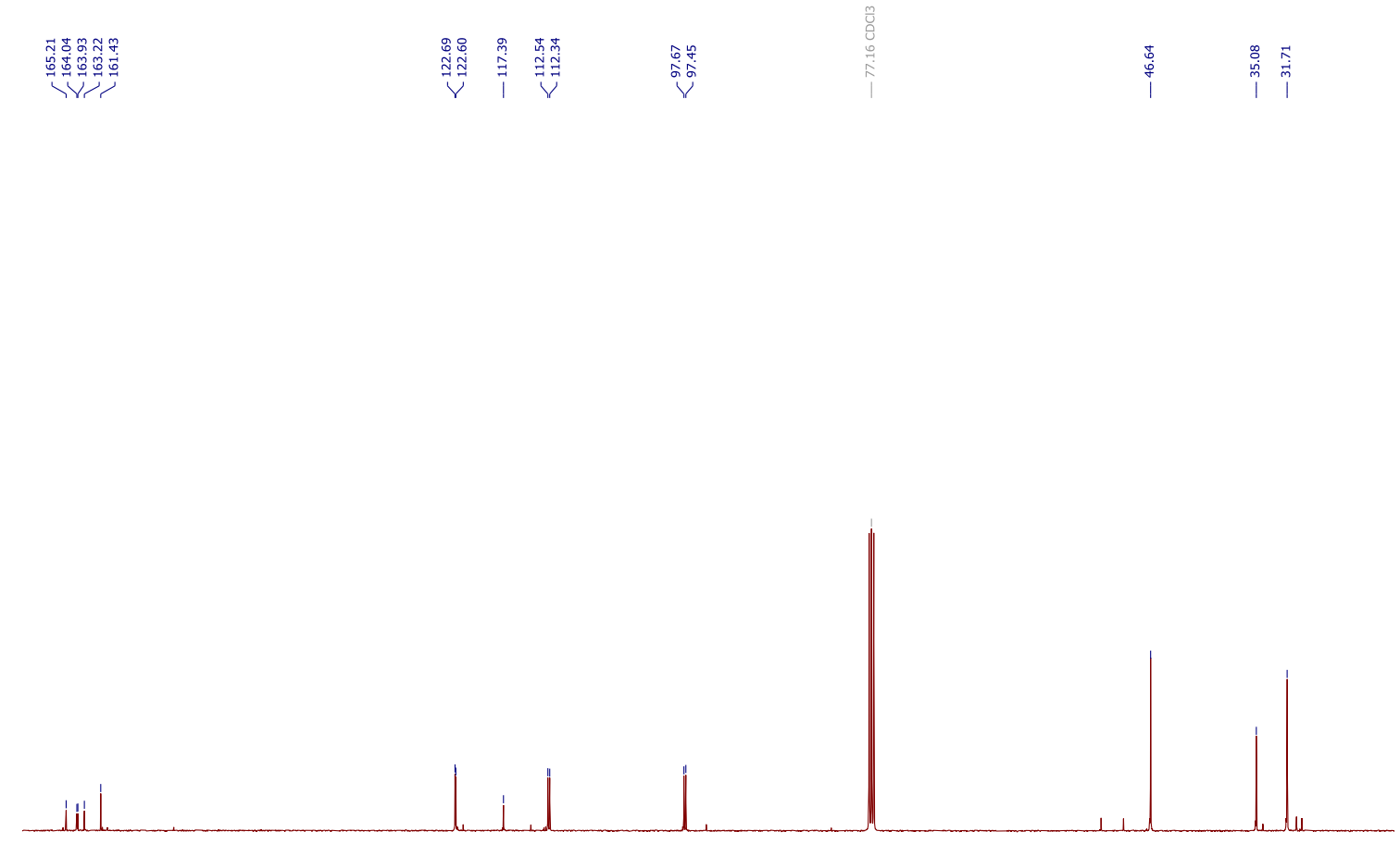

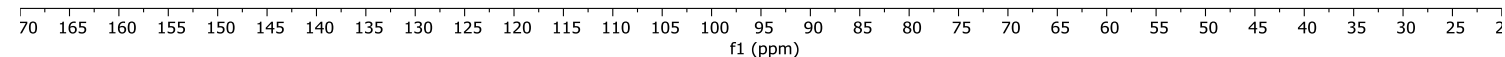


COSY NMR spectrum of 6-Fluoro-3-(piperidin-4-yl)benzo[d]isoxazole (3) $\left(\mathrm{CDCl}_{3}, 500\right.$ $\mathrm{MHz})$

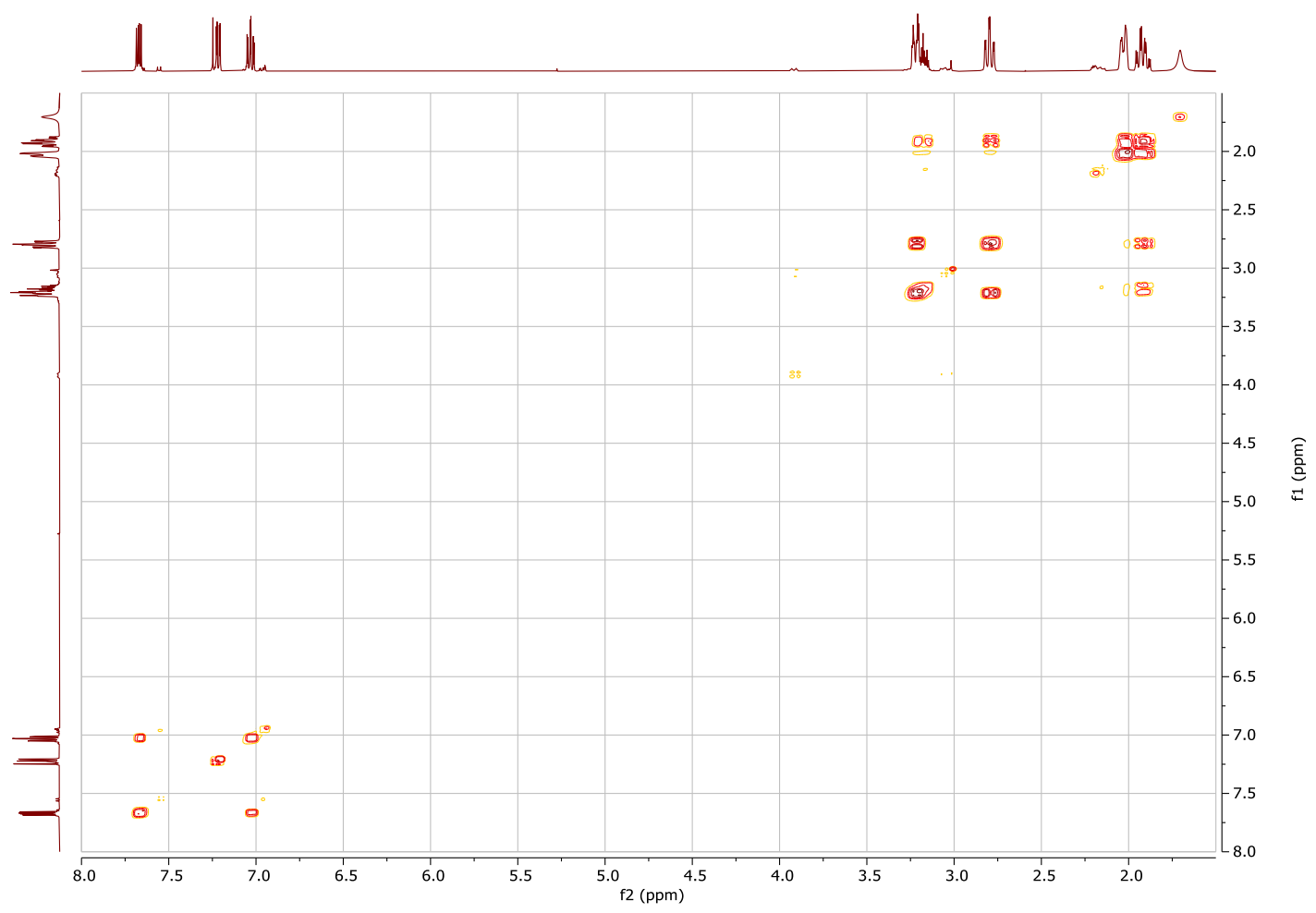


${ }^{1} \mathrm{H}$ NMR spectrum of 3-(Benzyloxy)propan-1-ol (13) $\left(\mathrm{CDCl}_{3}, 500 \mathrm{MHz}\right)$

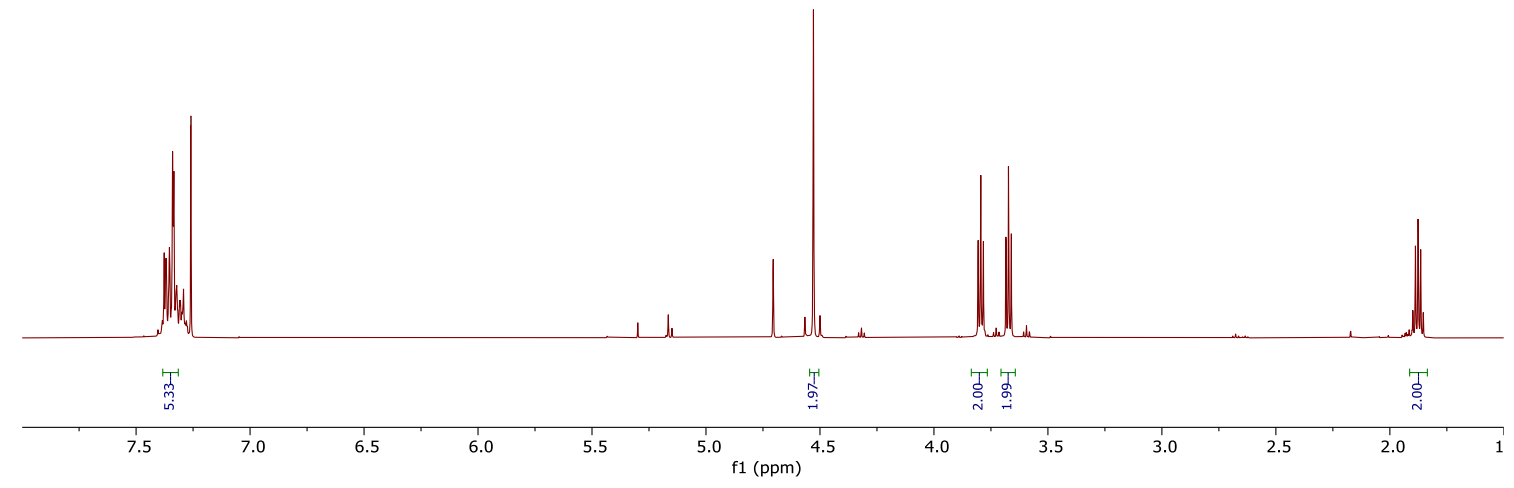

${ }^{13} \mathrm{C}$ NMR spectrum of 3-(Benzyloxy)propan-1-ol (13) $\left(\mathrm{CDCl}_{3}, 126 \mathrm{MHz}\right)$
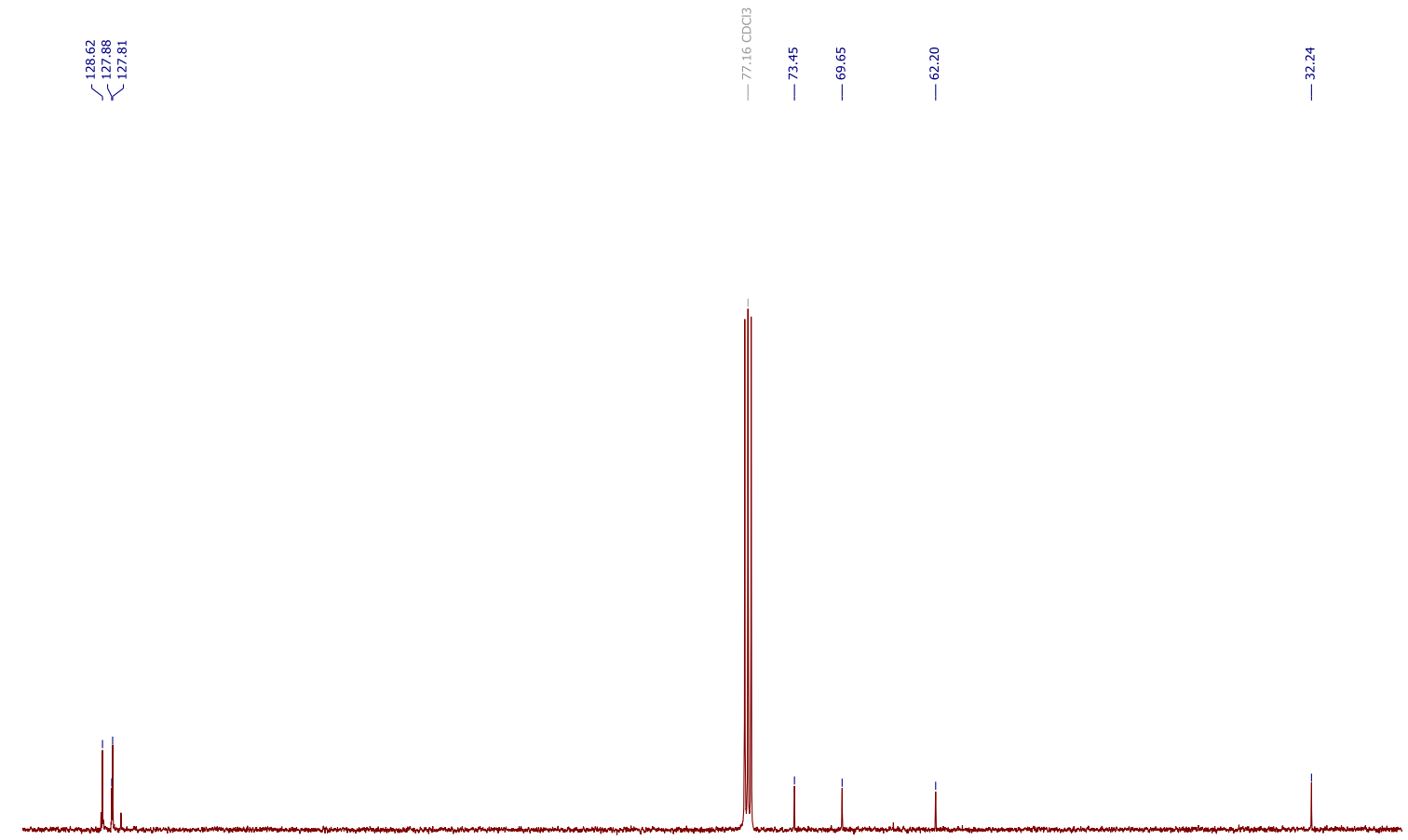

$\begin{array}{llllllllllllllllllllllllll}35 & 130 & 125 & 120 & 115 & 110 & 105 & 100 & 95 & 90 & 85 & 80 & 75 & 70 & 65 & 60 & 55 & 50 & 45 & 40 & 35 & 30 & 2\end{array}$ 
${ }^{1} \mathrm{H}$ NMR spectrum of 3-Benzyloxy-1-iodopropane (15) $\left(\mathrm{CDCl}_{3}, 500 \mathrm{MHz}\right)$

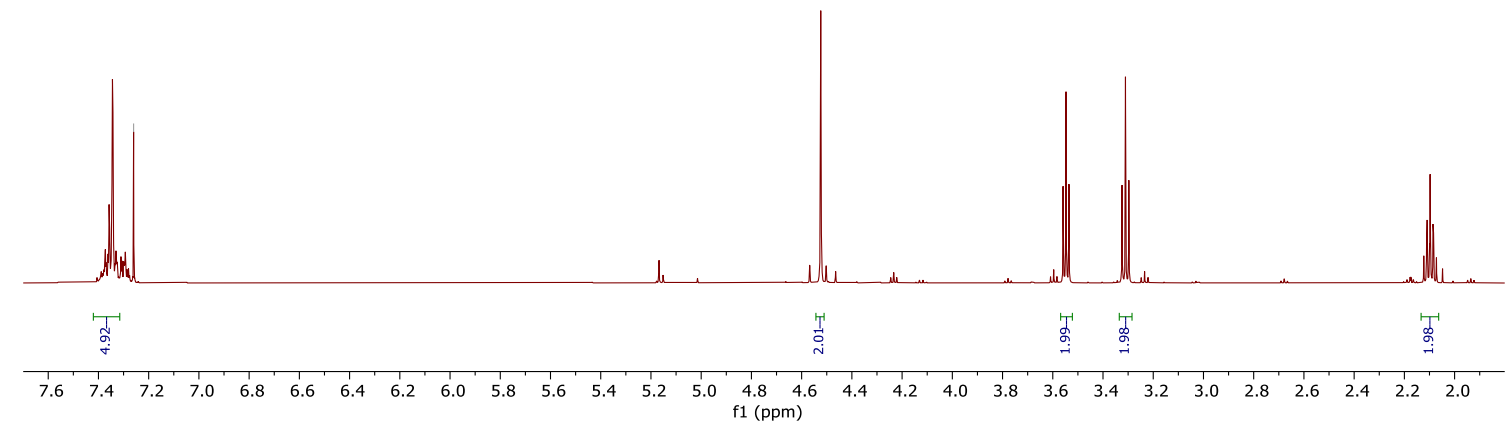

${ }^{13} \mathrm{C}$ NMR spectrum of 3-Benzyloxy-1-iodopropane (15) $\left(\mathrm{CDCl}_{3}, 126 \mathrm{MHz}\right)$

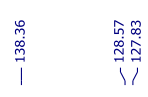

13

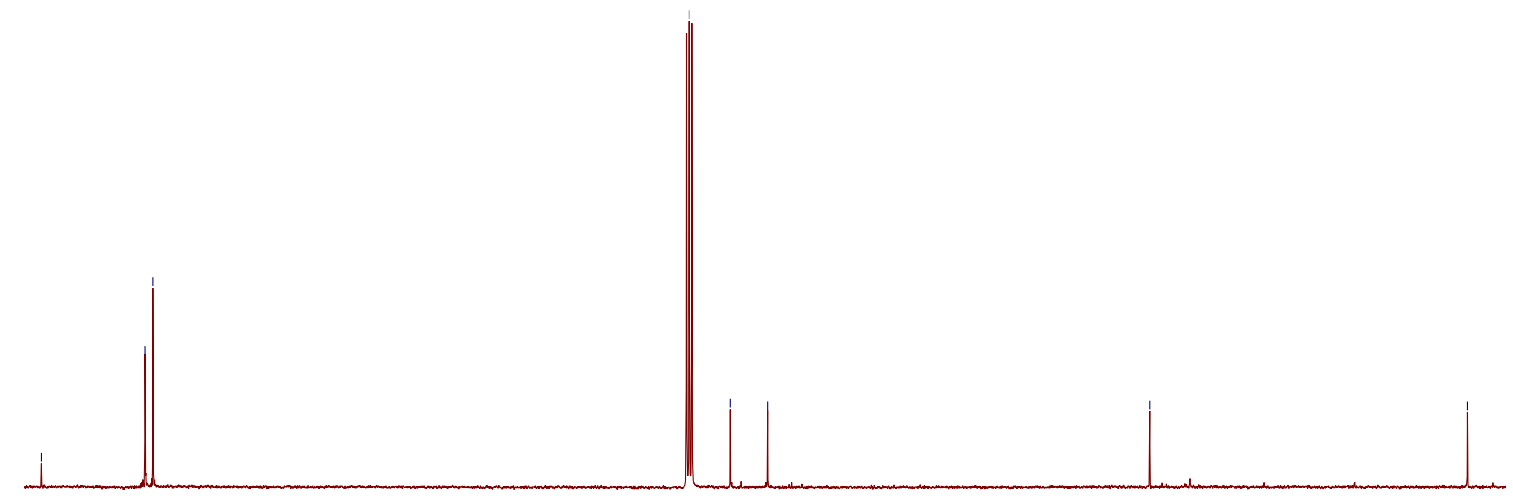

\begin{tabular}{lllllllllllllllllllllllllllllllllll}
\hline 40 & 135 & 130 & 125 & 120 & 115 & 110 & 105 & 100 & 95 & 90 & 85 & 80 & 75 & 70 & 65 & 60 & 55 & 50 & 45 & 40 & 35 & 30 & 25 & 20 & 15 & 10 & 5 & 1
\end{tabular} 
${ }^{1} \mathrm{H}$ NMR spectrum of Ethyl 2-acetyl-5-(benzyloxy)pentanoate (17) $\left(\mathrm{CDCl}_{3}, 500 \mathrm{MHz}\right)$
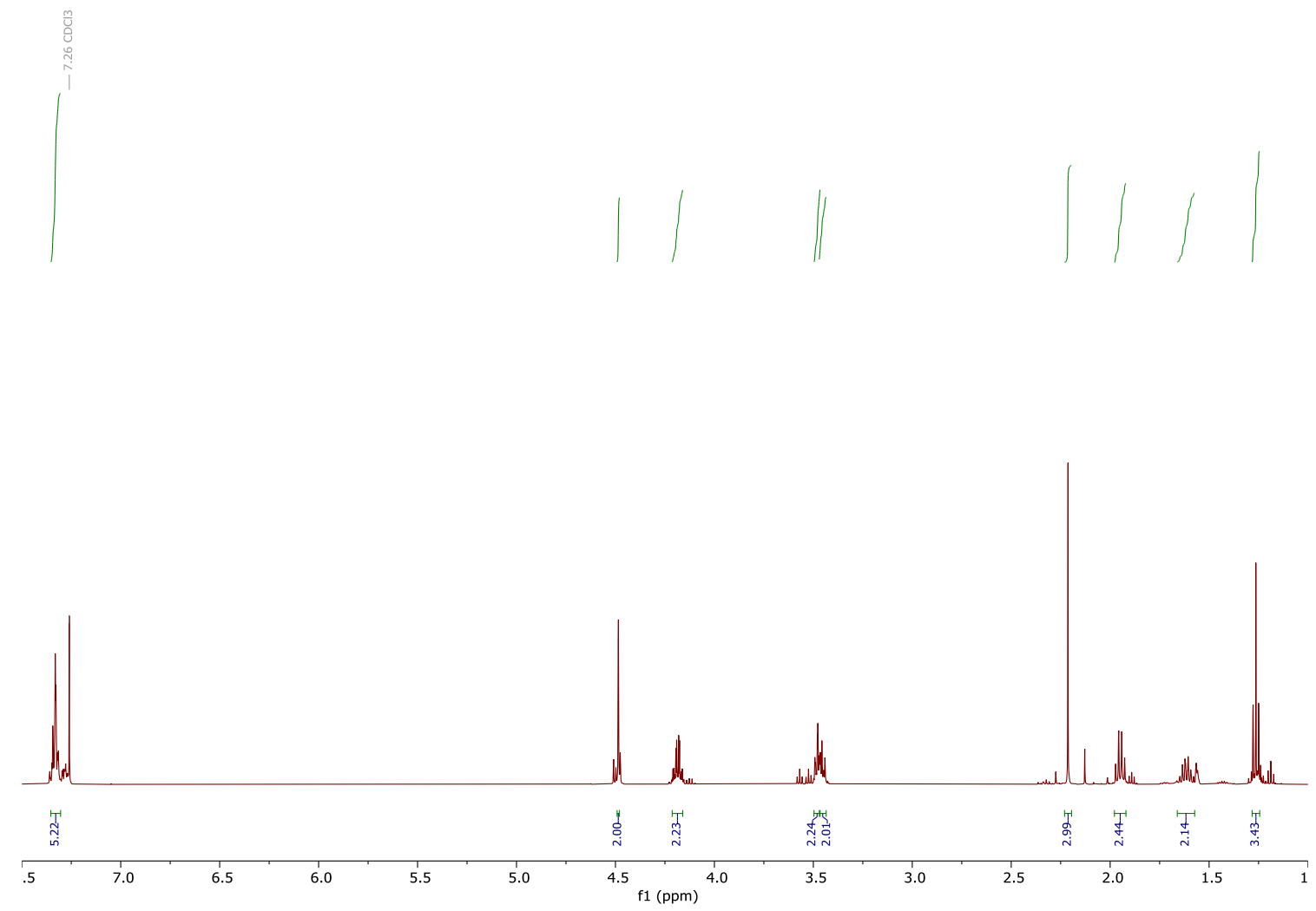

${ }^{13} \mathrm{C}$ NMR spectrum of Ethyl 2-acetyl-5-(benzyloxy)pentanoate (17) $\left(\mathrm{CDCl}_{3}, 126 \mathrm{MHz}\right)$
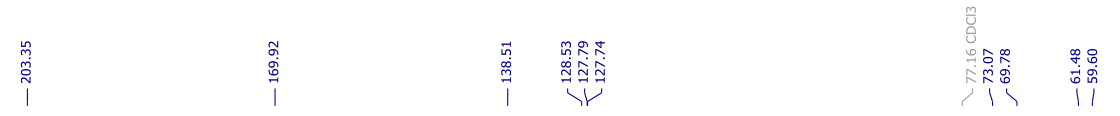

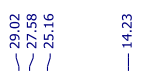

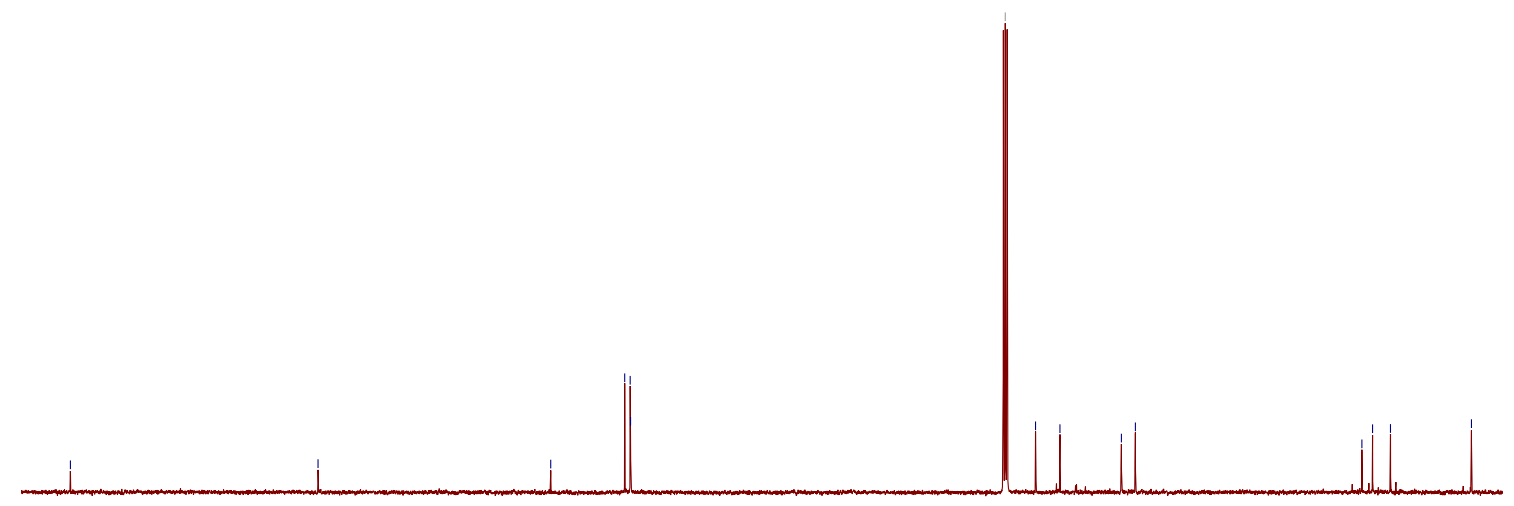

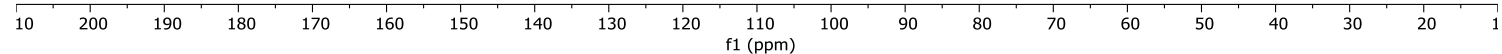


${ }^{1} \mathrm{H}$ NMR spectrum of 3-(3-(Benzyloxy)propyl)-2-methyl-4H-pyrido[1,2-a]pyrimidin-4-one (19) $\left(\mathrm{CDCl}_{3}, 500 \mathrm{MHz}\right)$

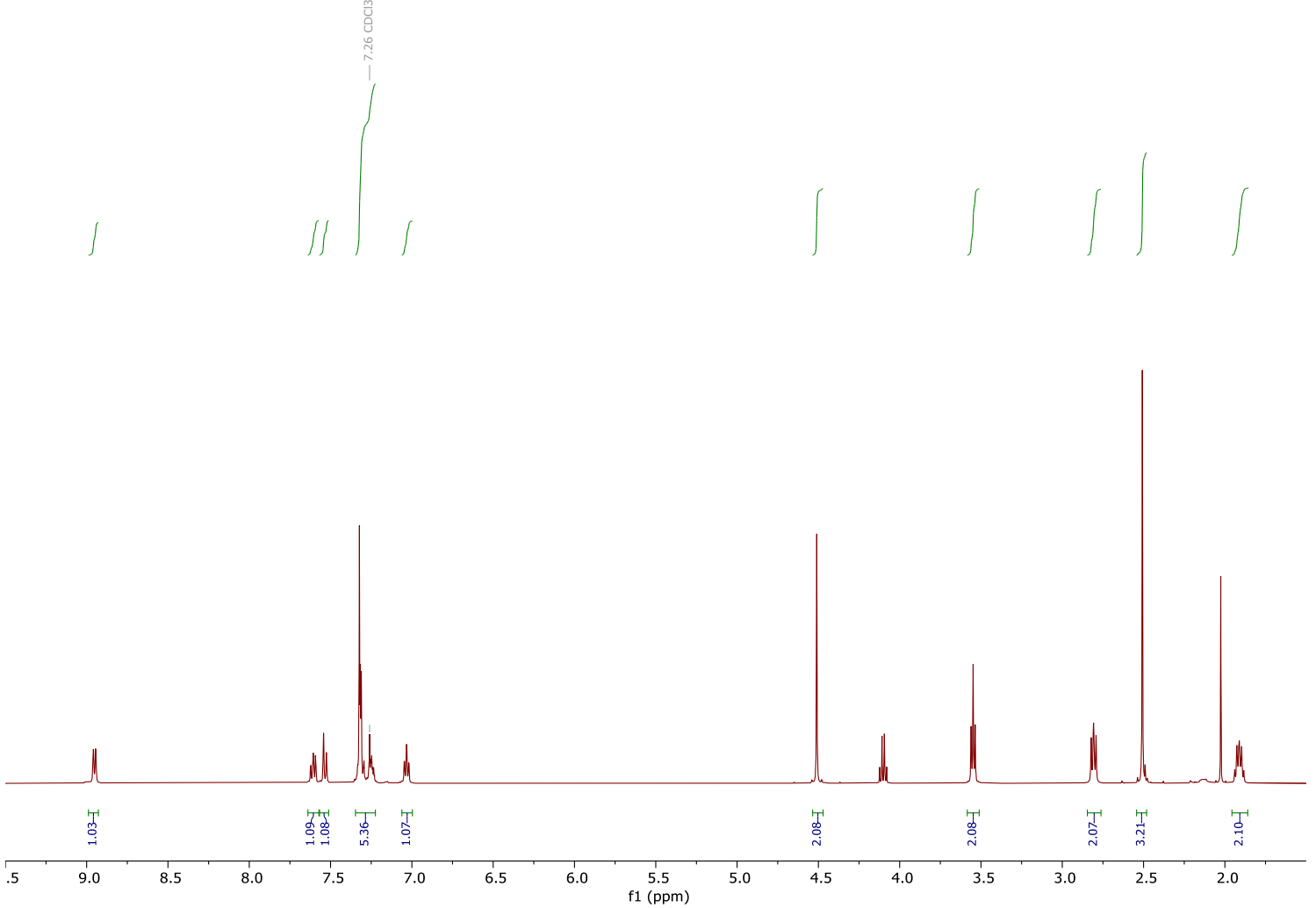

${ }^{13} \mathrm{C}$ NMR spectrum of 3-(3-(Benzyloxy)propyl)-2-methyl-4H-pyrido[1,2-a]pyrimidin-4-one (19) $\left(\mathrm{CDCl}_{3}, 126 \mathrm{MHz}\right)$

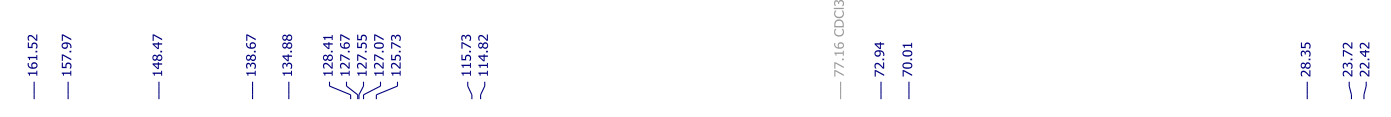

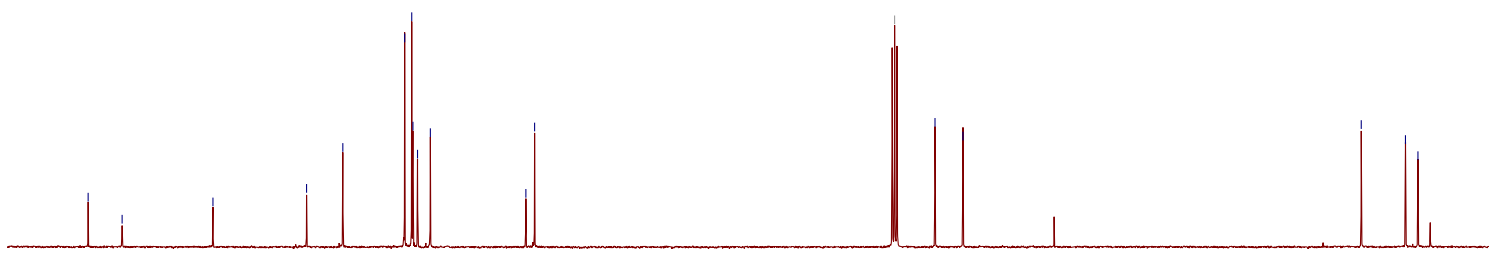

$\begin{array}{lllllllllllllllllllllllllllllllllllllllllll}165 & 160 & 155 & 150 & 145 & 140 & 135 & 130 & 125 & 120 & 115 & 110 & 105 & 100 & 95 & 90 & 85 & 80 & 75 & 70 & 65 & 60 & 55 & 50 & 45 & 40 & 35 & 30 & 25 & 20 & 1\end{array}$ 
COSY NMR spectrum of 3-(3-(Benzyloxy)propyl)-2-methyl-4H-pyrido[1,2-a]pyrimidin-4one (19) $\left(\mathrm{CDCl}_{3}, 500 \mathrm{MHz}\right)$

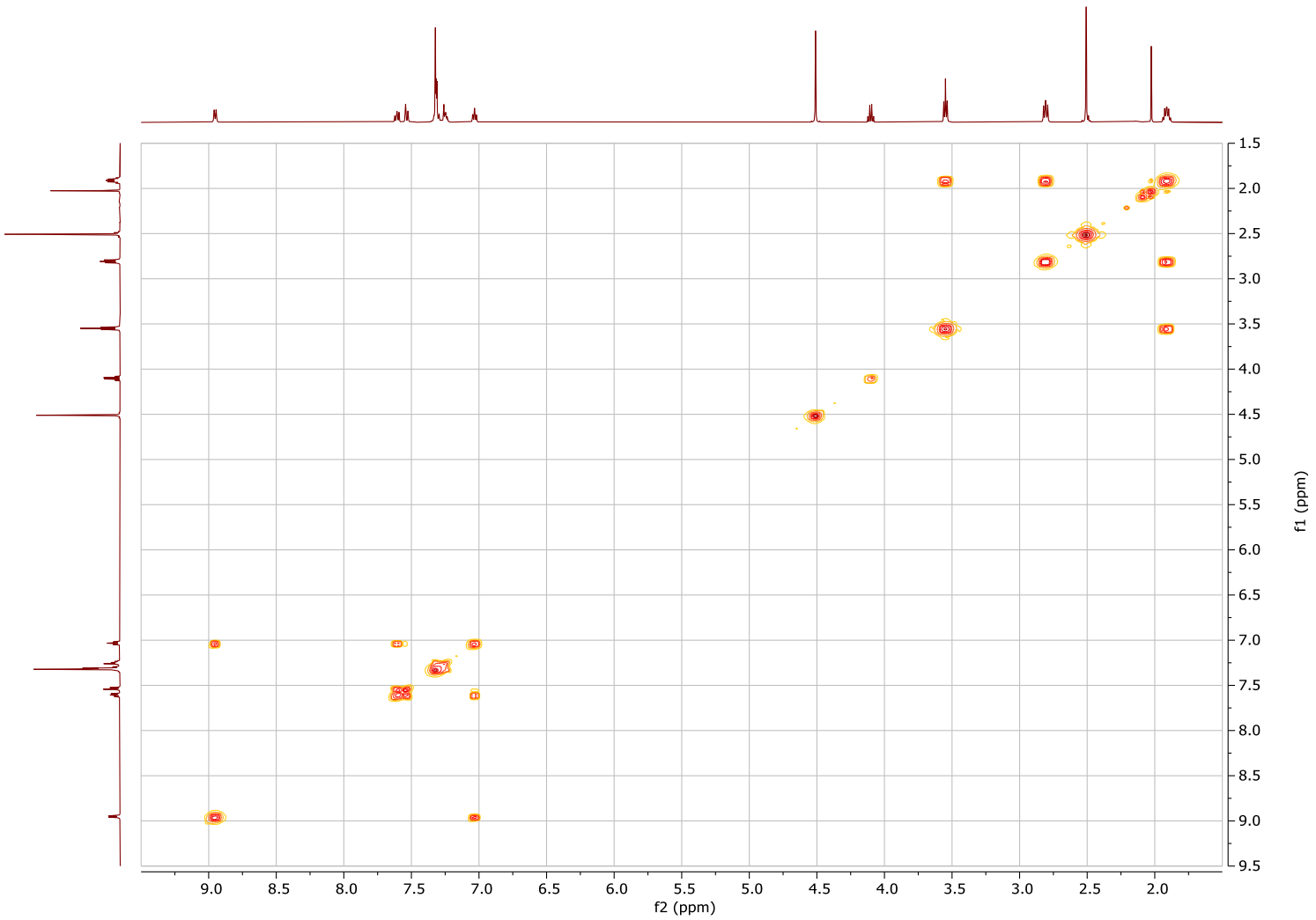

HSQC NMR spectrum of 3-(3-(Benzyloxy)propyl)-2-methyl-4H-pyrido[1,2-a]pyrimidin-4one (19) $\left(\mathrm{CDCl}_{3}, 500 \mathrm{MHz}\right)$

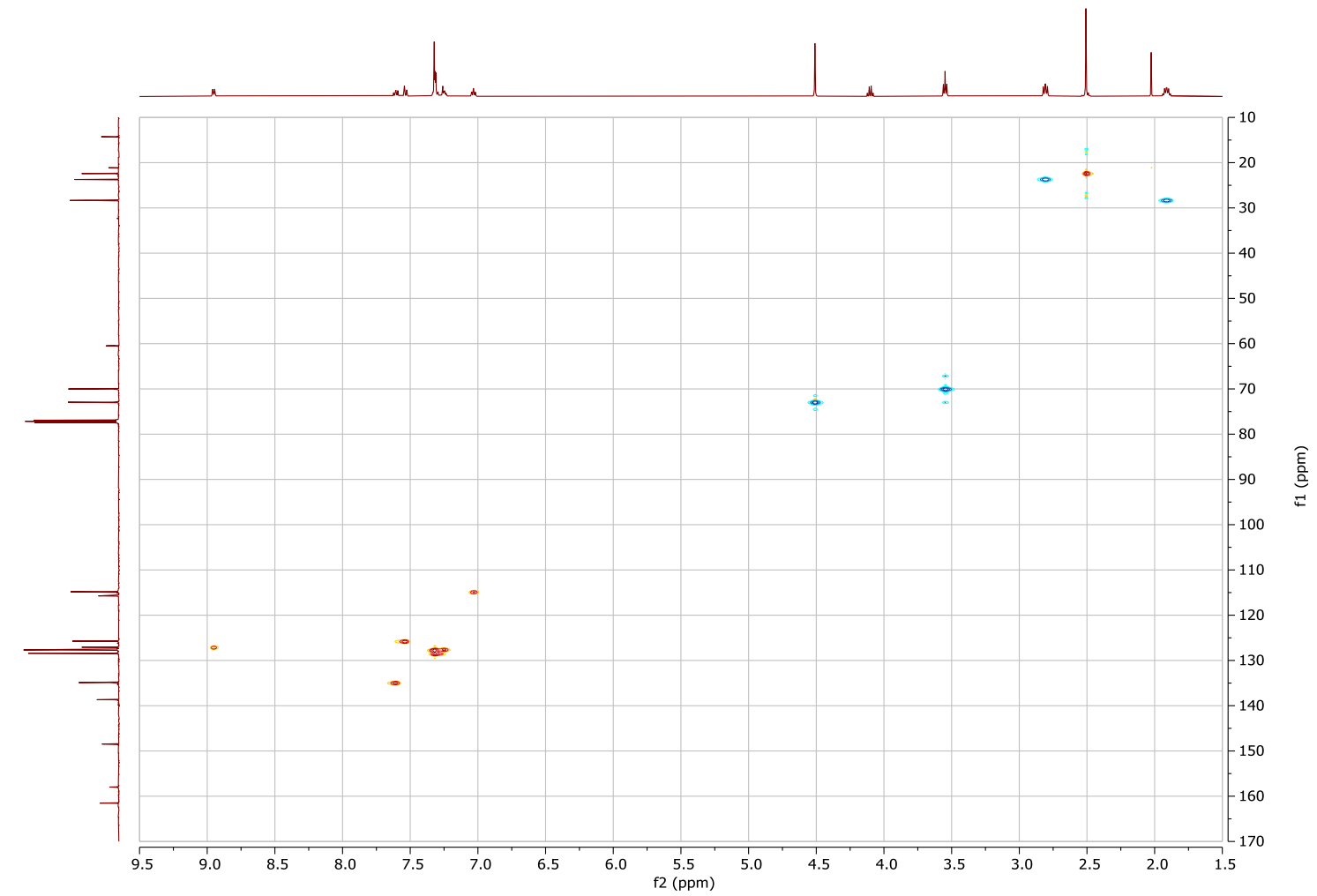


HMBC NMR spectrum of 3-(3-(Benzyloxy)propyl)-2-methyl-4H-pyrido[1,2-a]pyrimidin-4one (19) $\left(\mathrm{CDCl}_{3}, 500 \mathrm{MHz}\right)$

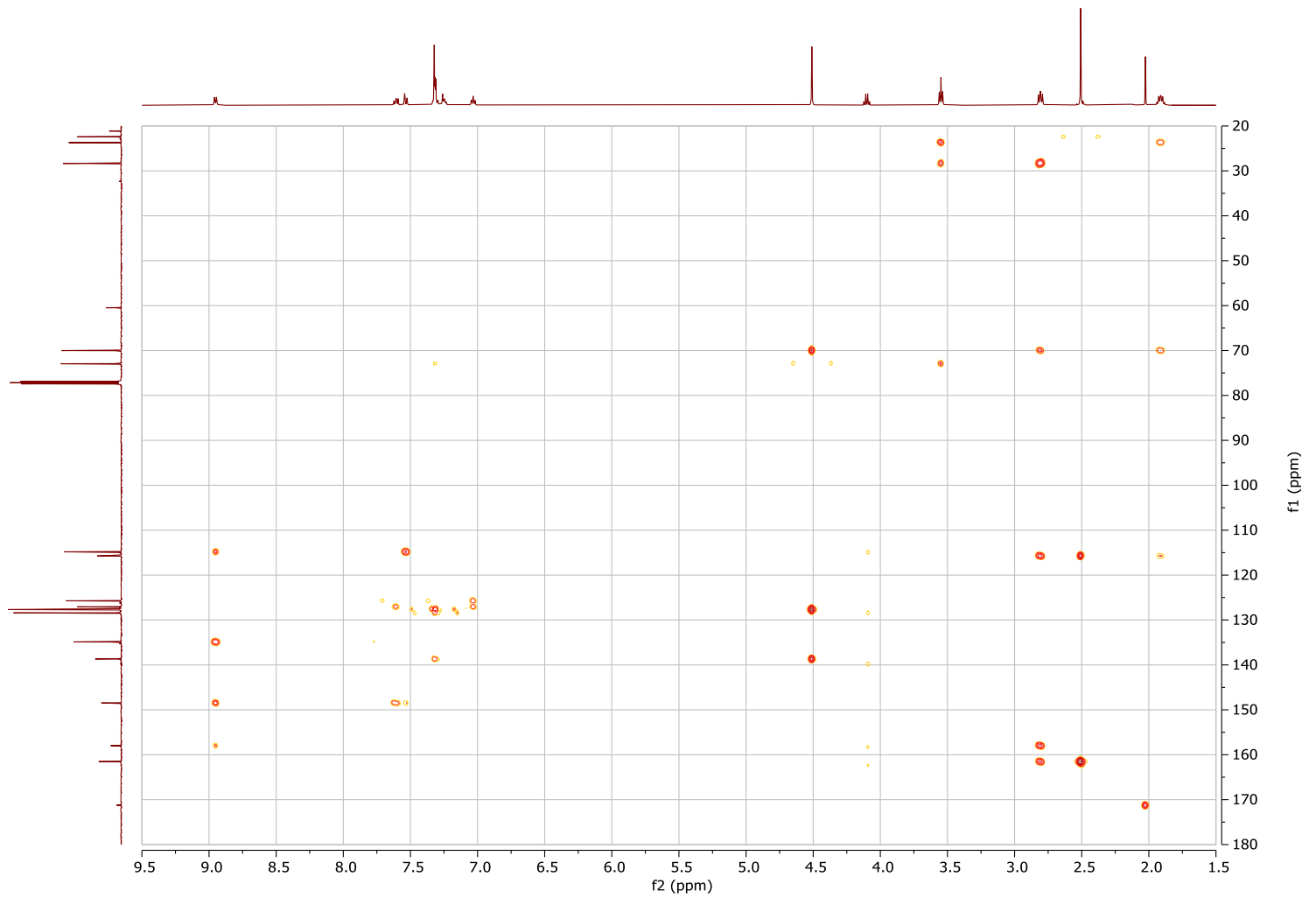


${ }^{1} \mathrm{H}$ NMR spectrum of 3-(3-(Benzyloxy)propyl)-2-methyl-6,7,8,9-tetrahydro-4H-pyrido[1,2$\alpha$ ]pyrimidin-4-one $(\mathbf{2 1})\left(\mathrm{CDCl}_{3}, 500 \mathrm{MHz}\right)$

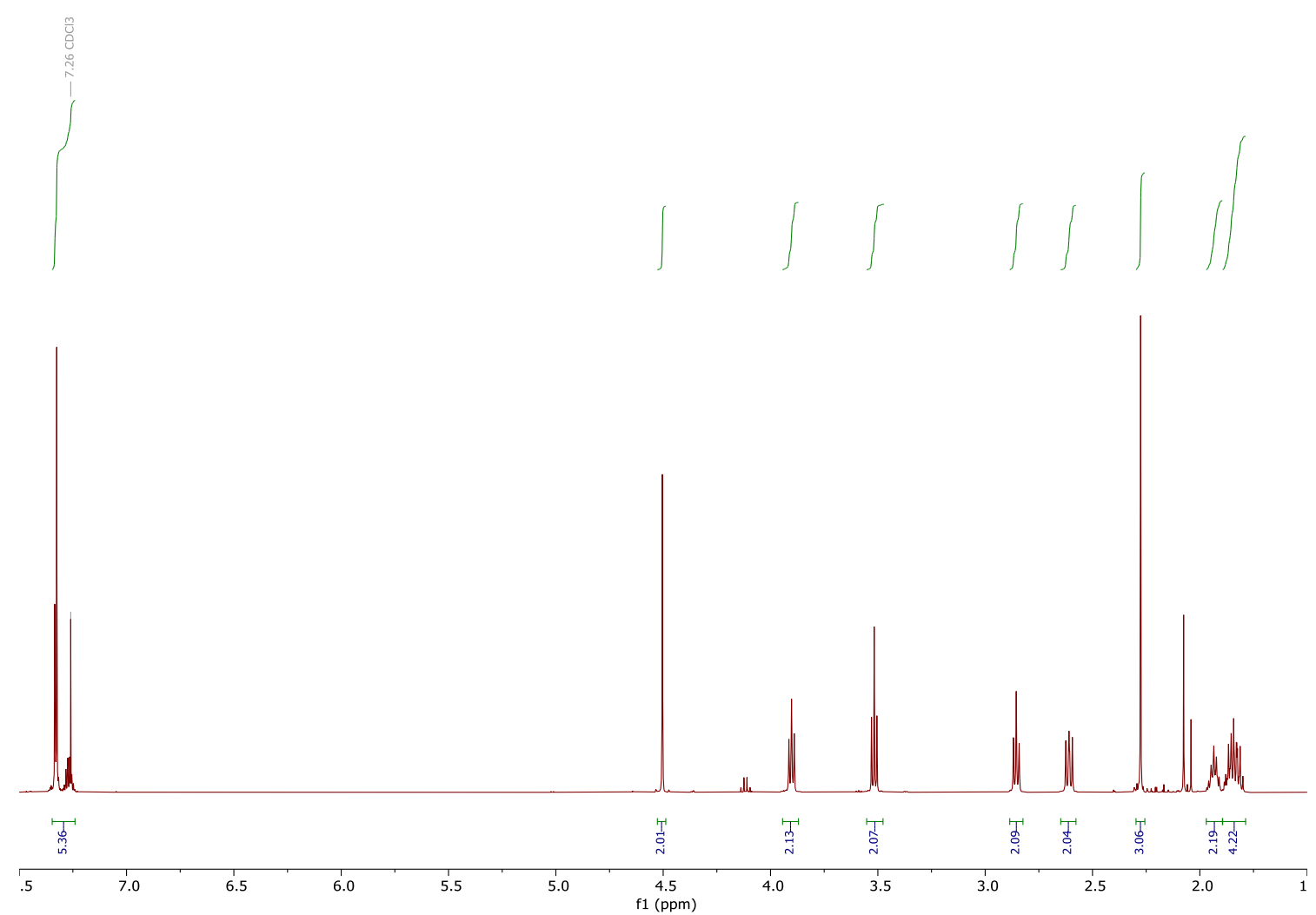

${ }^{13} \mathrm{C}$ NMR spectrum of 3-(3-(Benzyloxy)propyl)-2-methyl-6,7,8,9-tetrahydro-4H-pyrido[1,2$\alpha$ ]pyrimidin-4-one (21) $\left(\mathrm{CDCl}_{3}, 126 \mathrm{MHz}\right)$
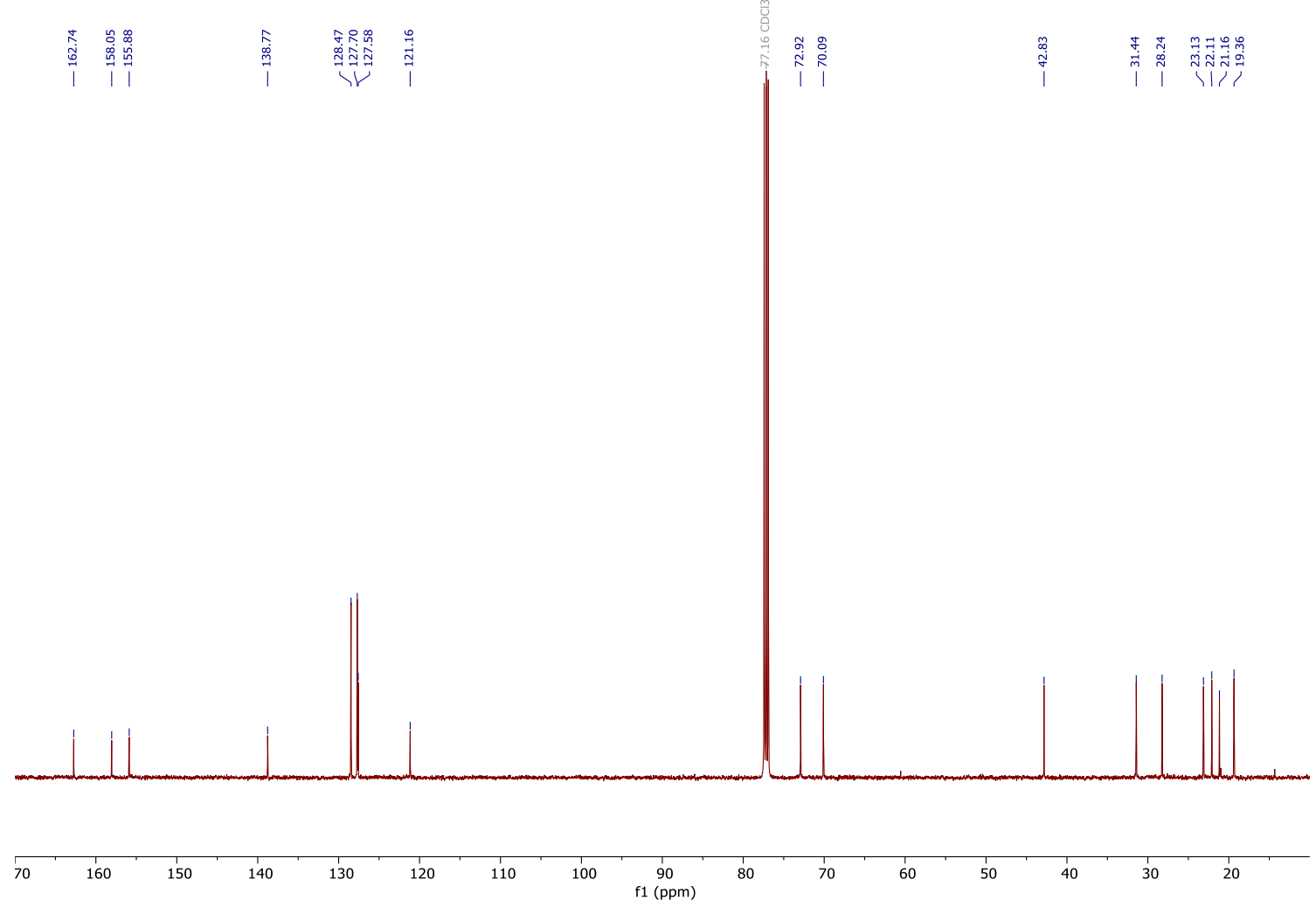
COSY NMR spectrum of 3-(3-(Benzyloxy)propyl)-2-methyl-6,7,8,9-tetrahydro-4Hpyrido[1,2- $\alpha$ ]pyrimidin-4-one (21) $\left(\mathrm{CDCl}_{3}, 500 \mathrm{MHz}\right)$

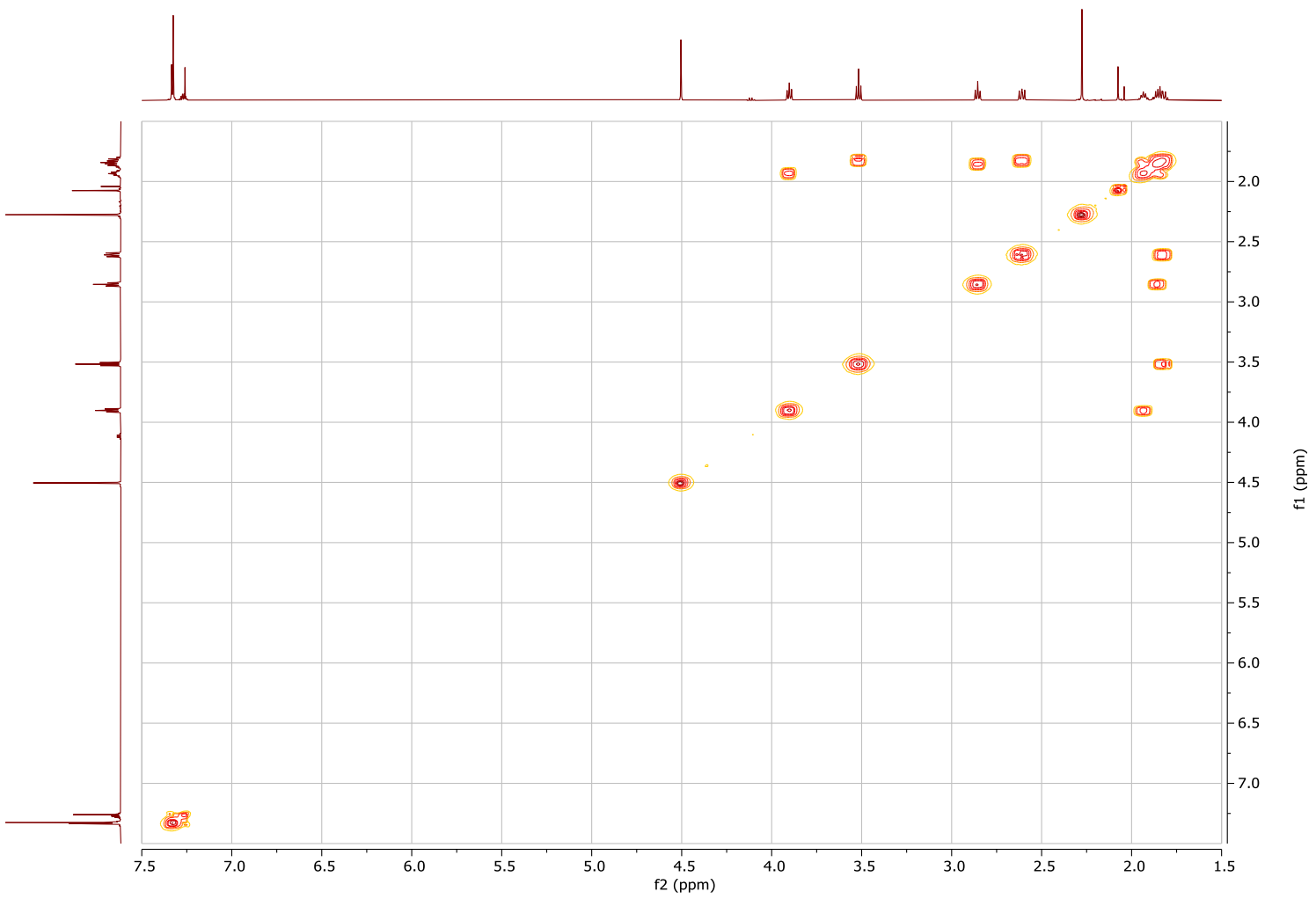

HSQC NMR spectrum of 3-(3-(Benzyloxy)propyl)-2-methyl-6,7,8,9-tetrahydro-4Hpyrido[1,2- $\alpha$ ]pyrimidin-4-one $(\mathbf{2 1})\left(\mathrm{CDCl}_{3}, 500 \mathrm{MHz}\right)$

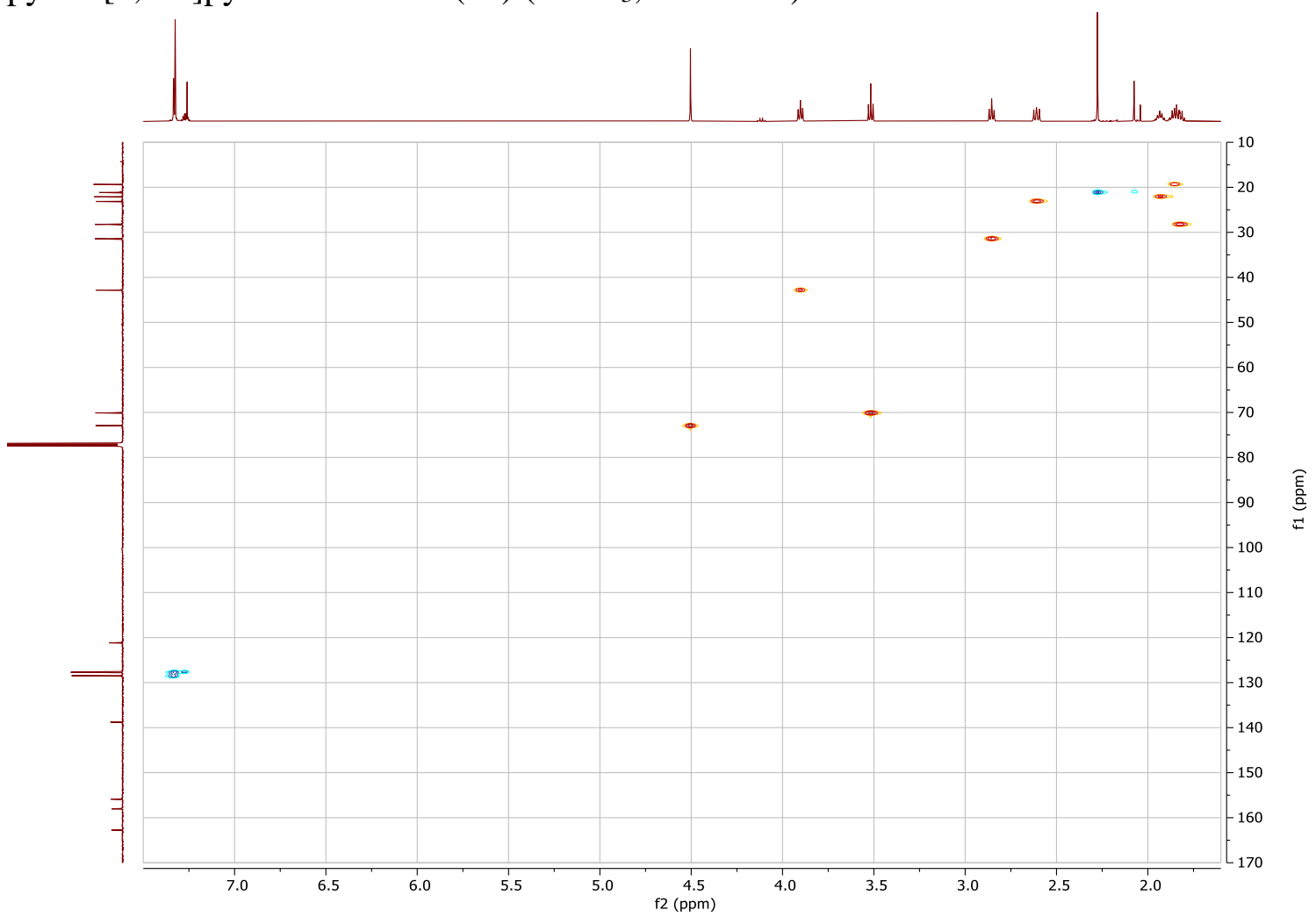


HMBC NMR spectrum of 3-(3-(Benzyloxy)propyl)-2-methyl-6,7,8,9-tetrahydro-4Hpyrido[1,2- $\alpha$ ]pyrimidin-4-one $(\mathbf{2 1})\left(\mathrm{CDCl}_{3}, 500 \mathrm{MHz}\right)$

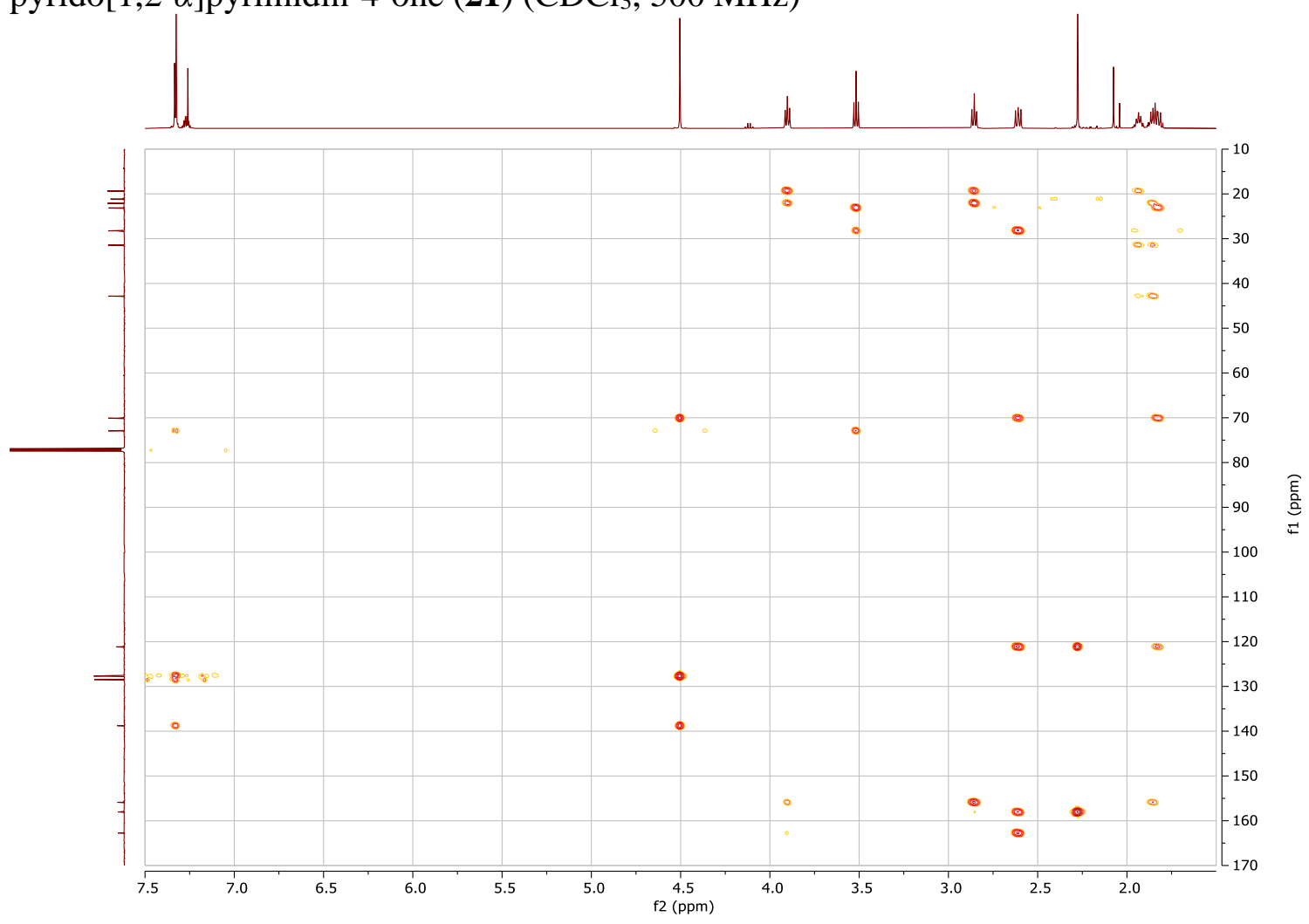


${ }^{1} \mathrm{H}$ NMR spectrum of 3-(3-Hydroxypropyl)-2-methyl-6,7,8,9-tetrahydro-4H-pyrido[1,2$\alpha]$ pyrimidin-4-one $(\mathbf{2 3})\left(\mathrm{CDCl}_{3}, 500 \mathrm{MHz}\right)$

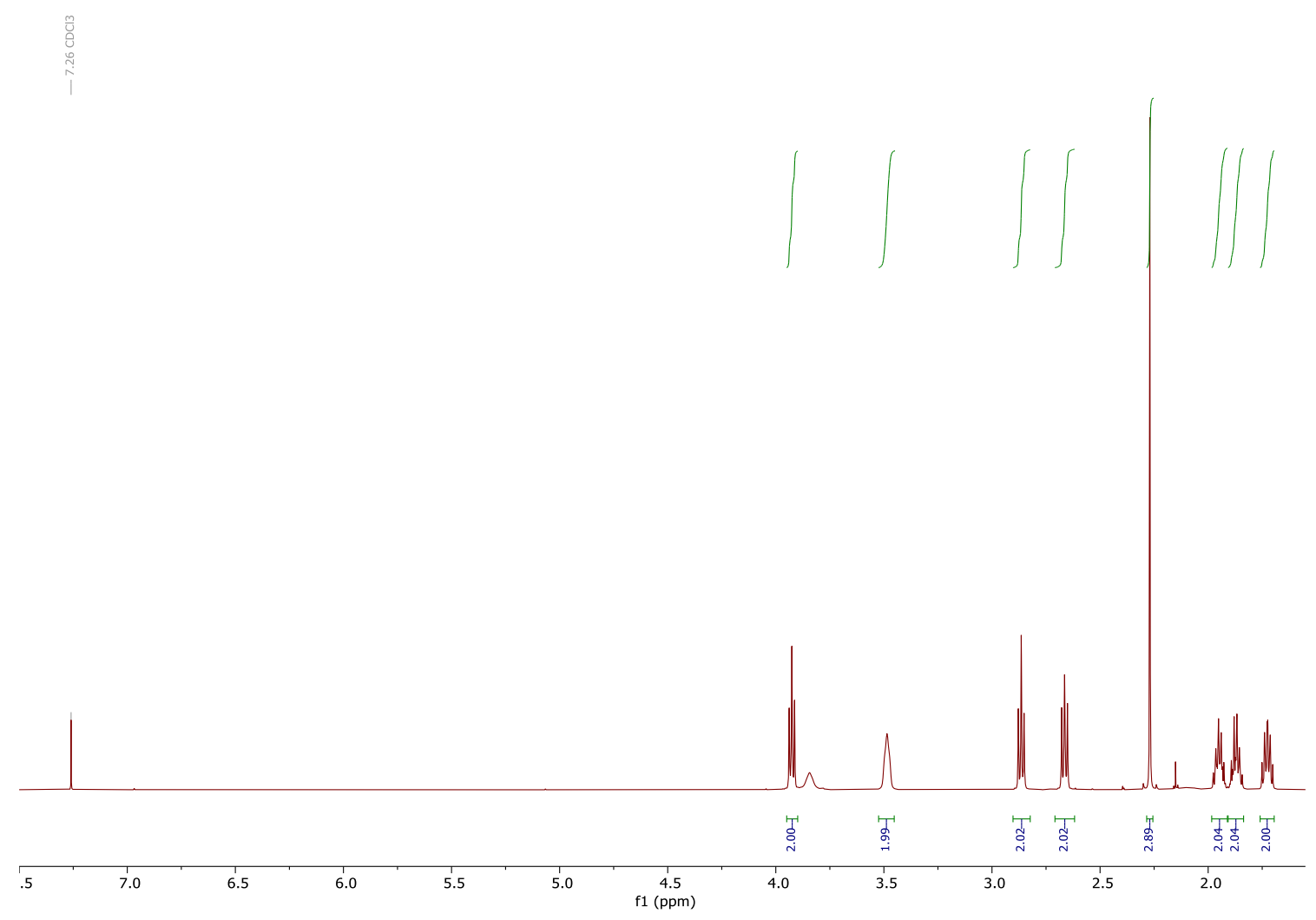

${ }^{13} \mathrm{C}$ NMR spectrum of 3-(3-Hydroxypropyl)-2-methyl-6,7,8,9-tetrahydro-4H-pyrido[1,2a]pyrimidin-4-one $(\mathbf{2 3})\left(\mathrm{CDCl}_{3}, 126 \mathrm{MHz}\right)$
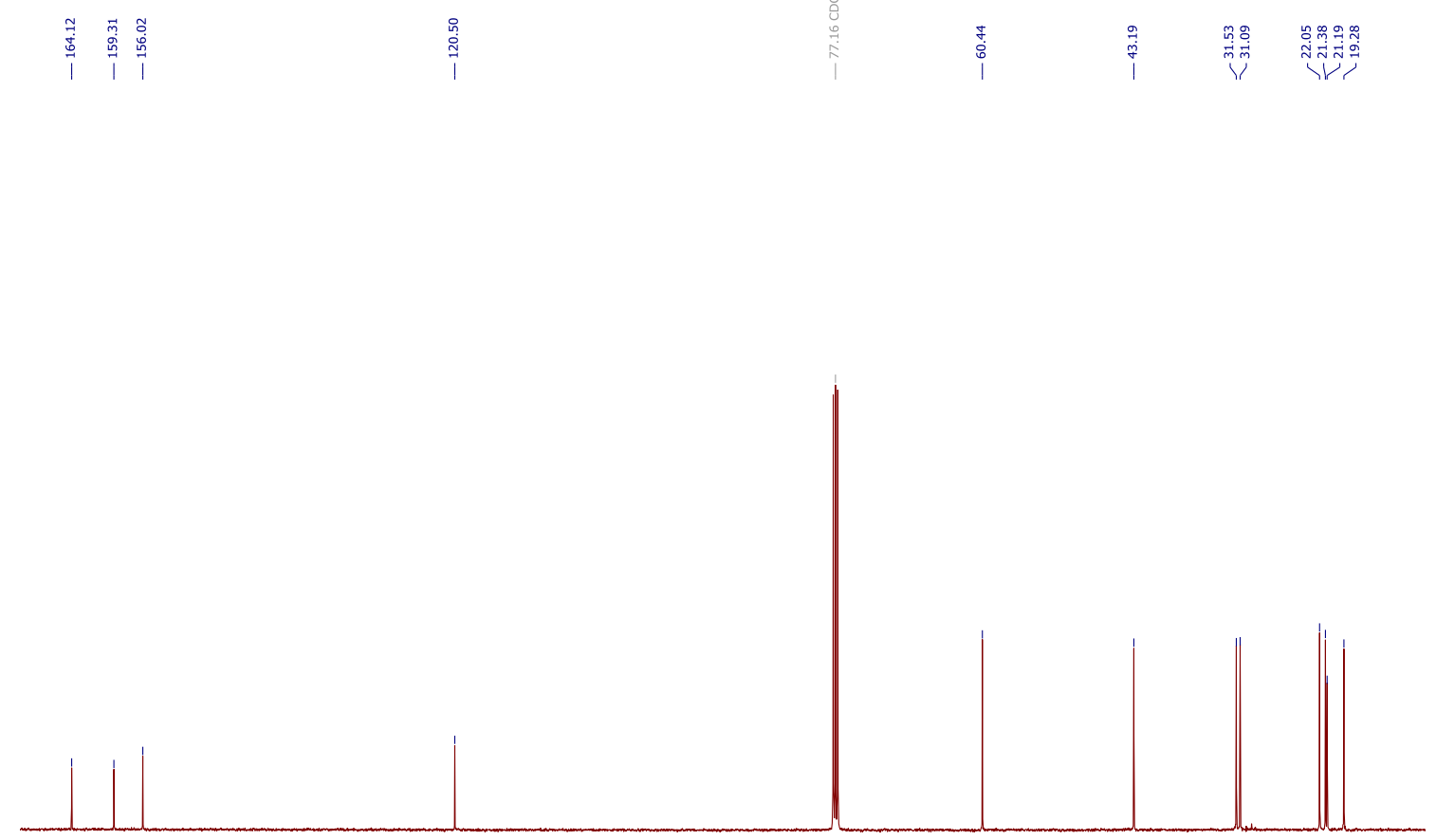

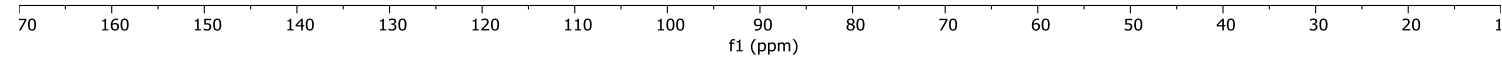


COSY NMR spectrum of 3-(3-Hydroxypropyl)-2-methyl-6,7,8,9-tetrahydro-4H-pyrido[1,2a]pyrimidin-4-one $(\mathbf{2 3})\left(\mathrm{CDCl}_{3}, 500 \mathrm{MHz}\right)$

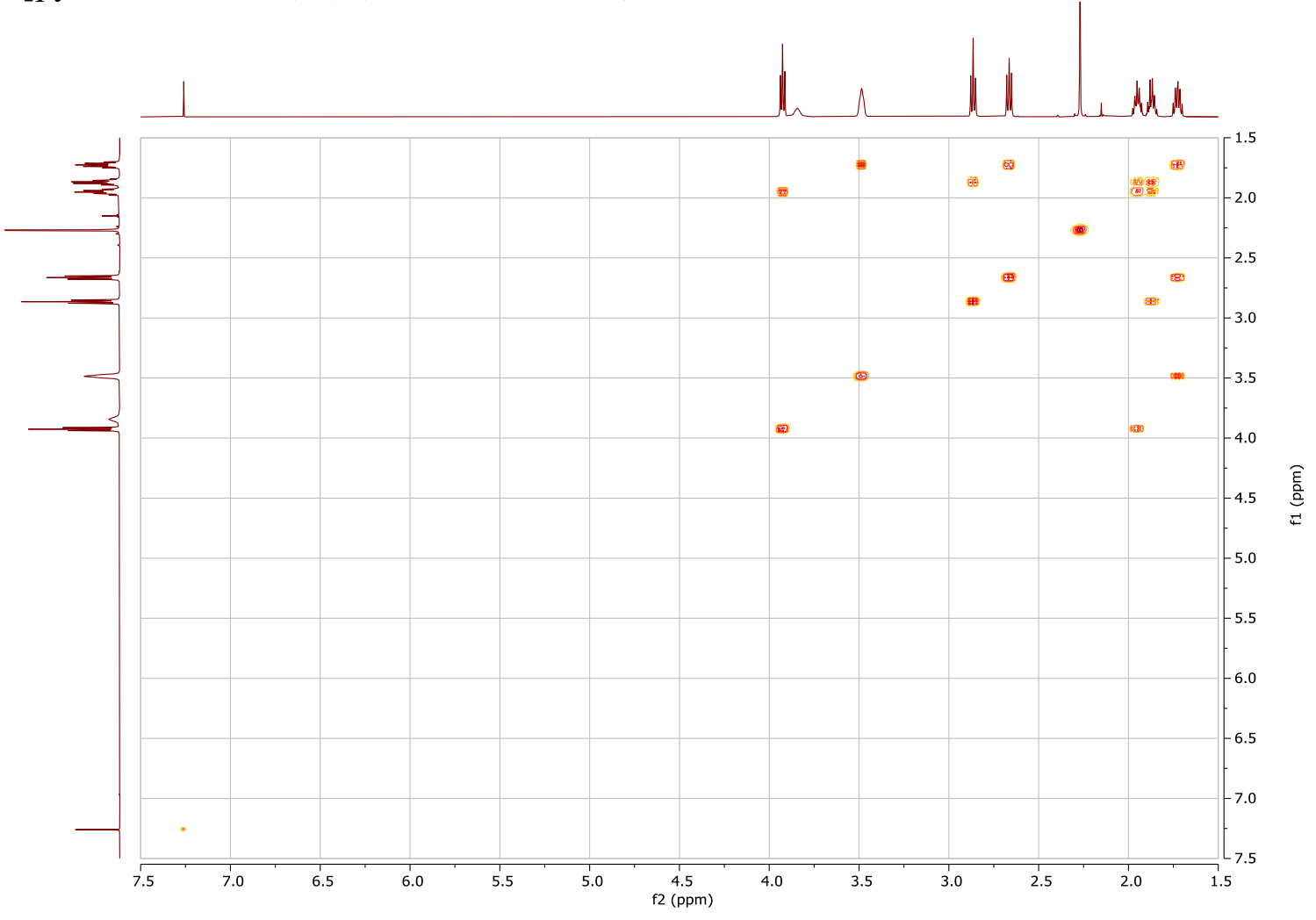

HSQC NMR spectrum of 3-(3-Hydroxypropyl)-2-methyl-6,7,8,9-tetrahydro-4H-pyrido[1,2a]pyrimidin-4-one $(\mathbf{2 3})\left(\mathrm{CDCl}_{3}, 500 \mathrm{MHz}\right)$

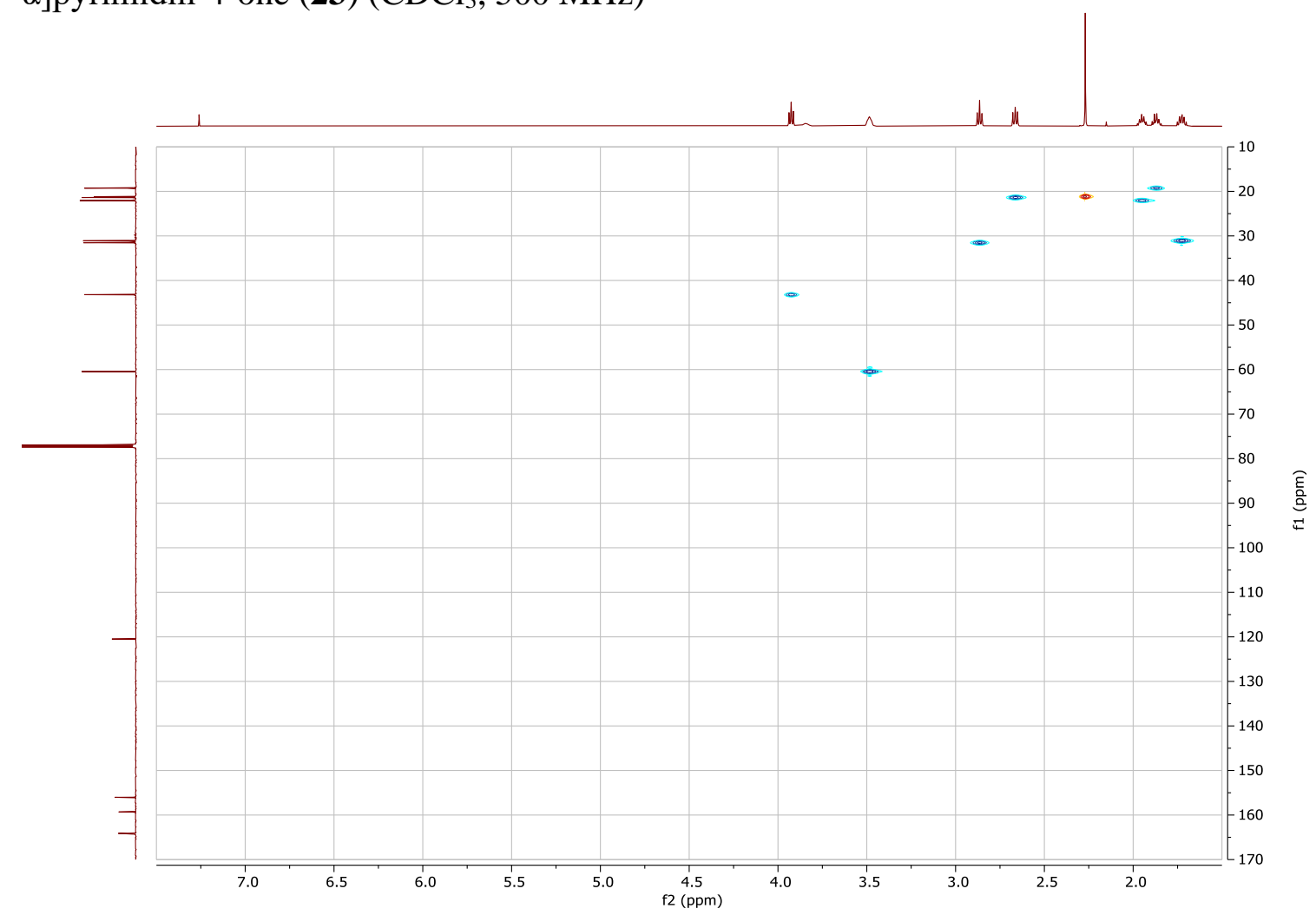


HMBC NMR spectrum of 3-(3-Hydroxypropyl)-2-methyl-6,7,8,9-tetrahydro-4H-pyrido[1,2a]pyrimidin-4-one (23) $\left(\mathrm{CDCl}_{3}, 500 \mathrm{MHz}\right)$

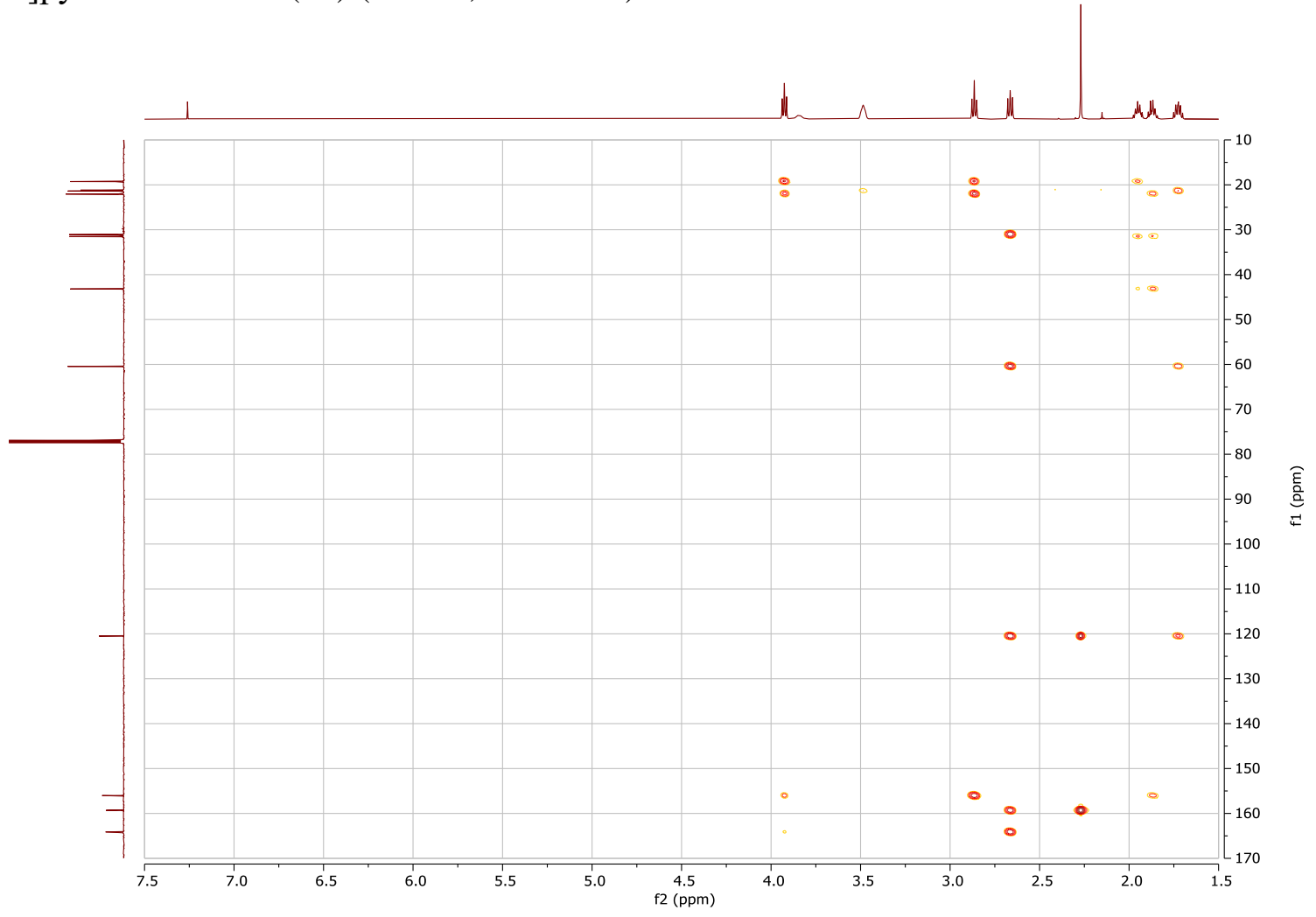


${ }^{1} \mathrm{H}$ NMR spectrum of 3-(3-Iodopropyl)-2-methyl-6,7,8,9-tetrahydro-4H-pyrido[1,2a]pyrimidin-4-one (25) $\left(\mathrm{CDCl}_{3}, 500 \mathrm{MHz}\right)$

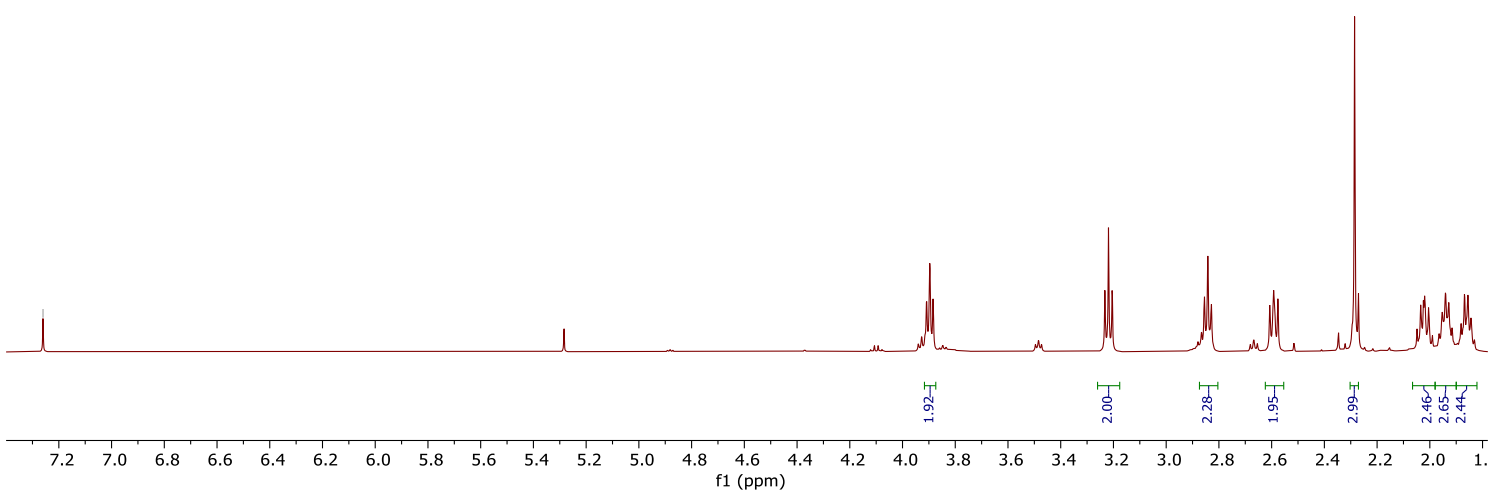

${ }^{13} \mathrm{C}$ NMR spectrum of 3-(3-Iodopropyl)-2-methyl-6,7,8,9-tetrahydro-4H-pyrido[1,2$\alpha]$ pyrimidin-4-one $(\mathbf{2 5})\left(\mathrm{CDCl}_{3}, 126 \mathrm{MHz}\right)$

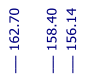

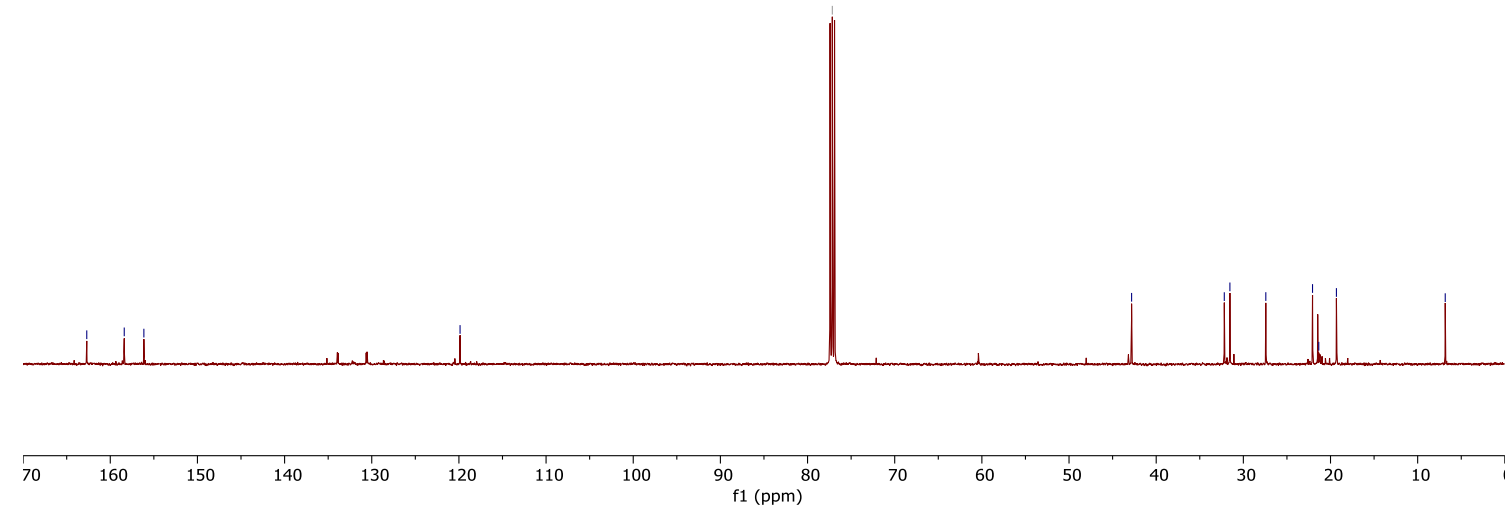


COSY NMR spectrum of 3-(3-Iodopropyl)-2-methyl-6,7,8,9-tetrahydro-4H-pyrido[1,2a]pyrimidin-4-one (25) $\left(\mathrm{CDCl}_{3}, 500 \mathrm{MHz}\right)$

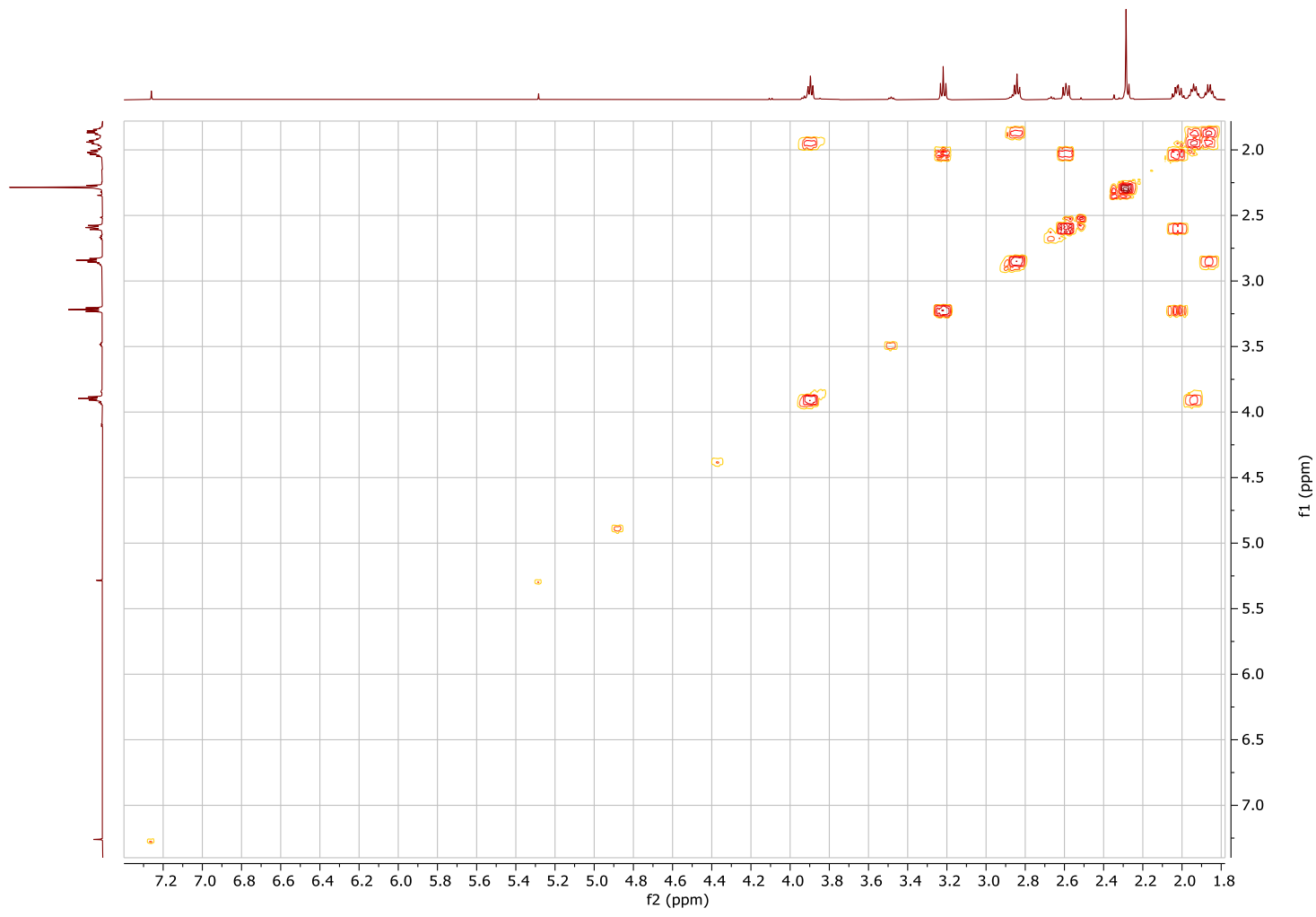

HSQC NMR spectrum of 3-(3-Iodopropyl)-2-methyl-6,7,8,9-tetrahydro-4H-pyrido[1,2a]pyrimidin-4-one (25) $\left(\mathrm{CDCl}_{3}, 500 \mathrm{MHz}\right)$

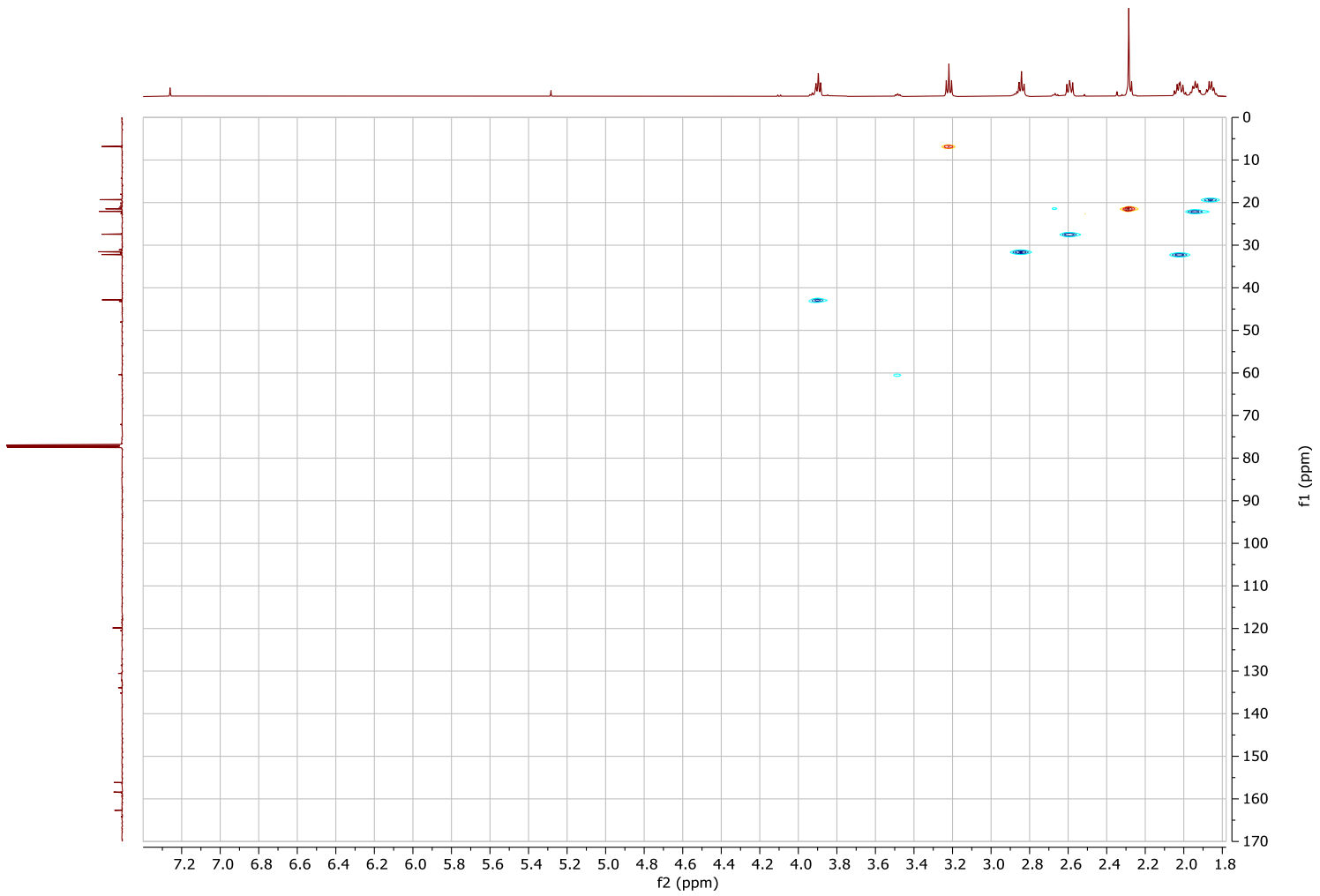


HMBC NMR spectrum of 3-(3-Iodopropyl)-2-methyl-6,7,8,9-tetrahydro-4H-pyrido[1,2a]pyrimidin-4-one (25) $\left(\mathrm{CDCl}_{3}, 500 \mathrm{MHz}\right)$

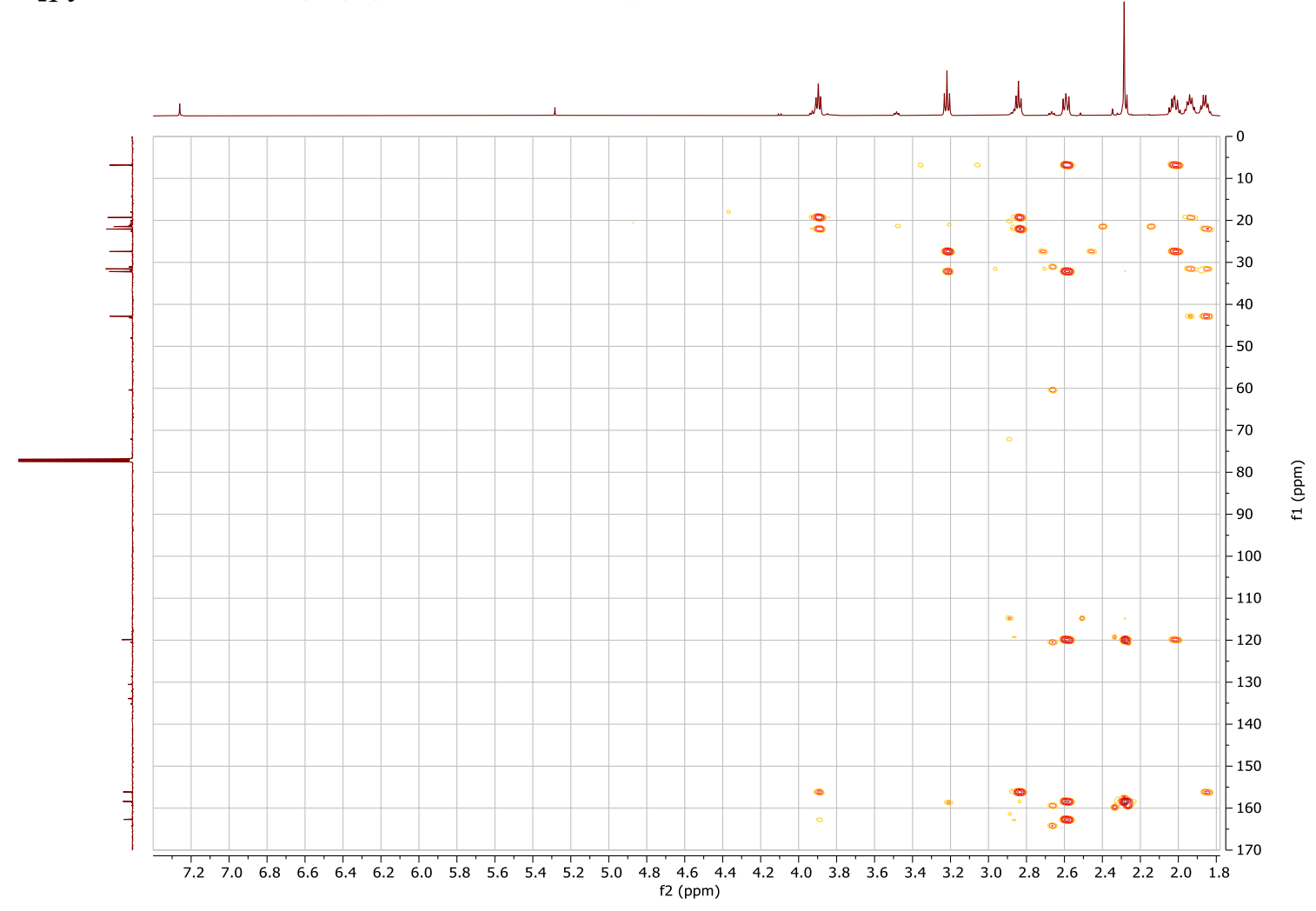


${ }^{1} \mathrm{H}$ NMR spectrum of 3-(3-(4-(6-Fluorobenzo[d]isoxazol-3-yl)piperidin-1-yl)propyl)-2methyl-6,7,8,9-tetrahydro-4H-pyrido[1,2- $\alpha$ ]pyrimidin-4-one $(\mathbf{8})\left(\mathrm{CDCl}_{3}, 500 \mathrm{MHz}\right)$
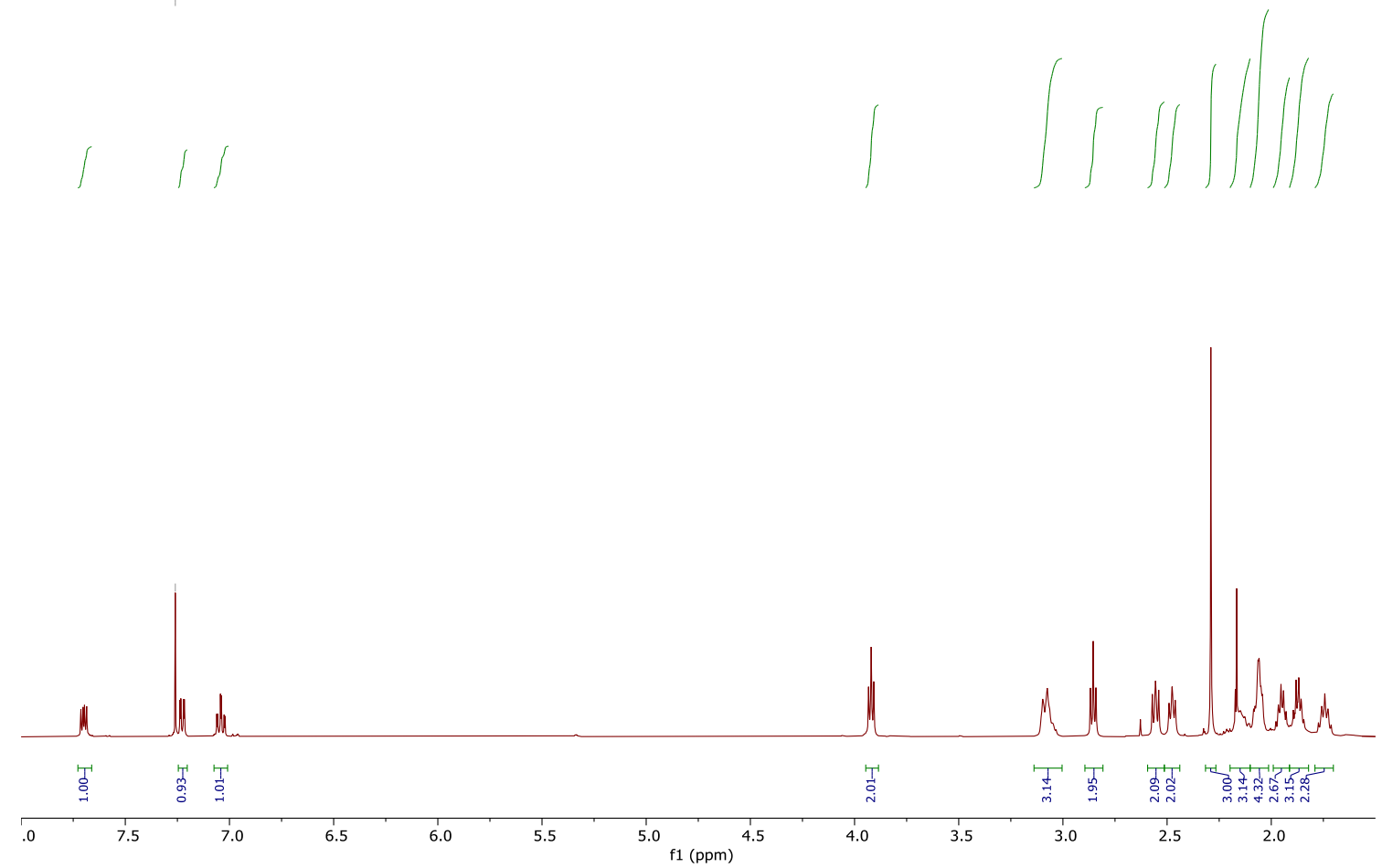

${ }^{13} \mathrm{C}$ NMR spectrum of 3-(3-(4-(6-Fluorobenzo[ $d$ ]isoxazol-3-yl)piperidin-1-yl)propyl)-2methyl-6,7,8,9-tetrahydro-4H-pyrido[1,2- $\alpha$ ]pyrimidin-4-one $(8)\left(\mathrm{CDCl}_{3}, 126 \mathrm{MHz}\right)$

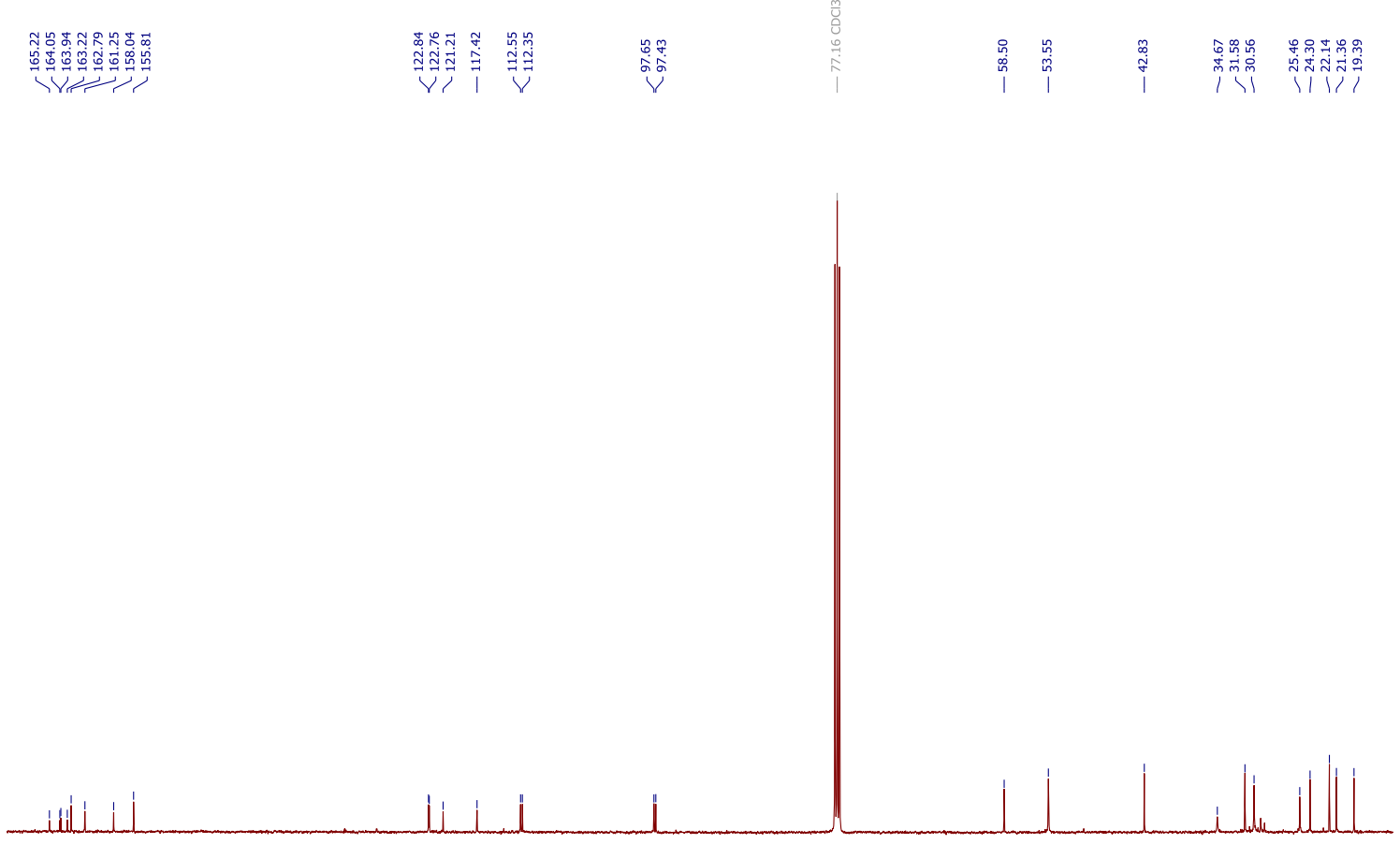

$\begin{array}{lllllllllllllllllllllllllllllllllllllllllll}165 & 160 & 155 & 150 & 145 & 140 & 135 & 130 & 125 & 120 & 115 & 110 & 105 & 100 & 95 & 90 & 85 & 80 & 75 & 70 & 65 & 60 & 55 & 50 & 45 & 40 & 35 & 30 & 25 & 20 & 1\end{array}$ 
COSY NMR spectrum of 3-(3-(4-(6-Fluorobenzo[ $d]$ isoxazol-3-yl)piperidin-1-yl)propyl)-2methyl-6,7,8,9-tetrahydro-4H-pyrido[1,2- $\alpha$ ]pyrimidin-4-one $(8)\left(\mathrm{CDCl}_{3}, 500 \mathrm{MHz}\right)$

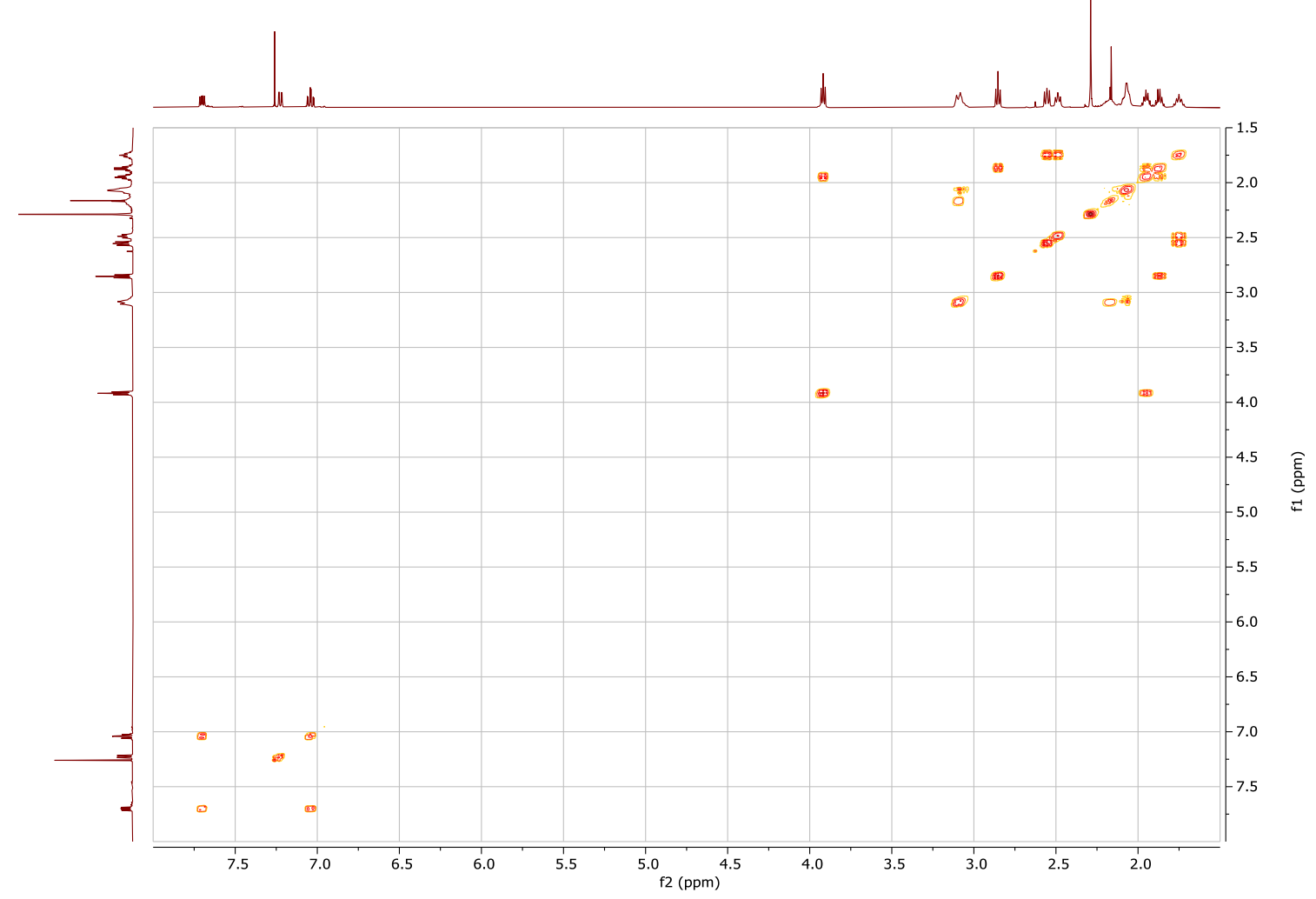

HSQC NMR spectrum of 3-(3-(4-(6-Fluorobenzo[d]isoxazol-3-yl)piperidin-1-yl)propyl)-2methyl-6,7,8,9-tetrahydro-4H-pyrido[1,2- $\alpha$ ]pyrimidin-4-one $(\mathbf{8})\left(\mathrm{CDCl}_{3}, 500 \mathrm{MHz}\right)$

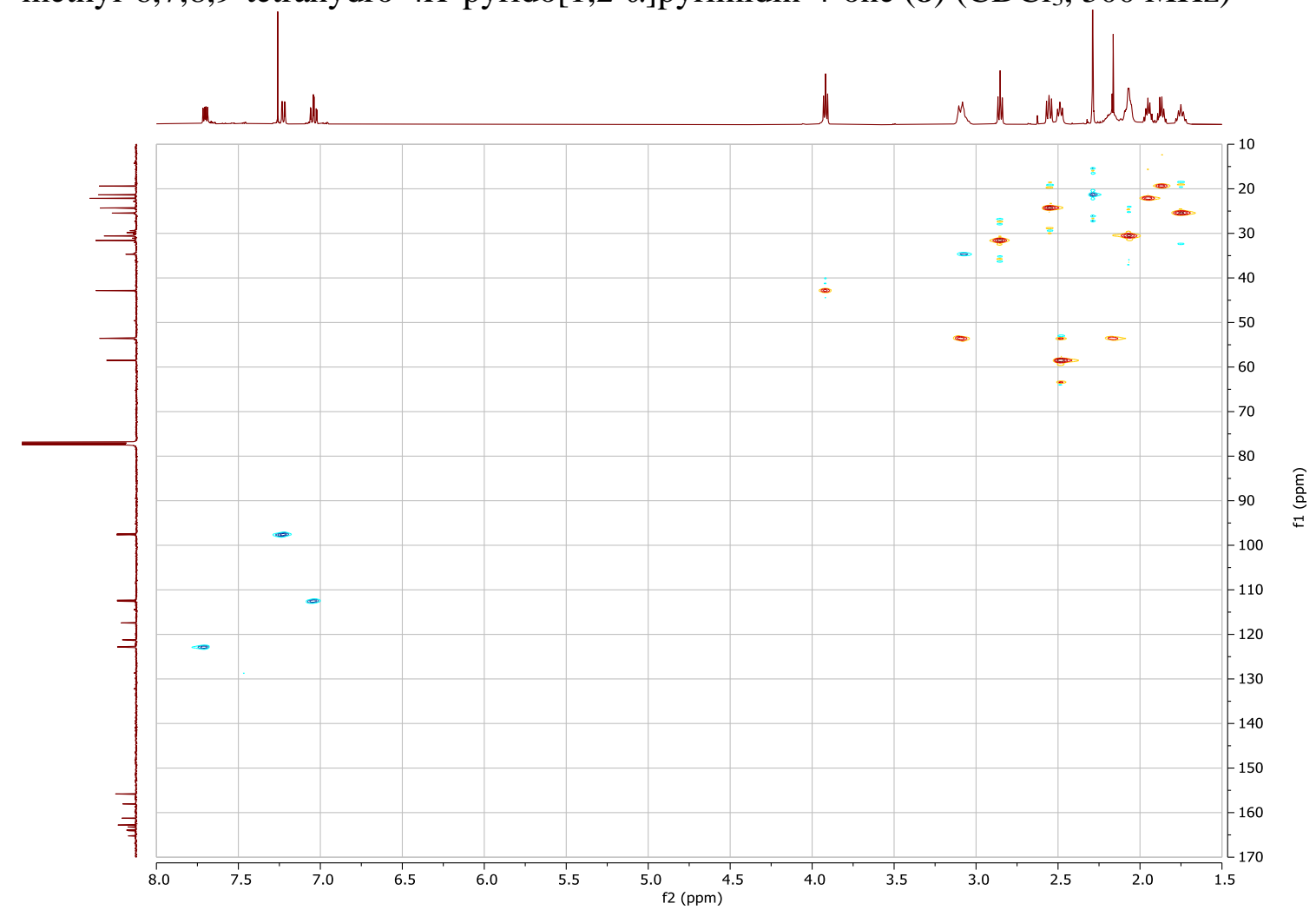


HMBC NMR spectrum of 3-(3-(4-(6-Fluorobenzo[d]isoxazol-3-yl)piperidin-1-yl)propyl)-2methyl-6,7,8,9-tetrahydro-4H-pyrido[1,2- $\alpha$ ]pyrimidin-4-one $(\mathbf{8})\left(\mathrm{CDCl}_{3}, 500 \mathrm{MHz}\right)$

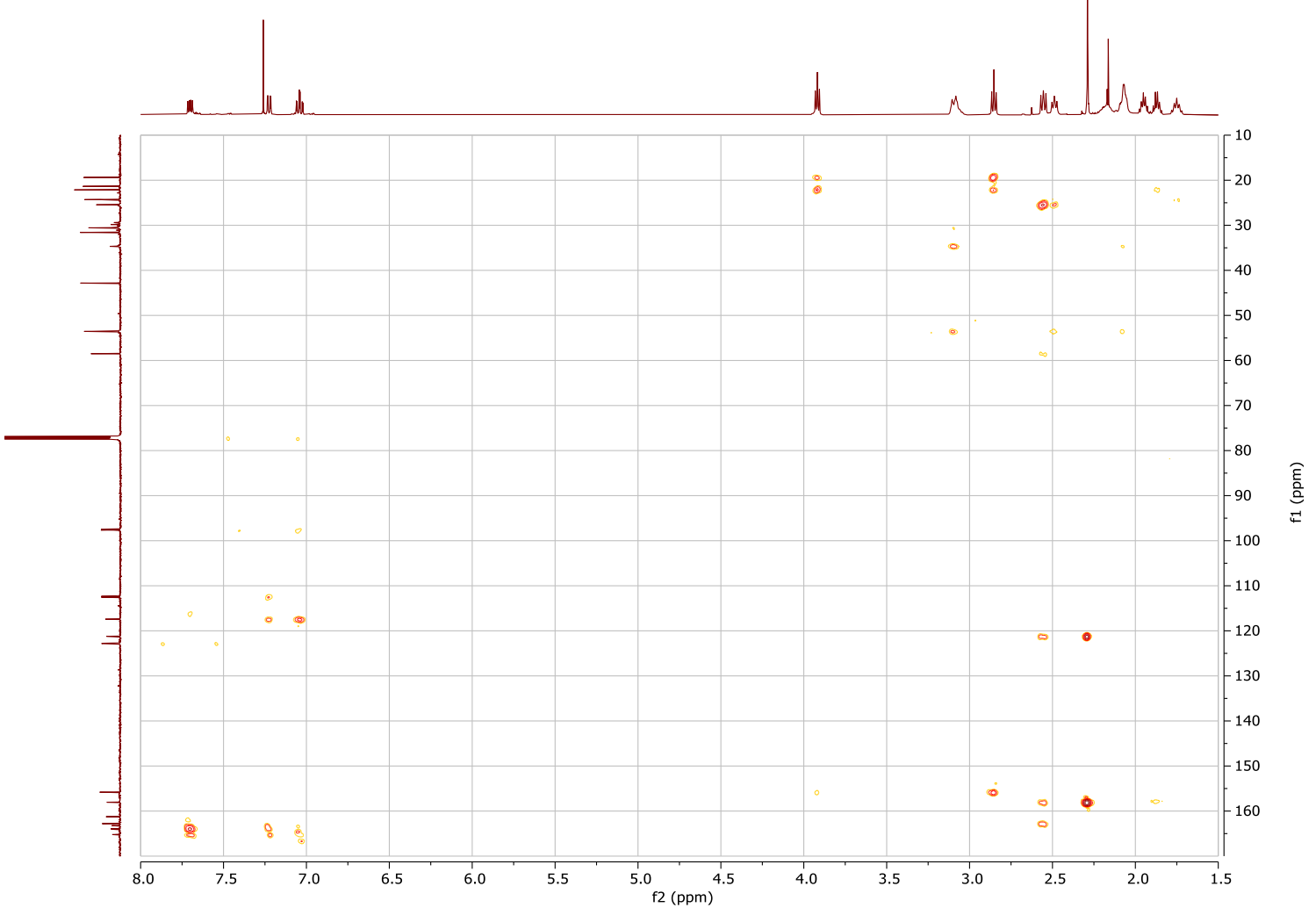


COSY NMR spectrum of 3-(3-hydroxypropyl)-2-methyl-4H-pyrido[1,2- $\alpha$ ]pyrimidin-4-one (27) $\left(\mathrm{CDCl}_{3}, 500 \mathrm{MHz}\right)$

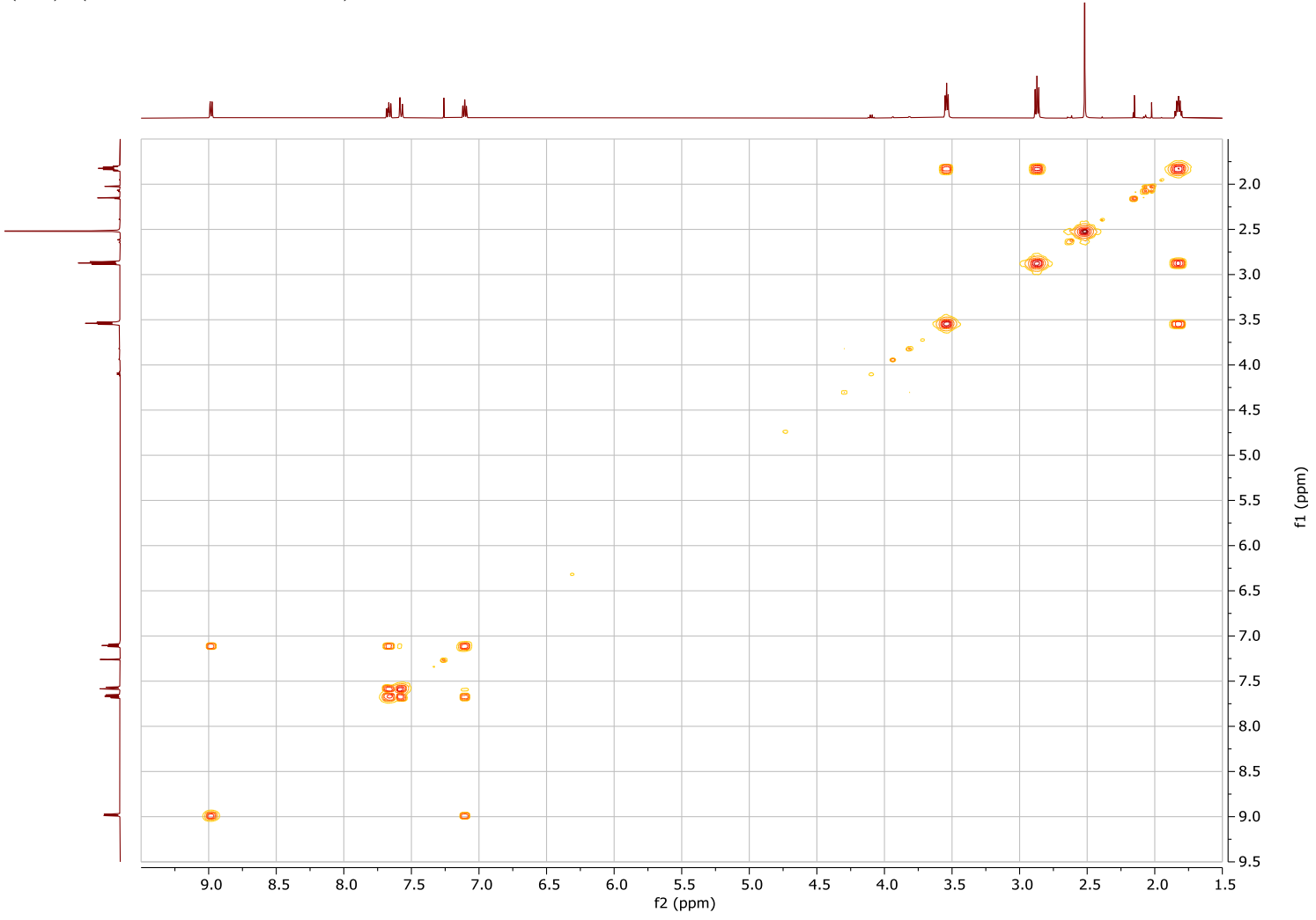

HSQC NMR spectrum of 3-(3-hydroxypropyl)-2-methyl-4H-pyrido[1,2- $\alpha$ ]pyrimidin-4-one (27) $\left(\mathrm{CDCl}_{3}, 500 \mathrm{MHz}\right)$

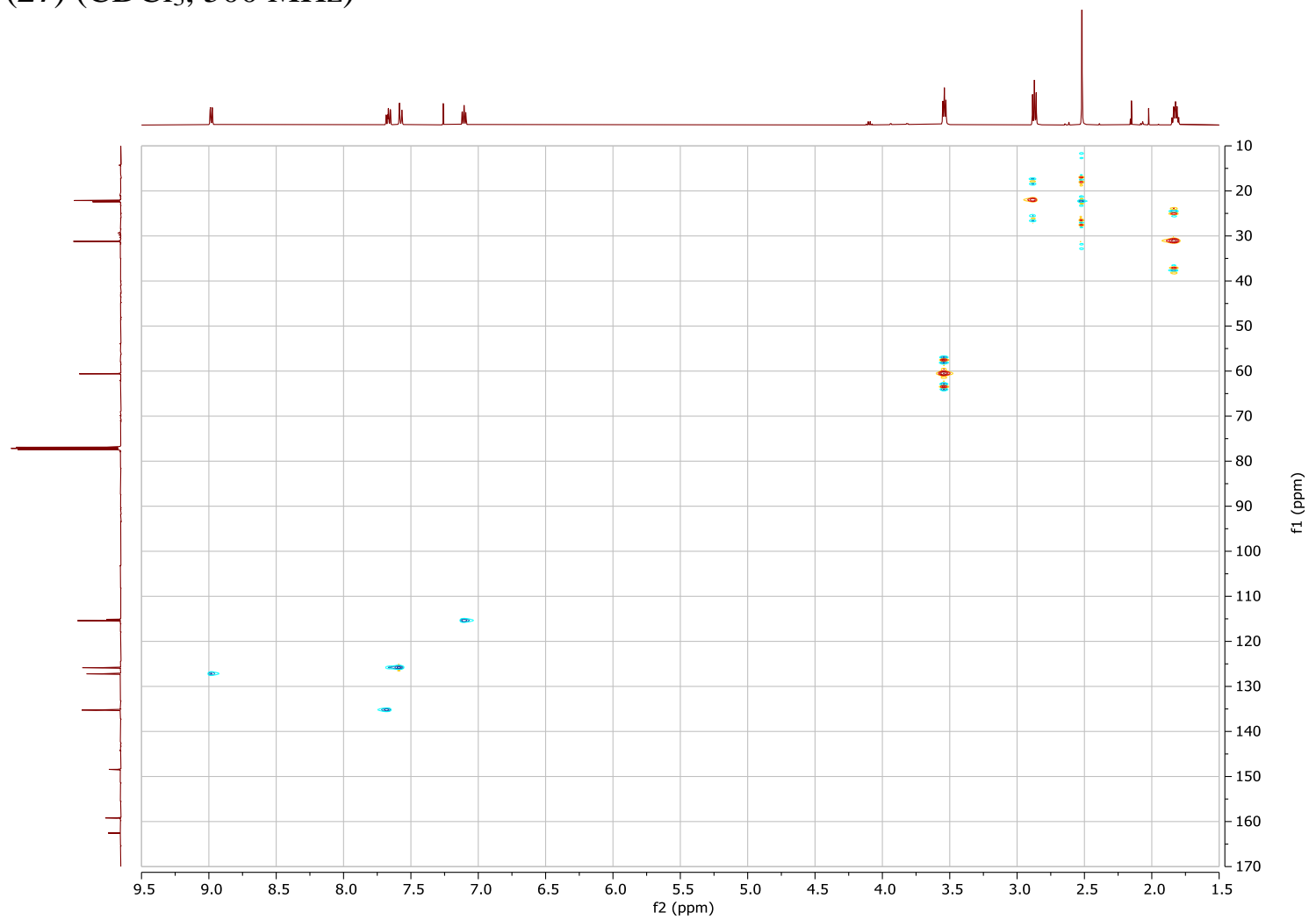


HMBC NMR spectrum of 3-(3-hydroxypropyl)-2-methyl-4H-pyrido[1,2- $\alpha$ ]pyrimidin-4-one (27) $\left(\mathrm{CDCl}_{3}, 500 \mathrm{MHz}\right)$

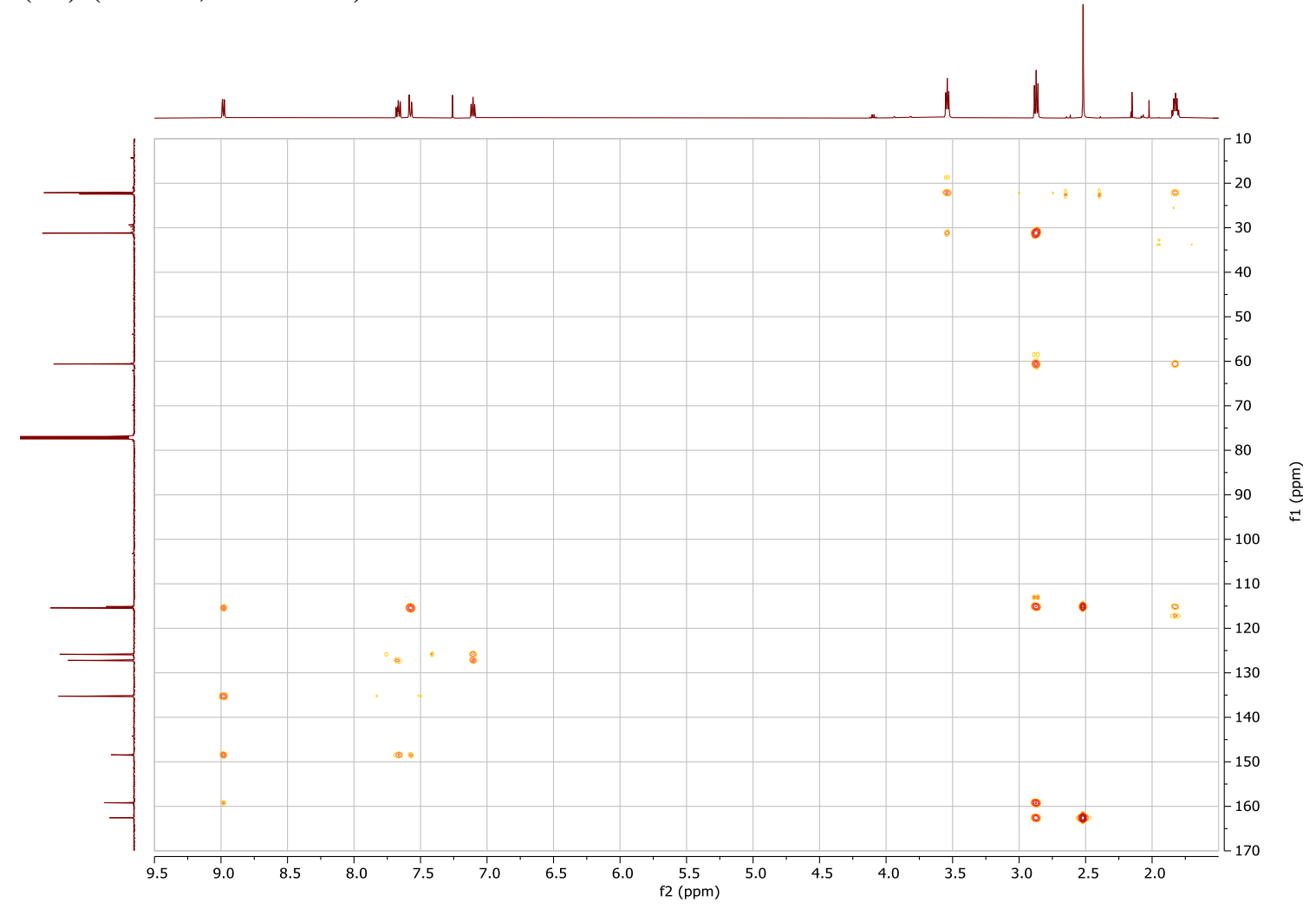


${ }^{1} \mathrm{H}$ NMR spectrum of 3-(3-Iodopropyl)-2-methyl-4H-pyrido[1,2- $\alpha$ ]pyrimidin-4-one (31) $\left(\mathrm{CDCl}_{3}, 500 \mathrm{MHz}\right)$

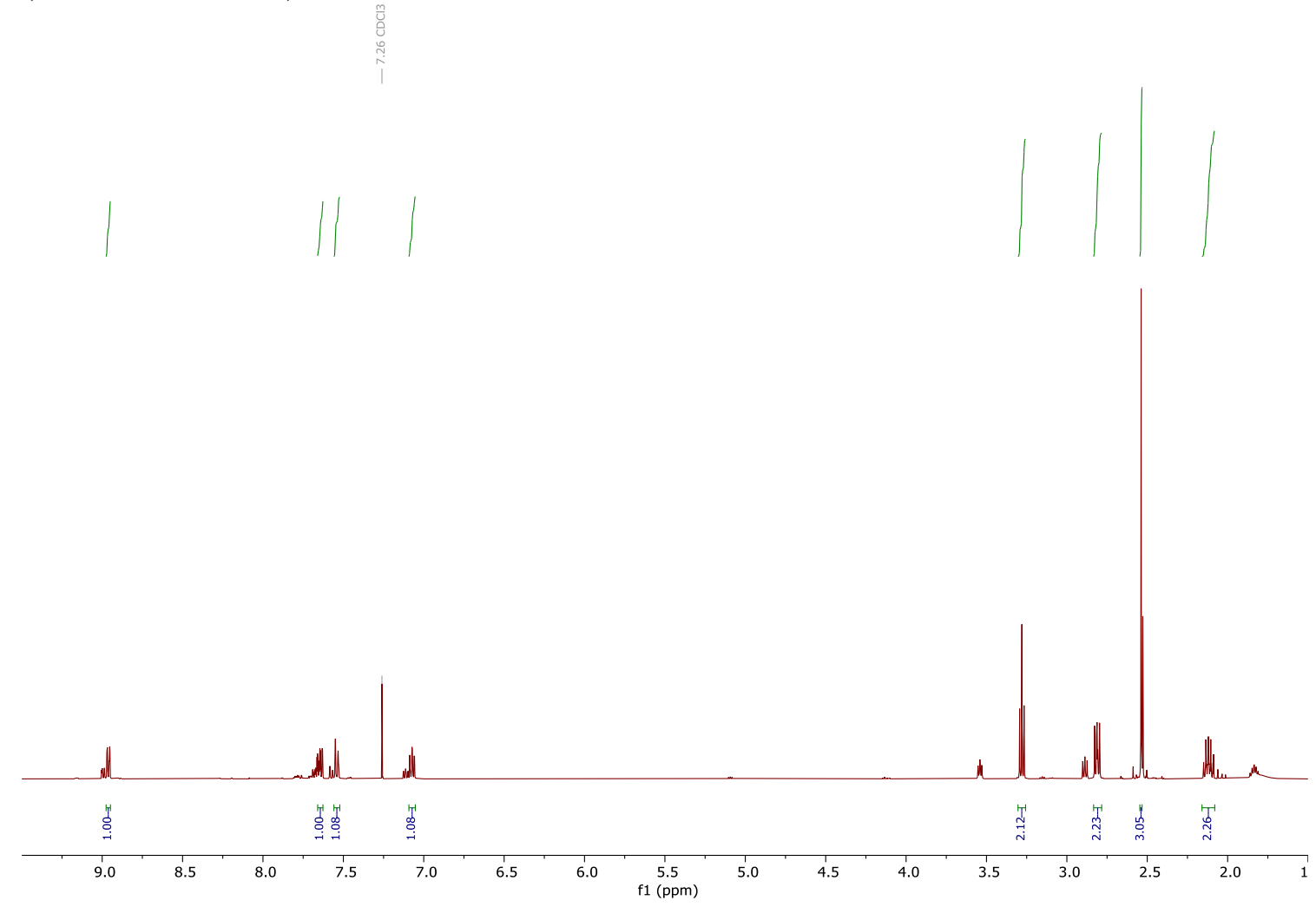


${ }^{1} \mathrm{H}$ NMR spectrum of 3-(3-(4-(6-Fluorobenzo[d]isoxazol-3-yl)piperidin-1-yl)propyl)-2methyl-4H-pyrido[1,2- $\alpha$ ]pyrimidin-4-one $(\mathbf{2 8})\left(\mathrm{CDCl}_{3}, 500 \mathrm{MHz}\right)$

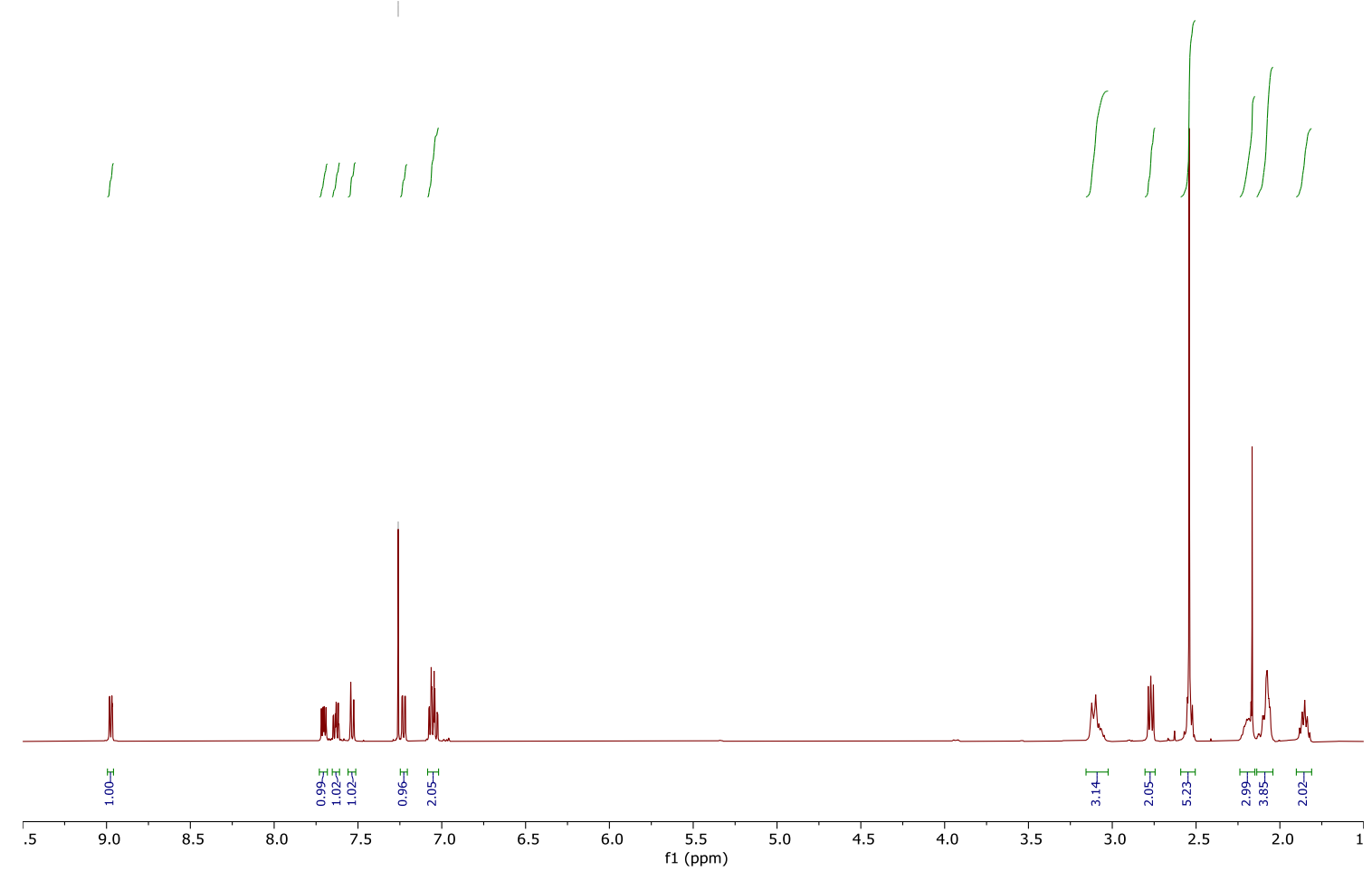

${ }^{13} \mathrm{C}$ NMR spectrum of 3-(3-(4-(6-Fluorobenzo[d]isoxazol-3-yl)piperidin-1-yl)propyl)-2methyl-4H-pyrido[1,2- $\alpha$ ]pyrimidin-4-one $(\mathbf{2 8})\left(\mathrm{CDCl}_{3}, 126 \mathrm{MHz}\right)$

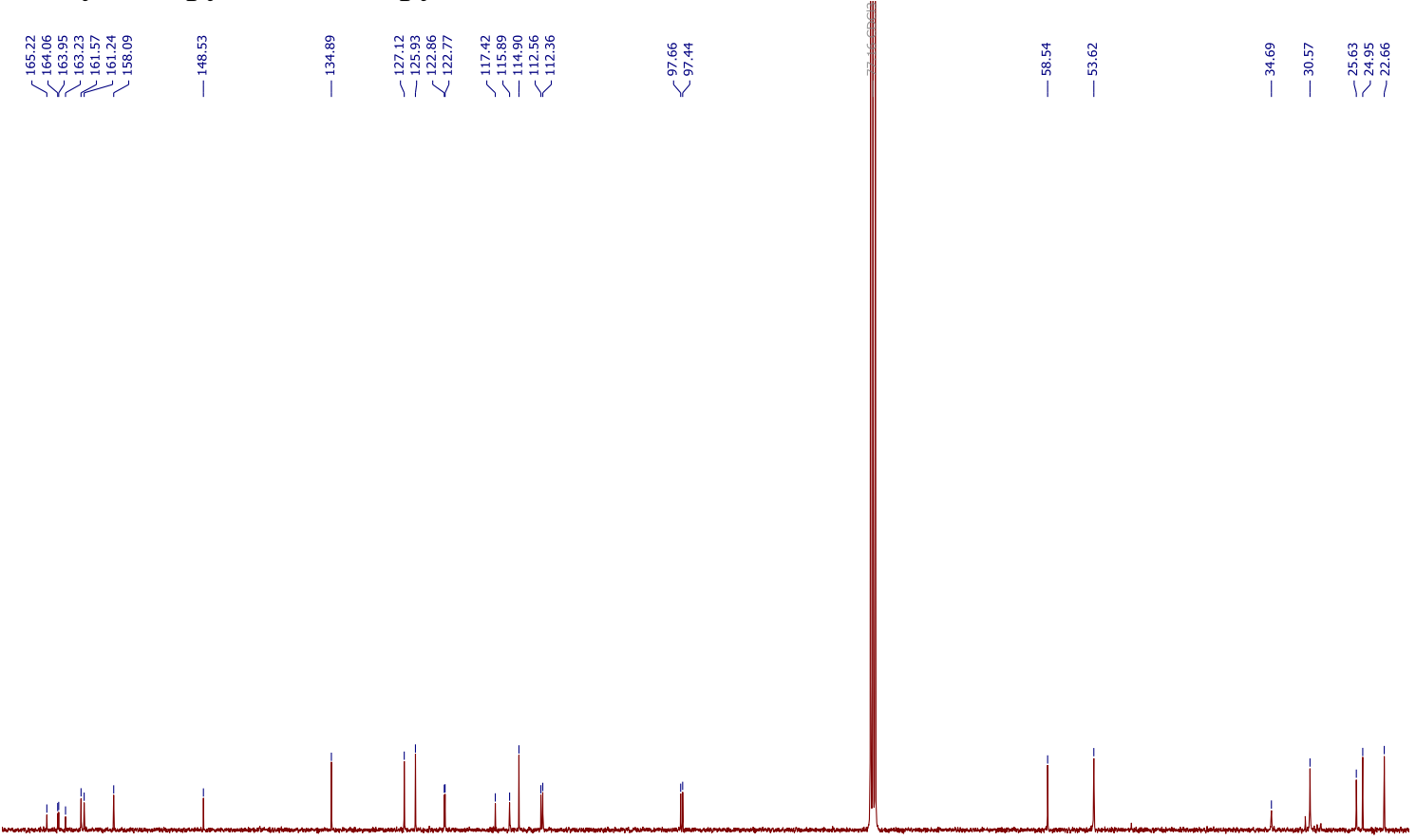

$\begin{array}{llllllllllllllllllllllllllllllllllllll}70 & 165 & 160 & 155 & 150 & 145 & 140 & 135 & 130 & 125 & 120 & 115 & 110 & 105 & 100 & 95 & 90 & 85 & 80 & 75 & 70 & 65 & 60 & 55 & 50 & 45 & 40 & 35 & 30 & 25 & 2\end{array}$ 
COSY NMR spectrum of 3-(3-(4-(6-Fluorobenzo[ $d]$ isoxazol-3-yl)piperidin-1-yl)propyl)-2methyl-4H-pyrido[1,2- $\alpha$ pyrimidin-4-one $(\mathbf{2 8})\left(\mathrm{CDCl}_{3}, 500 \mathrm{MHz}\right)$

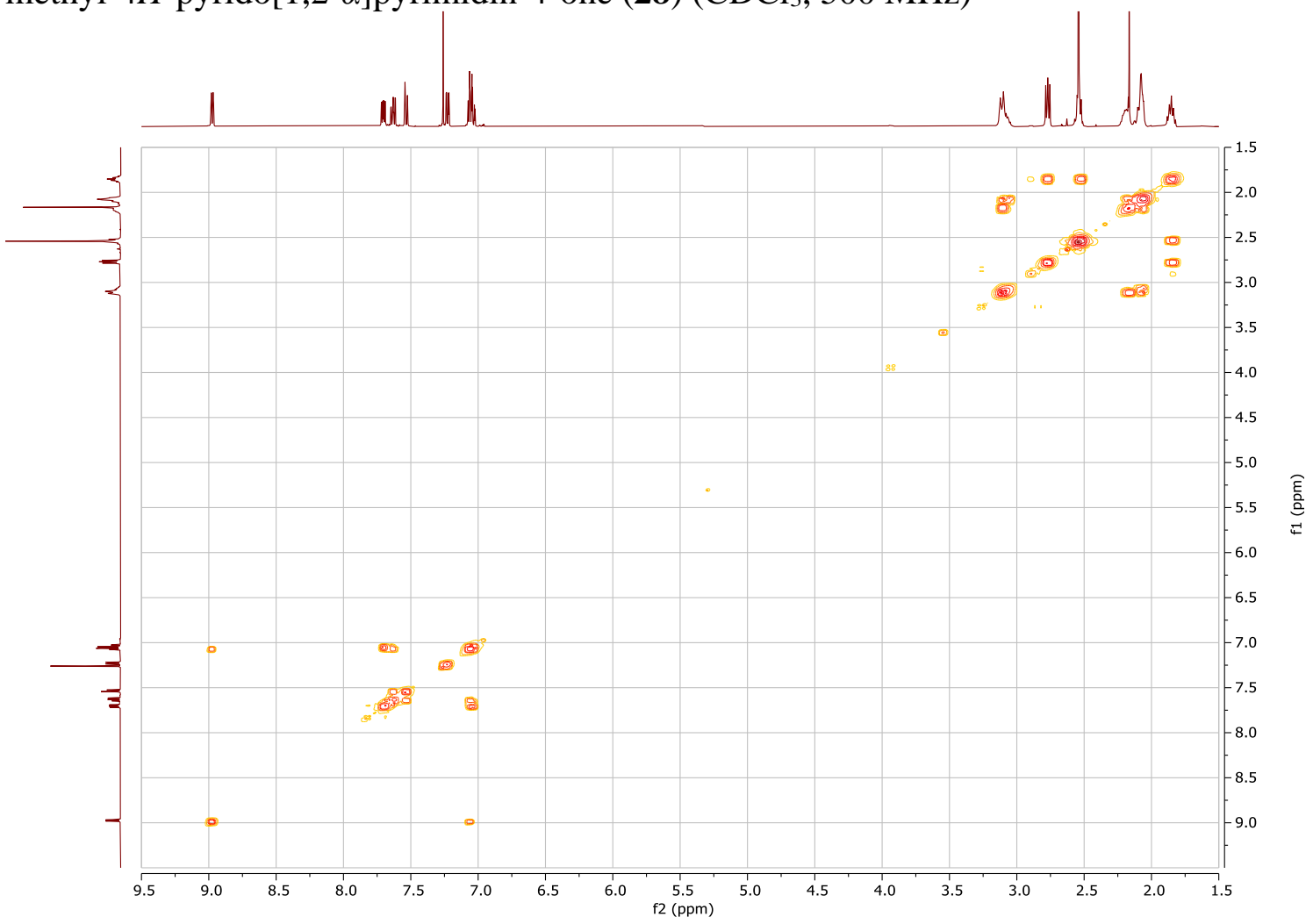

HSQC NMR spectrum of 3-(3-(4-(6-Fluorobenzo[d]isoxazol-3-yl)piperidin-1-yl)propyl)-2methyl-4H-pyrido[1,2- $\alpha$ ]pyrimidin-4-one $(28)\left(\mathrm{CDCl}_{3}, 500 \mathrm{MHz}\right)$

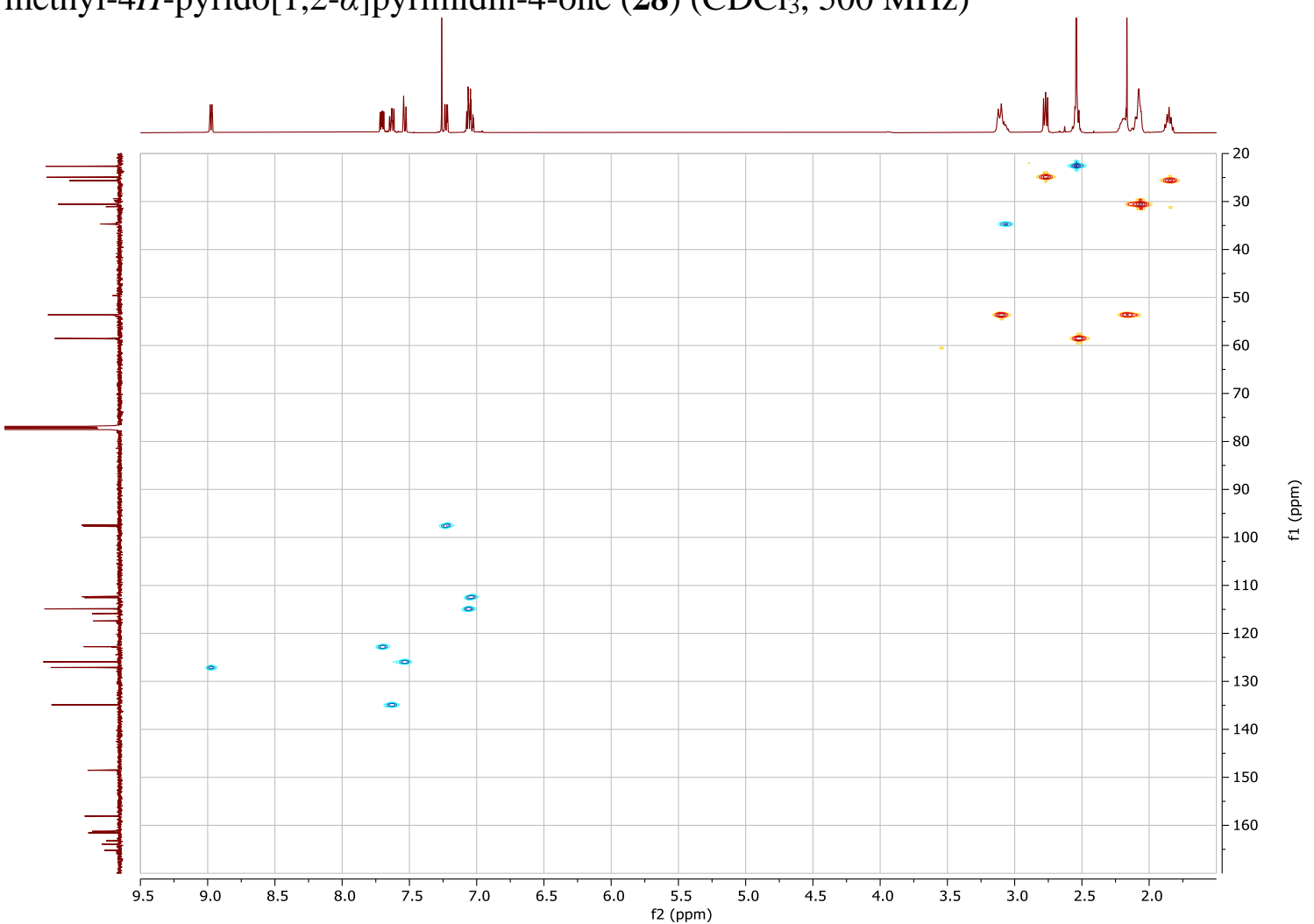


HMBC NMR spectrum of 3-(3-(4-(6-Fluorobenzo[d]isoxazol-3-yl)piperidin-1-yl)propyl)-2methyl-4H-pyrido[1,2- $\alpha$ ]pyrimidin-4-one $(\mathbf{2 8})\left(\mathrm{CDCl}_{3}, 500 \mathrm{MHz}\right)$

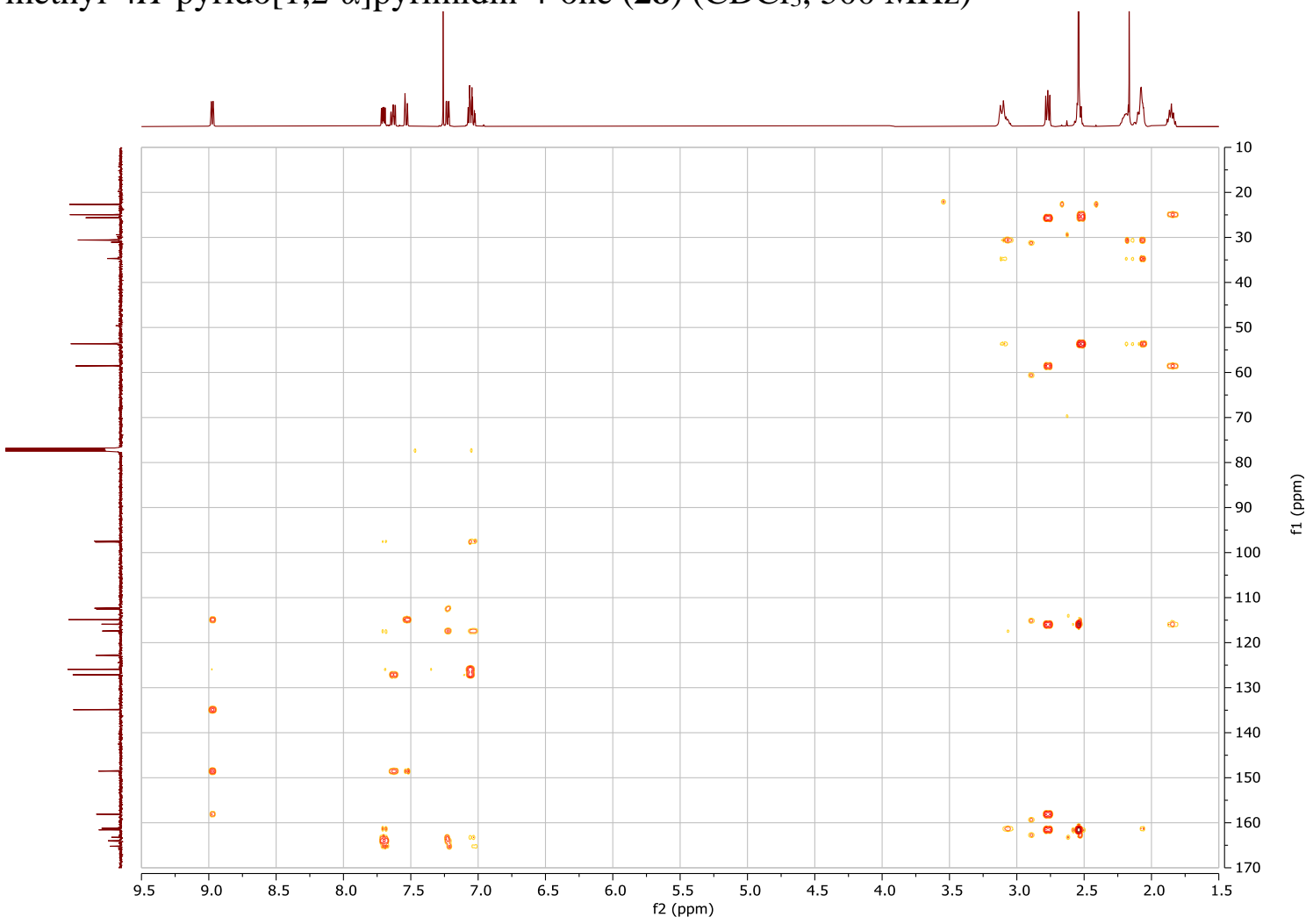


${ }^{1} \mathrm{H}$ NMR spectrum of 4-Benzyloxy-1-chlorobutane (14) $(\mathrm{CDCl} 3,500 \mathrm{MHz})$

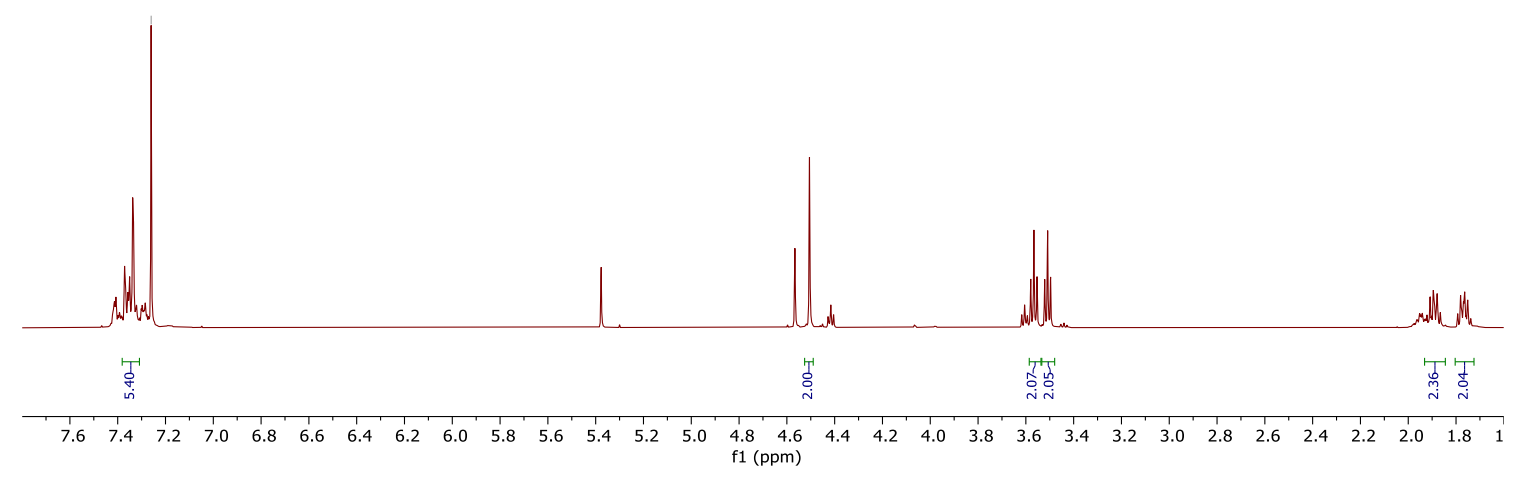


${ }^{1} \mathrm{H}$ NMR spectrum 4-Benzyloxy-1-iodobutane (16) $\left(\mathrm{CDCl}_{3}, 500 \mathrm{MHz}\right)$

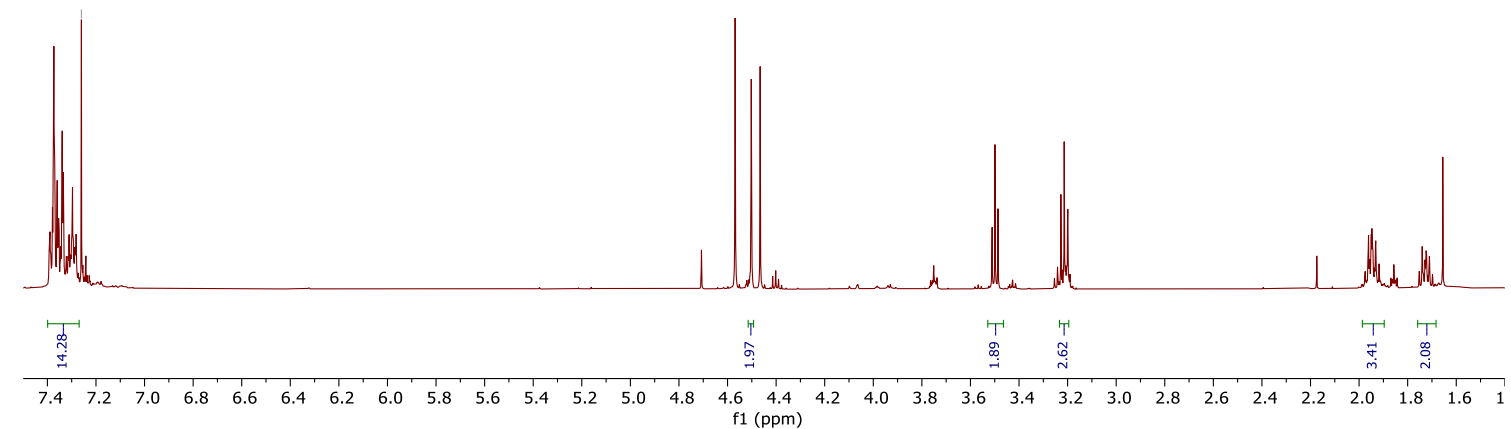


${ }^{1} \mathrm{H}$ NMR spectrum of Ethyl 2-acetyl-6-(benzyloxy)hexanoate (18) $\left(\mathrm{CDCl}_{3}, 500 \mathrm{MHz}\right)$
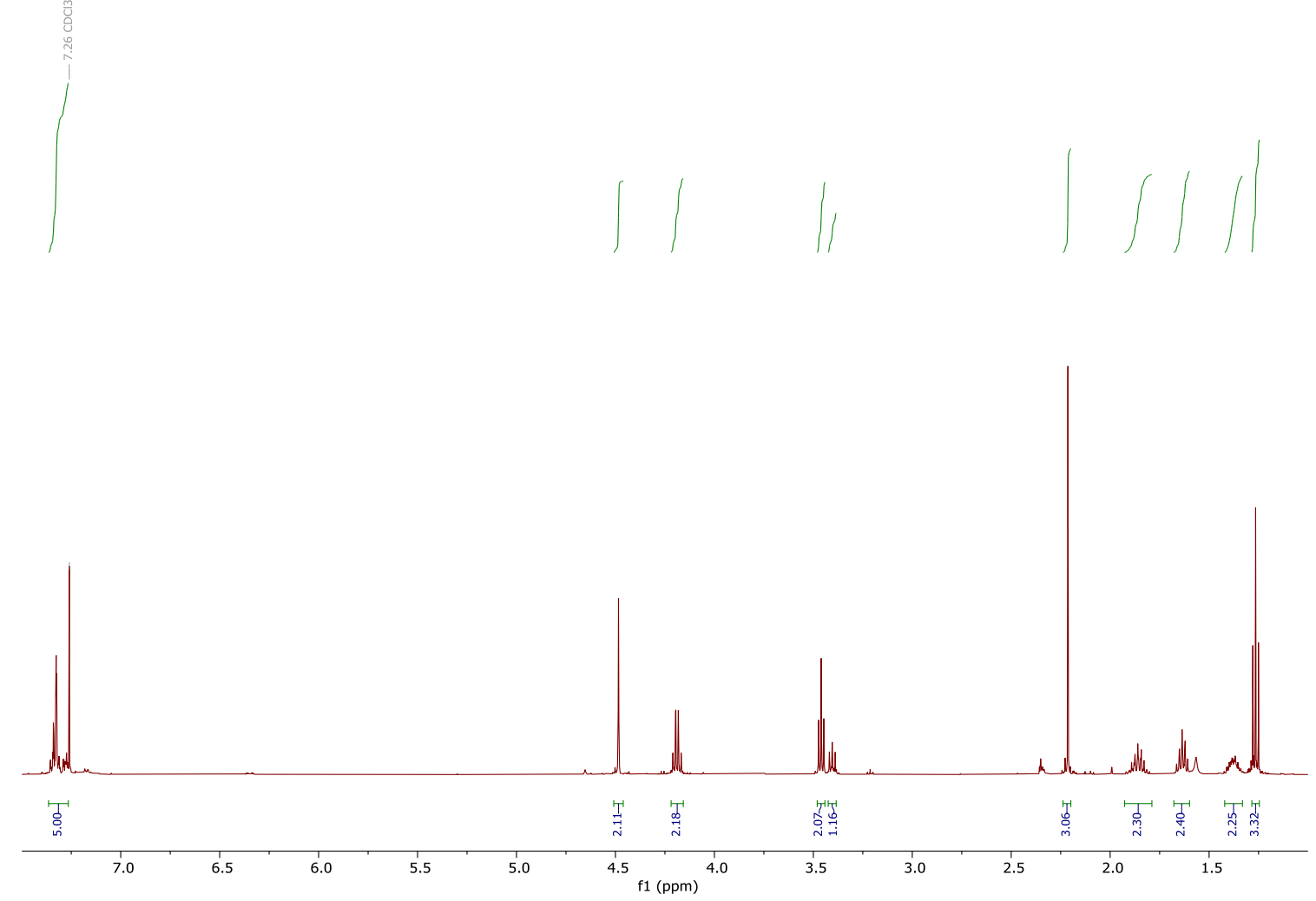

${ }^{13} \mathrm{C}$ NMR spectrum of Ethyl 2-acetyl-6-(benzyloxy)hexanoate (18) $\left(\mathrm{CDCl}_{3}, 126 \mathrm{MHz}\right)$

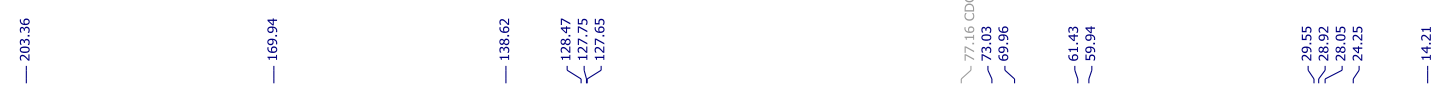
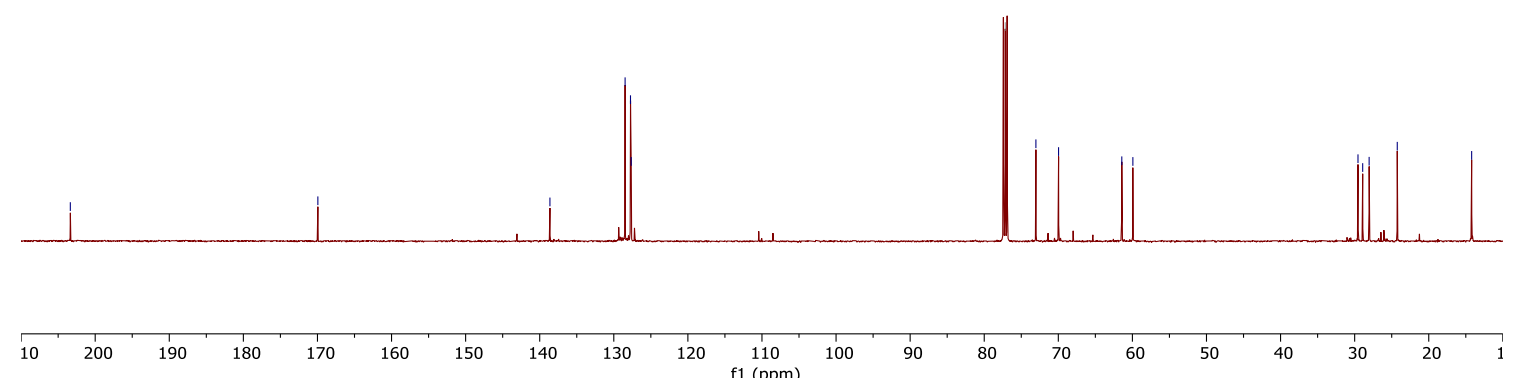
COSY NMR spectrum of Ethyl 2-acetyl-6-(benzyloxy)hexanoate (18) $\left(\mathrm{CDCl}_{3}, 500 \mathrm{MHz}\right)$

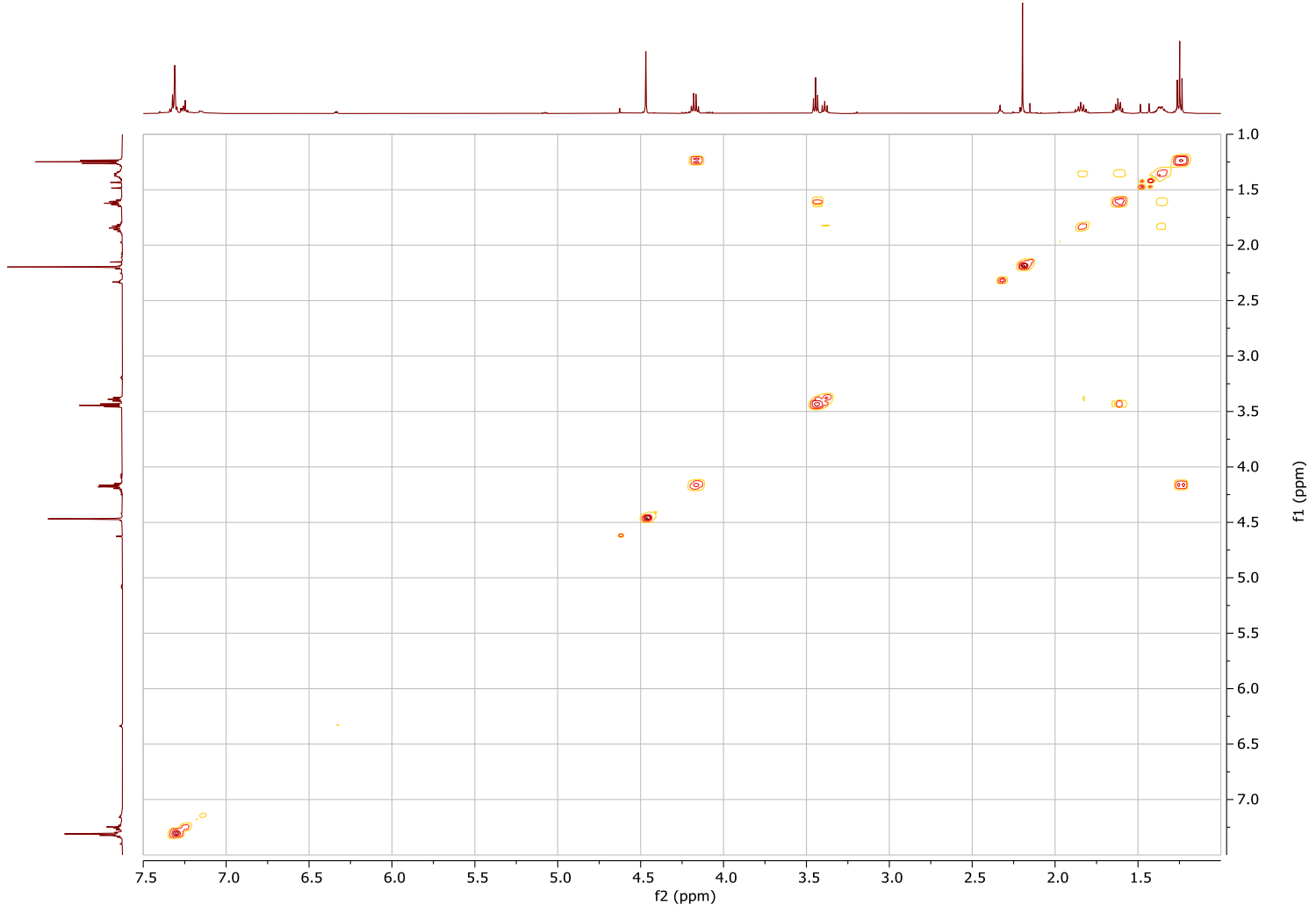

HSQC NMR spectrum of Ethyl 2-acetyl-6-(benzyloxy)hexanoate (18) $\left(\mathrm{CDCl}_{3}, 500 \mathrm{MHz}\right)$

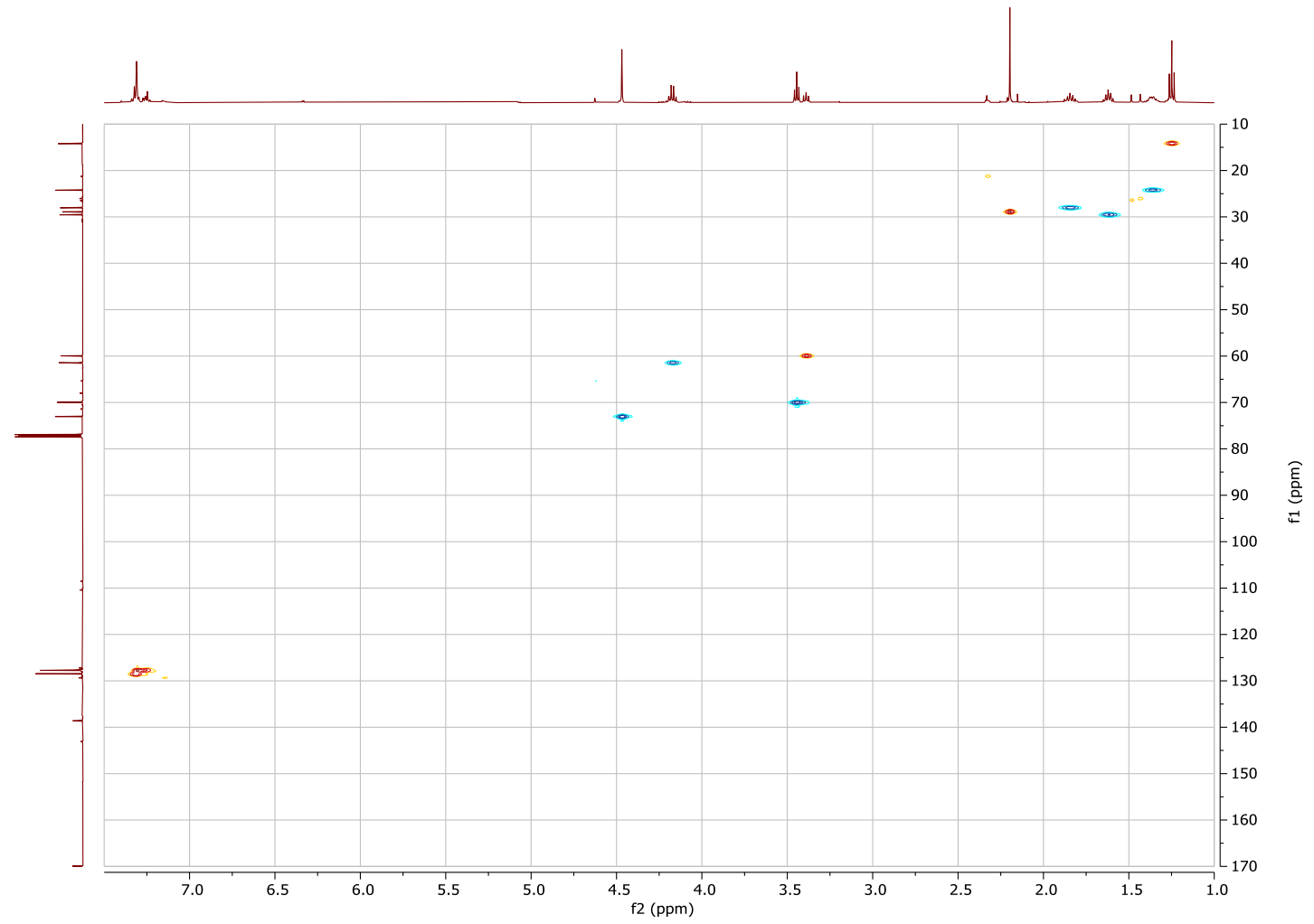


HMBC spectrum of Ethyl 2-acetyl-6-(benzyloxy)hexanoate (18) $\left(\mathrm{CDCl}_{3}, 500 \mathrm{MHz}\right)$

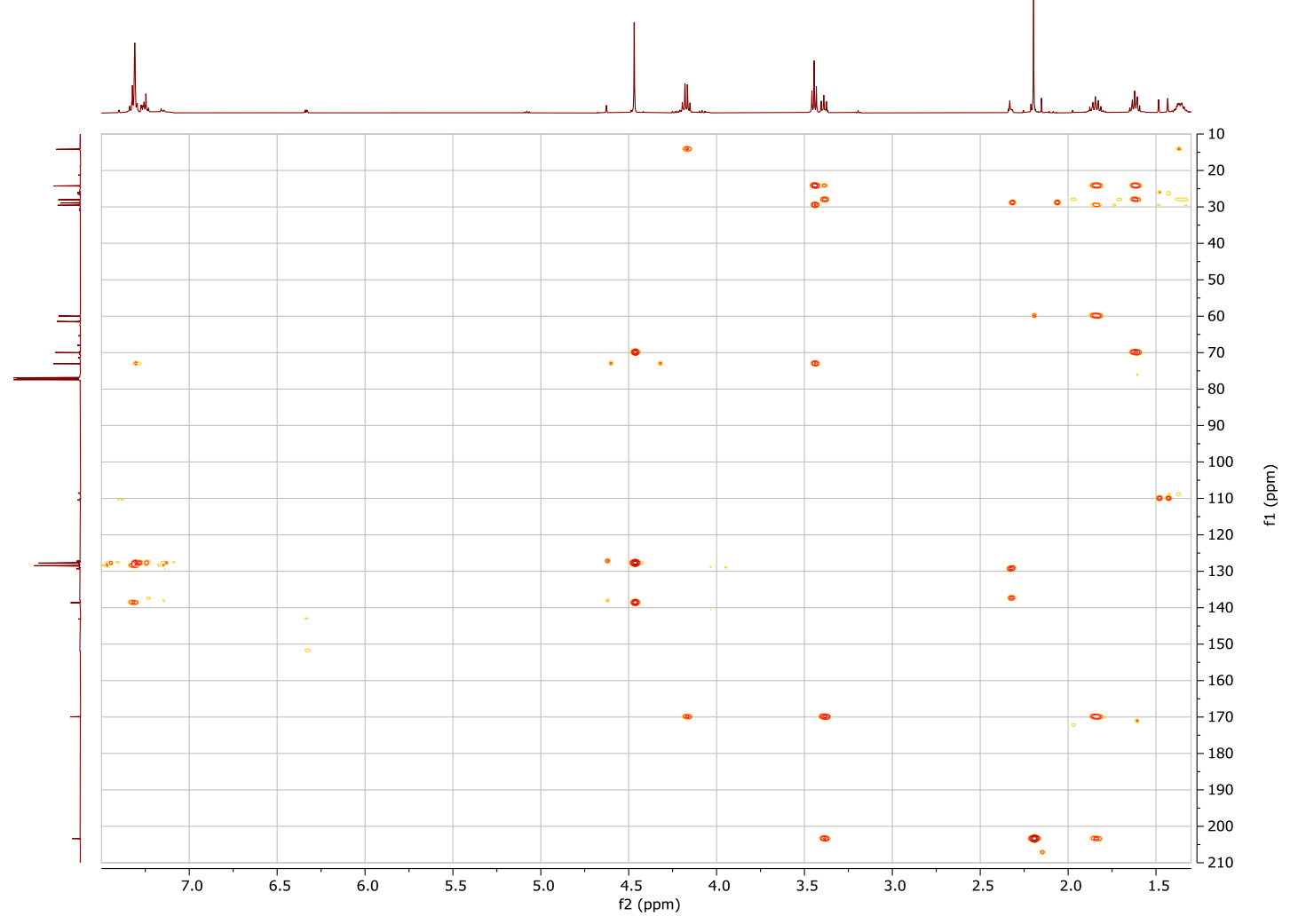


${ }^{1} \mathrm{H}$ NMR spectrum of 3-(4-(Benzyloxy)butyl)-2-methyl-4H-pyrido[1,2- $\left.\alpha\right]$ pyrimidin-4-one (20) $\left(\mathrm{CDCl}_{3}, 500 \mathrm{MHz}\right)$

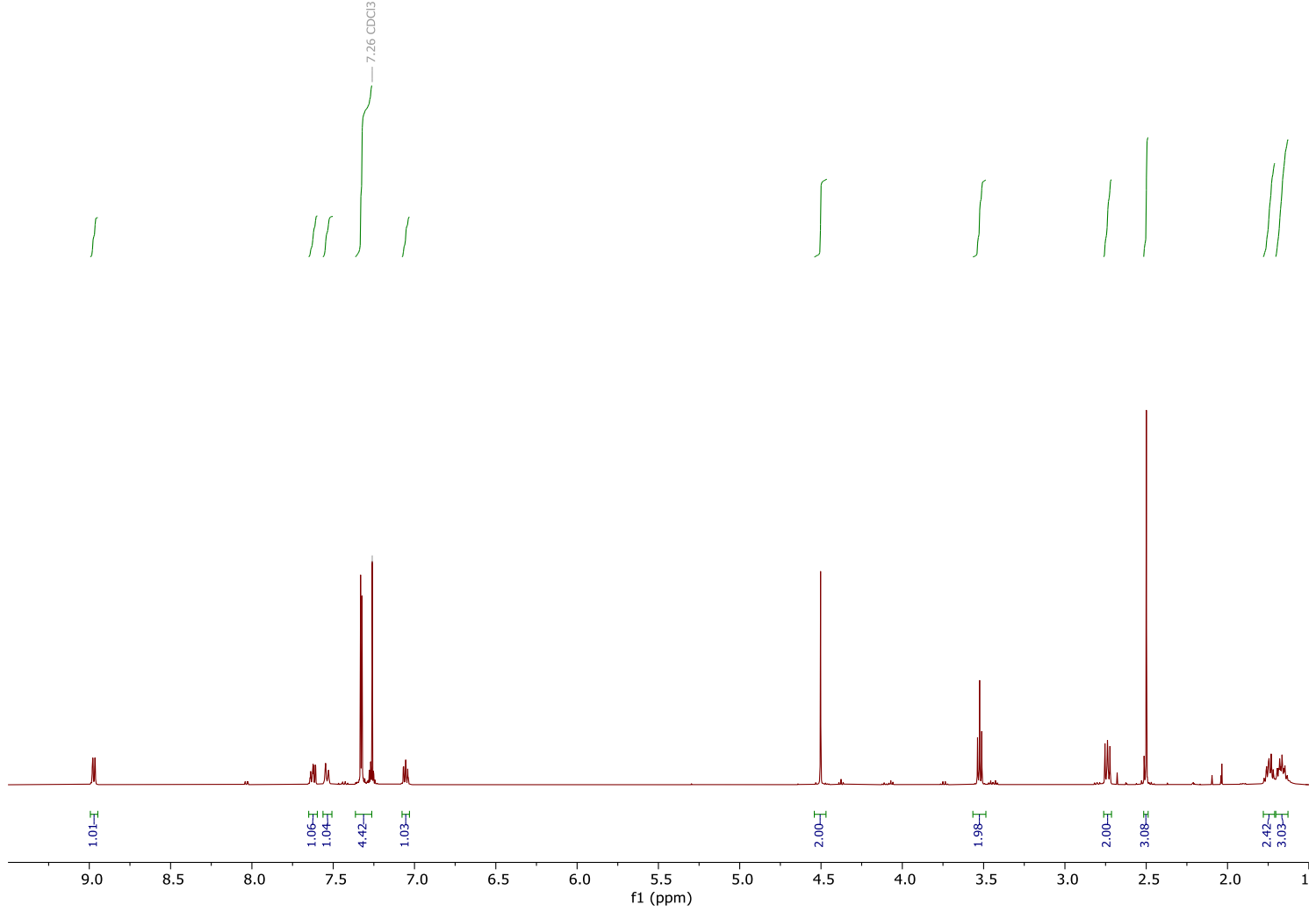

${ }^{13} \mathrm{C}$ NMR spectrum of 3-(4-(Benzyloxy)butyl)-2-methyl-4H-pyrido[1,2- $\left.\alpha\right]$ pyrimidin-4-one (20) $\left(\mathrm{CDCl}_{3}, 126 \mathrm{MHz}\right)$
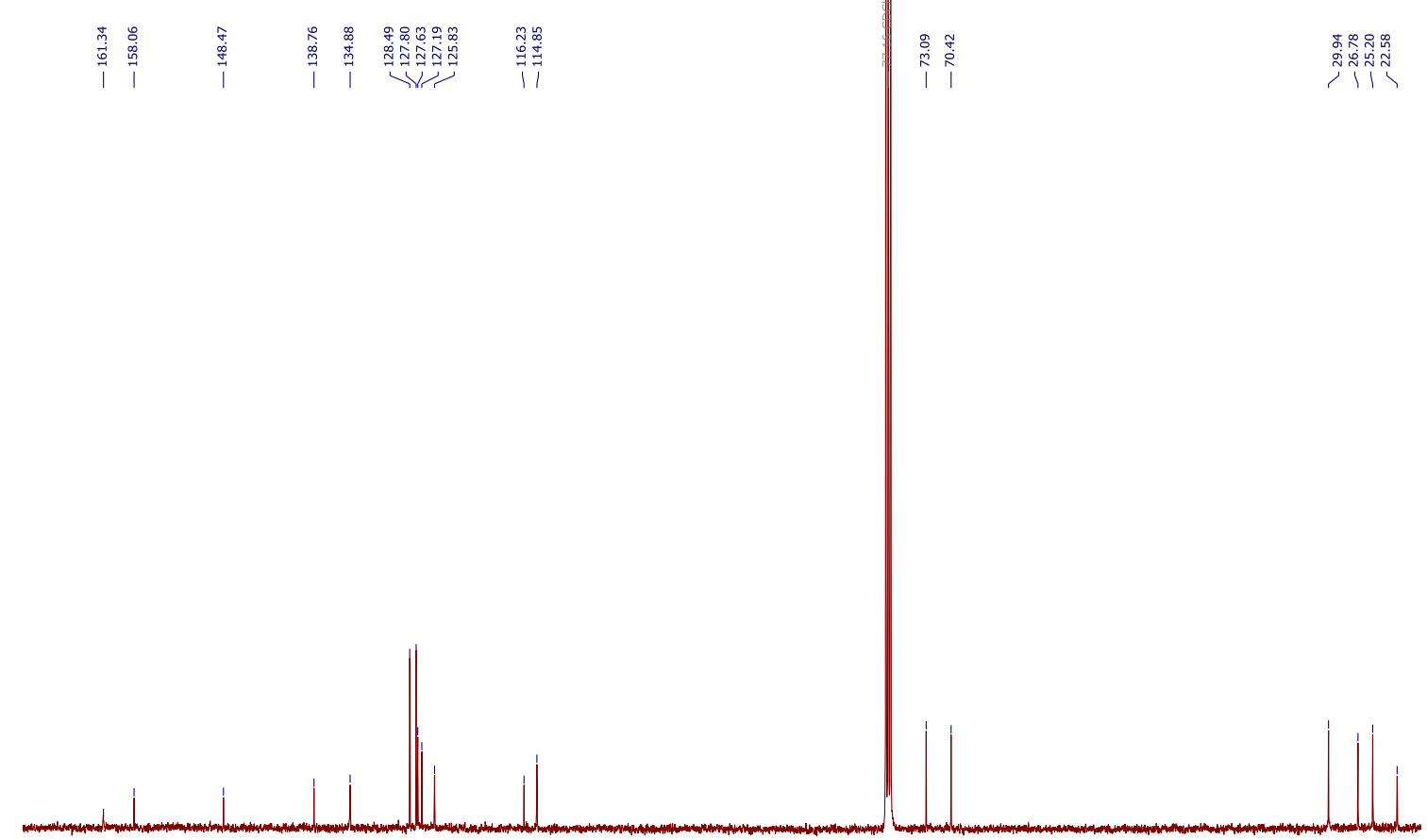

$\begin{array}{lllllllllllllllllllllllllllllllllllllll}165 & 160 & 155 & 150 & 145 & 140 & 135 & 130 & 125 & 120 & 115 & 110 & 105 & 100 & 95 & 90 & 85 & 80 & 75 & 70 & 65 & 60 & 55 & 50 & 45 & 40 & 35 & 30 & 25 & 2\end{array}$ 
COSY NMR spectrum of 3-(4-(Benzyloxy)butyl)-2-methyl-4H-pyrido[1,2- $\alpha$ ]pyrimidin-4-one (20) $\left(\mathrm{CDCl}_{3}, 500 \mathrm{MHz}\right)$

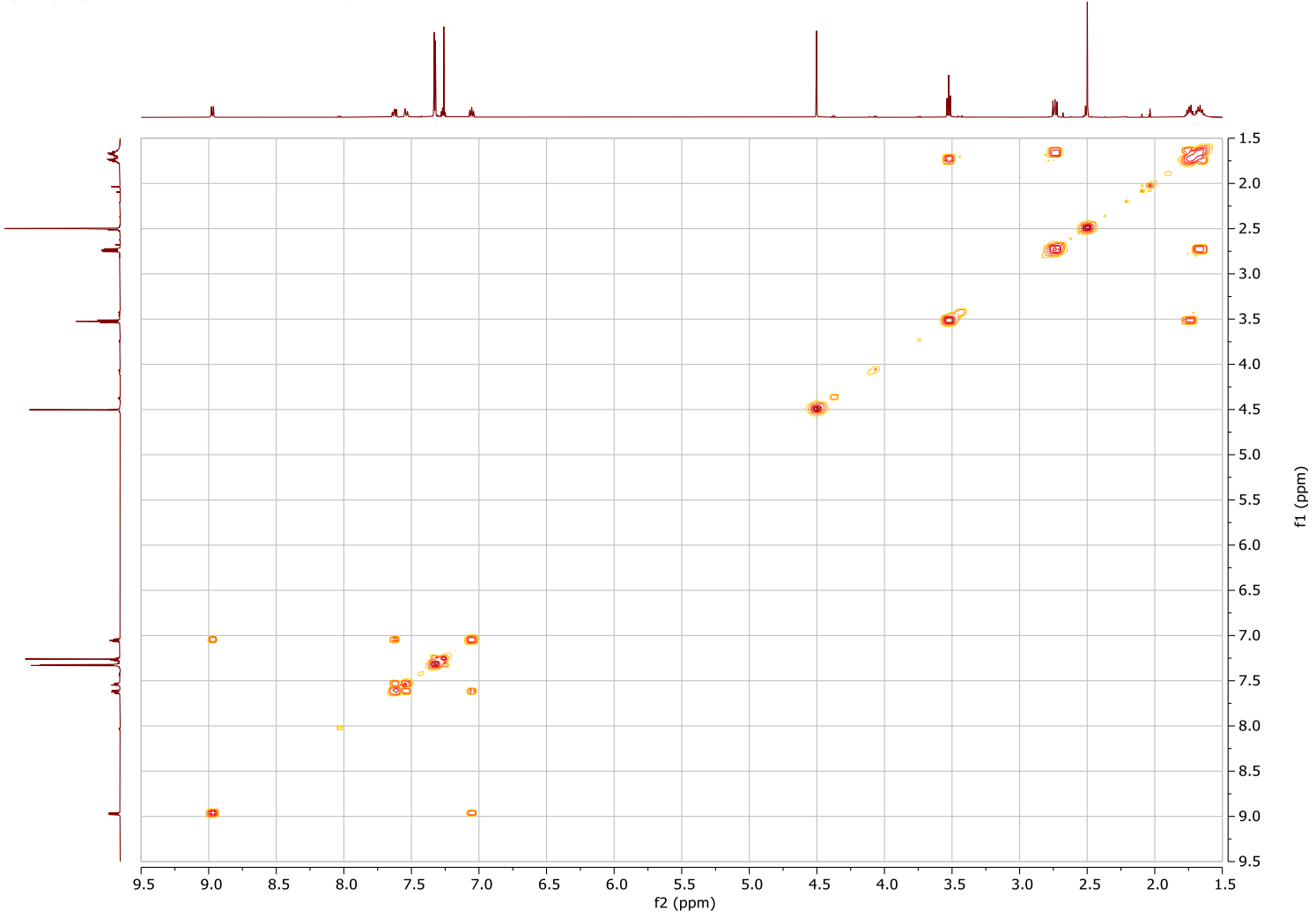

HSQC NMR spectrum of 3-(4-(Benzyloxy)butyl)-2-methyl-4H-pyrido[1,2- $\alpha$ ]pyrimidin-4-one (20) $\left(\mathrm{CDCl}_{3}, 500 \mathrm{MHz}\right)$

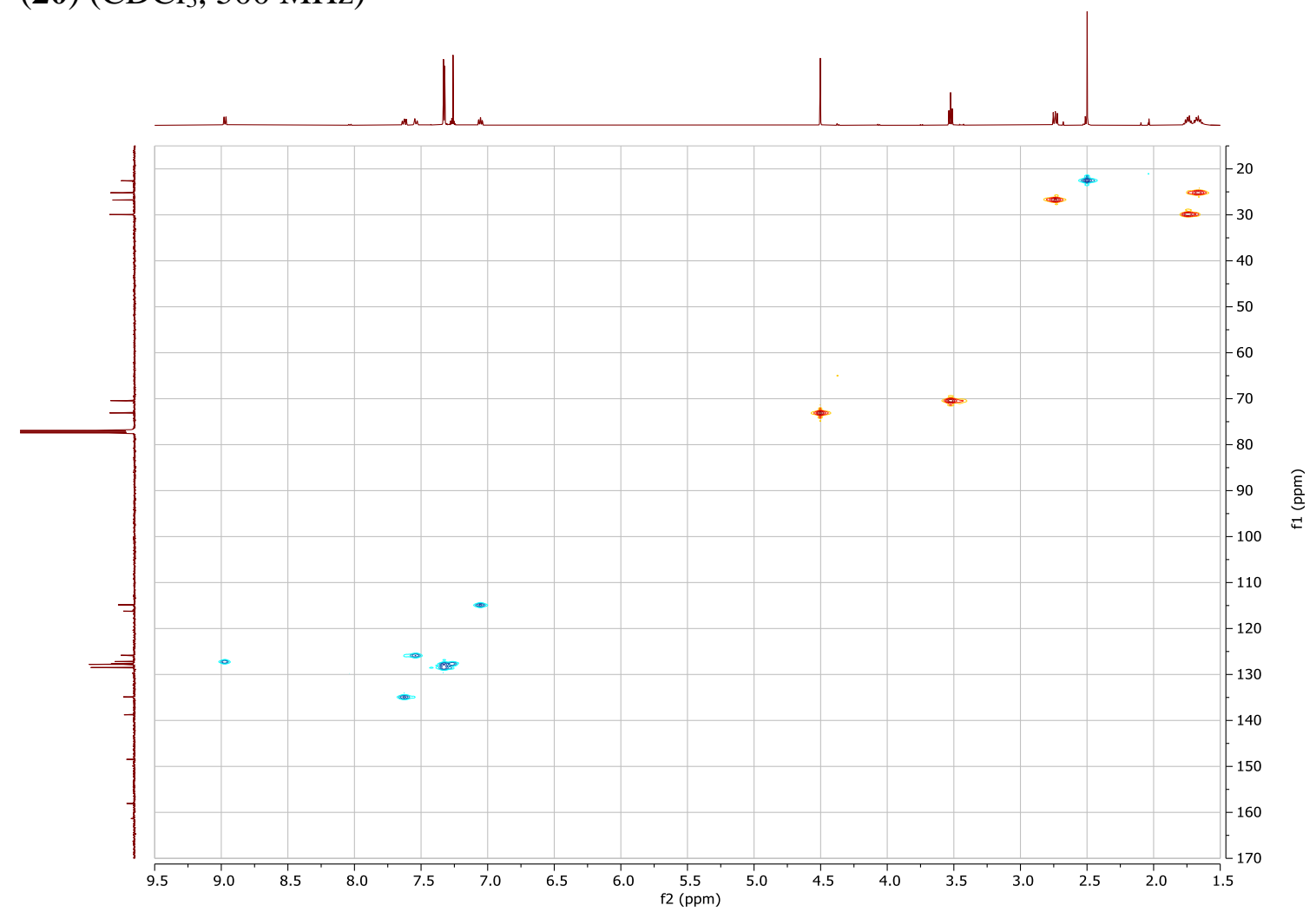


HMBC NMR spectrum of 3-(4-(Benzyloxy)butyl)-2-methyl-4H-pyrido[1,2- $\alpha$ pyrimidin-4one (20) $\left(\mathrm{CDCl}_{3}, 500 \mathrm{MHz}\right)$

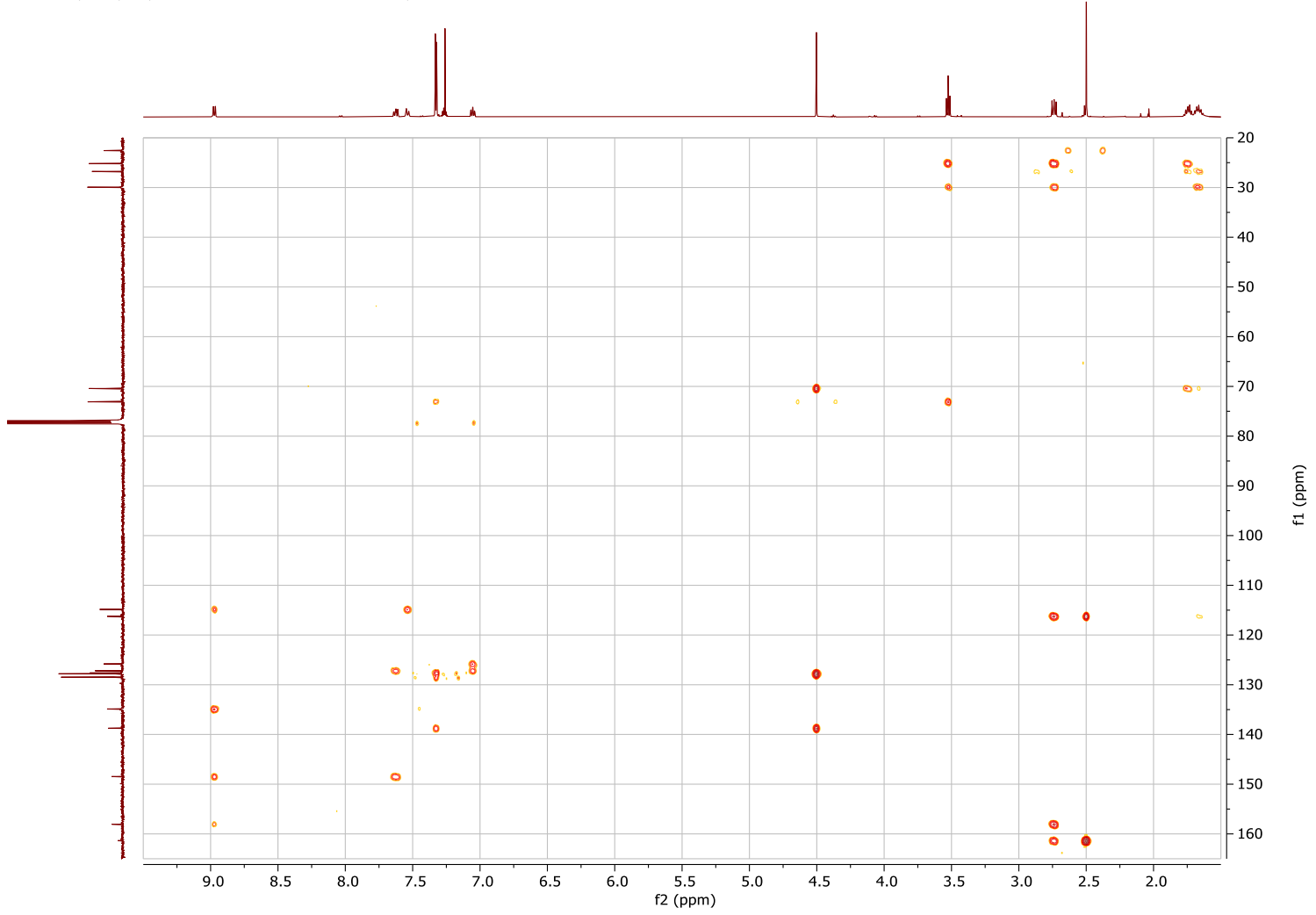


${ }^{1} \mathrm{H}$ NMR spectrum of 3-(4-(Benzyloxy)butyl)-2-methyl-6,7,8,9-tetrahydro-4H-pyrido[1,2$\alpha$ ]pyrimidin-4-one (22) $\left(\mathrm{CDCl}_{3}, 500 \mathrm{MHz}\right)$
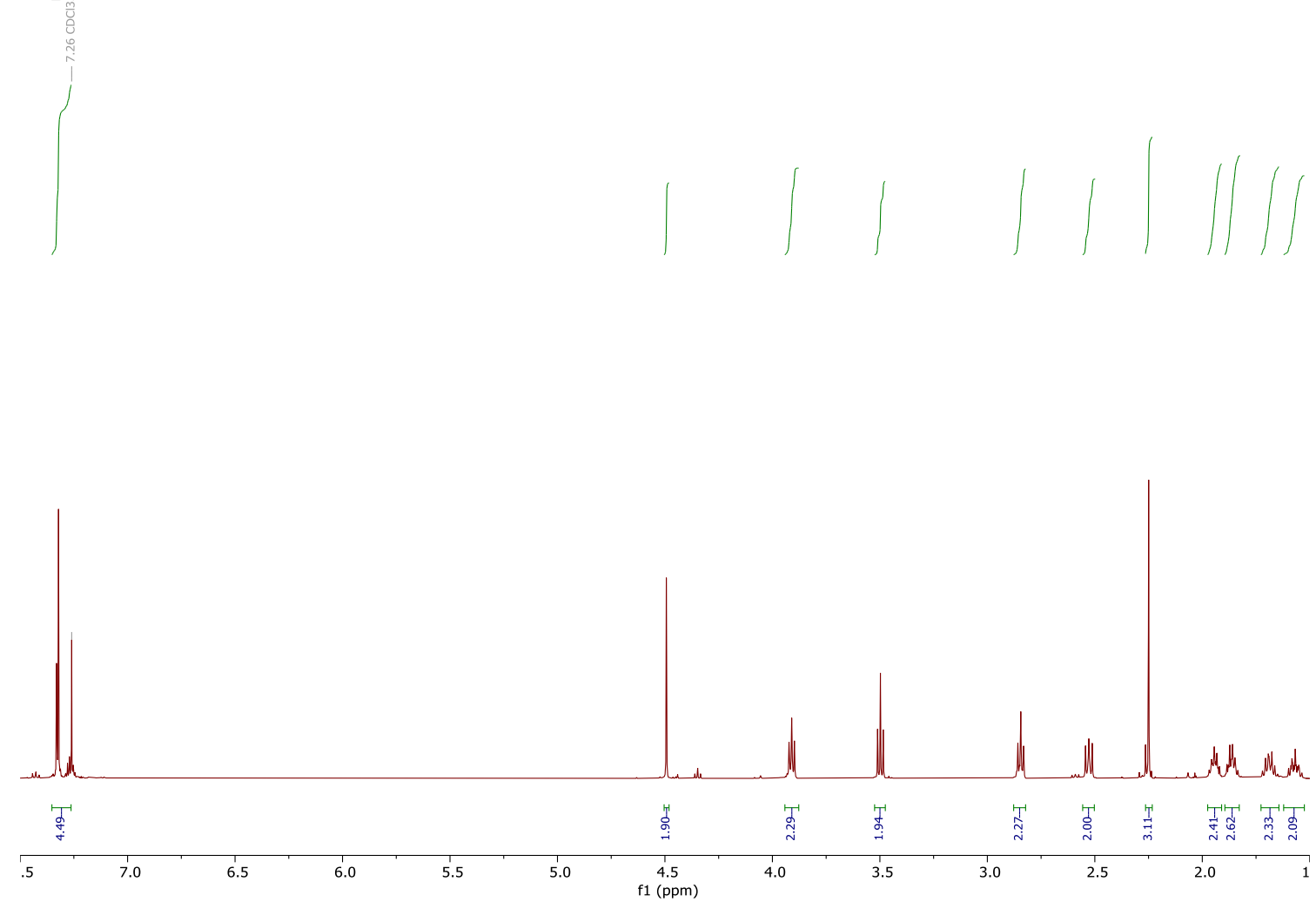

${ }^{13} \mathrm{C}$ NMR spectrum of 3-(4-(Benzyloxy)butyl)-2-methyl-6,7,8,9-tetrahydro-4H-pyrido[1,2$\alpha$ ]pyrimidin-4-one $(\mathbf{2 2})\left(\mathrm{CDCl}_{3}, 126 \mathrm{MHz}\right)$

\begin{tabular}{|c|c|c|}
\hline 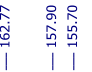 & $\begin{array}{c}\text { 尺 } \\
\infty \\
\stackrel{m}{m} \\
\mid\end{array}$ & 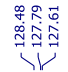 \\
\hline
\end{tabular}

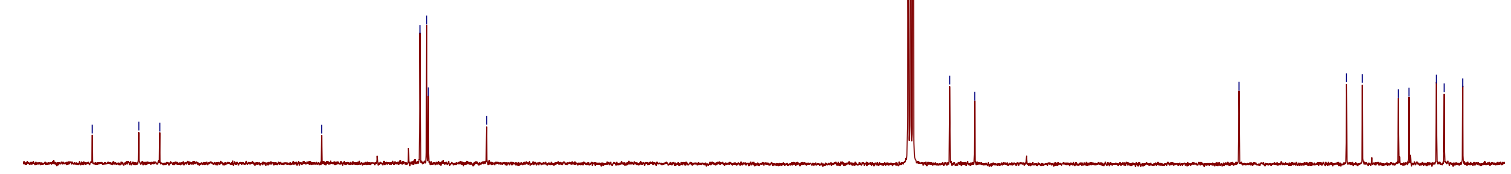

$\begin{array}{lllllllllllllllllllllllllllllllllllllllllll}165 & 160 & 155 & 150 & 145 & 140 & 135 & 130 & 125 & 120 & 115 & 110 & 105 & 100 & 95 & 90 & 85 & 80 & 75 & 70 & 65 & 60 & 55 & 50 & 45 & 40 & 35 & 30 & 25 & 20 & 1\end{array}$ 
COSY NMR spectrum of 3-(4-(Benzyloxy)butyl)-2-methyl-6,7,8,9-tetrahydro-4Hpyrido[1,2- $\alpha$ pyrimidin-4-one $(\mathbf{2 2})\left(\mathrm{CDCl}_{3}, 500 \mathrm{MHz}\right)$

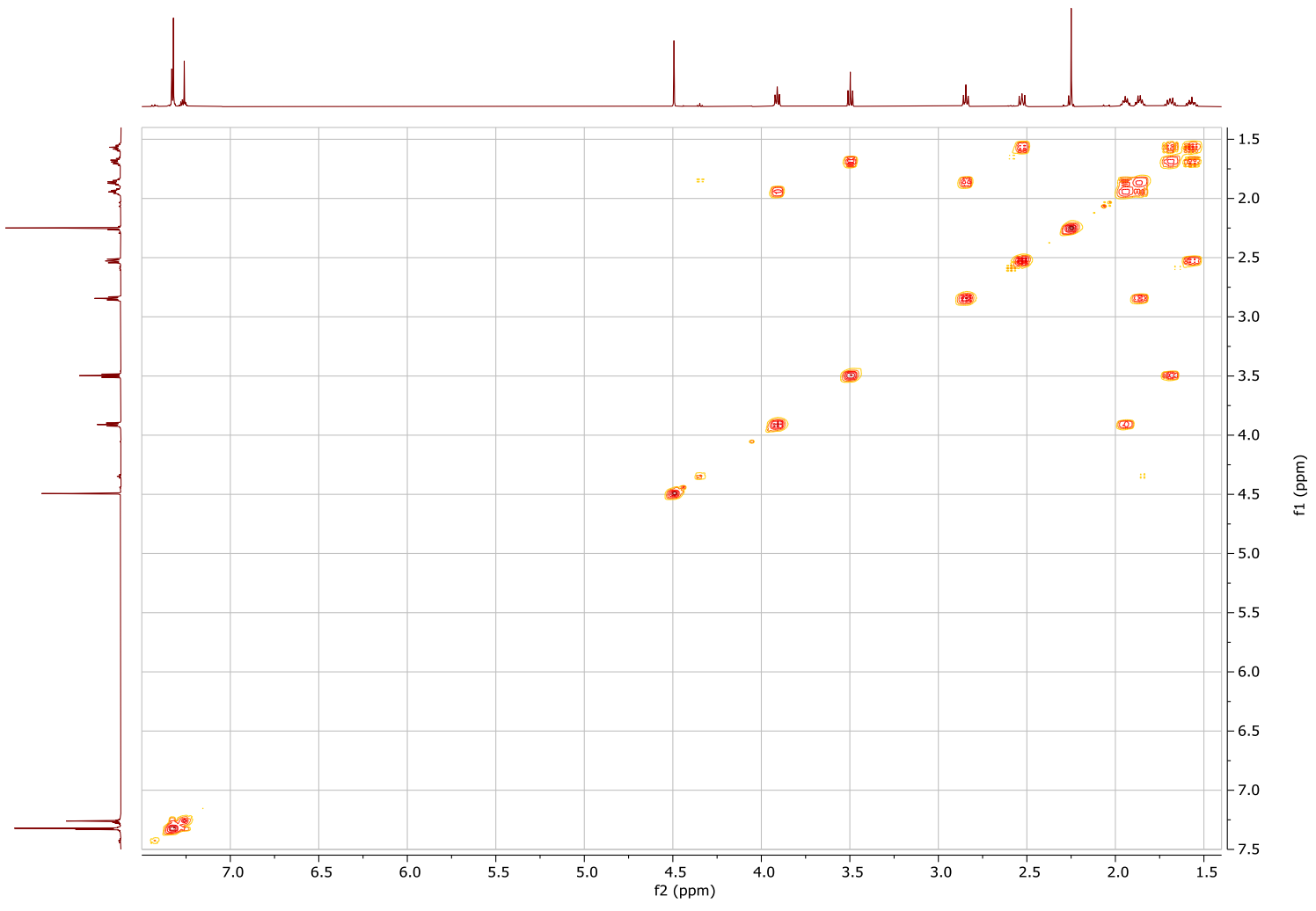

HSQC NMR spectrum of 3-(4-(Benzyloxy)butyl)-2-methyl-6,7,8,9-tetrahydro-4Hpyrido[1,2- $\alpha$ ]pyrimidin-4-one $(\mathbf{2 2})\left(\mathrm{CDCl}_{3}, 500 \mathrm{MHz}\right)$

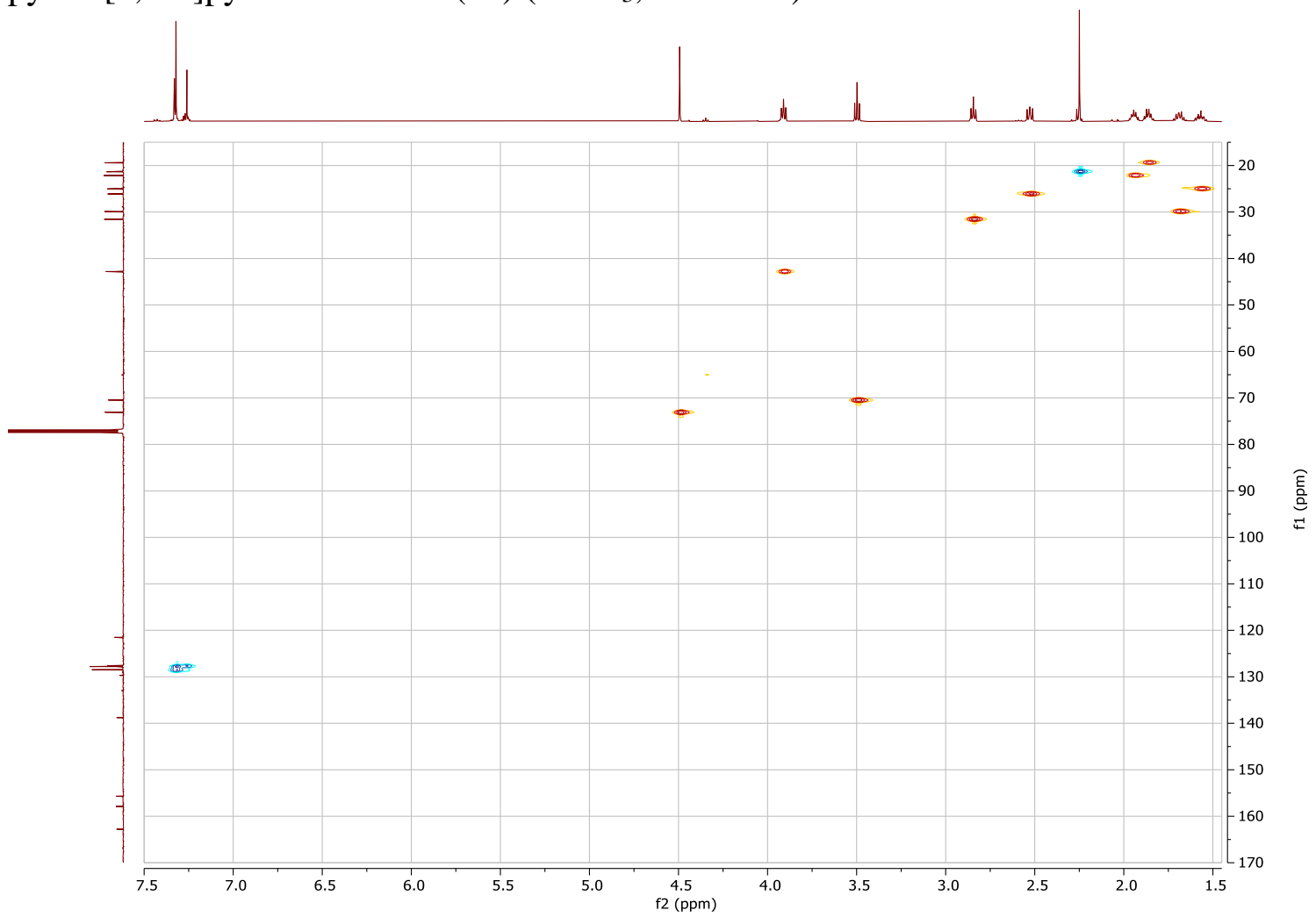


HMBC NMR spectrum of 3-(4-(Benzyloxy)butyl)-2-methyl-6,7,8,9-tetrahydro-4Hpyrido[1,2- $\alpha$ ]pyrimidin-4-one (20) $\left(\mathrm{CDCl}_{3}, 500 \mathrm{MHz}\right)$

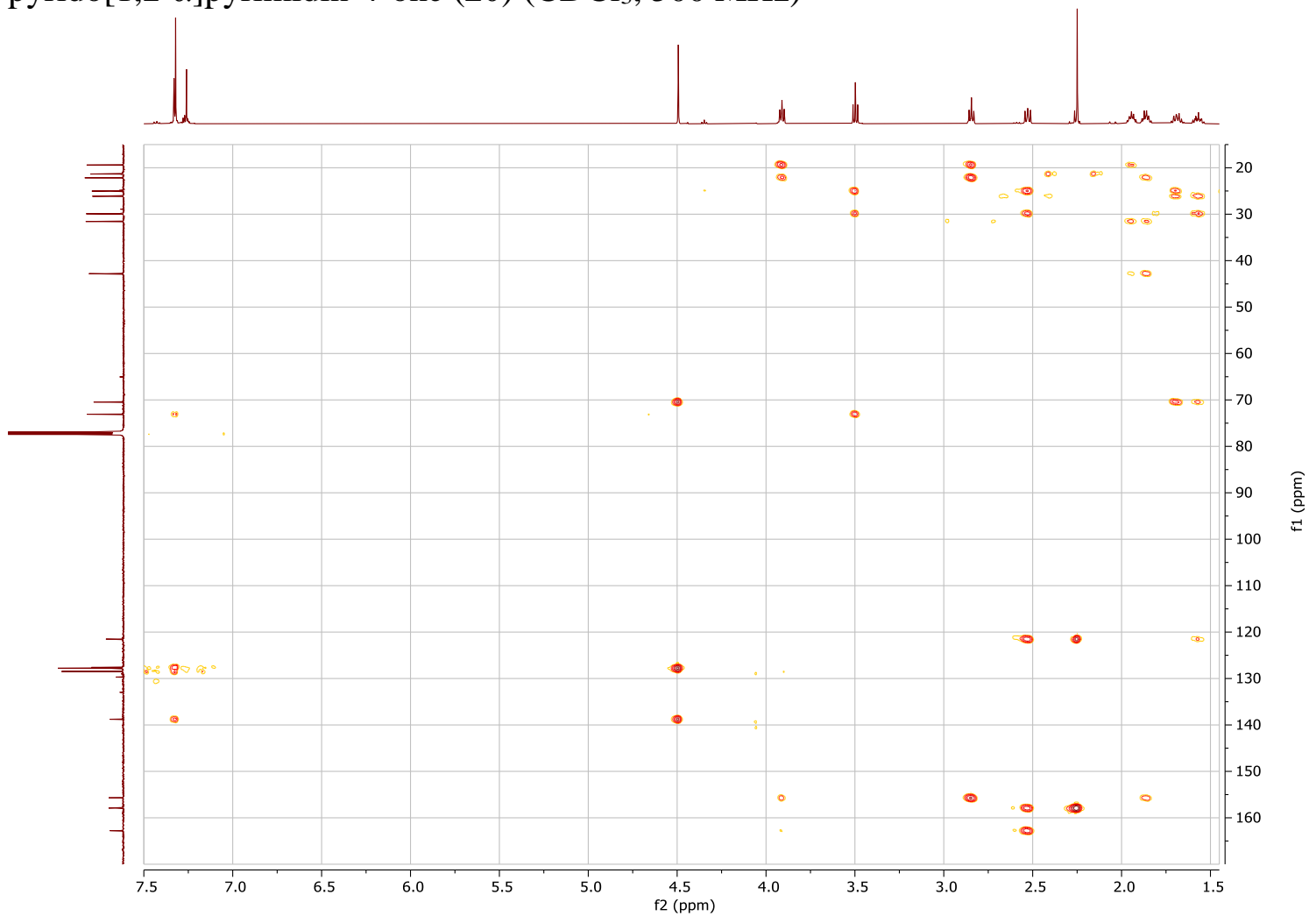


${ }^{1} \mathrm{H}$ NMR spectrum of 3-(4-Hydroxybutyl)-2-methyl-6,7,8,9-tetrahydro-4H-pyrido[1,2$\alpha$ ]pyrimidin-4-one (24) $\left(\mathrm{CDCl}_{3}, 500 \mathrm{MHz}\right)$
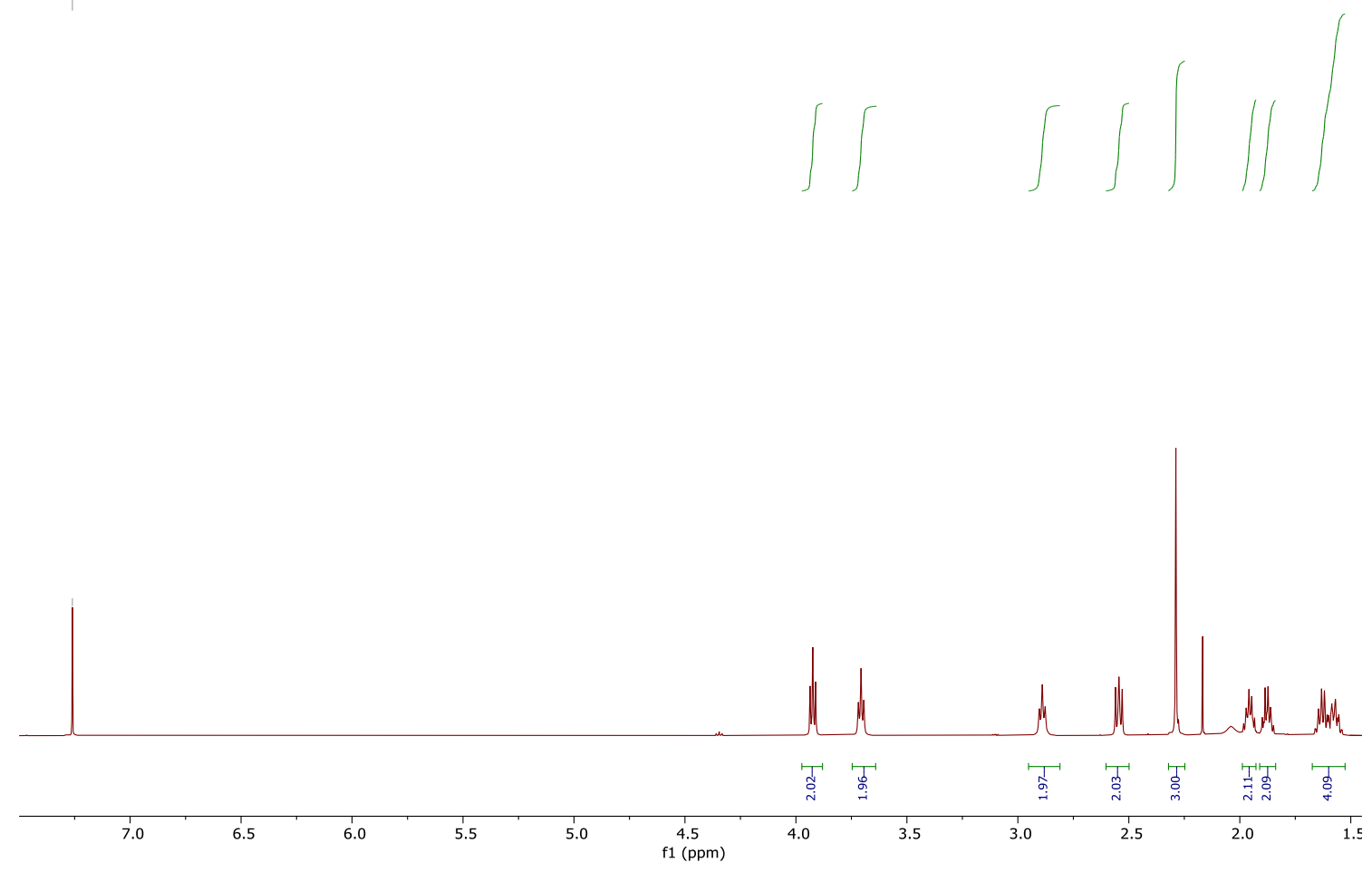

${ }^{13} \mathrm{C}$ NMR spectrum of 3-(4-Hydroxybutyl)-2-methyl-6,7,8,9-tetrahydro-4H-pyrido[1,2$\alpha$ ]pyrimidin-4-one $(\mathbf{2 4})\left(\mathrm{CDCl}_{3}, 126 \mathrm{MHz}\right)$

$$
\text { | }
$$
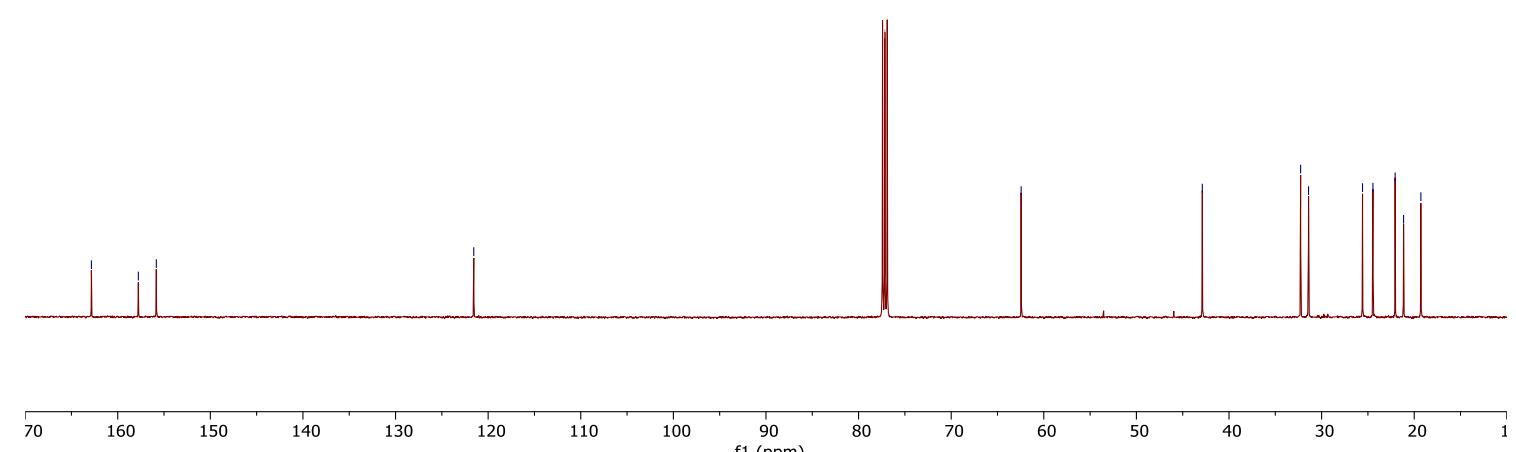
COSY NMR spectrum of 3-(4-Hydroxybutyl)-2-methyl-6,7,8,9-tetrahydro-4H-pyrido[1,2$\alpha$ ]pyrimidin-4-one (24) $\left(\mathrm{CDCl}_{3}, 500 \mathrm{MHz}\right)$

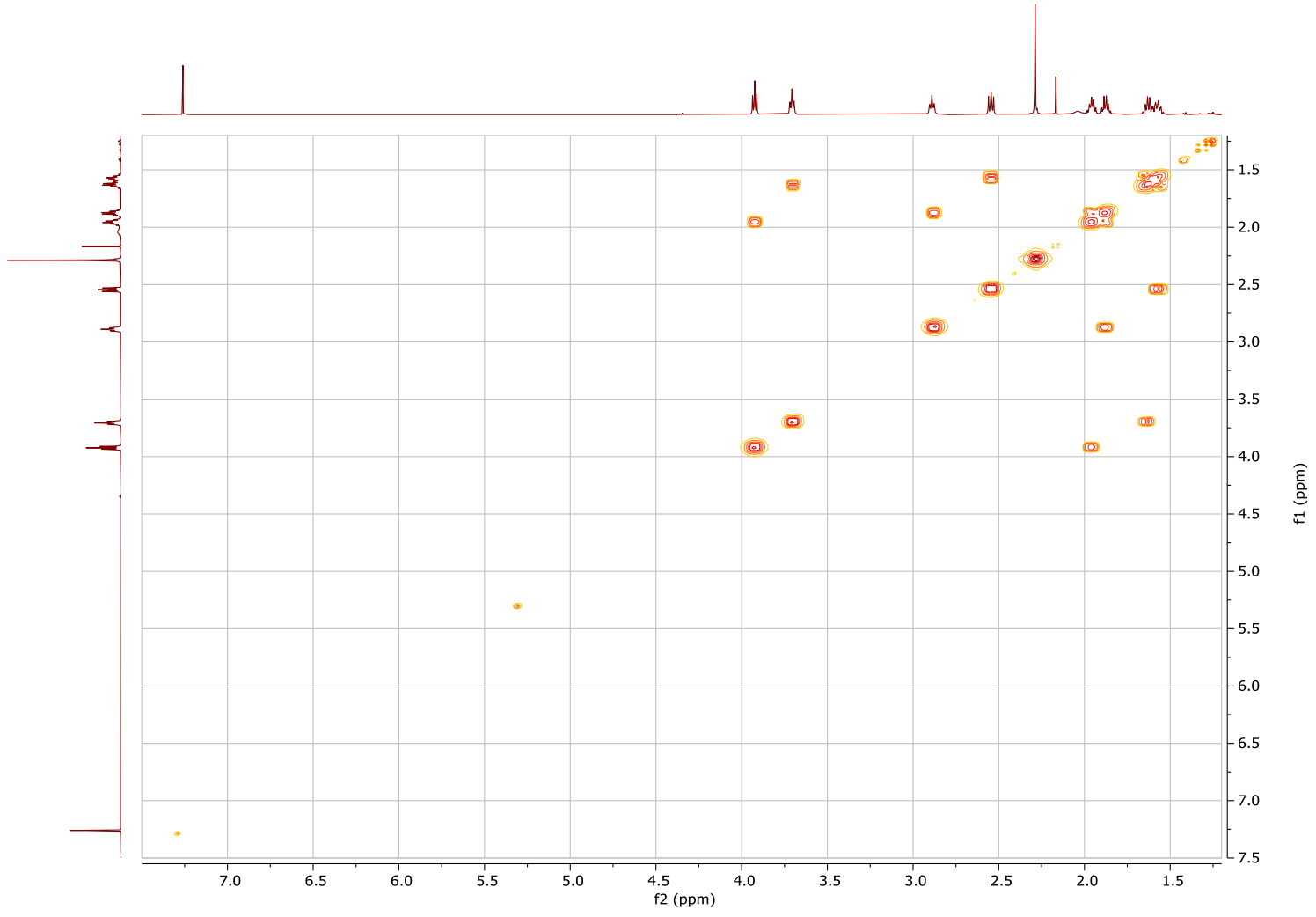

HSQC NMR spectrum of 3-(4-Hydroxybutyl)-2-methyl-6,7,8,9-tetrahydro-4H-pyrido[1,2$\alpha$ ]pyrimidin-4-one $(\mathbf{2 4})\left(\mathrm{CDCl}_{3}, 500 \mathrm{MHz}\right)$

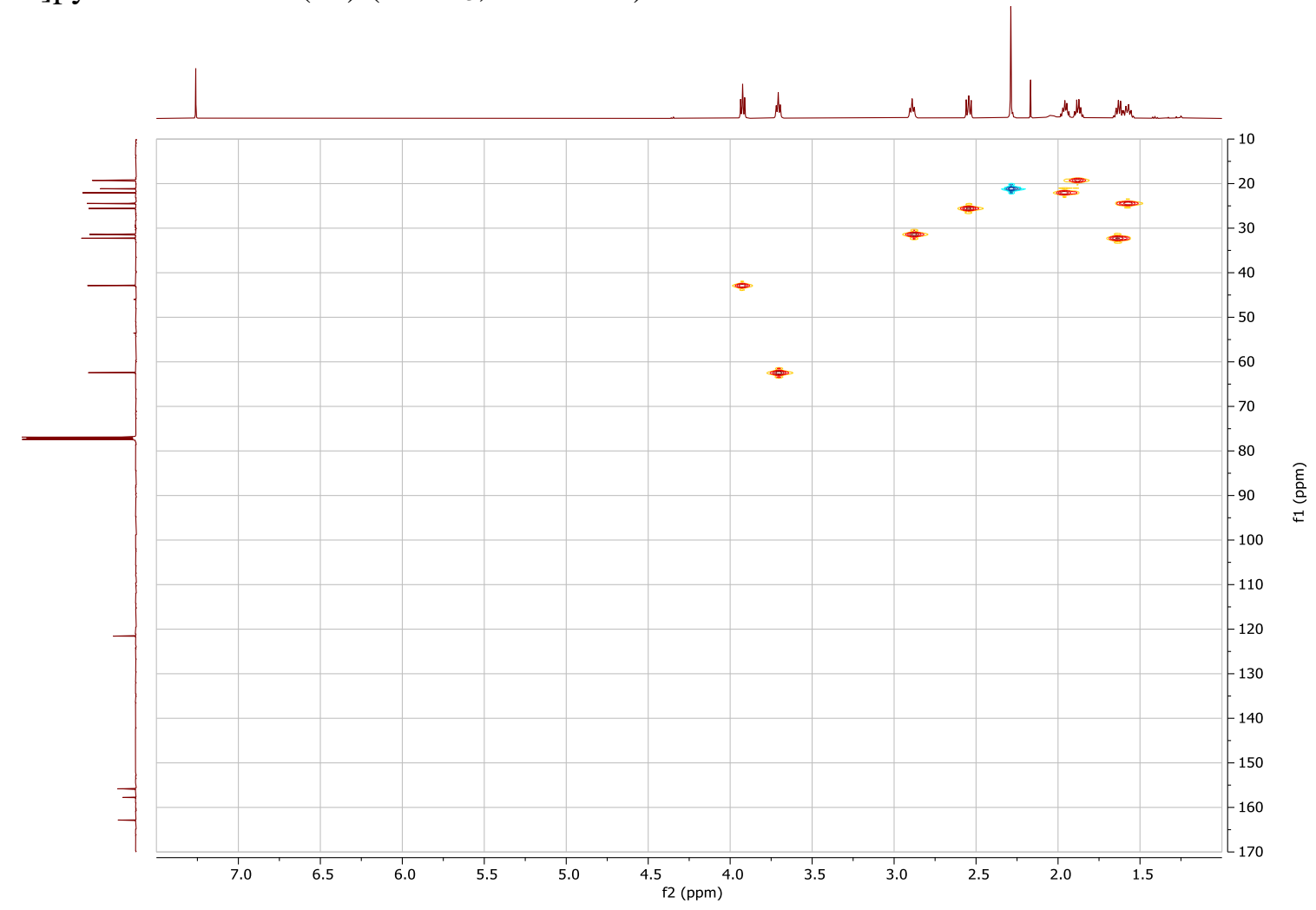


HMBC spectrum of 3-(4-Hydroxybutyl)-2-methyl-6,7,8,9-tetrahydro-4H-pyrido[1,2$\alpha$ ]pyrimidin-4-one (24) $\left(\mathrm{CDCl}_{3}, 500 \mathrm{MHz}\right)$

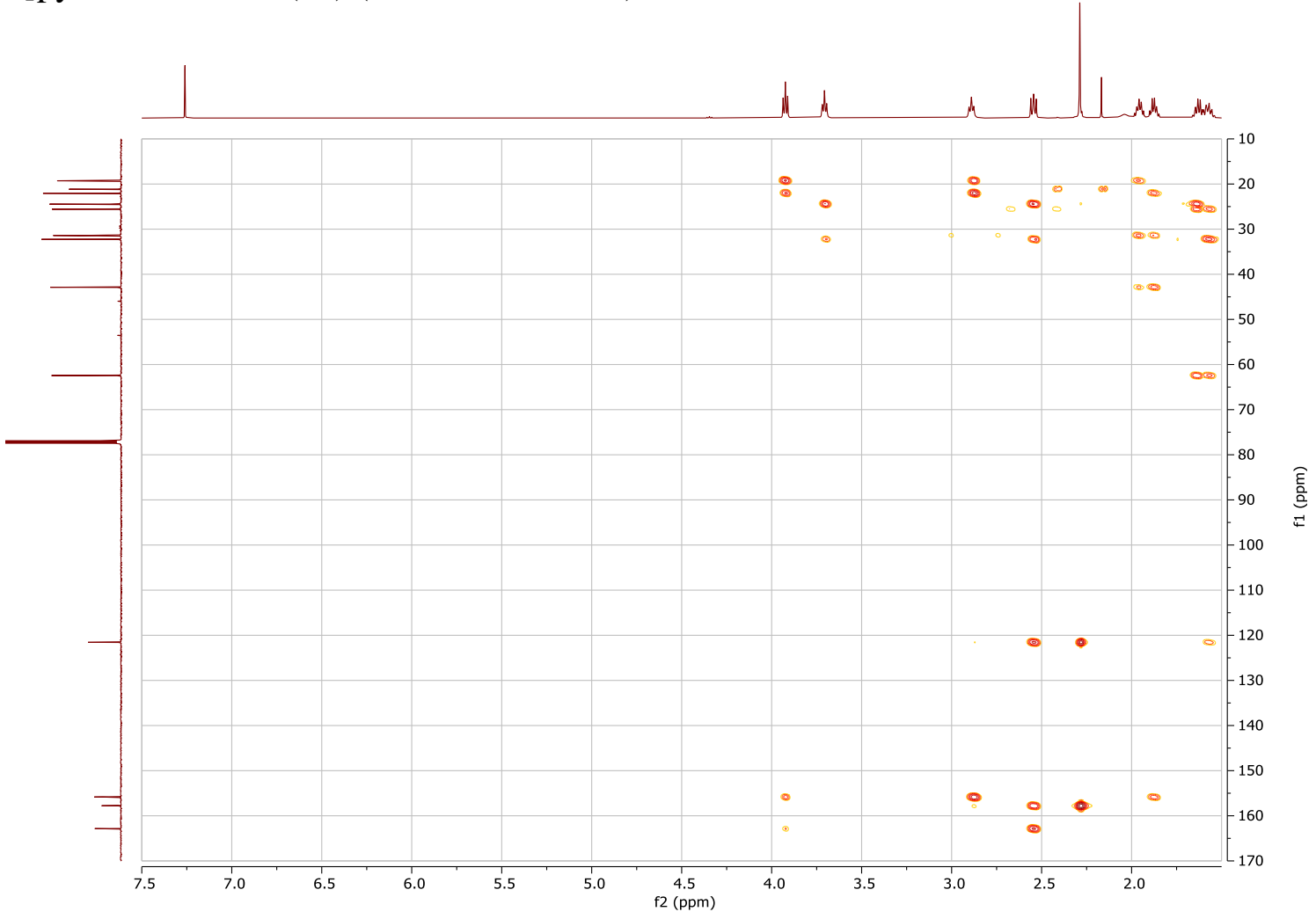


${ }^{1} \mathrm{H}$ NMR spectrum of 3-(4-Iodobutyl)-2-methyl-6,7,8,9-tetrahydro-4H-pyrido[1,2$\alpha$ ]pyrimidin-4-one $(\mathbf{2 6})\left(\mathrm{CDCl}_{3}, 500 \mathrm{MHz}\right)$
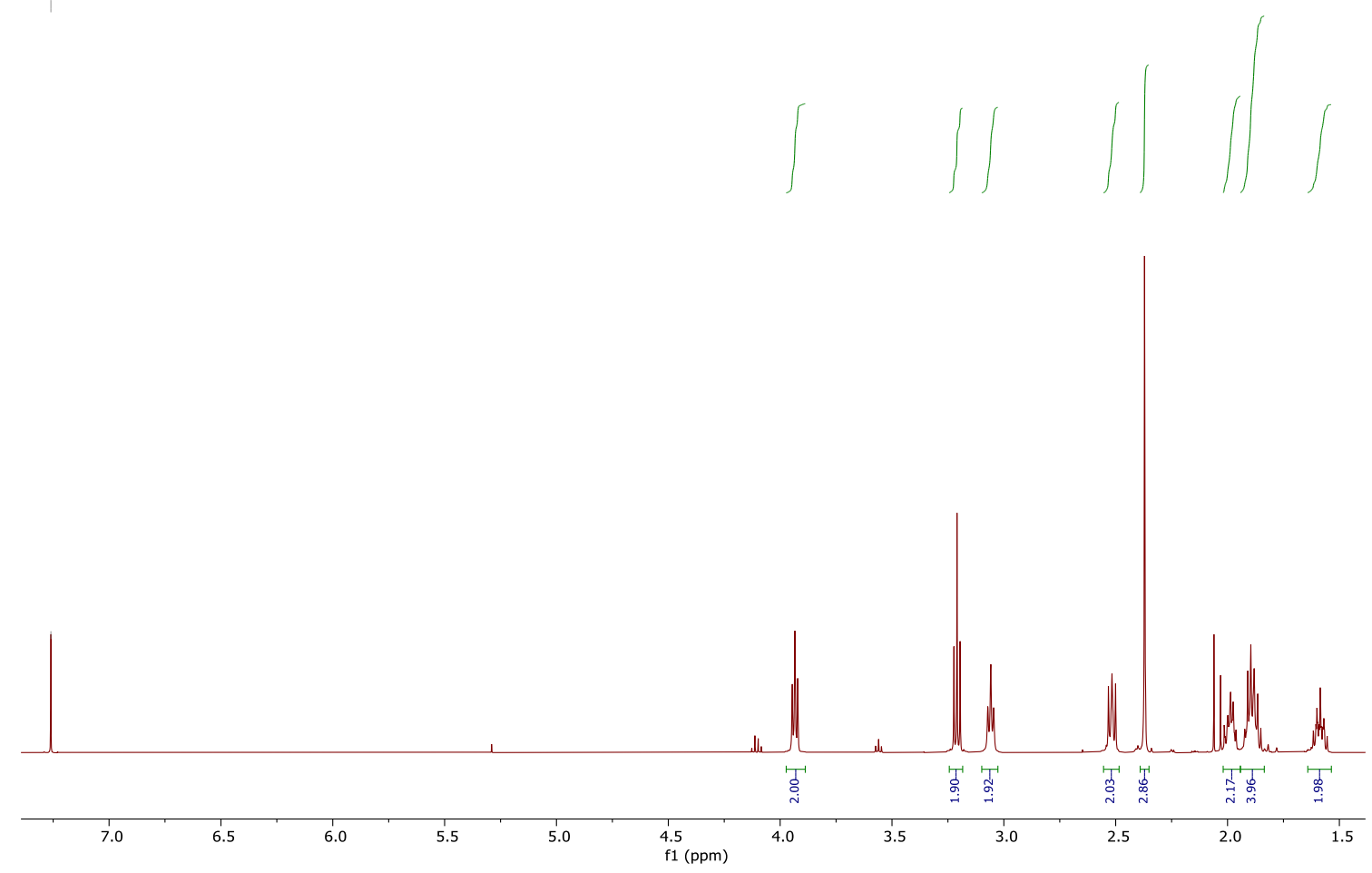
${ }^{1} \mathrm{H}$ NMR spectrum of 3-(4-(4-(6-Fluorobenzo[ $\left.d\right]$ isoxazol-3-yl)piperidin-1-yl)butyl)-2-methyl6,7,8,9-tetrahydro-4H-pyrido[1,2- $\alpha]$ pyrimidin-4-one $(9)\left(\mathrm{D}_{2} \mathrm{O}, 500 \mathrm{MHz}\right)$

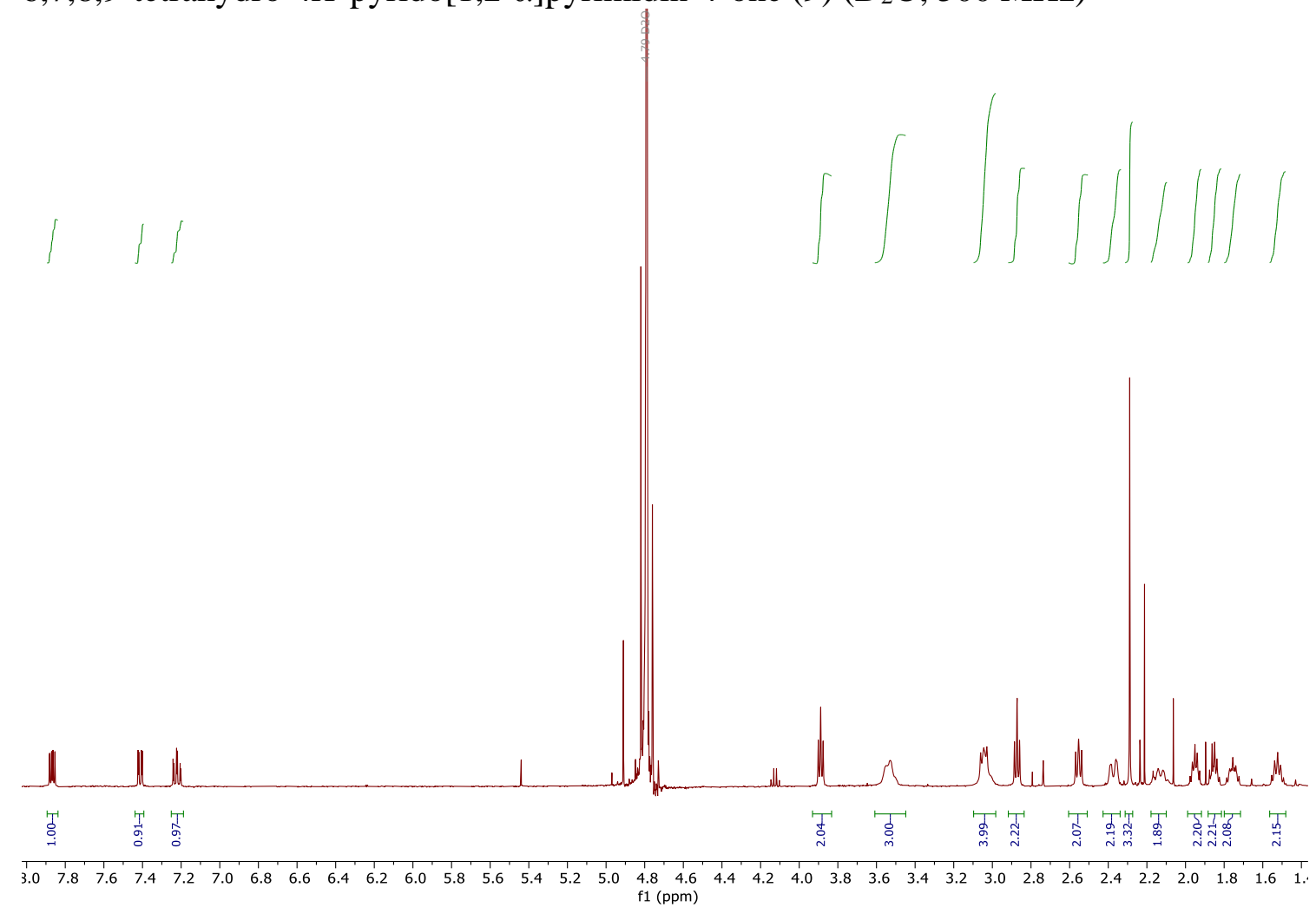

${ }^{1} \mathrm{H}$ NMR spectrum of 3-(4-(4-(6-Fluorobenzo[d]isoxazol-3-yl)piperidin-1-yl)butyl)-2-methyl6,7,8,9-tetrahydro-4H-pyrido[1,2- $\alpha]$ pyrimidin-4-one $(9)\left(\mathrm{CDCl}_{3}, 500 \mathrm{MHz}\right)$

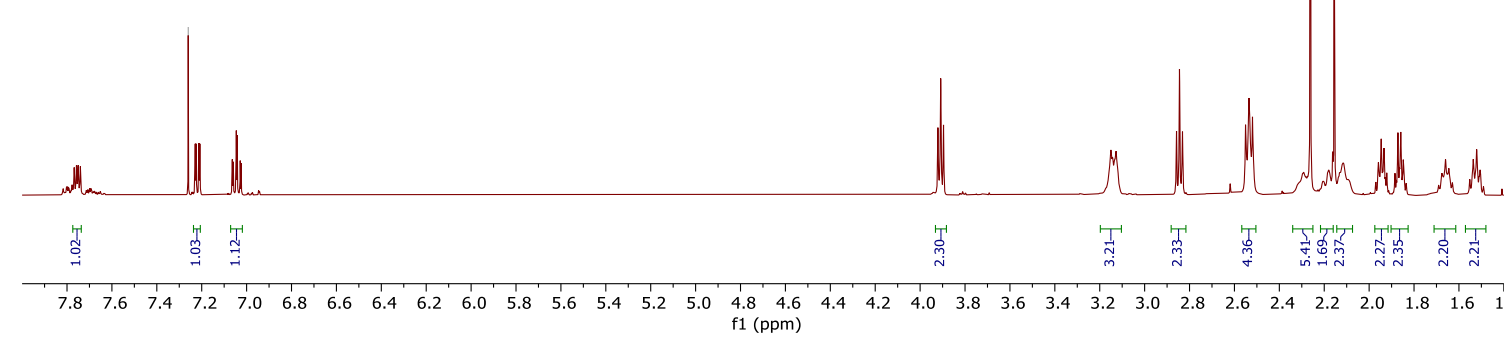


${ }^{13} \mathrm{C}$ NMR spectrum of 3-(4-(4-(6-Fluorobenzo[ $\left.d\right]$ isoxazol-3-yl)piperidin-1-yl)butyl)-2methyl-6,7,8,9-tetrahydro-4H-pyrido[1,2- $\alpha$ ]pyrimidin-4-one (9) $\left(\mathrm{CDCl}_{3}, 126 \mathrm{MHz}\right)$
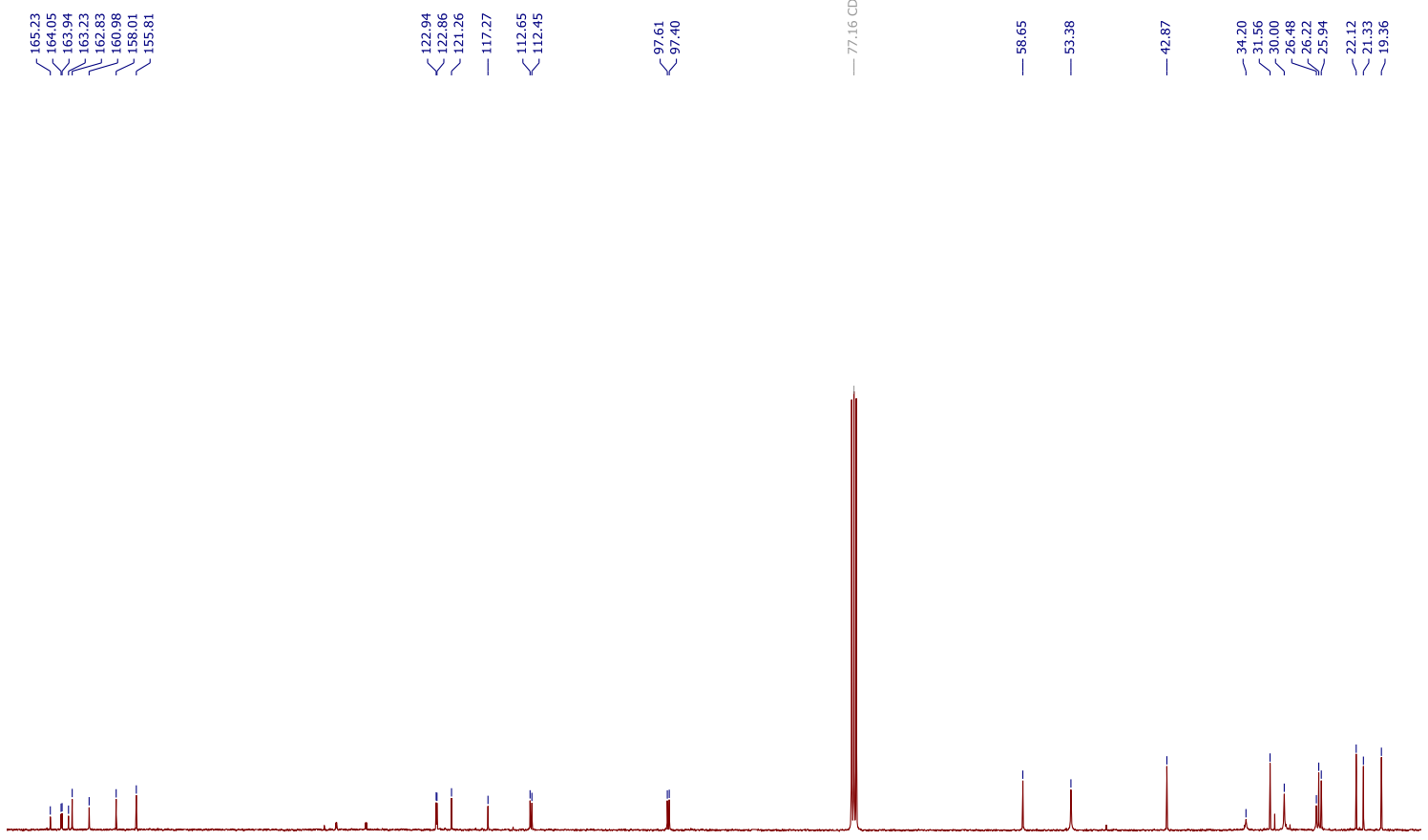

$\begin{array}{lllllllllllllllllllllllllllllllllllllll}70 & 165 & 160 & 155 & 150 & 145 & 140 & 135 & 130 & 125 & 120 & 115 & 110 & 105 & 100 & 95 & 90 & 85 & 80 & 75 & 70 & 65 & 60 & 55 & 50 & 45 & 40 & 35 & 30 & 25 & 20 & 1\end{array}$

COSY NMR spectrum of 3-(4-(4-(6-Fluorobenzo[ $d$ ]isoxazol-3-yl)piperidin-1-yl)butyl)-2methyl-6,7,8,9-tetrahydro-4H-pyrido[1,2- $\alpha$ ]pyrimidin-4-one (9) $\left(\mathrm{CDCl}_{3}, 500 \mathrm{MHz}\right)$

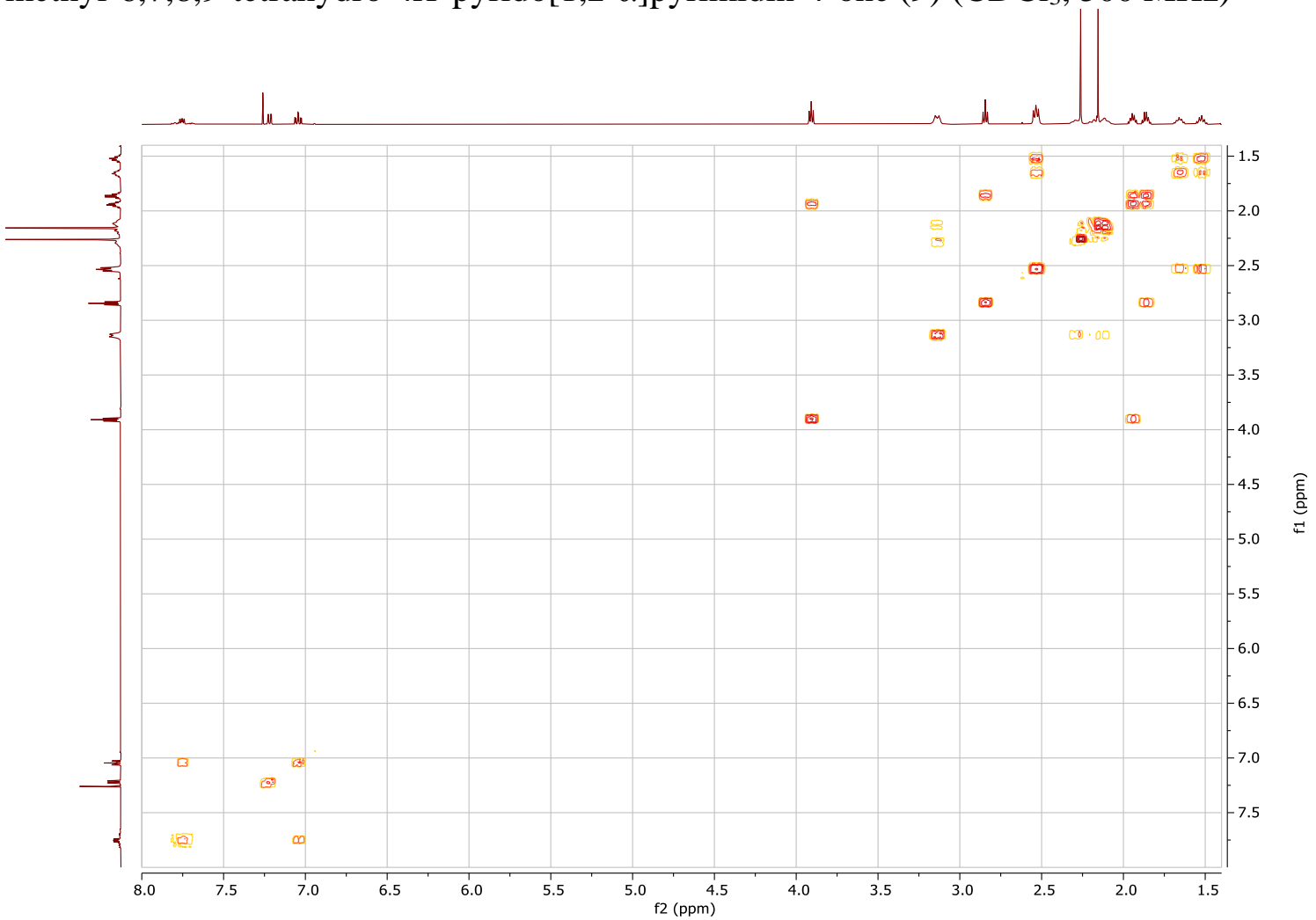


HSQC NMR spectrum of 3-(4-(4-(6-Fluorobenzo[ $d$ ]isoxazol-3-yl)piperidin-1-yl)butyl)-2methyl-6,7,8,9-tetrahydro-4H-pyrido[1,2- $\alpha$ ]pyrimidin-4-one (9) $\left(\mathrm{CDCl}_{3}, 500 \mathrm{MHz}\right)$

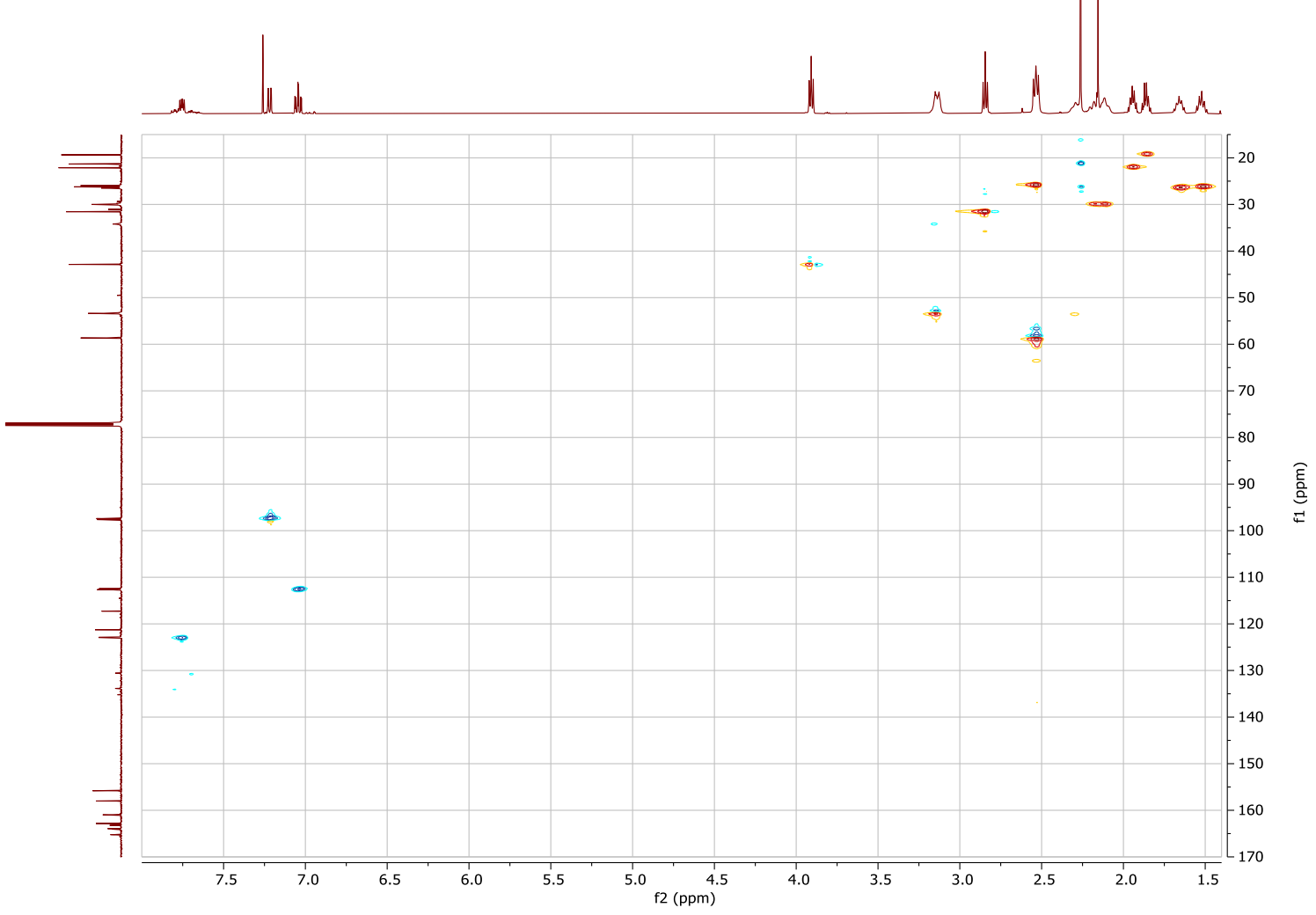

HMBC NMR spectrum of 3-(4-(4-(6-Fluorobenzo[d]isoxazol-3-yl)piperidin-1-yl)butyl)-2methyl-6,7,8,9-tetrahydro-4H-pyrido[1,2- $\alpha$ ]pyrimidin-4-one (9) $\left(\mathrm{CDCl}_{3}, 500 \mathrm{MHz}\right)$

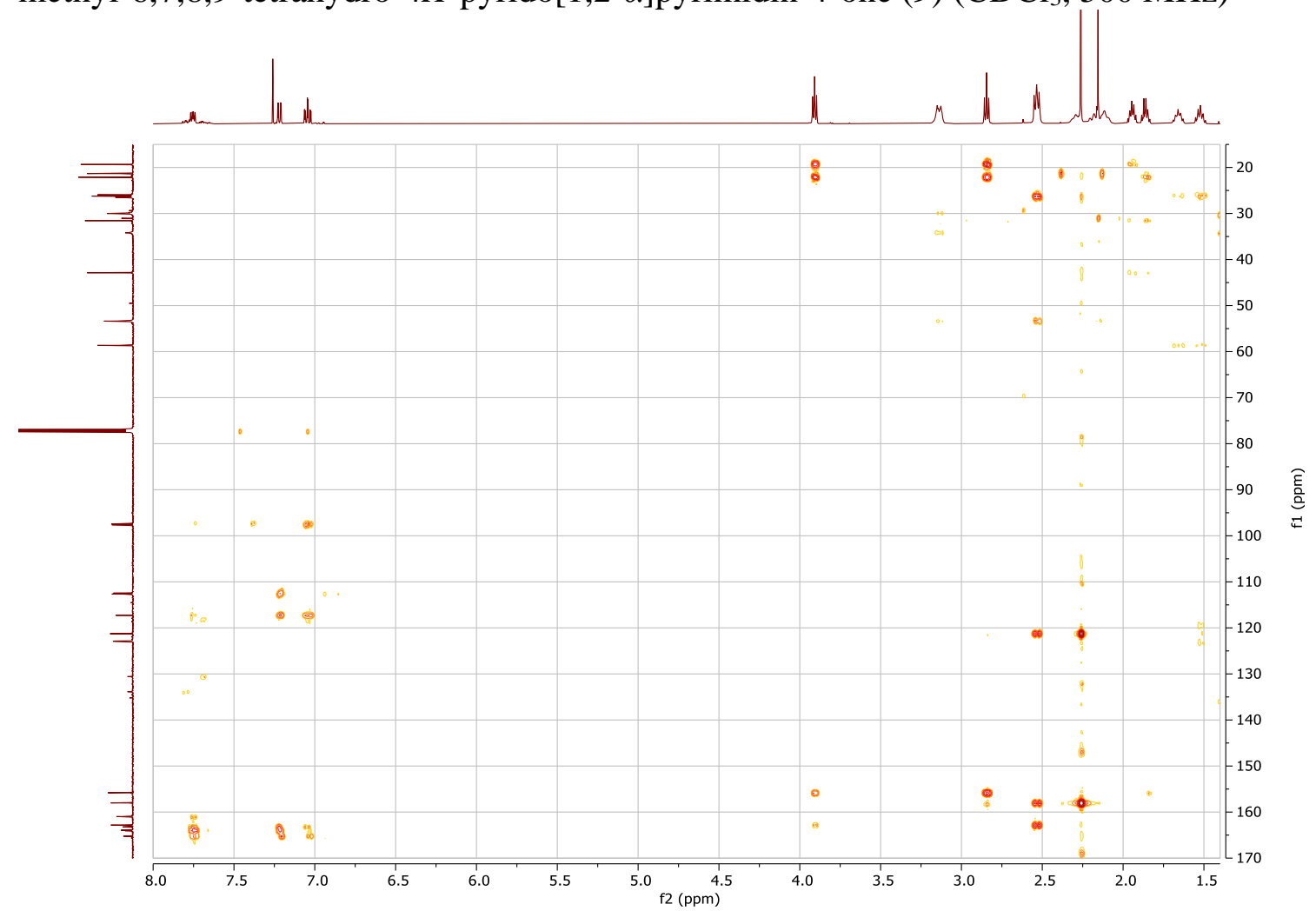


${ }^{1} \mathrm{H}$ NMR spectrum of 3-(4-Hydroxybutyl)-2-methyl-4H-pyrido[1,2- $\alpha$ ]pyrimidin-4-one (30) $\left(\mathrm{CDCl}_{3}, 500 \mathrm{MHz}\right)$

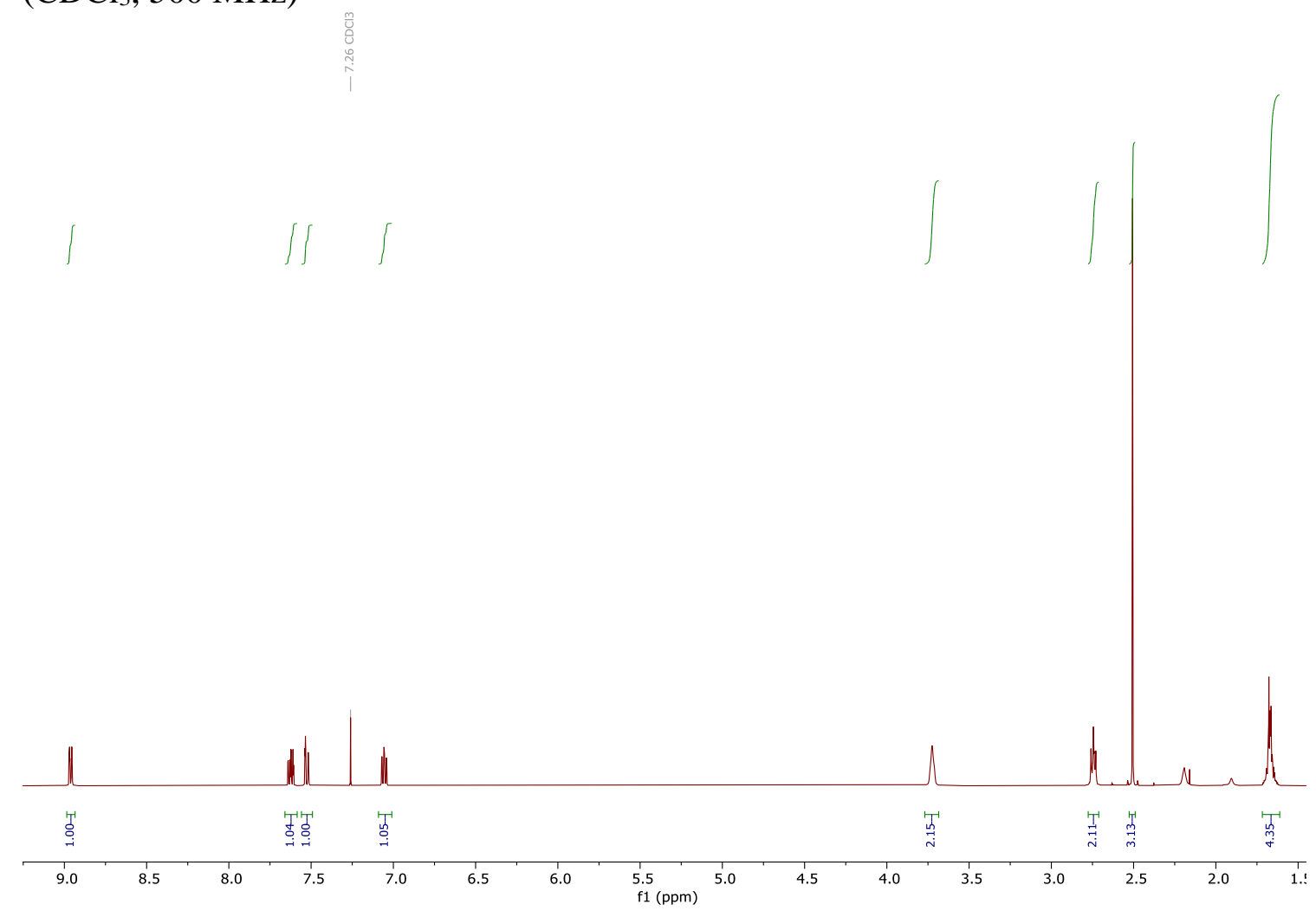

${ }^{13} \mathrm{C}$ NMR spectrum of 3-(4-Hydroxybutyl)-2-methyl-4H-pyrido[1,2- $\alpha$ ]pyrimidin-4-one (30) $\left(\mathrm{CDCl}_{3}, 126 \mathrm{MHz}\right)$

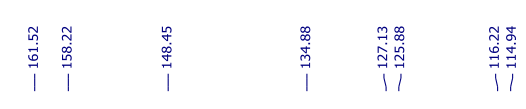

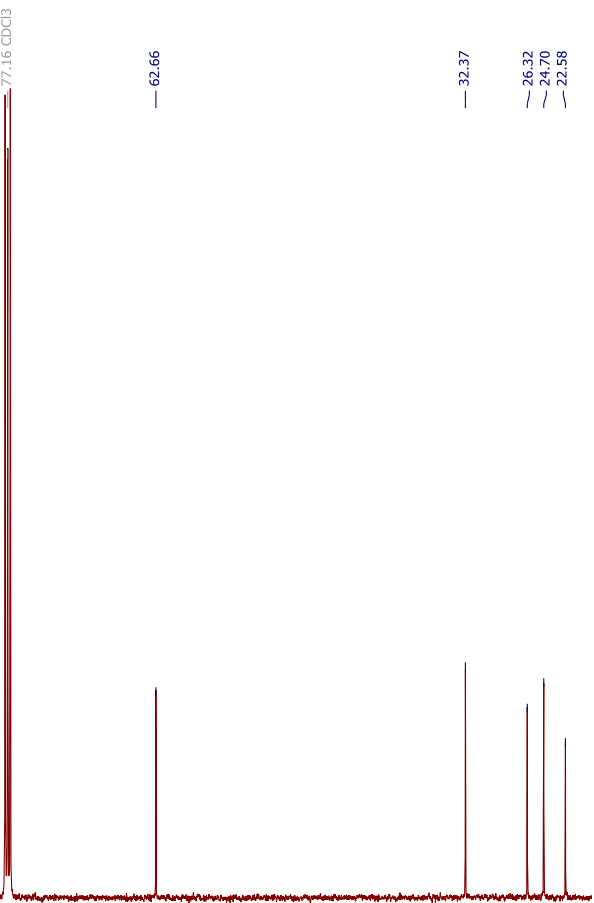

$\begin{array}{llllllllllllllllllllllllllllllllllll}160 & 155 & 150 & 145 & 140 & 135 & 130 & 125 & 120 & 115 & 110 & 105 & 100 & 95 & 90 & 85 & 80 & 75 & 70 & 65 & 60 & 55 & 50 & 45 & 40 & 35 & 30 & 25 & 2\end{array}$ 
COSY NMR spectrum of 3-(4-Hydroxybutyl)-2-methyl-4H-pyrido[1,2- $\alpha$ pyrimidin-4-one (30) $\left(\mathrm{CDCl}_{3}, 500 \mathrm{MHz}\right)$

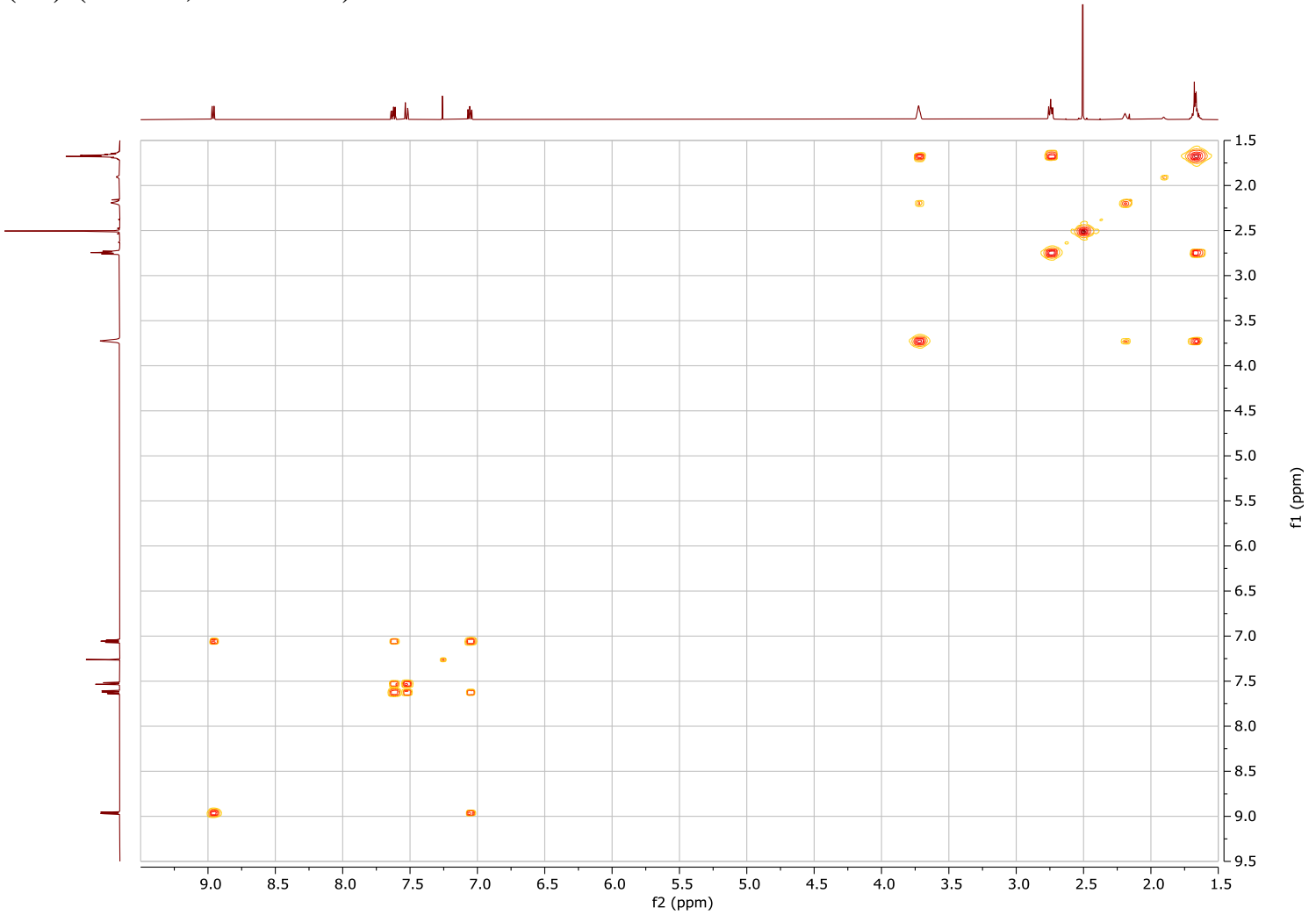

HSQC NMR spectrum of 3-(4-Hydroxybutyl)-2-methyl-4H-pyrido[1,2- $\alpha$ pyrimidin-4-one (30) $\left(\mathrm{CDCl}_{3}, 500 \mathrm{MHz}\right)$

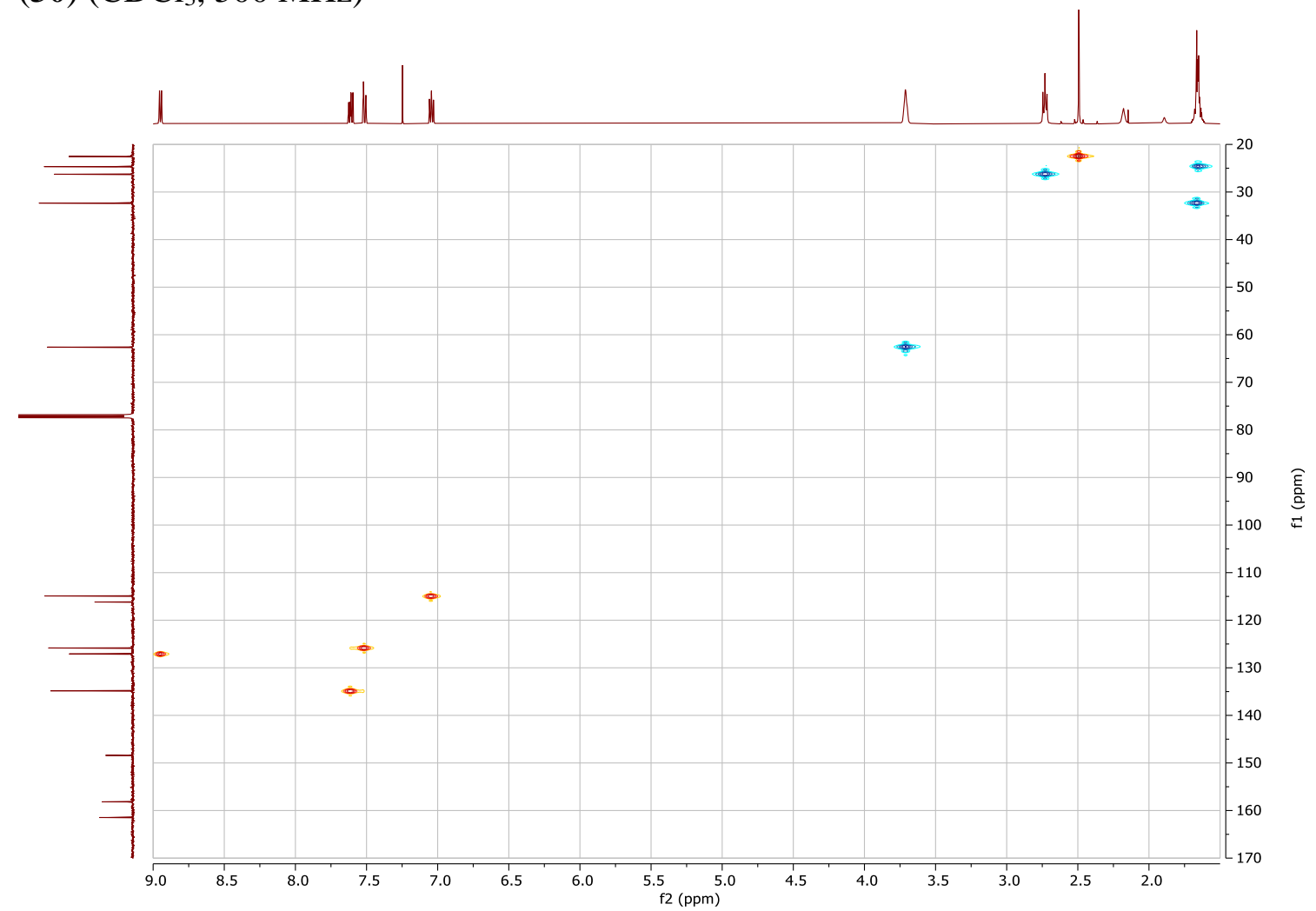


HMBC NMR spectrum of 3-(4-Hydroxybutyl)-2-methyl-4H-pyrido[1,2- $\alpha$ ]pyrimidin-4-one (30) $\left(\mathrm{CDCl}_{3}, 500 \mathrm{MHz}\right)$

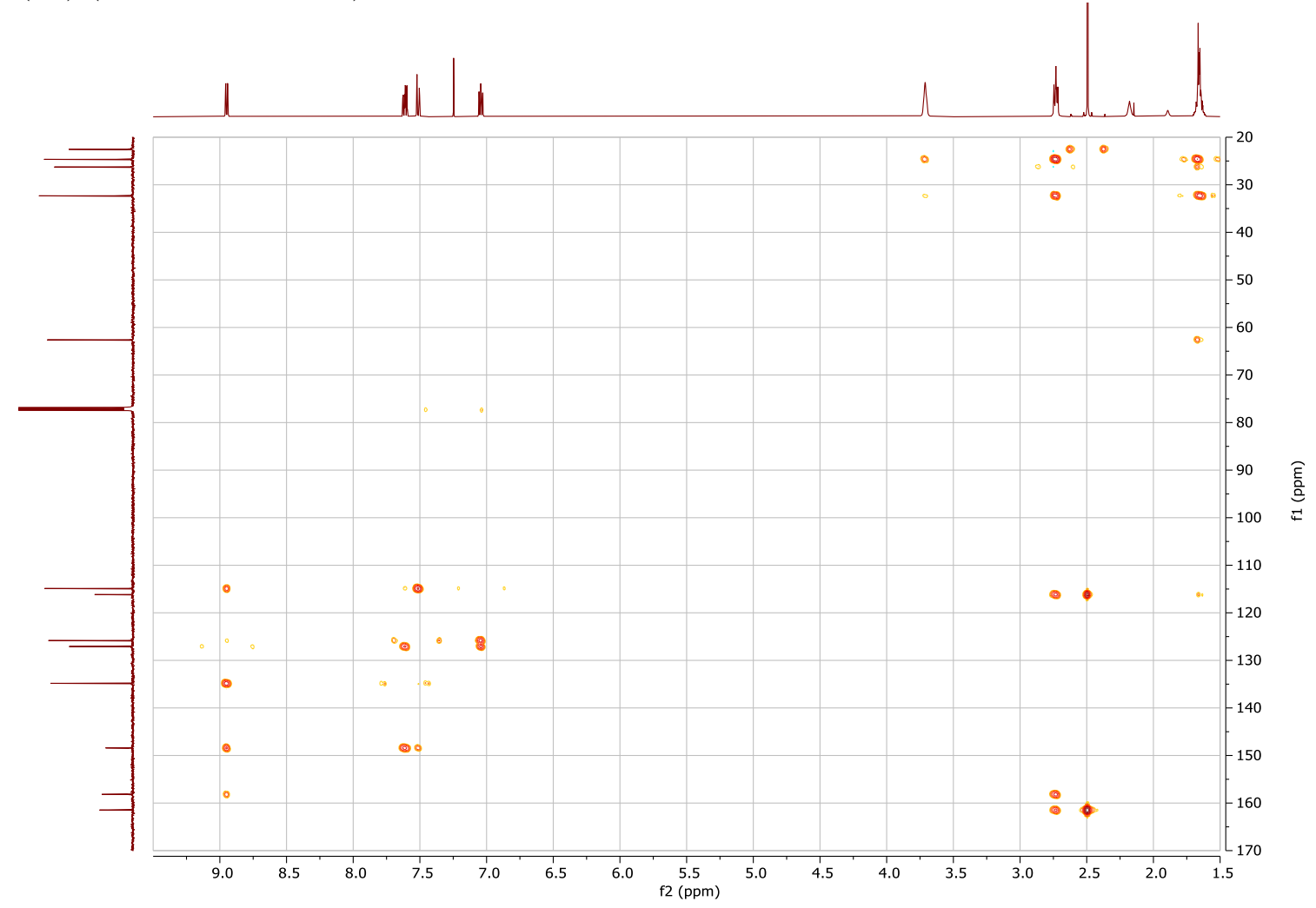


${ }^{1} \mathrm{H}$ NMR spectrum of 3-(4-Iodobutyl)-2-methyl-4H-pyrido[1,2- $\alpha$ ]pyrimidin-4-one (32) $\left(\mathrm{CDCl}_{3}, 500 \mathrm{MHz}\right)$

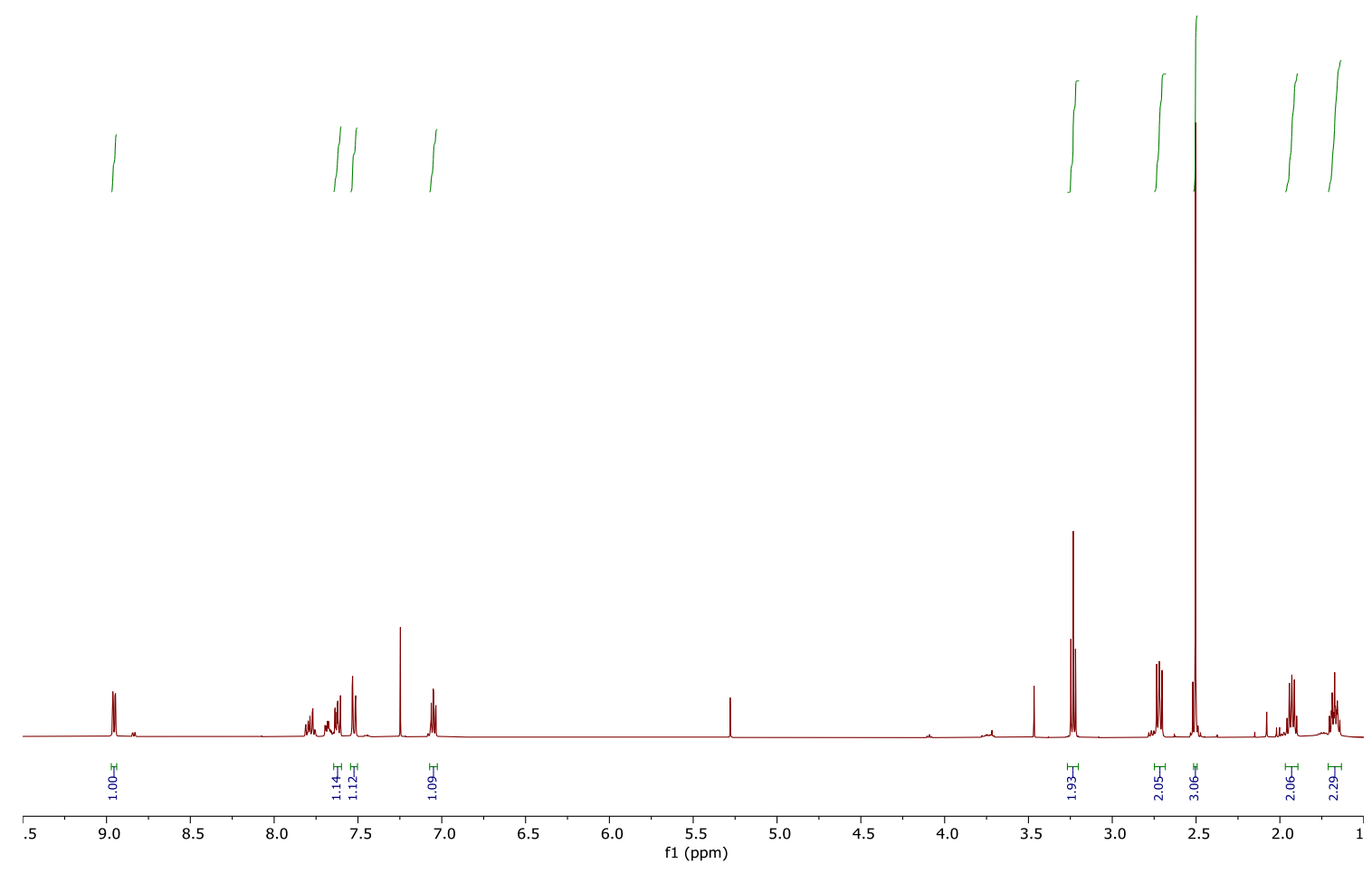


${ }^{1} \mathrm{H}$ NMR spectrum of 3-(4-(4-(6-Fluorobenzo[ $\left.d\right]$ isoxazol-3-yl)piperidin-1-yl)butyl)-2-methyl$4 H$-pyrido[1,2- $\alpha]$ pyrimidin-4-one $(\mathbf{2 9})\left(\mathrm{CDCl}_{3}, 500 \mathrm{MHz}\right)$

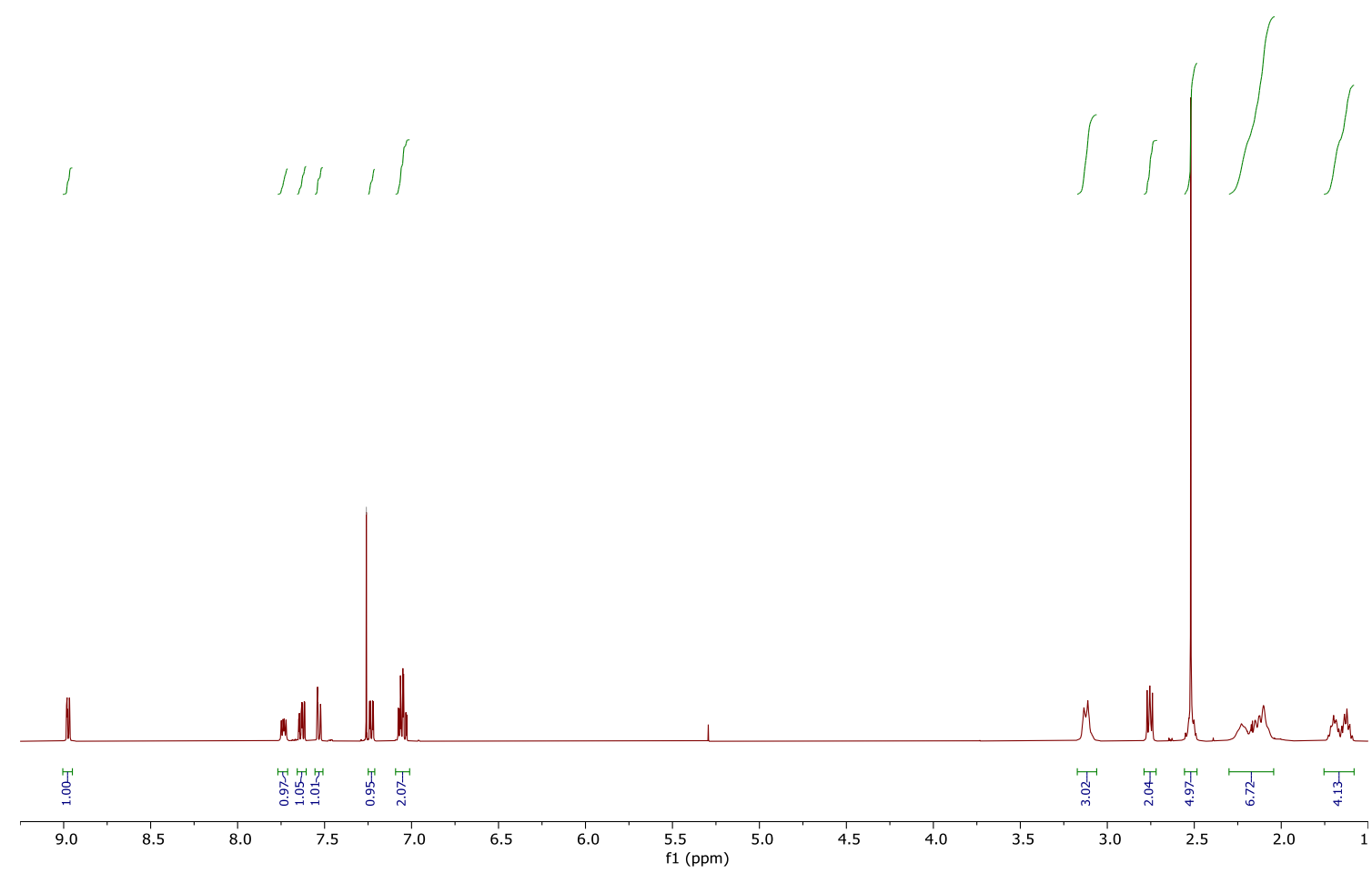

${ }^{13} \mathrm{C}$ NMR spectrum of 3-(4-(4-(6-Fluorobenzo[d]isoxazol-3-yl)piperidin-1-yl)butyl)-2methyl-4H-pyrido[1,2- $\alpha$ ]pyrimidin-4-one $(29)\left(\mathrm{CDCl}_{3}, 126 \mathrm{MHz}\right)$

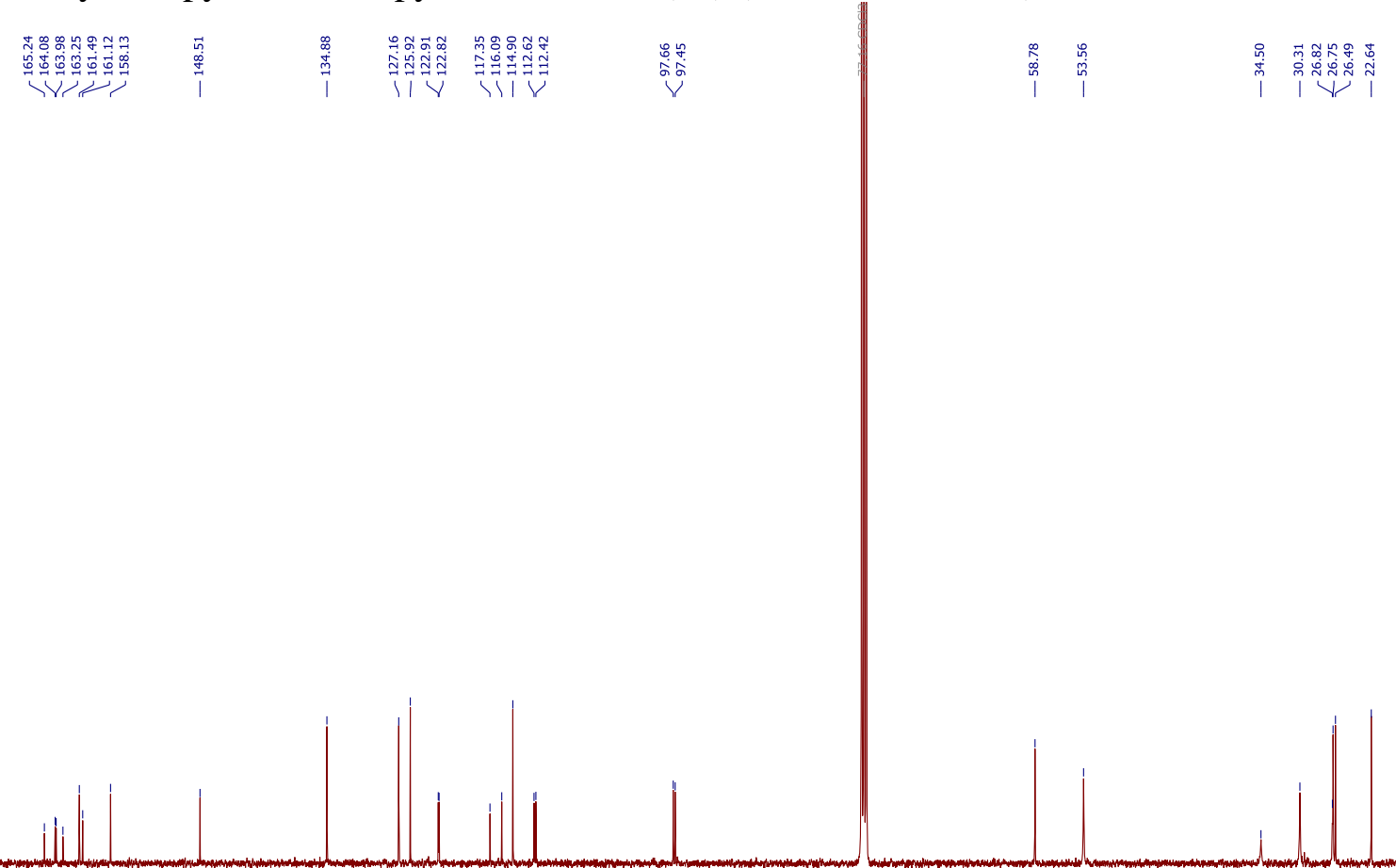

$\begin{array}{lllllllllllllllllllllllllllllllllllllllllllllllllll}70 & 165 & 160 & 155 & 150 & 145 & 140 & 135 & 130 & 125 & 120 & 115 & 110 & 105 & 100 & 95 & 90 & 85 & 80 & 75 & 70 & 65 & 60 & 55 & 50 & 45 & 40 & 35 & 30 & 25 & 2\end{array}$ 
COSY NMR spectrum of 3-(4-(4-(6-Fluorobenzo[d]isoxazol-3-yl)piperidin-1-yl)butyl)-2methyl-4H-pyrido[1,2- $\alpha$ ]pyrimidin-4-one $(29)\left(\mathrm{CDCl}_{3}, 500 \mathrm{MHz}\right)$

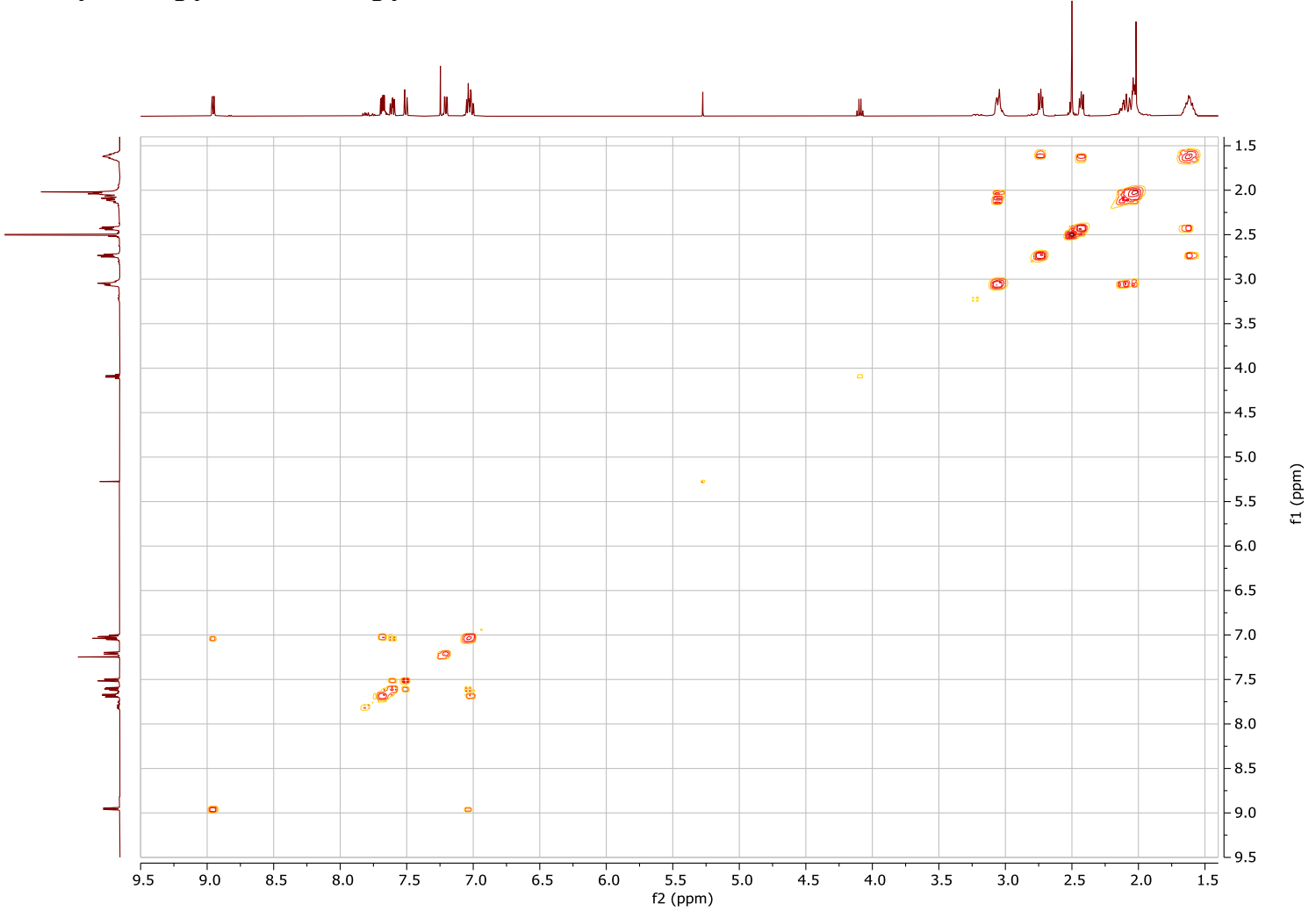

HSQC NMR spectrum of 3-(4-(4-(6-Fluorobenzo[ $d$ ]isoxazol-3-yl)piperidin-1-yl)butyl)-2methyl-4H-pyrido[1,2- $\alpha$ ]pyrimidin-4-one $(29)\left(\mathrm{CDCl}_{3}, 500 \mathrm{MHz}\right)$

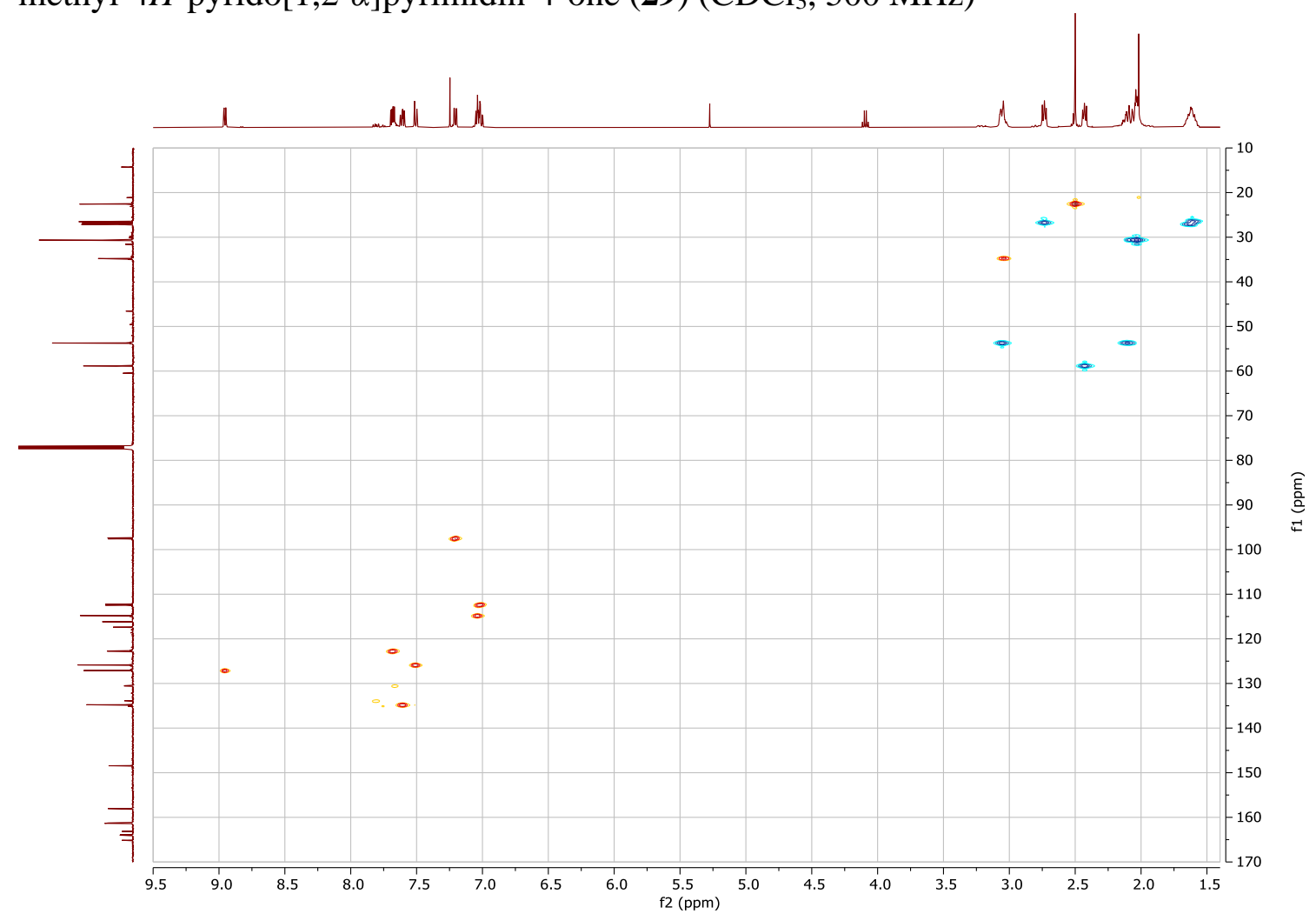


HSQC NMR spectrum of 3-(4-(4-(6-Fluorobenzo[ $d$ ]isoxazol-3-yl)piperidin-1-yl)butyl)-2methyl-4H-pyrido[1,2- $\alpha$ ]pyrimidin-4-one $(29)\left(\mathrm{CDCl}_{3}, 500 \mathrm{MHz}\right)$

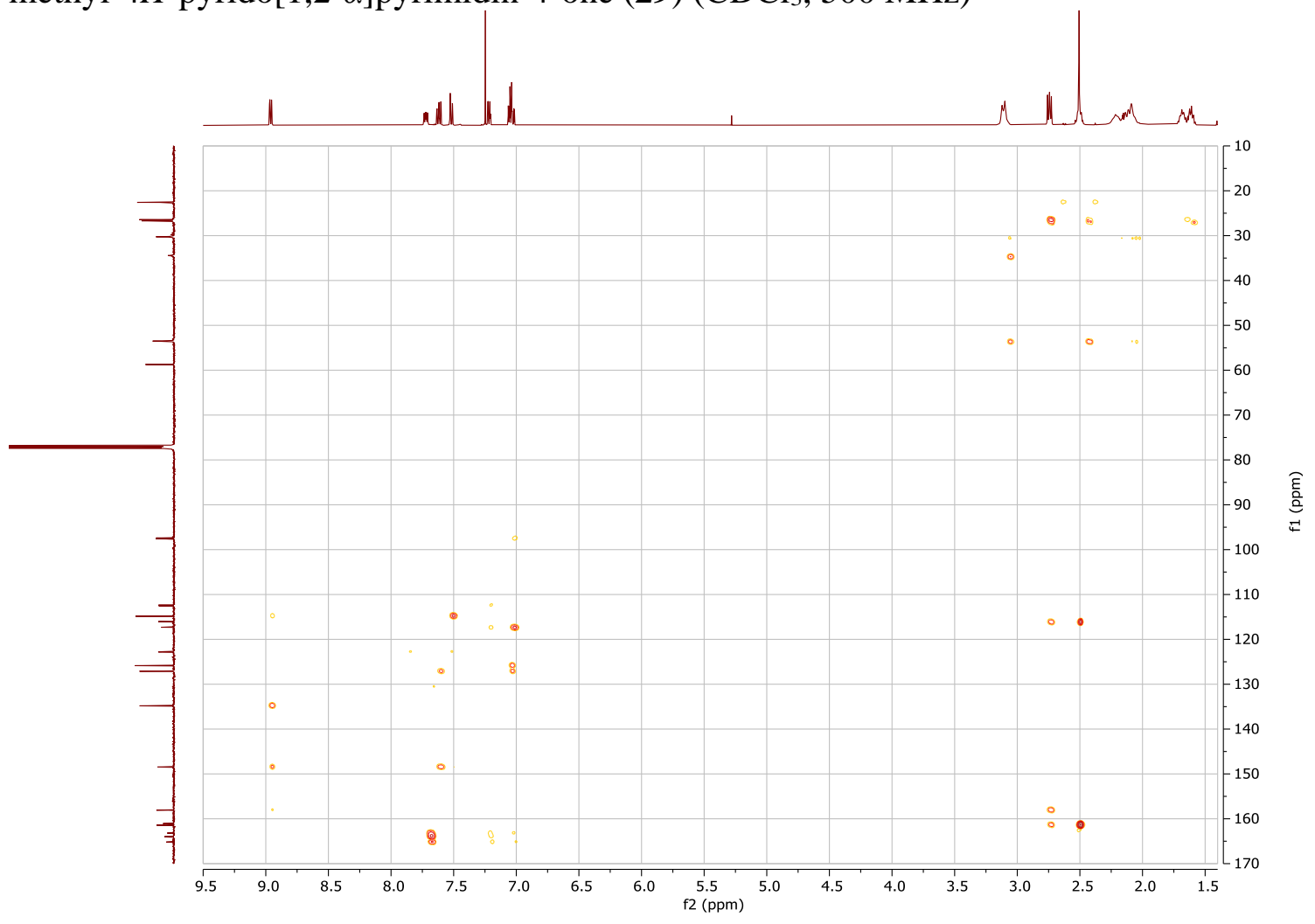


6.2 Buffers and Solutions

Cryopreservation Medium

Fetal calf serum $\mathbf{9 0 \%}$

DMSO $10 \%$

Lysis Buffer

HEPES 5 mM

Tween-20 0.5\%

in $\mathrm{APBS}$

Complete T cell media (CTCM; $100.1 \mathrm{~mL})$

Dulbecco's Modified Eagle Medium 86 mL

Fetal calf serum $10 \mathbf{~ m L}$

$\beta$-Mercaptoethanol (55 mM) 0.1 mL

Non-essential amino acids (10 nM) $1 \mathbf{~ m L}$

L-glutamate (200 mM) $1 \mathbf{~ m L}$

HEPES buffer (1 M) $1 \mathbf{~ m L}$

Penicillin/Streptomycin (100 U/ml/10 mg/ml) 1 mL

MTT Solution

MTT (in PBS) $5 \mathbf{~ m g / m L ~}$

Sterile filtered through $0.22 \mu \mathrm{M}$ syringe filter

MTT Solubiliser

SDS 10\%

DMF $45 \%$

$\mathrm{dH}_{2} \mathrm{O} 45 \%$

$\mathrm{pH}$ to 4.5 with acetic acid 
ELISA Capture Buffer

0.1M Na $2 \mathrm{HPO}_{4}$

$\mathrm{pH}$ to 9.0

ELISA Stop Solution

$0.18 \mathrm{M} \mathrm{H}_{2} \mathrm{SO}_{4}$

6.3 ELISA Reagents and Concentrations

IL-12 ELISA Reagents

\begin{tabular}{c|c|c|c} 
Reagent & Concentration & Diluent & Incubation \\
\hline $\begin{array}{c}\text { Purified rat anti mIL-12 p40/70 } \\
(\text { BD Biosciences, CA) }\end{array}$ & $1 \mu \mathrm{g} / \mathrm{mL}$ & $\begin{array}{c}0.1 \mathrm{M} \mathrm{Na}_{2} \mathrm{HPO}_{4}, \\
\mathrm{pH} 9.0\end{array}$ & $\begin{array}{c}\text { Overnight } \\
4{ }^{\circ} \mathrm{C}\end{array}$ \\
\hline Block (FCS) & $10 \%$ & $\mathrm{PBS} \mathrm{pH} \mathrm{7.4}$ & 2 hours RT \\
\hline Top standard (rmIL-12p40) & $4 \mathrm{ng} / \mathrm{mL}$ & $\mathrm{PBS}+5 \% \mathrm{FCS}$ & 2 hours RT \\
\hline $\begin{array}{c}\text { Biotin rat anti mIL-12p40 } \\
\text { (BD Biosciences, CA) }\end{array}$ & $1 \mu \mathrm{g} / \mathrm{mL}$ & $\mathrm{PBS}+5 \% \mathrm{FCS}$ & 1 hour RT \\
\hline $\begin{array}{c}\text { SA-HRP } \\
\text { (BD Biosciences, CA) }\end{array}$ & $1: 2000$ & $\mathrm{PBS}+5 \% \mathrm{FCS}$ & 1 hour RT
\end{tabular}




\begin{tabular}{c|c|c|c} 
Reagent & Concentration & Diluent & Incubation \\
\hline $\begin{array}{c}\text { Purified rat anti mIL-10 } \\
\text { (BD Biosciences, CA) }\end{array}$ & $5 \mu \mathrm{g} / \mathrm{mL}$ & $\begin{array}{c}0.1 \mathrm{M} \mathrm{Na}_{2} \mathrm{HPO}_{4}, \\
\mathrm{pH} 6.0\end{array}$ & $\begin{array}{c}\text { Overnight } \\
4{ }^{\circ} \mathrm{C}\end{array}$ \\
\hline Block (FCS) & $10 \%$ & $\mathrm{PBS} \mathrm{pH} 7.4$ & 2 hours RT \\
\hline Top standard (rmIL-10) & $25 \mathrm{ng} / \mathrm{mL}$ & $\mathrm{PBS}+10 \% \mathrm{FCS}$ & 2 hours RT \\
\hline $\begin{array}{c}\text { Biotin rat anti-mIL-10 } \\
(\text { BD Biosciences, CA) }\end{array}$ & $0.25 \mu \mathrm{g} / \mathrm{mL}$ & $\mathrm{PBS}+10 \% \mathrm{FCS}$ & 1 hour RT \\
\hline $\begin{array}{c}\text { SA-HRP } \\
\text { (BD Biosciences, CA) }\end{array}$ & $1: 1000$ & $\mathrm{PBS}+10 \% \mathrm{FCS}$ & 1 hour RT
\end{tabular}




\section{References}

1. Kennis, L. E. J.; Vandenberk, J. 1,2-BenzIsoxazol-3-yl and 1,2-benzIsothIazol-3-yl derivatives. EP 0196132 A2, 1986.

2. Sajatovic, M.; Subramoniam, M.; Fuller, M. A., Risperidone in the treatment of bipolar mania. Neuropsychiatr Dis Treat 2006, 2 (2), 127-138.

3. Dinnissen, M.; Dietrich, A.; van den Hoofdakker, B. J.; Hoekstra, P. J., Clinical and pharmacokinetic evaluation of risperidone for the management of autism spectrum disorder. Expert Opinion on Drug Metabolism \& Toxicology 2015, 11 (1), 111-124.

4. de Oliveira, I. R.; Miranda-Scippa, A. M. A.; de Sena, E. P.; Pereira, E. L. A.; Ribeiro, M. G.; de Castro-e-Silva, E.; Bacaltchuk, J., Risperidone versus haloperidol in the treatment of schizophrenia: a meta-analysis comparing their efficacy and safety. Journal of Clinical Pharmacy and Therapeutics 1996, 21 (5), 349-358.

5. Seeman, P.; Lee, T., Antipsychotic drugs: direct correlation between clinical potency and presynaptic action on dopamine neurons. Science 1975, 188 (4194), 1217-1219.

6. Remington, G.; Kapur, S., D2 and 5-HT2 receptor effects of antipsychotics: bridging basic and clinical findings using PET. Journal of Clinical Psychiatry 1999, 60 Suppl 10, 159.

7. Remington, G.; Kapur, S., Atypical antipsychotics: are some more atypical than others? Psychopharmacology 2000, 148 (1), 3-15.

8. Jafari, S.; Fernandez-Enright, F.; Huang, X.-F., Structural contributions of antipsychotic drugs to their therapeutic profiles and metabolic side effects. Journal of Neurochemistry 2012, 120 (3), 371-384.

9. Corena-McLeod, M., Comparative Pharmacology of Risperidone and Paliperidone. Drugs in $R \& D$ 2015, 15 (2), 163-174.

10. Wang, S.; Che, T.; Levit, A.; Shoichet, B. K.; Wacker, D.; Roth, B. L., Structure of the D2 dopamine receptor bound to the atypical antipsychotic drug risperidone. Nature 2018, $555,269$.

11. Kimura, K. T.; Asada, H.; Inoue, A.; Kadji, F. M. N.; Im, D.; Mori, C.; Arakawa, T.; Hirata, K.; Nomura, Y.; Nomura, N.; Aoki, J.; Iwata, S.; Shimamura, T., Structures of the 5HT2A receptor in complex with the antipsychotics risperidone and zotepine. Nature Structural \& Molecular Biology 2019, 26 (2), 121-128.

12. Michino, M.; Beuming, T.; Donthamsetti, P.; Newman, A. H.; Javitch, J. A.; Shi, L., What can crystal structures of aminergic receptors tell us about designing subtype-selective ligands? Pharmacological Reviews 2015, 67 (1), 198-213.

13. Marder, S. R.; Meibach, R. C., Risperidone in the treatment of schizophrenia. American Journal of Psychiatry 1994, 151 (6), 825-35.

14. Sampson, S.; Hosalli, P.; Furtado, V. A.; Davis, J. M., Risperidone (depot) for schizophrenia. Cochrane Database of Systematic Reviews 2016, (4).

15. Markowitz, J. S.; Brown, C. S.; Moore, T. R., Atypical Antipsychotics Part I: Pharmacology, Pharmacokinetics, and Efficacy. Annals of Pharmacotherapy 1999, 33 (1), 73-85.

16. Fang, J.; Bourin, M.; Baker, G. B., Metabolism of risperidone to 9hydroxyrisperidone by human cytochromes P450 2D6 and 3A4. Naunyn-Schmiedeberg's Archives of Pharmacology 1999, 359 (2), 147-51. 
17. Yasui-Furukori, N.; Hidestrand, M.; Spina, E.; Facciolá, G.; Scordo, M. G.; Tybring, G., Different Enantioselective 9-Hydroxylation of Risperidone by the Two Human CYP2D6 and CYP3A4 Enzymes. Drug Metabolism and Disposition 2001, 29 (10), 1263-1268.

18. Yoo, H.-D.; Lee, S.-N.; Kang, H.-A.; Cho, H.-Y.; Lee, I.-K.; Lee, Y.-B., Influence of ABCB 1 genetic polymorphisms on the pharmacokinetics of risperidone in healthy subjects with CYP2D6*10/*10. Br J Pharmacol 2011, 164 (2b), 433-443.

19. Leysen, J. E.; Gommeren, W.; Eens, A.; de Chaffoy de Courcelles, D.; Stoof, J. C.; Janssen, P. A., Biochemical profile of risperidone, a new antipsychotic. Journal of

Pharmacology and Experimental Therapeutics 1988, 247 (2), 661-670.

20. Leysen, J. E.; Janssen, P. M.; Gommeren, W.; Wynants, J.; Pauwels, P. J.; Janssen, P. A., In vitro and in vivo receptor binding and effects on monoamine turnover in rat brain regions of the novel antipsychotics risperidone and ocaperidone. Molecular Pharmacology 1992, 41 (3), 494-508.

21. Schotte, A.; Bonaventure, P.; Janssen, P. F.; Leysen, J. E., In vitro receptor binding and in vivo receptor occupancy in rat and guinea pig brain: risperidone compared with antipsychotics hitherto used. The Japanese Journal of Pharmacology 1995, 69 (4), 399-412. 22. Schotte, A.; Janssen, P. F.; Gommeren, W.; Luyten, W. H.; Van Gompel, P.; Lesage, A. S.; De Loore, K.; Leysen, J. E., Risperidone compared with new and reference antipsychotic drugs: in vitro and in vivo receptor binding. Psychopharmacology (Berl) 1996, $124(1-2), 57-73$.

23. Clarke, W. P.; Chavera, T. A.; Silva, M.; Sullivan, L. C.; Berg, K. A., Signalling profile differences: paliperidone versus risperidone. Br J Pharmacol 2013, 170 (3), 532-545. 24. Sullivan, L. C.; Clarke, W. P.; Berg, K. A., Atypical antipsychotics and inverse agonism at 5-HT2 receptors. Curr Pharm Des 2015, 21 (26), 3732-3738.

25. Strange, P. G., Antipsychotic Drugs: Importance of Dopamine Receptors for Mechanisms of Therapeutic Actions and Side Effects. Pharmacological Reviews 2001, 53 (1), 119-134.

26. Nyberg, S.; Farde, L.; Eriksson, L.; Halldin, C.; Eriksson, B., 5-HT2 and D2 dopamine receptor occupancy in the living human brain. Psychopharmacology 1993, 110 (3), 265-272.

27. Nyberg, S.; Eriksson, B.; Oxenstierna, G.; Halldin, C.; Farde, L., Suggested minimal effective dose of risperidone based on PET-measured D2 and 5-HT2A receptor occupancy in schizophrenic patients. American Journal of Psychiatry 1999, 156 (6), 869-75.

28. Meltzer, H. Y.; Matsubara, S.; Lee, J. C., Classification of typical and atypical antipsychotic drugs on the basis of dopamine D-1, D-2 and serotonin2 pKi values. Journal of Pharmacology and Experimental Therapeutics 1989, 251 (1), 238-246.

29. Kusumi, I.; Boku, S.; Takahashi, Y., Psychopharmacology of atypical antipsychotic drugs: From the receptor binding profile to neuroprotection and neurogenesis. Psychiatry and Clinical Neurosciences 2015, 69 (5), 243-258.

30. Haas, M.; Eerdekens, M.; Kushner, S.; Singer, J.; Augustyns, I.; Quiroz, J.; Pandina, G.; Kusumakar, V., Efficacy, safety and tolerability of two risperidone dosing regimens in adolescent schizophrenia: double-blind study. British Journal of Psychiatry 2009, 194 (2), 158-164.

31. Chouinard, G.; Kopala, L.; Labelle, A.; Beauclair, L.; Johnson, S. V.; Singh, K. I., Phase-IV Multicentre Clinical Study of Risperidone in the Treatment of Outpatients with Schizophrenia. The Canadian Journal of Psychiatry 1998, 43 (10), 1018-1025.

32. Smulevich, A. B.; Khanna, S.; Eerdekens, M.; Karcher, K.; Kramer, M.; Grossman, F., Acute and continuation risperidone monotherapy in bipolar mania: a 3-week placebocontrolled trial followed by a 9-week double-blind trial of risperidone and haloperidol. European Neuropsychopharmacology 2005, 15 (1), 75-84. 
33. Farde, L.; Nordström, A.-L.; Wiesel, F.-A.; Pauli, S.; Halldin, C.; Sedvall, G., Positron Emission Tomographic Analysis of Central D1 and D2 Dopamine Receptor Occupancy in Patients Treated With Classical Neuroleptics and Clozapine: Relation to Extrapyramidal Side Effects. JAMA Psychiatry 1992, 49 (7), 538-544.

34. Seeman, P., Atypical antipsychotics: mechanism of action. The Canadian Journal of Psychiatry 2002, 47 (1), 27-38.

35. Safer, D. J., A Comparison of Risperidone-Induced Weight Gain Across the Age Span. Journal of Clinical Psychopharmacology 2004, 24 (4), 429-436.

36. Richelson, E.; Souder, T., Binding of antipsychotic drugs to human brain receptors: Focus on newer generation compounds. Life Sciences 2000, 68 (1), 29-39.

37. Song, X.; Fan, X.; Li, X.; Zhang, W.; Gao, J.; Zhao, J.; Harrington, A.; Ziedonis, D.; Lv, L., Changes in pro-inflammatory cytokines and body weight during 6-month risperidone treatment in drug naïve, first-episode schizophrenia. Psychopharmacology 2014, 231 (2), 319-325.

38. Lassmann, H.; van Horssen, J.; Mahad, D., Progressive multiple sclerosis: pathology and pathogenesis. Nature Reviews Neurology 2012, 8, 647.

39. Wallin, M. T.; Culpepper, W. J.; Nichols, E.; Bhutta, Z. A.; Gebrehiwot, T. T.; Hay, S. I.; Khalil, I. A.; Krohn, K. J.; Liang, X.; Naghavi, M.; Mokdad, A. H.; Nixon, M. R.; Reiner, R. C.; Sartorius, B.; Smith, M.; Topor-Madry, R.; Werdecker, A.; Vos, T.; Feigin, V. L.; Murray, C. J. L., Global, regional, and national burden of multiple sclerosis 1990-2016: a systematic analysis for the Global Burden of Disease Study 2016. The Lancet Neurology 2019, 18 (3), 269-285.

40. Baranzini, S. E.; Oksenberg, J. R., The Genetics of Multiple Sclerosis: From 0 to 200 in 50 Years. Trends in Genetics 2017, 33 (12), 960-970.

41. Brownlee, W. J.; Hardy, T. A.; Fazekas, F.; Miller, D. H., Diagnosis of multiple sclerosis: progress and challenges. The Lancet 2017, 389 (10076), 1336-1346.

42. Polman, C. H.; O'Connor, P. W.; Havrdova, E.; Hutchinson, M.; Kappos, L.; Miller, D. H.; Phillips, J. T.; Lublin, F. D.; Giovannoni, G.; Wajgt, A.; Toal, M.; Lynn, F.; Panzara, M. A.; Sandrock, A. W., A Randomized, Placebo-Controlled Trial of Natalizumab for Relapsing Multiple Sclerosis. New England Journal of Medicine 2006, 354 (9), 899-910.

43. Antoniol, C.; Stankoff, B., Immunological Markers for PML Prediction in MS Patients Treated with Natalizumab. Front Immunol 2015, 5 (668).

44. Yousry, T. A.; Major, E. O.; Ryschkewitsch, C.; Fahle, G.; Fischer, S.; Hou, J.; Curfman, B.; Miszkiel, K.; Mueller-Lenke, N.; Sanchez, E.; Barkhof, F.; Radue, E.-W.; Jäger, H. R.; Clifford, D. B., Evaluation of Patients Treated with Natalizumab for Progressive Multifocal Leukoencephalopathy. New England Journal of Medicine 2006, 354 (9), 924-933. 45. Scannevin, R. H.; Chollate, S.; Jung, M.-y.; Shackett, M.; Patel, H.; Bista, P.; Zeng, W.; Ryan, S.; Yamamoto, M.; Lukashev, M.; Rhodes, K. J., Fumarates Promote Cytoprotection of Central Nervous System Cells against Oxidative Stress via the Nuclear Factor (Erythroid-Derived 2)-Like 2 Pathway. Journal of Pharmacology and Experimental Therapeutics 2012, 341 (1), 274-284.

46. Loewe, R.; Holnthoner, W.; Groger, M.; Pillinger, M.; Gruber, F.; Mechtcheriakova, D.; Hofer, E.; Wolff, K.; Petzelbauer, P., Dimethylfumarate inhibits TNF-induced nuclear entry of NF-kappa B/p65 in human endothelial cells. The Journal of Immunology 2002, 168 (9), 4781-7.

47. Mosayebi, G.; Ghazavi, A.; Ghasami, K.; Jand, Y.; Kokhaei, P., Therapeutic Effect of Vitamin D3 in Multiple Sclerosis Patients. Immunological Investigations 2011, 40 (6), 627 639.

48. Soilu-Hänninen, M.; Åivo, J.; Lindström, B.-M.; Elovaara, I.; Sumelahti, M.-L.; Färkkilä, M.; Tienari, P.; Atula, S.; Sarasoja, T.; Herrala, L.; Keskinarkaus, I.; Kruger, J.; 
Kallio, T.; Rocca, M. A.; Filippi, M., A randomised, double blind, placebo controlled trial with vitamin D3 as an add on treatment to interferon $\beta-1 \mathrm{~b}$ in patients with multiple sclerosis. Journal of Neurology, Neurosurgery \& Psychiatry 2012, 83 (5), 565-571.

49. Munger, K. L.; Levin, L. I.; Hollis, B. W.; Howard, N. S.; Ascherio, A., Serum 25Hydroxyvitamin D Levels and Risk of Multiple Sclerosis. JAMA 2006, 296 (23), 2832-2838.

50. Stein, M. S.; Liu, Y.; Gray, O. M.; Baker, J. E.; Kolbe, S. C.; Ditchfield, M. R.; Egan, G. F.; Mitchell, P. J.; Harrison, L. C.; Butzkueven, H.; Kilpatrick, T. J., A randomized trial of high-dose vitamin D2 in relapsing-remitting multiple sclerosis. Neurology 2011, 77 (17), 1611-1618.

51. Zhang, J.-M.; An, J., Cytokines, inflammation, and pain. Int Anesthesiol Clin 2007, 45 (2), 27-37.

52. Hafler, D. A.; Kent, S. C.; Pietrusewicz, M. J.; Khoury, S. J.; Weiner, H. L.; Fukaura, H., Oral Administration of Myelin Induces Antigen-specific TGF- $\beta 1$ Secreting T Cells in Patients with Multiple Sclerosisa. Annals of the New York Academy of Sciences 1997, 835 (1), 120-131.

53. Fukaura, H.; Kent, S. C.; Pietrusewicz, M. J.; Khoury, S. J.; Weiner, H. L.; Hafler, D. A., Induction of circulating myelin basic protein and proteolipid protein-specific transforming growth factor-beta1-secreting Th3 T cells by oral administration of myelin in multiple sclerosis patients. J Clin Invest 1996, 98 (1), 70-77.

54. Arango Duque, G.; Descoteaux, A., Macrophage cytokines: involvement in immunity and infectious diseases. Front Immunol 2014, 5, 491-491.

55. Wojdasiewicz, P.; Poniatowski; \#x141; A., u.; Szukiewicz, D., The Role of Inflammatory and Anti-Inflammatory Cytokines in the Pathogenesis of Osteoarthritis. Mediators of Inflammation 2014, 2014, 19.

56. Dinarello, C. A., Proinflammatory Cytokines. Chest 2000, 118 (2), 503-508.

57. Gee, K.; Guzzo, C.; Che Mat, N. F.; Ma, W.; Kumar, A., The IL-12 family of cytokines in infection, inflammation and autoimmune disorders. Inflammation \& Allergy Drug Targets 2009, 8 (1), 40-52.

58. Hoyer, K. K.; Dooms, H.; Barron, L.; Abbas, A. K., Interleukin-2 in the development and control of inflammatory disease. Immunological Reviews 2008, 226 (1), 19-28.

59. Opal, S. M.; DePalo, V. A., Anti-Inflammatory Cytokines. Chest 2000, 117 (4), 1162 1172.

60. Gold, R.; Linington, C.; Lassmann, H., Understanding pathogenesis and therapy of multiple sclerosis via animal models: 70 years of merits and culprits in experimental autoimmune encephalomyelitis research. Brain 2006, 129 (8), 1953-1971.

61. Constantinescu, C. S.; Farooqi, N.; O'Brien, K.; Gran, B., Experimental autoimmune encephalomyelitis (EAE) as a model for multiple sclerosis (MS). Br J Pharmacol 2011, 164 (4), 1079-1106.

62. Begolka, W. S.; Miller, S. D., Cytokines as intrinsic and exogenous regulators of pathogenesis in experimental autoimmune encephalomyelitis. Research in Immunology 1998, 149 (9), 771-81; discussion 843-4, 855-60.

63. Renno, T.; Taupin, V.; Bourbonnière, L.; Verge, G.; Tran, E.; De Simone, R.; Krakowski, M.; Rodriguez, M.; Peterson, A.; Owens, T., Interferon- $\gamma$ in Progression to Chronic Demyelination and Neurological Deficit Following Acute EAE. Molecular and Cellular Neuroscience 1998, 12 (6), 376-389.

64. Ferber, I. A.; Brocke, S.; Taylor-Edwards, C.; Ridgway, W.; Dinisco, C.; Steinman, L.; Dalton, D.; Fathman, C. G., Mice with a disrupted IFN-gamma gene are susceptible to the induction of experimental autoimmune encephalomyelitis (EAE). The Journal of Immunology 1996, 156 (1), 5-7. 
65. Balashov, K. E.; Comabella, M.; Ohashi, T.; Khoury, S. J.; Weiner, H. L., Defective regulation of IFNgamma and IL-12 by endogenous IL-10 in progressive MS. Neurology 2000, 55 (2), 192-198.

66. Kuroda, Y.; Shimamoto, Y., Human tumor necrosis factor- $\alpha$ augments experimental allergic encephalomyelitis in rats. Journal of Neuroimmunology 1991, 34 (2), 159-164.

67. Probert, L.; Akassoglou, K.; Pasparakis, M.; Kontogeorgos, G.; Kollias, G., Spontaneous inflammatory demyelinating disease in transgenic mice showing central nervous system-specific expression of tumor necrosis factor alpha. Proc Natl Acad Sci U S A 1995, 92 (24), 11294-11298.

68. Hofman, F. M.; Hinton, D. R.; Johnson, K.; Merrill, J. E., Tumor necrosis factor identified in multiple sclerosis brain. The Journal of Experimental Medicine 1989, 170 (2), 607-612.

69. Selmaj, K.; Raine, C. S.; Cannella, B.; Brosnan, C. F., Identification of lymphotoxin and tumor necrosis factor in multiple sclerosis lesions. Journal of Clinical Investigation 1991, 87 (3), 949-54.

70. Sharief, M. K.; Hentges, R., Association between Tumor Necrosis Factor- $\alpha$ and Disease Progression in Patients with Multiple Sclerosis. New England Journal of Medicine 1991, 325 (7), 467-472.

71. Smith, T.; Hewson, A. K.; Kingsley, C. I.; Leonard, J. P.; Cuzner, M. L., Interleukin12 induces relapse in experimental allergic encephalomyelitis in the Lewis rat. Am J Pathol 1997, 150 (6), 1909-1917.

72. Rejdak, K.; Eikelenboom, M. J.; Petzold, A.; Thompson, E. J.; Stelmasiak, Z.; Lazeron, R. H. C.; Barkhof, F.; Polman, C. H.; Uitdehaag, B. M. J.; Giovannoni, G., CSF nitric oxide metabolites are associated with activity and progression of multiple sclerosis. Neurology 2004, 63 (8), 1439-1445.

73. Windhagen, A.; Newcombe, J.; Dangond, F.; Strand, C.; Woodroofe, M. N.; Cuzner, M. L.; Hafler, D. A., Expression of costimulatory molecules B7-1 (CD80), B7-2 (CD86), and interleukin 12 cytokine in multiple sclerosis lesions. The Journal of Experimental Medicine 1995, 182 (6), 1985-1996.

74. Jankovic, S. M., Injectable interferon beta-1b for the treatment of relapsing forms of multiple sclerosis. J Inflamm Res 2010, 3, 25-31.

75. Wang, X.; Chen, M.; Wandinger, K. P.; Williams, G.; Dhib-Jalbut, S., IFN- $\beta-1 b$ Inhibits IL-12 Production in Peripheral Blood Mononuclear Cells in an IL-10-Dependent Mechanism: Relevance to IFN- $\beta-1 b$ Therapeutic Effects in Multiple Sclerosis. The Journal of Immunology 2000, 165 (1), 548-557.

76. Sironi, M.; Breviario, F.; Proserpio, P.; Biondi, A.; Vecchi, A.; Van Damme, J.; Dejana, E.; Mantovani, A., IL-1 stimulates IL-6 production in endothelial cells. The Journal of Immunology 1989, 142 (2), 549-553.

77. Kennedy, M. K.; Torrance, D. S.; Picha, K. S.; Mohler, K. M., Analysis of cytokine mRNA expression in the central nervous system of mice with experimental autoimmune encephalomyelitis reveals that IL-10 mRNA expression correlates with recovery. The Journal of Immunology 1992, 149 (7), 2496-2505.

78. Diab, A.; Zhu, J.; Xiao, B. G.; Mustafa, M.; Link, H., High IL-6 and Low IL-10 in the Central Nervous System Are Associated with Protracted Relapsing EAE in DA Rats. Journal of Neuropathology \& Experimental Neurology 1997, 56 (6), 641-650.

79. Frei, K.; Fredrikson, S.; Fontana, A.; Link, H., Interleukin-6 is elevated in plasma in multiple sclerosis. Journal of Neuroimmunology 1991, 31 (2), 147-153.

80. Schönrock, L. M.; Gawlowski, G.; Brück, W., Interleukin-6 expression in human multiple sclerosis lesions. Neuroscience Letters 2000, 294 (1), 45-48. 
81. Maimone, D.; Guazzi, G. C.; Annunziata, P., IL-6 detection in multiple sclerosis brain. Journal of the Neurological Sciences 1997, 146 (1), 59-65.

82. Sugino, H.; Futamura, T.; Mitsumoto, Y.; Maeda, K.; Marunaka, Y., Atypical antipsychotics suppress production of proinflammatory cytokines and up-regulate interleukin10 in lipopolysaccharide-treated mice. Progress in Neuro-Psychopharmacology and Biological Psychiatry 2009, 33 (2), 303-307.

83. MacDowell, K. S.; García-Bueno, B.; Madrigal, J. L. M.; Parellada, M.; Arango, C.; Micó, J. A.; Leza, J. C., Risperidone normalizes increased inflammatory parameters and restores anti-inflammatory pathways in a model of neuroinflammation. International Journal of Neuropsychopharmacology 2013, 16 (1), 121-135.

84. Cazzullo, C. L.; Sacchetti, E.; Galluzzo, A.; Panariello, A.; Adorni, A.; Pegoraro, M.; Bosis, S.; Colombo, F.; Trabattoni, D.; Zagliani, A.; Clerici, M., Cytokine profiles in schizophrenic patients treated with risperidone: a 3-month follow-up study. Prog Neuropsychopharmacol Biol Psychiatry 2002, 26 (1), 33-39.

85. Choi, J. E.; Widjaja, F.; Careaga, M.; Bent, S.; Ashwood, P.; Hendren, R. L., Change in plasma cytokine levels during risperidone treatment in children with autism. $J$ Child Adolesc Psychopharmacol 2014, 24 (10), 586-589.

86. Lu, L. X.; Guo, S. Q.; Chen, W.; Li, Q.; Cheng, J.; Guo, J. H., Effect of clozapine and risperidone on serum cytokine levels in patients with first-episode paranoid schizophrenia. $D i$ Yi Jun Yi Da Xиe Xue Bao = Academic journal of the first medical college of PLA 2004, 24 (11), 1251-4.

87. Juncal-Ruiz, M.; Riesco-Dávila, L.; Ortiz-García de la Foz, V.; Martínez-Garcia, O.; Ramírez-Bonilla, M.; Ocejo-Viñals, J. G.; Leza, J. C.; López-Hoyos, M.; Crespo-Facorro, B., Comparison of the anti-inflammatory effect of aripiprazole and risperidone in 75 drug-naïve first episode psychosis individuals: A 3 months randomized study. Schizophrenia Research 2018, 202, 226-233.

88. Kato, T.; Monji, A.; Hashioka, S.; Kanba, S., Risperidone significantly inhibits interferon- $\gamma$-induced microglial activation in vitro. Schizophrenia Research 2007, 92 (1), 108-115.

89. Zhou, P.; Xiang, L.; Zhao, D.; Ren, J.; Qiu, Y.; Li, Y., Synthesis, biological evaluation, and structure activity relationship (SAR) study of pyrrolidine amide derivatives as $\mathrm{N}$-acylethanolamine acid amidase (NAAA) inhibitors. MedChemComm 2019, 10 (2), 252262.

90. Volk, B.; Barkóczy, J.; Hegedus, E.; Udvari, S.; Gacsályi, I.; Mezei, T.; Pallagi, K.; Kompagne, H.; Lévay, G.; Egyed, A.; Hársing, J. L. G.; Spedding, M.; Simig, G., (Phenylpiperazinyl-butyl)oxindoles as Selective 5-HT7 Receptor Antagonists. Journal of Medicinal Chemistry 2008, 51 (8), 2522-2532.

91. Perrone, R.; Berardi, F.; Colabufo, N. A.; Lacivita, E.; Leopoldo, M.; Tortorella, V.,

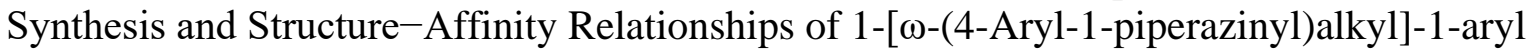
Ketones as 5-HT7 Receptor Ligands. Journal of Medicinal Chemistry 2003, 46 (4), 646-649. 92. Zajdel, P.; Marciniec, K.; Maślankiewicz, A.; Satała, G.; Duszyńska, B.; Bojarski, A. J.; Partyka, A.; Jastrzębska-Więsek, M.; Wróbel, D.; Wesołowska, A.; Pawłowski, M., Quinoline- and isoquinoline-sulfonamide derivatives of LCAP as potent CNS multireceptor-5-HT1A/5-HT2A/5-HT7 and D2/D3/D4 - agents: The synthesis and pharmacological evaluation. Bioorganic \& Medicinal Chemistry 2012, 20 (4), 1545-1556. 93. Bojarski, A. J.; Duszyńska, B.; Kołaczkowski, M.; Kowalski, P.; Kowalska, T., The impact of spacer structure on 5-HT7 and 5-HT1A receptor affinity in the group of long-chain arylpiperazine ligands. Bioorg Med Chem Lett 2004, 14 (23), 5863-5866.

94. Smid, P.; Coolen, H. K. A. C.; Keizer, H. G.; van Hes, R.; de Moes, J.-P.; den Hartog, A. P.; Stork, B.; Plekkenpol, R. H.; Niemann, L. C.; Stroomer, C. N. J.; Tulp, M. T. M.; van 
Stuivenberg, H. H.; McCreary, A. C.; Hesselink, M. B.; Herremans, A. H. J.; Kruse, C. G., Synthesis, Structure-Activity Relationships, and Biological Properties of 1-Heteroaryl-4-[ $\omega$ (1H-indol-3-yl)alkyl]piperazines, Novel Potential Antipsychotics Combining Potent Dopamine D2 Receptor Antagonism with Potent Serotonin Reuptake Inhibition. Journal of Medicinal Chemistry 2005, 48 (22), 6855-6869.

95. O'Sullivan, D.; Green, L.; Stone, S.; Zareie, P.; Kharkrang, M.; Fong, D.; Connor, B.; La Flamme, A. C., Treatment with the Antipsychotic Agent, Risperidone, Reduces Disease Severity in Experimental Autoimmune Encephalomyelitis. PLOS ONE 2014, 9 (8), e104430. 96. La Flamme, A. C.; Abernethy, D.; Sim, D.; Phil, M.; Goode, L.; Bourke, D.; Milner, I.; Garrill, T.-M.; Joshi, P.; Watson, E.; Smyth, D.; Lance, S.; Barrett, J.; Conner, B., P031 Crisp: Clozapine and Risperidone for the Treatment of Progressive Multiple Sclerosis. Multiple Sclerosis Journal 2018, 24 (1_suppl), 25.

97. Zareie, P.; Moore, P. W.; Wang, J.; Harvey, J. E.; La Flamme, A. C., Structural modifications to risperidone significantly alter immunomodulatory activity in macrophages: investigations of truncated and unsaturated analogues. Unpublished work 2015.

98. Durrant, B. The Synthesis of Extended Linker Analogues of Risperidone: Towards New Treatments for Multiple Sclerosis. Honours, Victoria University of Wellington, 2015. 99. Shroff, M., Misuse of Drugs (Classification of Fantasy) Order 2001. Health, M. o., Ed. 2001.

100. Radha Krishna, P.; Narasimha Reddy, P. V., Stereoselective total synthesis of (-)decarestrictine D from 1-malic acid. Tetrahedron Letters 2006, 47 (42), 7473-7476.

101. Sudhakar, G.; Kadam, V. D.; Bayya, S.; Pranitha, G.; Jagadeesh, B., Total Synthesis and Stereochemical Revision of Acortatarins A and B. Organic Letters 2011, 13 (20), 54525455.

102. Kadam, S. M.; Nayak, S. K.; Banerji, A., Low-valent titanium : A new approach to deprotection of allyl and benzyl groups. Tetrahedron Letters 1992, 33 (35), 5129-5132.

103. Murali, C.; Shashidhar, M. S.; Gopinath, C. S., Hydroxyl group deprotection reactions with $\mathrm{Pd}(\mathrm{OH}) 2 / \mathrm{C}$ : a convenient alternative to hydrogenolysis of benzyl ethers and acid hydrolysis of ketals. Tetrahedron 2007, 63 (19), 4149-4155.

104. Bieg, T.; Szeja, W., Removal of O-Benzyl Protective Groups by Catalytic Transfer Hydrogenation. Synthesis 1985, 1985 (01), 76-77.

105. Walker, D.; Hiebert, J. D., 2,3-Dichloro-5,6-dicyanobenzoquinone and Its Reactions. Chemical Reviews 1967, 67 (2), 153-195.

106. Wuts, P., Greene's Protective Groups in Organic Synthesis: Fifth Edition. 2014; p 11360.

107. Ikemoto, N.; Schreiber, S. L., Total synthesis of (-)-hikizimycin employing the strategy of two-directional chain synthesis. Journal of the American Chemical Society 1992, 114 (7), 2524-2536.

108. Rahim, M. A.; Matsumura, S.; Toshima, K., Deprotection of benzyl ethers using 2,3dichloro-5,6-dicyano-p-benzoquinone (DDQ) under photoirradiation. Tetrahedron Letters 2005, 46 (43), 7307-7309.

109. Bogie, J. F. J.; Stinissen, P.; Hendriks, J. J. A., Macrophage subsets and microglia in multiple sclerosis. Acta Neuropathologica 2014, 128 (2), 191-213.

110. La Flamme, A. C.; Kharkrang, M.; Stone, S.; Mirmoeini, S.; Chuluundorj, D.; Kyle, R., Type II-Activated Murine Macrophages Produce IL-4. PLOS ONE 2012, 7 (10), e46989. 111. Tierney, J. B.; Kharkrang, M.; La Flamme, A. C., Type II-activated macrophages suppress the development of experimental autoimmune encephalomyelitis. Immunology \& Cell Biology 2009, 87 (3), 235-240.

112. Hu, D. X.; Grice, P.; Ley, S. V., Rotamers or Diastereomers? An Overlooked NMR Solution. The Journal of Organic Chemistry 2012, 77 (11), 5198-5202. 
113. Sardella, D. J.; Boger, E., 1H and 13C spectra of fluorine-containing polycyclic aromatic hydrocarbons. 1H-19F and 13C-19F coupling across bay regions. Magnetic Resonance in Chemistry 1989, 27 (1), 13-20.

114. Lutnaes, B. F.; Luthe, G.; Brinkman, U. A. T.; Johansen, J. E.; Krane, J., Characterization of monofluorinated polycyclic aromatic compounds by $1 \mathrm{H}, 13 \mathrm{C}$ and $19 \mathrm{~F}$ NMR spectroscopy. Magnetic Resonance in Chemistry 2005, 43 (7), 588-594.

115. Bouzide, A.; Sauvé, G., Highly selective silver(I) oxide mediated monoprotection of symmetrical diols. Tetrahedron Letters 1997, 38 (34), 5945-5948.

116. Zhou, X.-T.; Carter, R. G., Synthesis of the ABCD and ABCDE ring systems of azaspiracid-1. Chemical Communications 2004, (19), 2138-2140.

117. Muñoz, L.; Bosch, M. P.; Rosell, G.; Guerrero, A., Asymmetric synthesis of (R)- and (S)-4-methyloctanoic acids. A new route to chiral fatty acids with remote stereocenters.

Tetrahedron: Asymmetry 2009, 20 (4), 420-424.

118. Hasserodt, J.; Janda, K. D.; Lerner, R. A., Formation of Bridge-Methylated Decalins by Antibody-Catalyzed Tandem Cationic Cyclization. Journal of the American Chemical Society 1997, 119 (26), 5993-5998.

119. Penov Gaši, K. M.; Kuhajda, K. N.; Cvjetićanin, S. M.; Đurendić, E. A.; MedićMijačević, L. D.; Pejanović, V. M.; Sakač, M. N., Synthesis of Some Diol Derivatives as Potential Reagents in Steroid Chemistry. Acta Periodica Technoligica 2003, (34), 111-118. 120. Grygoriv, G. V.; Lega, D. A.; Zaprutko, L.; Gzella, A. K.; Wieczorek-Dziurla, E.; Chernykh, V. P.; Shemchuk, L. A., Synthesis of novel spiro-condensed 2-amino-4H-pyrans based on 1,2-benzoxathiin-4(3H)-one 2,2-dioxide. Chemistry of Heterocyclic Compounds 2019, 55 (3), 254-260.

121. El-Naggar, M.; Eldehna, W. M.; Almahli, H.; Elgez, A.; Fares, M.; Elaasser, M. M.; Abdel-Aziz, H. A., Novel Thiazolidinone/Thiazolo[3,2-a]Benzimidazolone-Isatin Conjugates as Apoptotic Anti-proliferative Agents Towards Breast Cancer: One-Pot Synthesis and In Vitro Biological Evaluation. Molecules 2018, 23 (6), 1420.

122. Cheng, C.; Xu, J.; Zhu, R.; Xing, L.; Wang, X.; Hu, Y., A highly efficient Pd-C catalytic hydrogenation of pyridine nucleus under mild conditions. Tetrahedron 2009, 65 (41), 8538-8541.

123. Ren, Y.; Wang, Y.; Li, X.; Zhang, Z.; Chi, Q., Selective hydrogenation of quinolines into 1,2,3,4-tetrahydroquinolines over a nitrogen-doped carbon-supported Pd catalyst. New Journal of Chemistry 2018, 42 (20), 16694-16702.

124. Jiang, F.; Wang, H.-J.; Jin, Y.-H.; Zhang, Q.; Wang, Z.-H.; Jia, J.-M.; Liu, F.; Wang, L.; Bao, Q.-C.; Li, D.-D.; You, Q.-D.; Xu, X.-L., Novel Tetrahydropyrido[4,3-d]pyrimidines as Potent Inhibitors of Chaperone Heat Shock Protein 90. Journal of Medicinal Chemistry 2016, 59 (23), 10498-10519.

125. Radhakrishnan, T. V.; Sathe, D. G.; Suryavanshi, C. V. A process for the preparation of anti-psychotic 3-2- 4-(6-fluoro-1,2-benzisoxazol-3-yl)-1-piperidinyl]ethyl]-6,7,8,9-

tetrahydro-2-methyl-4h-pyrido 1,2,-a]pyrimidin-4-one. EP1280804 B1, 2004.

126. Suri, K. A.; Suri, O. P.; Amina, M.; Wakhloo, B. P.; Satti, N. K., Unequivocal total assignment of 13C and 1H NMR spectra of some pyrido[1,2-a]pyrimidine derivatives by 2DNMR. Magnetic Resonance in Chemistry 2003, 41 (9), 747-749.

127. Kim, D.-m.; Kang, M.-S.; Kim, J. S.; Jeong, J.-H., An efficient synthesis of risperidone via stille reaction: Antipsychotic, 5-HT2, and dopamine-D2-antagonist. Archives of Pharmacal Research 2005, 28 (9), 1019-1022.

128. Hirokami, S.; Takahashi, T.; Nagata, M.; Hirai, Y.; Yamazaki, T., Photochemistry of 2,3,6-trialkyl-4-pyrimidinones in liquid ammonia-ether solution. Chemistry of Dewar 4pyrimidinones. The Journal of Organic Chemistry 1981, 46 (9), 1769-1777. 
129. Sajiki, H., Selective inhibition of benzyl ether hydrogenolysis with $\mathrm{Pd} / \mathrm{C}$ due to the presence of ammonia, pyridine or ammonium acetate. Tetrahedron Letters 1995, 36 (20), 3465-3468.

130. Horita, K.; Yoshioka, T.; Tanaka, T.; Oikawa, Y.; Yonemitsu, O., On the selectivity of deprotection of benzyl, mpm (4-methoxybenzyl) and dmpm (3,4-dimethoxybenzyl) protecting groups for hydroxy functions. Tetrahedron 1986, 42 (11), 3021-3028.

131. Oikawa, Y.; Yoshioka, T.; Yonemitsu, O., Specific removal of o-methoxybenzyl protection by DDQ oxidation. Tetrahedron Letters 1982, 23 (8), 885-888.

132. Ikeuchi, K.; Murasawa, K.; Ohara, K.; Yamada, H., p-Methylbenzyl Group: Oxidative Removal and Orthogonal Alcohol Deprotection. Organic Letters 2019, 21 (17), 6638-6642. 133. Shih, T. L.; Fang, Y. C., Expeditious Synthesis of New 3,4,6-Trihydroxythiepanes from d-(-)-Quinic Acid. Synthetic Communications 2007, 37 (19), 3337-3349.

134. Hori, H.; Nishida, Y.; Ohrui, H.; Meguro, H., Regioselective de-O-benzylation with Lewis acids. The Journal of Organic Chemistry 1989, 54 (6), 1346-1353.

135. Mallampudi, N. A.; Srinivas, B.; Reddy, J. G.; Mohapatra, D. K., Total Synthesis and Structural Revision of Monocillin VII. Organic Letters 2019, 21 (15), 5952-5956.

136. Somarathne, K. K.; McCone, J. A. J.; Brackovic, A.; Rivera, J. L. P.; Fulton, J. R.; Russell, E.; Field, J. J.; Orme, C. L.; Stirrat, H. L.; Riesterer, J.; Teesdale-Spittle, P. H.; Miller, J. H.; Harvey, J. E., Synthesis of Bioactive Side-Chain Analogues of TAN-2483B. Chemistry - An Asian Journal 2019, 14 (8), 1230-1237.

137. Su, Q.; Dakin, L. A.; Panek, J. S., [4 + 2]-Annulations of Chiral Organosilanes: Application to the Total Synthesis of Leucascandrolide A. The Journal of Organic Chemistry 2007, 72 (1), 2-24.

138. West, L. The Isolation of Secondary Metabolites from New Zealand Marine Sponges. Victoria University of Wellington, 2001.

139. S Ševčík, J.; Hostinová, E.; Solovicová, A.; Gašperík, J.; Dauter, Z.; Wilson, K. S., Structure of the complex of a yeast glucoamylase with acarbose reveals the presence of a raw starch binding site on the catalytic domain. The FEBS Journal 2006, 273 (10), 2161-2171. 140. Imamura, H.; Fushinobu, S.; Yamamoto, M.; Kumasaka, T.; Jeon, B.-S.; Wakagi, T.; Matsuzawa, H., Crystal Structures of 4- $\alpha$-Glucanotransferase from Thermococcus litoralis and Its Complex with an Inhibitor. Journal of Biological Chemistry 2003, 278 (21), 1937819386.

141. Haupt, V. J.; Daminelli, S.; Schroeder, M., Drug Promiscuity in PDB: Protein Binding Site Similarity Is Key. PLOS ONE 2013, 8 (6), e65894.

142. Rabasseda, X., Brivudine: a herpes virostatic with rapid antiviral activity and oncedaily dosing. Drugs of Today 2003, 39 (5), 359-371.

143. Heinrich, J.-C.; Tuukkanen, A.; Schroeder, M.; Fahrig, T.; Fahrig, R., RP101 (brivudine) binds to heat shock protein HSP27 (HSPB1) and enhances survival in animals and pancreatic cancer patients. Journal of Cancer Research and Clinical Oncology 2011, 137 (9), 1349.

144. Gao, M.; Skolnick, J., Structural space of protein-protein interfaces is degenerate, close to complete, and highly connected. Proceedings of the National Academy of Sciences 2010, 107 (52), 22517-22522.

145. Campbell, S. J.; Gold, N. D.; Jackson, R. M.; Westhead, D. R., Ligand binding: functional site location, similarity and docking. Current Opinion in Structural Biology 2003, 13 (3), 389-395.

146. Laskowski, R. A.; Luscombe, N. M.; Swindells, M. B.; Thornton, J. M., Protein clefts in molecular recognition and function. Protein Science 1996, 5 (12), 2438-52.

147. Gao, M.; Skolnick, J., A comprehensive survey of small-molecule binding pockets in proteins. PLoS Comput Biol 2013, 9 (10), e1003302-e1003302. 
148. Fang, Z.; Song, Y. n.; Zhan, P.; Zhang, Q.; Liu, X., Conformational restriction: an effective tactic in 'follow-on'-based drug discovery. Future Medicinal Chemistry 2014, 6 (8), 885-901.

149. Zareie, P. Investigating the mechanism by which the atypical antipsychotic clozapine reduces disease in experimental autoimmune encephalomyelitis. Victoria University of Wellington, 2017. 